Institutional

frameworks for

social policy in

Latin America and

the Caribbean

RODRIGO MARTÍNEZ

Editor

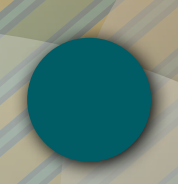

UNITED NATIONS

E C L A C

german

cooperation

DEUTSCHE ZUSAMMENARBEIT 


\section{Thank you for your interest in}

this ECLAC publication

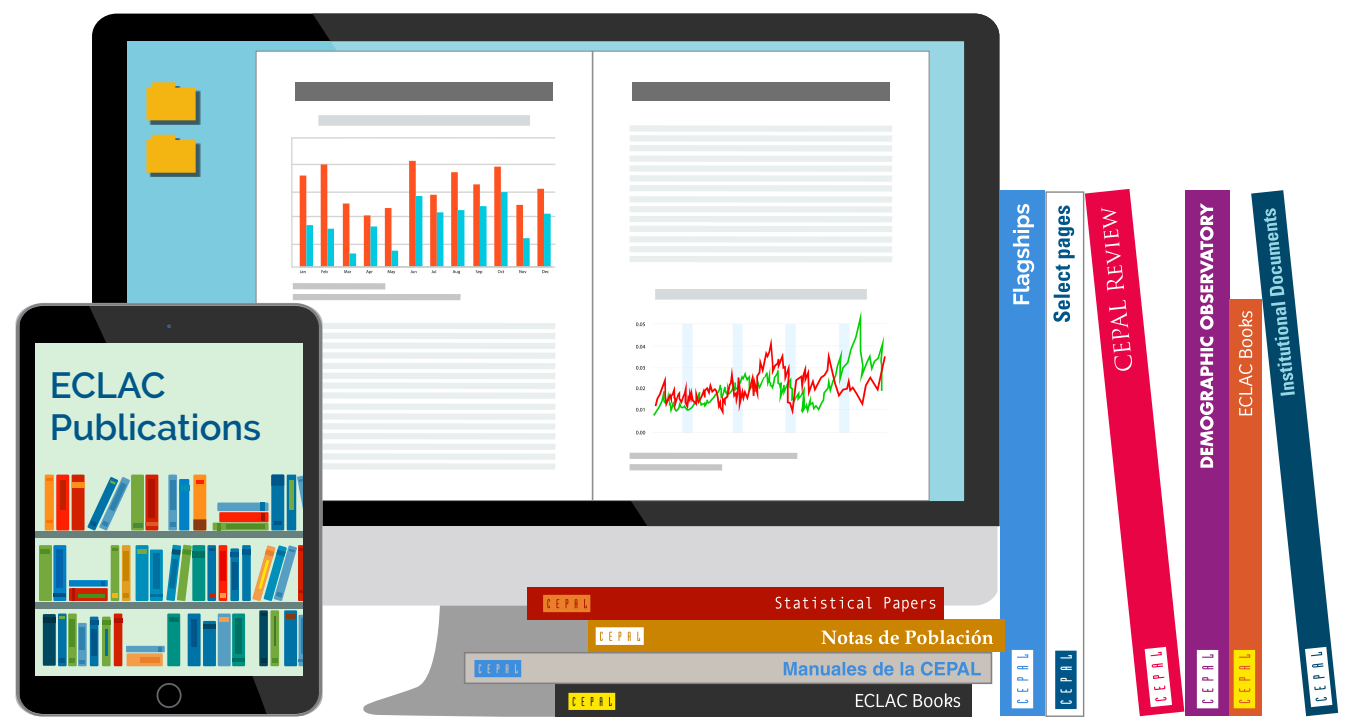

Please register if you would like to receive information on our editorial products and activities. When you register, you may specify your particular areas of interest and you will gain access to our products in other formats.

\section{Register}
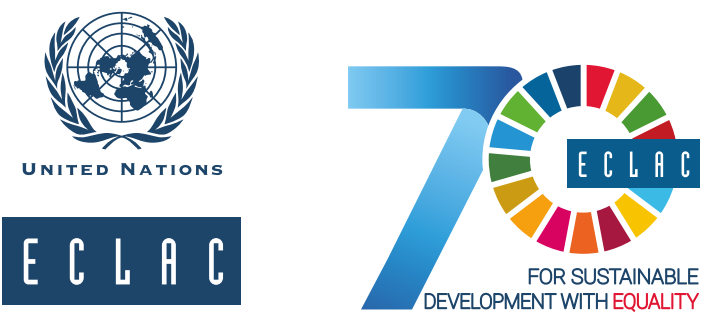

www.cepal.org/en/suscripciones 


\section{Institutional frameworks for social policy in Latin America and the Caribbean}

Rodrigo Martínez

Editor
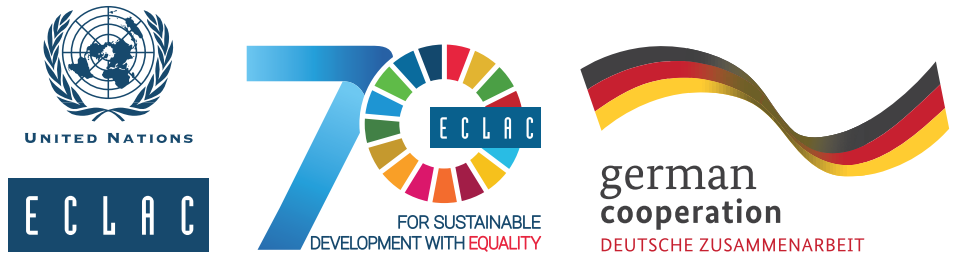
ECLAC Books

\author{
146 \\ Alicia Bárcena \\ Executive Secretary \\ Mario Cimoli \\ Deputy Executive Secretary \\ Raúl García-Buchaca \\ Deputy Executive Secretary \\ for Management and Programme Analysis \\ Laís Abramo \\ Chief, Social Development Division \\ Ricardo Pérez \\ Chief, Publications and Web Services Division
}

This document has been prepared by Rodrigo Martínez, Senior Social Affairs Officer in the Social Development Division of the Economic Commission for Latin America and the Caribbean (ECLAC), in the framework of the projects "Social protection, rights-based approach and inequality in Latin America", under the programme Structural change for sustainable and inclusive development in Latin America and the Caribbean, and "Institution-building for universal and sustainable social protection", under the programme Support for the implementation of the 2030 Agenda for Sustainable Development in Latin America and the Caribbean, which are implemented by ECLAC jointly with the German Agency for International Cooperation (GIZ) and financed by the German Federal Ministry for Economic Cooperation and Development (BMZ).

The chapters of the book were prepared by Carlos Maldonado, Rodrigo Martínez, Marta Rangel, María Nieves Rico, Claudia Robles, Daniela Trucco, Heidi Ullmann, Andras Uthoff and Mario Velásquez.

Particular gratitude is due to Laís Abramo and Martín Hopenhayn for their comments on all the chapters.

The views expressed in this document are those of the authors and do not necessarily reflect the views of the Organization.

Cover design: María Luisa Avaria U.

United Nations publication

ISBN: 978-92-1-121986-9 (print)

ISBN: 978-92-1-058624-5 (pdf)

ISBN: 978-92-1-358091-2 (ePub)

Sales No.: E.17.II.G.15

LC/PUB.2017/14-P/-*

Distribution: $\mathrm{G}$

Original: Spanish

Copyright (C) United Nations, 2018

All rights reserved

Printed at United Nations, Santiago

S.18-00484

This publication should be cited as: Rodrigo Martínez (ed.), Institutional frameworks for social policy in Latin America and the Caribbean, ECLAC Books, No. 146 (LC/PUB.2017/14-P/-*), Santiago, Economic Commission for Latin America and the Caribbean (ECLAC), 2018.

Applications for authorization to reproduce this work in whole or in part should be addressed to the Economic Commission for Latin America and the Caribbean (ECLAC), Publications and Web Services Division, publicaciones.cepal@un.org. Member States and their governmental institutions may reproduce this work without prior authorization, but are requested to mention the source and to inform ECLAC of such reproduction. 


\section{Contents}

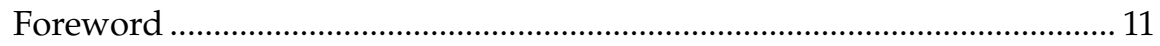

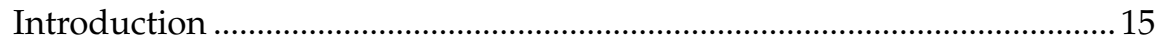

Part 1

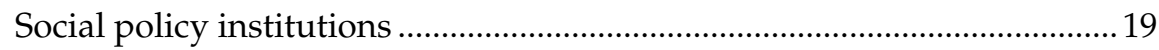

Chapter I

Institutional framework for social development.

Rodrigo Martínez, Carlos Maldonado Valera

Introduction

A. Social policy institutions: basic concepts ........................................2 23

B. The thematic and geographical scope of the institutional

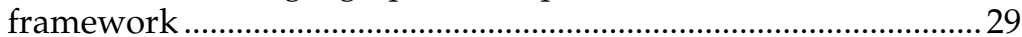

C. The dimensions of the social policy institutional framework .......32

1. The legal and regulatory dimension .............................................32

2. The organizational dimension ..................................................... 34

3. The technical and operational dimension ....................................40

4. The financing dimension .............................................................. 43

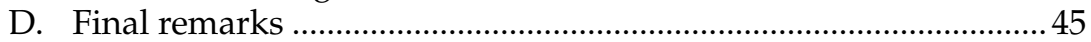

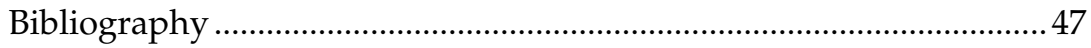

Chapter II

Social development and social protection institutions in Latin America and the Caribbean: overview and challenges

Rodrigo Martínez, Carlos Maldonado Valera

Introduction 
A. International, regional and national legal and regulatory frameworks 50

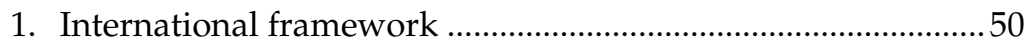

2. National regulatory frameworks for social development .......53

B. Organizational characteristics and social authority .........................56

1. Regional mandates and forums dedicated to social development in Latin America and the Caribbean.

2. The social agendas of selected intergovernmental forums .......61

3. Modalities of social authority

4. Ministries and secretariats of development and social inclusion

5. The institutional affiliation of income transfer and non-contributory pension programmes

6. The challenges of coordination and articulation between social protection actors.

C. Management tools and the technical and operational dimension .75

D. Financing 79

E. Final remarks 82

Bibliography 85

Annex II.A1 86

\section{Part 2}

Components and institutional framework of social protection .95

Chapter III

Labour market regulation and social protection: institutional challenges. 97 Mario D. Velásquez Pinto

Introduction.

A. Labour regulations and flexibility in Latin America........................98

B. Labour market regulations and social protection...........................101

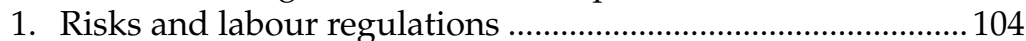

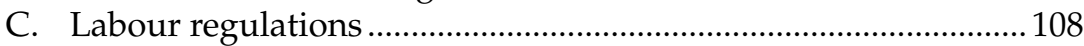

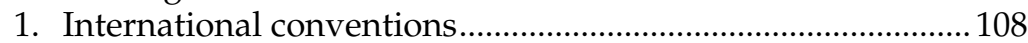

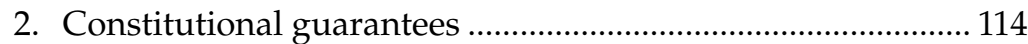

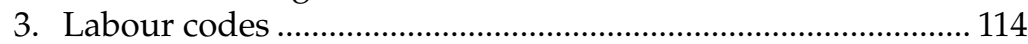

D. Organizational dimension for regulatory compliance...................130

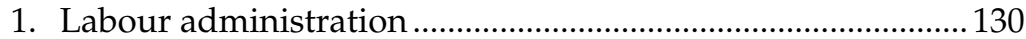

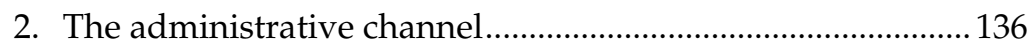

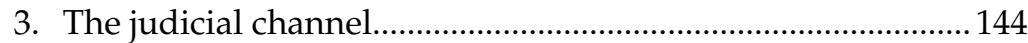

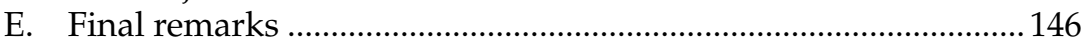

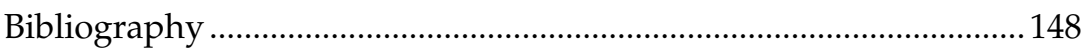

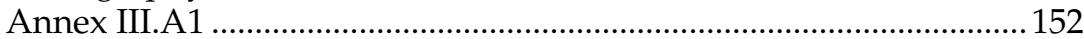




\section{Chapter IV}

Institutional aspects of Latin America's pension systems

Andras Uthoff

Introduction

A. Pension system and social security...........................................157

1. Pension system design options.

2. Classification of pension systems

B. Institutional challenges

1. Elements for resolving the conflict between efficiency and solidarity

2. Elements for sustainability associated with the ageing process

3. Some experiences with reforms to address ageing ..................189

C. Final thoughts

Bibliography

\section{Chapter V}

Care as a pillar of social protection: rights, policies and institutions in Latin America

María Nieves Rico, Claudia Robles

Introduction

A. Care as a public good: elements for policy design ....................... 207

B. Integrated care policies as a pillar of social protection: institutional challenges

1. The nascent institutionalization of care policies in Latin America: opportunities and challenges in their articulation with social protection systems.

2. A common and differentiated regulatory framework: is the right to care established?

C. Care policies and programmes: programmatic diversity and low tax burden

D. From programmes to integrated care systems? Creating and strengthening the institutional framework.....

E. Is mainstreaming advancing?...................................................... 227

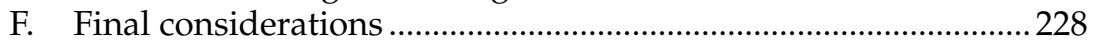

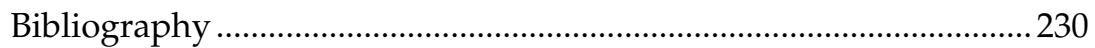

Part 3

Policies for specific populations and their institutional framework

Chapter VI

Life cycle and social policies: youth institutions in the region.

Daniela Trucco

Introduction

A. National (and supranational) legal frameworks for youth policies. 
B. Organizational dimension: the governance of youth policies ...... 242

1. Coordinating institutions and authority ………........................2242

2. Citizen participation channels ..................................................2247

C. Sectoral plans or policies and access to resources ..........................2249

D. Fiscal dimension and the financing of youth policies.................... 251

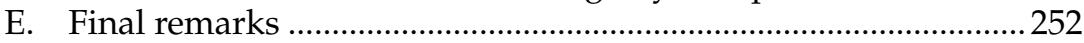

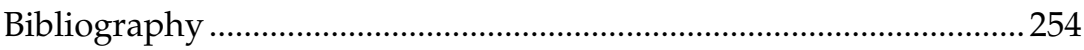

Chapter VII

Disability and public policy: institutional progress and challenges

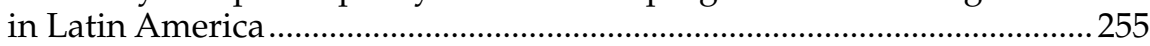
Heidi Ullmann

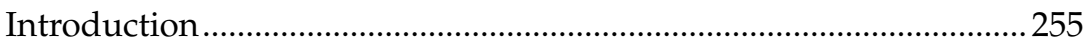

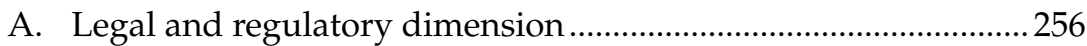

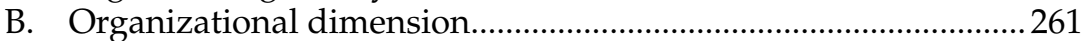

1. National institutions and their characteristics ........................262

2. Citizen participation in disability agencies................................266

3. Mechanisms for coordination ..................................................... 268

C. The technical and operational dimension.......................................2272

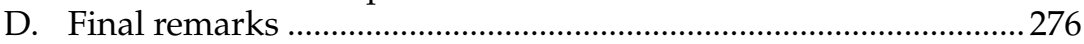

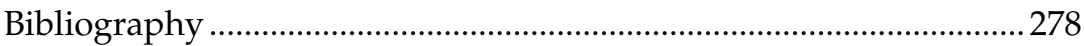

Chapter VIII

Latin American Afrodescendants: institutional framework and public policies

Marta Rangel

Introduction

A. The legal and regulatory framework...............................................281

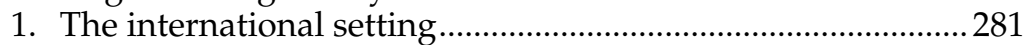

2. Legislation in the countries ........................................................283

B. The organizational dimension: features and characteristics........286

C. The technical-operational dimension: tools management ...........296

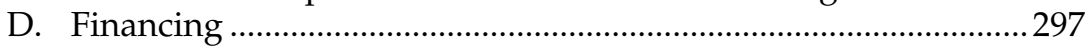

E. Key policies for Afrodescendants .....................................................299

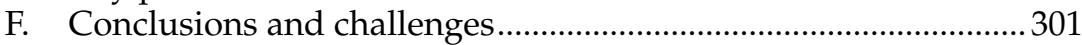

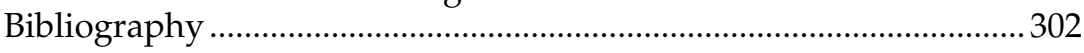

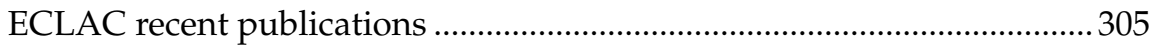

\section{Tables}

II.1 Latin America and the Caribbean (33 countries): existence of constitutional and specific laws on sectoral social issues and references to specific segments of the population

II.2 Latin America and the Caribbean: intergovernmental forums on social development, by type of institution to which they are attached, 2015.

II.3 Latin America and the Caribbean: main thematic pillars of selected intergovernmental social development forums 
II.4 Latin America and the Caribbean (22 countries): type of authority that coordinates the social cabinet or the main intersectoral collegial entity of the social area.

II.5 Latin America and the Caribbean (21 countries): entities responsible for the main cash transfer and non-contributory pension programmes

II.6 Latin America and the Caribbean (22 countries): summary of selected tools for the management, planning, evaluation and transparency of social programmes, 2015

II.7 Latin America (18 countries): social spending in three groups of countries with different results in terms of protection and social promotion (simple average of each group), around 2015.

II.8 Latin America and the Caribbean (14 countries): budget of the Ministry of Social Development or equivalent entity as a proportion of budgeted primary expenditure, around 2015

II.A1.1 Latin America and the Caribbean (27 countries): government agencies devoted to social development, 2015 .....

II.A1.2 Latin America and the Caribbean (21 countries): composition of collegiate intersectoral social policies coordination bodies, 2015

III.1 Latin America (14 countries): rate and composition of non-agricultural informal employment by occupational category, 2013

III.2 Analytical matrix of labour market regulation according to life-cycle risks

III.3 ILO Conventions in Latin American countries related to the stages of the life cycle.

III.4 Latin America (19 countries): ILO conventions ratified and in force, 2015

III.5 Latin America (19 countries): constitutional protection against work-related risks by stages of the life cycle, 2015 .

III.6 Latin America (16 countries): current labour codes and year of creation, 2015.

III.7 Latin America (16 countries): labour regulations in labour codes associated with social protection, by stages of the life cycle

III.8 Latin America (14 countries): labour regulation and social protection institutions, 2015.

III.9 Brazil and Chile: dimensions of labour inspection.

III.10 Latin America (14 countries): strength of labour inspection, selected indicators

III.11 Latin America (18 countries): coverage against risks in the life cycle, selected indicators.

III.A1.1 Benefits provided for in ILO Convention No. 102 and in subsequent conventions 
IV.1 Options for the design of a pension system ………….................... 164

IV.2 Latin America and the Caribbean (10 countries): coverage indicators for defined contribution systems,

by affiliated members

IV.3 Latin America and the Caribbean (8 countries): coverage indicators for defined contribution systems,

by contributing members

IV.4 Initiatives to reconcile equivalence between contracts and solidarity

IV.5 Brazil, Chile and Uruguay: pension system profiles......................175

IV.6 Latin America and the Caribbean (19 countries): different transitions in fertility and mortality

IV.7 Latin America and the Caribbean (19 countries): simulated cost of universal pensions as a percentage of national GDP

IV.8 Initiatives to protect systems from risks caused by population ageing

IV.9 Latin America and the Caribbean: main parametric changes in public pay-as-you-go programmes, 2009-2015

V.1 Latin America and the Caribbean (12 countries): care laws passed between 2015 and 2017

VI.1 Latin America (18 countries): national legal framework for youth

VI.2 Latin America and the Caribbean (26 countries): articulation and oversight of government agencies dedicated to young people

VI.3 Latin America (8 countries): participation channels of youth institutions

VII.1 Latin America (19 countries): year of ratification or adhesion to the Inter-American Convention on the Elimination of All Forms of Discrimination Against Persons with Disabilities (1999) and the Convention on the Rights of Persons with Disabilities (2006), as of 1 April 2017

VII.2 Latin America (19 countries): main legislation on the rights of persons with disabilities

VII.3 Latin America (19 countries): main institutions responsible for persons with disabilities

VII.4 Latin America (12 countries): examples of citizen participation mechanisms in the main disability agencies

VII.5 Latin America (10 countries): examples of inter-institutional or intersectoral coordination mechanisms and methods used by the main disability agencies

VII.6 Latin America (11 countries): examples of territorial coordination mechanisms in the main disability agencies

VII.7 Latin America (14 countries): national plans or strategies

for promoting the rights of persons with disabilities. 
VIII.1 Latin America: mechanisms tasked with promoting racial equality

VIII.2 Latin America: financial resources available for government agencies for the promotion of racial equality, 2016 298

\section{Figures}

II.1 Latin America and the Caribbean (33 countries): signature and ratification or accession of agreements, conventions and conventions related to economic, social and cultural rights 52

II.2 Latin America and the Caribbean (22 countries): year of creation of ministries or other mechanisms devoted to social development.....

II.3 Latin America and the Caribbean (26 countries): main government agencies formally responsible for coordinating services for various population segments

III.1 Latin America (14 countries): non-agricultural informal employment, 2009 and 2011-2015.

IV.1 Latin America (18 countries): ageing indicators, 1950-2100 ........ 177

VI.1 Latin America (14 countries): main policy pillars or youth sector plan.

VII.1 Latin America (19 countries): rights enshrined in the main laws on disability.

\section{Boxes}

I.1 Desirable components of a social policy institutional framework according to various specialized studies.........................25

IV.1 Fundamental principles of social security ..................................... 157

IV.2 Different pay-as-you-go mechanisms................................................. 161

IV.3 Chile: funding the transition towards the individual funded model (extract from the report of Chile's recent Presidential Advisory Commission).

IV.4 The Chilean case: funding in individual savings accounts .......... 194

VII.1 The evolution of approaches towards disability..............................274

\section{Diagrams}

I.1 Components of the organizational dimension at the central government level

I.2 Types and scope of social authorities .............................................37

II.1 Selected segments of the target population in social policy regulatory frameworks.

III.1 Classical organizational structure of a labour ministry .................. 131

V.1 Components of an integrated care policy ……................................210 



\section{Foreword}

As the Economic Commission for Latin America and the Caribbean (ECLAC) has pointed out in successive editions of the Social Panorama of Latin America, the region has made substantial progress on social issues in recent decades. Examples include the reduction of poverty and inequality in income distribution and improvements in indicators of access and outcomes in areas such as health care, education, housing, sanitation and female employment.

However, positive trends in certain indicators have tailed off during the current decade, even as economic growth rates have slowed sharply. Meanwhile, inequality in rights, resources and opportunities is still a characteristic of the region, replicating a social inequality matrix that is underpinned by a culture of privilege and structurally heterogeneous production processes.

This is happening at a time when the world is at a turning point. First, the various transformations associated with volatile economic growth, climate change, the technological revolution, migration and the demographic transition are posing new challenges and demand greater resilience both from the people affected and from the institutions responsible for designing and implementing better public policies.

Second, the commitments accepted in the 2030 Agenda for Sustainable Development (adopted by the countries in 2015) and its 17 Sustainable Development Goals also mark a radical shift. The Agenda reflects a new way of confronting the challenges of development, integrating the economic, social and environmental pillars in a coordinated and synergistic way and emphasizing the principle that no one should be left behind. 
Continuing on from the Millennium Development Goals, the commitments of the 2030 Agenda for Sustainable Development are a milestone in the progressive institutional development of public policies globally and have allowed increasing importance to be assigned to efforts to combat poverty and reduce inequalities in health care, education, employment and housing and those linked to gender, race or ethnicity. They also follow on from the different international agreements and covenants that have guided public policymaking in the twentieth and twenty-first centuries, such as the Universal Declaration of Human Rights, the agreements of the International Labour Organization (ILO), the International Covenant on Economic, Social and Cultural Rights (ICESCR), the American Convention on Human Rights and Additional Protocol to the American Convention on Human Rights in the Area of Economic, Social and Cultural Rights (Protocol of San Salvador), the Convention on the Elimination of All Forms of Discrimination against Women, the Beijing Declaration and Platform for Action, the Convention on the Rights of the Child and the Durban Declaration and Programme of Action, among many others.

These agreements and commitments have translated into different legal and organizational adjustments in the region. Of the organizational adjustments, particular mention may be made of new ministries, secretariats, ministerial councils, institutes and other agencies with a national and subnational remit, together with regional and subregional mechanisms such as conferences, forums and integration and information-sharing agreements. In recent decades, this has been clearly reflected in social policies and those oriented towards the social protection and development of particular populations.

Given this context of changes and added commitments, new and increased efforts to enhance the coverage and quality of public policies will be required to continue the social progress made in Latin America and the Caribbean, ensure no ground is lost and attain the goals of the 2030 Agenda for Sustainable Development while ensuring that no one is left behind. Consequently, as emphasized in the document presented by ECLAC in 2016, Horizons 2030: Equality at the Centre of Sustainable Development, it is essential to consolidate existing institutions. There is a vital need at both the regional and the national level for countries to have institutions capable of meeting current and future challenges, securing viable and sustainable achievements and guaranteeing the universal exercise of rights.

This book reviews elements of the institutional framework of social policy in the region. Focusing on social protection policies, it reviews the leading concepts pertaining to institutions and the social authority 
and proposes four complementary analytical dimensions by which to study them: (i) the legal and regulatory dimension, (ii) the organizational dimension, (iii) the technical and operational dimension and (iv) the financing dimension. On the basis of these, it analyses progress and discusses what still needs to be done at the regional and national level.

The studies presented here were carried out as part of the cooperation programmes Structural Change for Sustainable and Inclusive Development in Latin America and the Caribbean (2014-2016) and Support for the Implementation of the 2030 Agenda for Sustainable Development in Latin America and the Caribbean (2016-2018), executed by ECLAC in conjunction with the German Agency for International Cooperation (GIZ), with financing from Germany's Federal Ministry for Economic Cooperation and Development (BMZ). The two institutions thereby aim to contribute to improved social policy analysis, design and implementation and thus to progress towards the Sustainable Development Goals on the basis of a rights approach.

\author{
Alicia Bárcena \\ Executive Secretary \\ Economic Commission for \\ Latin America and the Caribbean (ECLAC)
}





\section{Introduction}

The Latin America and Caribbean region has made substantial social advances in recent decades. Examples include improvements in poverty levels, income distribution, educational attainment and health and social protection indicators. However, slowing and volatile economic growth in the region and the new conditions created by climate change, the technological revolution, the demographic transition and migration dynamics are posing new public policy challenges.

In this context, sustaining progress, avoiding reverses and attaining the goals of the 2030 Agenda for Sustainable Development without leaving anyone behind will require new and increased public policy efforts to improve coverage and quality, making it essential for there to be institutions with the legal security, management capacity and resources to meet the challenges.

The Economic Commission for Latin America and the Caribbean (ECLAC) is aware of how important institutions are for attaining public policy goals and has placed them at the centre of its research and concerns. Thus, the latest ECLAC session document emphasized how indispensable it was to consolidate existing institutions if the 2030 Agenda for Sustainable Development was to be implemented with any prospect of success. Likewise, the quality of social policies and the study of the institutions responsible for them have long held an important place in the work of the ECLAC Social Development Division and were an important topic of discussion for the national authorities meeting at the First Regional Conference on Social Development, held in Lima in November 2015. 
This book presents a compilation of recent studies on the institutional framework of social policy in Latin America and the Caribbean, conducted as part of the last two cooperation programmes between ECLAC and Germany's cooperation agency. ${ }^{1}$ These studies analyse government bodies whose central mission is the design and implementation of the countries' social development and anti-poverty strategies, including ministries, secretariats and coordinating offices. The analysis also includes international agencies and agreements that facilitate or guide the institutionalization of social policies.

Apart from social development policies as a general framework, emphasis is placed on social protection and its components. The book describes how these have evolved in recent decades and discusses the institutional challenges involved in guaranteeing the exercise of universal rights, dealing with the specific issues and needs of different population segments and meeting the social development commitments that countries have entered into.

Progress with the region's social indicators over recent years has been accompanied by major challenges with the design and implementation of policies and the establishment of an institutional basis for them. Each country has followed its own path, but there are also common elements that reflect the current state of social policy institutions in the region's countries.

A first element to be considered when it comes analysing the scope and orientating discussion of social policy are the concepts of development, inclusion and social protection. The concept of social development includes the idea of progress in all social policy spheres and functions, such as health care, education, social protection, employment, housing and food and nutritional security. The concept of social inclusion, for its part, centres on making it possible for the whole population to receive the benefits of development by narrowing divides and fomenting participation in social, economic and political life. Social protection is a public policy area whose function is to secure a level of economic and social well-being at least sufficient to lift the population out of poverty and protect it from the risk of falling into it. Another purpose is to facilitate access to social and support services that enable people to acquire capabilities, exercise their rights and develop throughout their life cycle. The tools available for this are contributory and non-contributory components, labour market regulation and care systems (Cecchini and Martínez, 2012).

A second important element is the geographical scope of the analysis. Social institutions operate within specific national frameworks in terms of laws and the organizational structure responsible for policy. This includes

\footnotetext{
Programmes of cooperation between ECLAC and the German Federal Ministry for Economic Cooperation and Development (BMZ)/German Agency for International Cooperation (GIZ): Structural Change for Sustainable and Inclusive Development in Latin America and the Caribbean (2014-2016) and Support for the Implementation of the 2030 Agenda for Sustainable Development in Latin America and the Caribbean (2016-2018).
} 
not only the central level but also subnational and local levels, where policy implementation and follow-up of outcomes are carried out more directly. It also extends to the international sphere, via the global, regional and subregional bodies that set goals and targets and lay down ethical and legal foundations for all governments. These same criteria apply to bodies created by the international system to carry out follow-up, share experiences and pursue implementation agreements, such as the forums set up to promote the region's social development: the Economic Commission for Latin America and the Caribbean (ECLAC), the Organization of American States (OAS), the Community of Latin American and Caribbean States (CELAC), the Union of South American Nations (UNASUR), the Central American Integration System (SICA) and the Andean Community, among others.

A third element is the way the institutional framework of social policy and the social authority are defined and the analytical dimensions to be considered when studying them. The definitions and scope of these concepts reflect different interpretations and analytical priorities that, unless clarified, could lead to different interpretations of a single reality. Consequently, the starting point for the studies presented in this book is a conceptual discussion and an analytical framework featuring four major dimensions that frame the effort to carry forward the study of social institutions: the legal and regulatory underpinning on which policy rests, the organizational model used to implement it (including the social authority and coordination schemes), the management tools developed to pursue the goals set, and the availability, source and sustainability of funding for policies.

The design and operation of social policy institutions pose a permanent challenge in terms of their organizational models and the scope of the social authority. This is, first, because they need to be able to fulfil the social functions of government (social protection, health care, education, housing, recreation, etc.) in order to achieve goals in particular spheres of public policy. Second, it is because they need to serve population segments determined by gender, racial and ethnic, life cycle or disability characteristics, among others, in a way that meets their particular needs and narrows divides, with a view to guaranteeing rights for all in diversity. Thus, alongside the traditional sectoral ministries, some countries have recently built up new departments that focus on these populations and divide their time between coordinating actors and implementing programmes of their own.

The elements indicated provided the basis for the work described in the present book, which falls into eight chapters, grouped into three parts. The first part includes an overview of social institutions in Latin America and the Caribbean, with the first chapter reviewing some of the basic concepts underlying the analysis of institutions in the light of the positions 
developed in the region over recent decades. A framework of analysis for considering social institutions is then presented, starting with some reflections on their thematic and geographical scope and continuing with a conceptual discussion of the four dimensions mentioned earlier, which are of particular relevance for the analysis, design and implementation of social policies, and which served to orient the studies included in the following chapters of the book. Building on this conceptual discussion, the second chapter presents an overview of social institutions in the region from the last decades of the twentieth century to the present, stressing the progress made and challenges encountered from the point of view of the development of a high-quality social protection policy.

The second part comprises three chapters that analyse the institutional progress and challenges associated with three components of social protection in Latin America. The third chapter begins with a discussion of decent work and the institutional requirements for labour market regulation and continues with an overview of progress in this area. The fourth chapter then presents an analysis of pension systems in the region and the institutional challenges facing agencies in charge of social security in the light of the principles underlying this and the future of population ageing. Lastly, the fifth chapter reviews care policies and their institutional development in the region, taking into consideration their importance as a social protection component and the major role played by women and unpaid work in this area.

The analysis of the third part centres on institutional arrangements for social policies targeted at specific populations, highlighting their particular requirements and the progress made in the region in this area. Thus, the sixth chapter analyses the case of the young as an object of particular policies over the life cycle. The seventh analyses the institutions in charge of public policies oriented towards people with disabilities, their achievements and their challenges. Lastly, the eighth chapter discusses the institutional framework of policies oriented towards the Afrodescendent population, the path followed in recent decades and the steps that seem necessary in this area.

Although an exhaustive analysis is not aimed at, the idea is that the reader should obtain an overview of the models, advances and challenges of social policy institutional frameworks in the region's countries. This information should also act as a stimulus to further study and institutional development aimed at progressively advancing with the implementation of high-quality (effective, efficient, sustainable and transparent) social policies. This progress should help to reduce the social footprint of development, guarantee rights and meet the targets set for the goals of the 2030 Agenda for Sustainable Development. 
Part 1

Social policy institutions 



\section{Chapter I \\ Institutional framework for social development}

Rodrigo Martínez ${ }^{1}$

Carlos Maldonado Valera ${ }^{2}$

\section{Introduction}

The institutional framework of social development policy has long been studied at the Economic Commission for Latin America and the Caribbean (ECLAC) and have been among the subjects covered in recent major publications of the Social Development Division (ECLAC, 2015 and 2016b). The position document of the thirty-sixth session of the Commission in 2016 highlighted the indispensable need to consolidate existing institutions in order to implement the 2030 Agenda for Sustainable Development and emphasized that "the social sphere in countries of the region is still segmented by sector and, worse, kept separate from the economic sphere, and there is a hierarchical structure that subordinates social institutions to the economic authorities" (ECLAC, 2016a, p. 162).

Senior Social Affairs Officer of the Social Development Division of the Economic Commission for Latin America and the Caribbean (ECLAC).

2 Social Affairs Officer of the Social Development Division of the Economic Commission for Latin America and the Caribbean (ECLAC). 
The present chapter sets out a framework of analysis for social policy institutions that will be used over the course of this book to describe elements of the current situation of social institutions in the countries, drawing on the official information available.

The main focus of the analysis are government bodies whose core responsibility is the design and implementation of strategies for social development, social protection and poverty reduction in the countries. These bodies include ministries, secretariats and coordinating cabinets.

It is important first of all to differentiate between the concepts of development, inclusion and social protection. While social development centres on the idea of advancing in all the spheres and functions that make up social policy, the goal of social inclusion is to ensure that the whole population is part of and benefits from the development process. Social protection is a public policy area whose function is to secure a level of economic and social well-being at least sufficient to lift the population out of poverty, protect it from the risk of falling into it and facilitate access to social and promotion services that enable people to acquire capabilities, exercise their rights and develop throughout their life cycles (Cecchini and Martínez, 2012).

The geographical scope of the institutional framework is also an essential consideration in its analysis, which should encompass both the national sphere, with its different administrative levels (central, subnational in the form of states, departments, provinces or regions, and local), and the international sphere (global, regional and subregional).

Nonetheless, progress towards this goal requires prior reflection on the definitions of social policy institutions and authorities and the analytical dimensions to be considered when examining them. These elements are the starting point of the study presented here.

The chapter is structured into four parts. The first discusses basic concepts relating to institutions and authorities, together with their functions and responsibilities. The second briefly reviews the thematic, demographic and geographical scope of this topic. The third deals with the analytical approach that is the basis of this study, emphasizing the importance of four dimensions that complement one another in the analysis of social policy institutions. The fourth and last presents some conclusions and observations. 


\section{A. Social policy institutions: basic concepts}

The discussion of social policy institutions has a substantial history in the region. A number of studies have argued for the importance of social policies and programmes being subject to explicit, transparent and generally accepted rules and standards so that their contribution to the attainment of objectives and the effective enforcement of rights is maximized and the use of idiosyncratic, political or simply inefficient criteria is as far as possible minimized. They have also highlighted the desirable characteristics of these institutions, mainly centring on programme operation and management (Franco and Székely, 2010; Székely, 2015) and the best way of orienting the planning, budgeting, execution, evaluation and other phases of the policy cycle towards concrete outcomes (Kaufmann, Sanginés and García Moreno, 2015). Some approaches have highlighted the desirability of policy continuity (Machinea and Cruces, 2010), concrete programmes (Irarrázaval, 2006) and even the actors involved in policies (Braun and Vélez, 2004). This idea of continuity does not imply immobility or immutability. Rather, it means that policy alterations should follow a pattern of structured change, subject to certain established (non-arbitrary) rules and procedures.

A vision of the social policy institutional framework that looks beyond operational aspects should also be concerned with ensuring that policies and programmes are capable of responding to new expectations and demands and of better guaranteeing rights. In other words, social policies need to be able to change, not in an arbitrary and disorganized way, but through identifiable and predictable procedures and mechanisms that endow them with continuity and responsiveness to new social demands and challenges (Stein and others, 2008).

Social policy presents similarities to other sectors in terms of the structural challenges entailed by the sometimes stark contrast between formal institutions and social and government practices. This gap between theory and practice is a recurrent feature in the region's countries. It does not negate but rather underlines the importance of consolidating ambitious legal and institutional frameworks, even if they become fully operational only gradually (Gargarella, 2013a and 2013b).

According to Repetto (2004), the social policy institutional framework is constituted by the set of formal and informal ground rules (including organizational habits and routines) that come into 
play to process and prioritize social problems and, at the same time, to frame the content and the administrative and political dynamics of social policies. Thus, social institutions represent interlocking incentives that structure the limits and opportunities for negotiation and action of social policy actors. However, the existence of a stable framework does not remove the scope for more or less far-reaching transformation. Because an emphasis on informal rules and practices is difficult to flesh out without qualitative analysis and case studies, however, an approach that grounds comparative analysis in formal institutional frameworks is advisable.

Some authors (Irarrázaval, 2006; Machinea and Cruces, 2010) include territorial considerations when expounding the attributes of social institutions. These include decentralization processes and the implications of territorial peculiarities for social policy, factors which make it important to incorporate this dimension by applying specific mechanisms that represent the interests of subnational actors within the framework of the institutions analysed, together with the establishment of bodies to coordinate between different levels of government, as part of sectoral policies.

Another consideration is the capacity of institutions for governance, regulation and interaction with the market. This attribute is related to: (a) protection of access, (b) the design of service quality and content standards, (c) improvements to the efficiency of private management, (d) measures to secure conditions of market competition and organization that avoid harmful practices, (e) the production and dissemination of accurate and timely information on an egalitarian basis and (f) the establishment of mechanisms capable of adjudicating conflicts between suppliers and the user population (Machinea and Cruces, 2010). Private actors can be regarded as part of civil society in a broad sense, together with other non-governmental actors (social organizations, academic institutions, etc.), insofar as they affect social policy cycles, even if their regulation ultimately rests with the State. This is a necessary condition to ensure that rights and legal requirements generally are safeguarded, especially in countries where privatization or outsourcing in specific social policy fields (health care, social security, education, etc.) is further advanced.

Box I.1 summarizes some of the elements that are desirable in social institutions, as enumerated by various studies. 


\section{Box I.1}

\section{Desirable components of a social policy institutional framework} according to various specialized studies

There have been a variety of suggestions as to which components a suitable social policy institutional framework ought to include. Most recognize the following attributes:

- The existence of a long-term strategy that is coherent and sustained and does not alter in its essentials with changes of government, political crises or temporary economic shifts. This does not imply that social policy should be rigid and unresponsive to the socioeconomic situation. What is does mean is that it should respond appropriately to economic shocks, but not change arbitrarily with movements in political balances.

- Consideration of the rights and gender approaches as prescriptive and practical axes orienting the design and implementation of social policies and programmes. This assumes, first, that these approaches have as their ultimate objective the effective enjoyment of rights and, second, that gender equity should be systematically pursued.

- The existence of clear rules known to all actors as an attribute for determining how programmes operate, what population they are targeted at, what type of support they offer, what enrolment and beneficiary selection criteria are followed, and what their joint responsibilities are. Furthermore, it is in operating rules that mechanisms for facilitating and systematizing citizen participation can be established. Operating rules (and guidelines generally) serve, among other things, for public sector employees to have a clear understanding of how social programmes should be implemented and to make their actions consistent, thereby enabling public resources to be used in an efficacious, efficient, timely, transparent and equitable way. In addition, clear rules facilitate horizontal and vertical coordination by ensuring that concrete responsibilities, obligations and resources are allocated to each government department or level.

- The existence of arrangements for coordination between different government actors responsible for implementing social policy. These involve actors from different levels of government (central, provincial or regional, municipal or mayoral) or sectors. This makes it indispensable to establish arrangements whereby, for example, information can be shared, efforts coordinated and resources allocated effectively and efficiently.

- The development of permanent technical capacities in the bodies responsible for the different stages of social policy. To conduct an effective social policy, it is essential to have professional executives trained for the different functions. 
Box I.1 (concluded)

- The existence of mechanisms for collecting and analysing reliable information that can be used to evaluate the progress of the strategy and improve programmes. Any social strategy needs to ensure that scarce resources are used efficiently to deal with the most pressing social issues. To this end, it is essential to have adequate information for decisionmaking, with institutions devoting part of their capacity to the evaluation and follow-up of social actions and their impact. Specifically, institutional attributes related to transparency and accountability translate into the availability of social programme information through different channels (including electronic ones). Some of the information it is advisable to make public is: registers of recipients, the programme operating budget, expenditure reports and the availability of programme evaluations.

- The incorporation of oversight and auditing mechanisms that provide a basis for accountability and make it possible to discipline officials who do not comply with the rules. This means it is important for social programmes to have indicators that can be used to measure their progress or performance. Furthermore, the performance and outcomes of social programmes should be evaluated periodically so that the specific political dynamics of each can be revealed and understood in order to determine whether they are being used for electoral purposes. Lastly, social programmes should include complaint and reporting mechanisms for when any anomalies arise or they are used for political ends. These mechanisms and their method of use should be publicized both among the organization's staff and among the target population. Responsibility for this oversight could be entrusted to another public body, be it internal or external (intra-State mechanisms), or to civil society actors (social mechanisms).

- The participation of social actors to consolidate programme continuity. There are a variety of social actors with longer planning horizons than government actors and the ability to strengthen some social programmes. This offers a safeguard against programmes being discontinued because of short-term political shifts and creates extra programme capacity through specific collaboration and demands.

Source: John Ackerman, Organismos autónomos y democracia: el caso de México, Mexico City, Siglo XXI, 2007; Rolando Franco and Miguel Székely, "Institucionalidad social en América Latina", Project Documents (LC/W.312), Santiago, Economic Commission for Latin America and the Caribbean (ECLAC), 2010; Miguel Székely, "Cambios en la institucionalidad de la política de protección social en América Latina y el Caribe: avances y nuevos desafíos", Technical Note, No. 810, Washington, D.C., Inter-American Development Bank (IDB), 2015; Simone Cecchini and Rodrigo Martínez, Inclusive Social Protection in Latin America: a Comprehensive, Rights-Based Approach, ECLAC Books, No. 111 (LC/G.2488-P), Santiago, Economic Commission for Latin America and the Caribbean (ECLAC), 2012; Fabián Repetto and Fernanda Potenza, "Documento final de consultoría. Institucionalidad social y autoridad social en América Latina y el Caribe. Abordaje conceptual, avances y desafíos de la institucionalidad de la política social y de la protección social", 2015, unpublished; Eduardo Bohórquez, "Hacia una nueva arquitectura de la información pública y política social en el Distrito Federal", Ensayos para la Transparencia en el Distrito Federal, No. 9, Mexico City, Federal Institute for Access to Public Information, 2009; José Luis Machinea and Guillermo Cruces, "Instituciones de la política social: objetivos, principios y atributos", Institucionalidad social en América Latina, R. Franco and M. Székely (coords.), Project Documents (LC/W.312), Santiago, Economic Commission for Latin America and the Caribbean (ECLAC), 2010; Magdalena Sepúlveda, "The rights-based approach to social protection in Latin America: from rhetoric to practice", Social Policy series, No. 189 (LC/L.3788), Santiago, Economic Commission for Latin America and the Caribbean (ECLAC), 2014. 
The more highly developed social policy institutional framework is, the better the prospects of putting in place high-quality (effective, efficient, sustainable and transparent) social policies, be they sectoral, promotion or protection policies. ${ }^{3}$

Considering what has been said so far, the social policy institutional framework can be said to comprise the set of rules, resources and organizational structures upon and with which social policy operates, from diagnosis and prioritization of objectives to implementation and the evaluation of outcomes.

The social authority, for its part, is the State body responsible for discharging the government social policy function. Legitimized by the parties and with political support, it has the power to direct and coordinate social institutions and exercise leadership. Thus, supplementing what has been said by Acuña and Repetto (2007), the responsibilities associated with its governance function include:

- Setting and prioritizing the goals and targets that will guide policy, on the basis of a comprehensive overview of the issues involved.

- Setting standards, rules and regulations on the basis of which policy is to be designed and implemented;

- Designing plans, strategies and methodologies for action.

- Deciding on operational models and allocating responsibilities and functions to the areas and actors involved with the issue.

- Distributing resources as required to conduct the activities necessary to fulfil the responsibilities and functions assigned.

- Coordinating and regulating the actions of government and nongovernment, civil society and private sector actors participating in the different stages of social policy and programmeimplementation.

- Monitoring progress with activities, execution of the action methodology and achievement of operating targets in respect of quantity, time, form and costs.

- Systematizing relevant information and evaluating the results of policy implementation.

- Redefining the policy (scope, goals, targets and action methodology) in the light of the evaluation findings.

This is not all necessarily the responsibility of a single body, as authority may be collegiate or shared between a number of departments. Thus, intersectoral coordination bodies such as a social cabinet or economic and social council may be defined as the "social authority". 
There is also the possibility of identifying sectoral authorities and thematic social authorities (a national children's council, for example) that operate as specialized intersectoral commissions for dealing with some social issue or the needs of some population group or segment, and the sectoral authorities themselves when some ministry has governance and coordination capacities in some area of social policy.

Thus, the question must be which bodies formally possess the legitimate power to exercise the government function in the different spheres or sectors of social policy and its various components, and whether they have the formal and actual capacity to carry out this function.

Social problems are usually multifactorial in their causes and multidimensional in their manifestations. They thus call for comprehensive approaches in which the coordination function becomes crucial to the measures taken by the social authority and the thematic social authorities. ${ }^{4}$ This function concerns the relationships between actors, who need to be brought together with their different powers and resources to deal with complex problems and act in coordination when executing tasks and responsibilities within the framework of a common strategic direction.

A distinction is drawn between high-intensity and low-intensity intersectoral coordination, depending on how far-reaching it is (Cunill-Grau, Repetto and Bronzo, 2015; Repetto and Potenza, 2015a). Coordination is high-intensity when the various sectors work jointly on the different phases of the cycle of a policy or programme, i.e., when they participate in its design, execution and evaluation, sharing information and even financial resources, to deal with a problem they have jointly identified. It is low-intensity when public action is the sum of sectoral actions, with a basic action plan coordinated by some central authority. In this case, planning, budgeting and evaluation continue to be dealt with independently by the sectors, and coordination revolves mainly around operational matters.

Specific organizational models aside, it is important when analysing institutions to evaluate the degree of intersectoral coordination and likewise sectoral scope and coverage. For example, intersectoral action

\footnotetext{
4 To ensure comprehensiveness, the design of the programmes operated by a social protection system must include two axes: the horizontal axis (the different sectors of social policy action, such as social development, employment, health care, education, etc.) and the vertical axis (the administrative levels at which the policy and its programmes are executed, including private sector actors, civil society and the beneficiaries themselves). Another two axes need to be included if the range of programmes is to be really comprehensive and reflect the heterogeneity of the target population: a longitudinal axis (reflecting the characteristics of the different stages of the life cycle) and a transversal axis (identifying specificities of gender, race and ethnicity, labour market formality and area of residence, among others) (Cecchini and Martínez, 2011).
} 
may be oriented by a cross-cutting objective, such as the incorporation of the gender perspective or rights approach into all policies. It may also be designed to address some specific challenge, such as the eradication of extreme poverty or the establishment of integrated social protection systems. Thus, it may involve a set of specialized organizations or all actors concerned with social programmes, or indeed bodies in any area of public policy (PAHO/WHO, 2015).

Some analytical dimensions based on the considerations and references analysed will now be presented with a view to furthering the study of social institutions in the region, at the level both of overall social policy and of social protection systems in particular.

\section{B. The thematic and geographical scope of the institutional framework}

In recent decades, different institutional development processes have been undertaken in Latin America and the Caribbean with a view to improving the quality of social policies in general and social protection systems in particular. Thus, a first point for discussion is what social policies social institutions encompass.

The earliest studies of social policy institutions and authorities came out in the 1990s, at the same time as social investment funds were being developed. These funds, which spread throughout the region, were focused on efforts to combat poverty and its effects by expanding the coverage of health services, education and water and sanitation services, mainly by expanding infrastructure. This does not mean that social policies only arose in this period, since sectoral ministries have a long history of development in the region. However, the emergence of these new organizations created an interest in analysing the social policy institutional framework and its scope.

Thus, a discussion about the institutional framework of social policy should deal with two different levels of thematic coverage or scope:

(i) Extended. There are approaches that include the whole gamut of policies associated with the social functions of government and the public and private bodies involved in implementing them. Namely:

- sectoral policies, whose goal is to improve quality of life and guarantee rights through the provision of goods and services in the areas of health, education and housing, among others; 
- $\quad$ social promotion policies, which aim to develop capabilities by enhancing human capital and improving conditions in the environment (such as employment intermediation or training) in order to enhance workers' productivity and autonomous earning capacity;

- social protection, oriented towards ensuring universal access to basic levels of well-being and the exercise of economic, social and cultural rights. Following Cecchini and Martínez (2011, pp. 117 to 119), social protection functions are: (a) guaranteeing an income that makes it possible to sustain the basic quality of life deemed essential for personal development, which means that each country needs to determine this standard of living in the light of its conditions and resources; (b) identifying unmet demand and ensuring access to social services (including health, education and housing) and to promotion services by referring people to the institutions responsible for providing them; and (c) fostering decent work by promoting better labour policies to help overcome labour market risks, ensuring that people of working age are incorporated into the formal labour market.

(ii) Restricted. Other analyses focus only on policies related to poverty reduction efforts and non-contributory social protection, and on the government bodies with authority in these areas. With this second approach, the organizations usually meant by social institutions are social development ministries or secretariats and inter-agency coordination bodies dealing with these matters.

A second element that is vital to consider in the case of social policies particularly is their population coverage and the extent to which they apply to the population as a whole or are restricted to certain specific or priority segments or groups. Thus, two types of population coverage are identified:

(i) Universal. This is when institutions cover the whole population of a country without distinction.

(ii) Targeted. This term describes actions undertaken by institutions to guarantee the rights and meet the needs of certain segments of the population whose characteristics call for specialized public action. This category includes policies aimed at improving the welfare and enforcing the rights of children, those oriented towards the development of indigenous areas or peoples, and those centring on the inclusion and rights of persons with disabilities, among many others. 
Unlike the idea of thematic scope, which refers to specific goals relating to particular social functions, in the distinction based on population coverage the stress is on the characteristics of a policy's target population. Discussions of institutional arrangements for targeted policies usually take these policies to include all the social functions applicable to the population concerned, given the particular needs and wants affecting it. This distinction may seem simple in analytical terms, but it is of great importance when it comes to organizing the institutional framework. This is particularly true as regards the authority in charge of policy in each country and the coordination required between agencies responsible for themes and those focused on populations.

A third element observed in the work of institutions in the region are the differences in geographical scope, and thence the greater or lesser coverage and autonomy of the authority concerned. This scope may be national and subnational, or supranational and international.

(i) National. Institutions and authorities whose work is confined to the national sphere are usually the first to come to mind. This means, first of all, the central level, but it also encompasses the subnational scale (states, provinces, departments) and the local level as the main stages on which social policies are implemented.

(ii) Supranational or international. Working through different international and integration bodies, States have advanced with the development of social institutions at the global, regional and subregional levels. The agreements and commitments arrived at in these bodies and the cooperation policies deriving from them also contribute between them to the development of social institutions with synergistic effects that are important for national public policies and for the creation of shared tendencies and even common agendas for social development.

In view of all this, it is important when speaking of social policy institutional frameworks and their progress to consider and specify their thematic, population and geographical coverage and scope. These factors serve to frame the different governmental and international bodies involved, their coordination and linkage capacity (sectoral or horizontal at the central government level and vertical or territorial between different levels of government), their consistency when it comes to formally recognizing and effectively guaranteeing rights (particularly economic, social and cultural rights), the participation of different actors and accountability to participants, citizens and civil society, and the financial and management resources mobilized. 


\section{The dimensions of the social policy institutional framework}

Besides analysing the scope of the institutional framework of social policy, it is necessary to consider which elements or dimensions this study should focus on and how they interact to configure characteristic models, particularly at the national level, but also supranationally.

To this end, and in an effort to take the broadest possible view of the characteristics and diversity of models, the present chapter centres on four dimensions: the legal and regulatory dimension, the organizational dimension, the technical and operational dimension and the financing dimension.

\section{The legal and regulatory dimension}

As democracy has consolidated in the region and the rights approach has gained ground in the social sphere, the legal and regulatory dimension of social institutions has become very important. This is the legal underpinning upon which policies are designed and implemented and which regulates the participation of the different actors.

This dimension comprises each country's system of constitutional frameworks, laws and regulations. In addition, there are international treaties and agreements that have been signed or ratified and have domestic legal force or serve as a touchstone for commitments accepted by States in the social area at the national or international level.

Identifying and studying this set of legal and regulatory elements provides an initial indication of the commitments a country has accepted in the area of social policy vis-à-vis both the international community and its own citizens, and makes it possible to clearly identify the legal basis and hierarchical level of government actions in this area. The hierarchical level depends on whether the mandate for these actions originates in international commitments, the national constitution, organic or ordinary laws or lower-level regulations such as decrees or administrative instructions.

In summary, depending on its geographical coverage, this dimension comprises:

- International legislation: The commitments accepted by each country at the international level are embodied in the treaties or agreements they have acceded to, signed or ratified. In particular, it is important to know how a country stands with regard to the International Covenant on Economic, Social and Cultural 
Rights (ICESCR) and other treaties or conventions that may be linked to a specific social policy area or relate to a given target population, such as the Convention on the Rights of the Child or the Convention on the Rights of Persons with Disabilities. ${ }^{5}$ Lastly, consideration should be given to regional or subregional agreements and commitments that may constitute more ambitious and exhaustive frameworks. In the inter-American sphere, for example, there are a number of conventions and treaties of great social importance for the defence of human rights generally (the American Convention on Human Rights and its Additional Protocol in the Area of Economic, Social and Cultural Rights, or Protocol of San Salvador) and for specific issues and groups (the Inter-American Convention on the Prevention, Punishment, and Eradication of Violence against Women).

The importance of adding this international dimension to the analysis of the social policy institutional framework lies in the fact that it is often the source of mandates for the creation or reformulation of institutions, which are embodied in agencies that discharge the social functions of government. They can also be an incentive for civil society actors to mobilize and voice new social demands and for political and governmental actors themselves to offer policy proposals.

- National legislation: Where national legislation on social matters is concerned, it is first necessary to ascertain the extent to which the constitution incorporates and provides guarantees for the enforcement of economic, social and cultural rights. The existence of this legal underpinning contributes to the continuity in time of these strategic goals.

It can also happen that guarantees for these rights are included in lower-level legal frameworks, such as organic, general or sectoral laws, codes and regulations. In this case, it is important to consider both social rights in general (education, employment, health, housing, etc.) and specific aspects of development or social protection (contributory or non-contributory and care-related actions) or particular populations (children, women, indigenous people, etc.).

Major instruments include the international conventions on the rights of the child, the International Labour Organization (ILO) Social Security (Minimum Standards) Convention, 1952 (No. 102), the Convention on the Elimination of All Forms of Discrimination against Women and the Convention on the Rights of Persons with Disabilities. 
Legal support may also be found in the administrative decrees regulating a government's social policy or in more context-specific instruments that embody the vision of development in a particular period (whether development in general or social development specifically) and the strategies proposed in consequence. These definitions are contained in management instruments such as national development plans or strategic plans for each social area or for certain population segments.

Lastly, besides the commitments, rights and guarantees stipulated in the different laws and regulations, it is important to emphasize the legal underpinnings that define, orient or serve as a framework for the other institutional dimensions. These include, for example, legal provisions defining the mandates, responsible authorities and other actors involved in social policy design and implementation, and likewise the regulations governing operational procedures and tools and the laws structuring budgets for policy implementation.

From the point of view of the rights approach, the formalization of commitments to guarantee social rights is usually regarded as a necessary, although not sufficient, feature of social institutions. This specific guarantee also depends on the availability of resources and the political will to gradually deploy them and establish the policies, mechanisms and programmes needed to make them effective (Sepúlveda, 2014).

\section{The organizational dimension}

This dimension encompasses the formal structure and models for decisionmaking and for communication and coordination between the different actors participating in policy implementation. On the supranational level, this includes international, regional and subregional agencies. On the national level it involves the central, subnational and local levels together with civil society organizations, the private sector and the target population itself, each with its own role.

Deriving from the legal and regulatory framework and from the general organization of each State, the organizational dimension refers to the organizations with authority over and thus responsibility for coordination and governance functions in social matters. It also refers to the governmental structure characterizing the different organizations 
and the scope of their mandates. In short, it reflects the distribution of functions in social matters, something that may encompass social policy as a whole or some particular area of it.

In combination with the legal basis, and reflecting the level of institutional development, the hierarchical level of each body has to have been prescribed in a constitutional provision or in an organic or ordinary law, a presidential decree or a ministerial resolution. The higher-ranking the legal statute in which it originates, the greater the expectations will be for its sustainability over time and the degree of recognition by the actors involved in its implementation and operation. In addition, the legal underpinning by which the structure is upheld, the social authority designated, the latter's mandate determined and power distributed is crucial to the legitimacy of processes and decision-making.

Of course, a clear statutory allocation of coordination models and responsibilities is not necessarily reflected in practice. It is a necessary condition, however. If there is legal confusion or vagueness, it will be difficult to achieve coordination and complementarity between the actors involved. Considerations of this kind are particularly important in social policy areas that fall within the remit of subnational governments (decentralized policies) or involve strong participation by social organizations and the private sector (policies that are participatory or involve outsourcing or privatization).

As indicated, besides social policy as a whole, consideration is also given in the organizational dimension to aspects involved in the creation of agencies with specific mandates (reducing poverty, implementing social protection policies or social development mechanisms). This information provides a basis for comprehending the structure and functions of social policy in a given country (see diagram I.1). Certain questions need to be asked. What legal status do the different agencies have and what is the status of the law creating them? Which areas of central government are in charge of social policy? What is their rank (ministries, secretariats, presidential offices)? What institutional mechanisms do they use to relate to one another? Which area exercises governance and coordination functions (as applicable) over social policy as a whole? Which areas exercise governance and coordination functions over specific components of social policy that have an inter-agency character? Which government and non-government actors are part of the different bodies at each organizational level? 


\section{Diagram I.1}

\section{Components of the organizational dimension at the central government level}

Levels of coordination and government structure
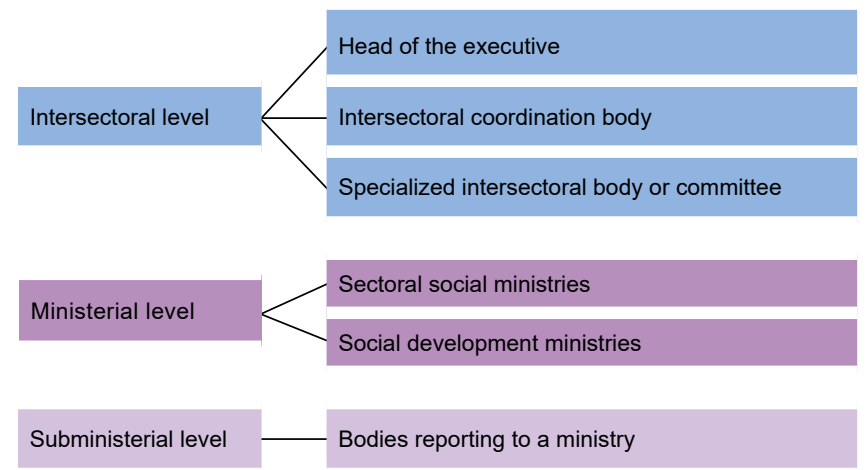

Source: Prepared by the authors, on the basis of F. Repetto and F. Potenza, "Institucionalidad social y autoridad social en América Latina y el Caribe: abordaje conceptual, avances y desafíos de la institucionalidad de la política social y de la protección social", 2015, unpublished.

On the basis of what has been said so far, the elements to be considered when characterizing the organizational dimension of institutions at the national level include:

- Authority: As already indicated, a central element in the analysis of the organizational dimension consists in determining which organizations fulfil the functions of a social authority and whether authority is concentrated in a single body or is shared. For example, it might be divided between collegiate bodies, such as a social cabinet coming under the auspices of the office of the president, or between intersectoral coordination councils specializing in a social issue (such as poverty reduction) or in a population group (such as children). There may also be cases where a particular sectoral authority has a general mandate to coordinate the other ministries in the social area (see diagram I.2).

The legal basis on which roles and responsibilities are determined is a key indicator of the degree of institutionalization attained in the formation of the authority. The date when the social authority was created is also important, reflecting its stability over time, since it makes a great difference whether these bodies are of very recent creation, or have yet to pass the test of outliving the government that founded them, or are of long standing, with an accumulated history and track record.

The higher the level of these social authorities in the government structure, the greater their potential influence over decisionmaking and policy development will be. 


\section{Diagram I.2}

\section{Types and scope of social authorities}

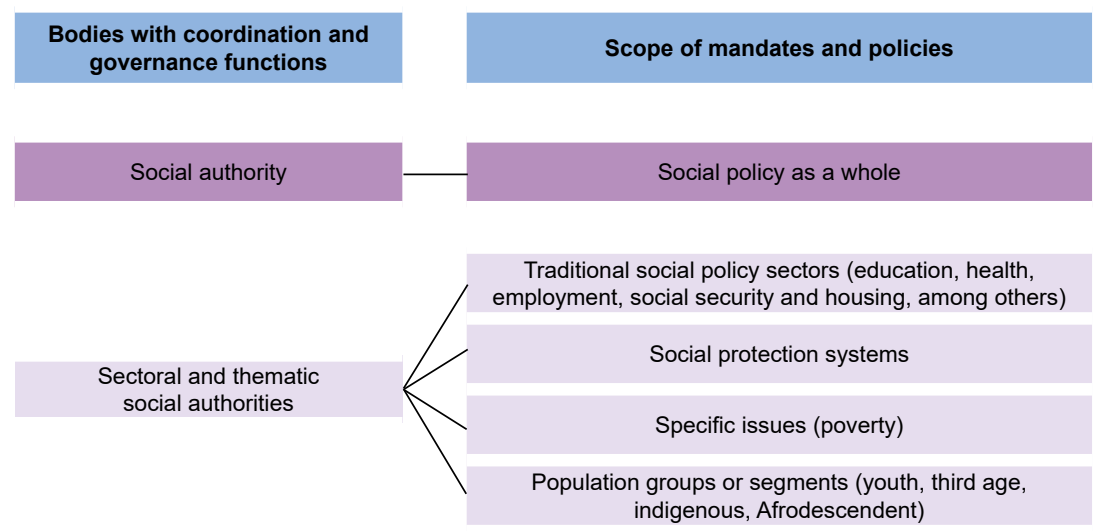

Source: Prepared by the authors, on the basis of F. Repetto and F. Potenza, "Institucionalidad social y autoridad social en América Latina y el Caribe: abordaje conceptual, avances y desafíos de la institucionalidad de la política social y de la protección social”, 2015, unpublished.

- Government structure: The second thing to determine is which organizations and actors form part of social policy implementation (office of the president or vice president and its delegates, ministries, secretariats, institutes, offices and programmes, among others) or involve themselves in it, how authority is delegated between the different levels of government (central, subnational and local) and what role is played by external agencies, community and non-governmental organizations and the population at large.

In cases where there is a collegiate social authority, its structure reflects the level of sectoral commitment and autonomy in decision-making (e.g., when the office of the president or vice president directly participates), the degree of coordination with other government functions (e.g., when economy ministries participate) and the role assigned to actors outside the government (representatives of academic institutions, civil society organizations, etc.).

Characterizing the structure also makes it possible to determine the extent to which authority is concentrated or dispersed, and thence the scope for operational autonomy. In other words, whether implementation is centralized, deconcentrated or decentralized, whether certain functions or services are outsourced and whether civil society participation is encouraged.

This information is supplemented by the type of functions allocated to each actor in the structure, particularly the social authority dealing with strategic planning and prioritization 
(policy guidelines and orientations, involvement in the budgeting process, monitoring and evaluation), governance, coordination and regulation of other non-governmental actors and the resolution of conflicts between institutional actors in the sector.

The area of responsibility and type of functions allocated present certain peculiarities if the focus is placed on the level of "sectoral authorities". In this case, it is worth knowing their internal structure, with the sections making them up and the specific issues and populations targeted by each. This description should also include current and previous processes of organizational change and their rationale, goals and linkages to policy objectives.

The more participatory and decentralized the structure is, the greater the demands will be in terms of inter-agency coordination. This need for coordination includes both vertical linkage (between levels of government) and horizontal linkage (between sectors).

One way of organizing the information on how social institutions are structured is to consider three levels:

(i) The interministerial level, to identify the bodies carrying out the work of coordination at the central level and having authority over social matters (office of the president, interministerial or ministerial body, etc.) and the bodies responsible for coordination between ministries and other divisions of the executive that decide the directions and priorities of public policy in relation to social development (e.g., social cabinets, economic and social councils and internal coordination departments in the office of the president or prime minister). Besides interministerial coordination, this level may involve mechanisms for territorial coordination between the central government and other levels of government. Lastly, it may include intersectoral coordination bodies that are thematically specialized or focused on meeting the needs of specific population groups (e.g., national children's councils).

(ii) The ministerial level itself, to analyse the configuration of the different social ministries (or equivalent bodies in the executive) in charge of social or governance functions. It is necessary to consider their mandates (functions allocated to them) and legal status to ascertain the relative importance of social development within the central government structure and its degree of autonomy and specialization by comparison with other sectoral areas of government. In particular, it is 
important to know whether there is a social development ministry, not only to ascertain the degree of importance given to the subject, but to learn what its functions are, what policy areas and population groups it concerns itself with and what resources and capabilities it has for the purpose.

(iii) Lastly, there is the subministerial structure, comprising the bodies that implement and operate specific social actions and programmes, which can be divided by policy area (e.g., care, disability) or specific target population groups (e.g., youth or older adult institutes). Also included are a variety of mechanisms for the management and operational coordination of social programmes, which may be intraministerial and territorial (the relationship between levels of government in particular), each with their own peculiarities as regards the powers and autonomy of the subnational levels (depending on how each country is divided for political and administrative purposes).

The degree and type of responsibility taken on by each of the actors in the organizational structure is also an element characterizing this institutional dimension. Székely (2010 and 2015) argues that the legal systems of the Latin American countries establish at least three types of codes of conduct governing the behaviour of a public employee, each of which provides for causes of liability and the corresponding penalties. The first concerns political liability and is intended to sanction higher-ranking public officials (the president, vice presidents, ministers, legislators, local authorities). The second concerns the administrative liabilities someone may incur by failing to meet public service obligations. The third concerns the penal liability that arises when a crime is committed.

- Models of communication: The way decisions are taken and notified among actors has particular characteristics in each country, associated with the structure of its institutions and the laws in force.

The formalization of communications and the establishment of protocols for disseminating them (internally and externally) are measures that favourably impact the clarity of decision-making processes and of the roles of the actors involved in them. This helps to make communications predictable and mitigate implementation risks, thereby enhancing institutional depth. The downside is that instruments of this type may exacerbate the more negative aspects of bureaucracy, making it less flexible and efficient at dealing with changing situations. 
These characteristics provide an initial overview of the limitations and opportunities these bodies may encounter when exercising coordination and governance functions. A corollary is that the more specialization there is, in the absence of a capacity for institutional coordination, the greater the risk of dispersion, duplication and fragmentation of public action. As noted earlier, the more formalized and explicit the structure responsible for implementation, the more firmly grounded and sustainable the institution will presumably be.

As is pointed out further on, consistency between mandates, the government structure, management instruments and the sums or resources managed is a major determinant of policy and programme outcomes in the social area.

\section{The technical and operational dimension}

The third analytical dimension of the social policy institutional framework is the technical and operational dimension. Included in it are the instruments and tools needed to implement policy in a way that is efficacious (so that implementation and coverage goals are met), efficient (in the use of resources), effective (policy goals are achieved), transparent and participatory. Most earlier studies of social institutions have paid the greatest attention to this dimension, to the detriment of the legal and regulatory dimension (which is central to the rights approach), the organizational dimension and the financing dimension. This may be understood as the result of increased interest during the 1990s in the introduction of efficiency and effectiveness criteria into the organizations in charge of poverty reduction programmes.

This dimension requires consideration of the procedures, physical resources and technical capacities available for the implementation of public policies generally, or social policies alone. To analyse it, three major categories may be highlighted: (i) strategic planning instruments and processes; (ii) information systems for diagnosis, monitoring and evaluation; and (iii) transparency and accountability tools.

(i) Planning and programming: This refers to the prioritization and implementation tools available to the social authority and the different actors in the structure so that they can meet their institutional goals effectively and efficiently. They may be determined by the same law as defines their functions (law on ministries) or specified in their institutional regulations and plans (national development plans or lower-ranking strategic plans). In summary, the point is to detect the existence and functioning of formal procedures for the implementation of strategic planning and operating plans to guide results-based management, and 
likewise the availability of tools, with clear targets, process maps, deadlines and budgets, as well as sufficient technical resources for their implementation (physical capacity and sufficient professional and technical workers of the requisite quality).

It is not just a matter of there being formal procedures, but of knowing what type of planning is involved. In particular, it is important to know whether planning is results-oriented and whether instruments for managing quality are available. Examples are process planning, the programming-budget link, the appropriateness of the organizational structure and formal monitoring, auditing and oversight procedures.

The instruments described can be used to limit operatives' margin for discretionary action, particularly as regards how programmes work and the way the goods or services they provide are allocated or distributed. Although the social authority or the thematic social authority may prompt and even compel resolution of these issues, the development and practical application of such instruments are up to each of the sectors. Of great importance is the existence of programme and service operating rules, with clearly defined criteria and procedures for sharing out the resources on offer, together with a legal framework to regulate and sanction inappropriate behaviour.

(ii) Information, monitoring and evaluation systems: This is about the availability of in-house procedures for gathering and analysing data on the social situation, together with registers or records of participants and follow-up of physical and budgetary implementation. In other words, systems that yield information useful for decision-making in the different operational stages (diagnosis, formulation, monitoring and process and impact evaluation). Here it is necessary to determine not only whether systems exist and what their characteristics are, but how closely they are integrated.

Besides analysing the fit between the processes associated with each operational stage, it is particularly important to know whether these systems are circumscribed to the management of specific programmes or projects or encompass a policy in its entirety. In the case of the social authority and the thematic social authority, it is especially important to know the extent to which they have been able to pursue the production of evaluations of policies (considered in their entirety) and not just of isolated programmes or actions. 
Of particular importance is the comprehensiveness of the evaluation function, since its final contribution differs depending on the stage in the life cycle of the project it is used for. If applied ex ante, during formulation, it provides decision-making criteria for accepting a specific policy proposal or ranking the alternatives considered by their cost-impact (or cost-benefit) ratios. If applied ex post, during operation or after completion, it can be used to determine the degree to which performance and outcome goals have been met and the cost that has been incurred. It also means that the operation can be reoriented by updating the design or adapting to changing circumstances. It likewise makes it possible to learn from experience. Thus, evaluation and monitoring serve as a reference framework for formulating a programme or project and for measuring the efficacy, efficiency, effects and impacts of this initiative and the relationships between actions and outcomes. Consequently, it is crucial to consider ex ante and ex post evaluation (Martínez, 2015; Cohen and Martínez, 2004).

The evaluation function involves a number of stages, most particularly the clear identification of the indicators that will be used to evaluate programmes (especially outcome or impact indicators), the existence of mechanisms to enable information to be regularly obtained and analysed, the implementation of monitoring processes, the performance of periodic evaluations and the combined analysis of the two processes.

From a macro perspective, it is also necessary to know the extent to which evaluations are comprehensive or are isolated exercises by particular agencies. In this context, the social authority or the thematic social authority can play a central role by prioritizing the evaluations that need carrying out (in agreement with the highest authorities in the country and the actors involved in each case) and determining their scope. Specific technical assistance may be provided both by these authorities themselves and by specialized bodies in each country's institutions, such as the National Council for the Evaluation of Social Development Policy (CONEVAL) in Mexico.

(iii) Accountability and transparency mechanisms: These turn on the relationship between internal policy management, resource use and budgetary allocations, which ultimately brings in new actors (such as the legislature, which approves and oversees funding) and links the work of the social authority (and other agencies in this area) to the economic authority. 
These procedures also include transparency and citizen oversight mechanisms, enabling the authorities to report on their actions. To carry out these processes, it is vital to have established bodies responsible for apprising citizens of results and to strengthen the use of information and communication technologies.

Mention should be made of the distinction between vertical (or social) accountability and horizontal (or intra-State) accountability. In the first case, government actors have to respond to the questionings and demands of different social actors (public opinion, civil society, programme beneficiaries and so on), and transparency and social oversight play a key role. Horizontal accountability mechanisms, meanwhile, involve one government body having legal and formal authority to oversee the actions of another public body as part of a "legal institutionalization of mistrust" (Mainwaring and Welna, 2003; O'Donnell, 2003).

Although this last aspect can be related to the role played by social policy and programme information, monitoring and evaluation systems, the responsibility falls on more general auditing and public policy oversight mechanisms at the different levels of government. Thus, it is indispensable to advance with both dimensions so that social policies and programmes are as little subject as possible to political exploitation or clientelism and generate far-reaching social legitimacy, with implementation that is subject to verifiable rules and procedures, complies with the law and is open to public scrutiny.

\section{The financing dimension}

The fourth dimension proposed is financing, study of which contributes two significant elements to the analysis of the social policy institutional framework. First, considering the scale of the resources allocated to social policy financing provides an idea of the priority given to these issues in a particular country from the perspective of public policymakers. Second, the level of resourcing is also indicative of public officials' room for manoeuvre. Budgets that are small or inadequate to deal with complex and far-reaching social issues are an insuperable barrier for social policy, exceeding the potential of management as such.

The aspects that serve as important indicators for understanding this dimension include in particular:

- Funding sources: The first thing to consider in this dimension is where resources come from. When these mainly depend on a country's own revenues and are set by a special law 
or are a protected item in the national budget, the policies financed with them are likely to be financially secure and stable and institutionally entrenched. Conversely, when they depend on loans, donations from abroad or private voluntary contributions, financing is likely to be vulnerable and the degree of institutionalization inadequate.

The rules underpinning these financing sources also facilitate or limit the autonomy or discretion agencies have in the use they make of the resources allocated to them.

- Adequate resourcing: It is difficult to identify whether or not the budget allocated to a particular social area is adequate to deal with the problems that need solving. However, it is possible to arrive at a characterization by calculating its per capita amount and rate of growth as a share of total spending or gross domestic product (GDP), or from the point of view of its historical evolution. These indicators can be used to analyse both the availability of resources to fund social policy and their stability over time.

From the point of view of social institutions, and in the light of the information available, two important indicators should be considered: (i) the relative amount of social spending from a functional perspective and (ii) the amount and proportion of fiscal resources controlled by key government authorities, such as social development ministries.

- Implementation capacity: Irrespective of the scale of funding, it is also important to determine the implementation capacity of the bodies in charge of social policy and the difference between the funding allocated and that actually spent. Possible reasons for inadequate execution are usually connected to elements in the technical and operational dimension, particularly the profile of the team in charge of the policy or programme, and to the political, social, economic and environmental context in which a policy is carried out. Incorporating information on these subjects provides an overview of what is happening in social areas by contrast with other sectors of public policy. It also provides a basis for internal comparison and analysis (e.g., of the implementation capacity of the agencies responsible for contributory social protection vis-à-vis that of those in charge of non-contributory social protection).

Lastly, it should be mentioned that a more detailed analysis of financing also provides a greater insight into the connection between the social authority and the economic authority. This sheds light on certain 
matters of particular interest, such as the way decisions are taken about the scale of resources allotted to a particular sector, policy or programme; the true extent of the social authority's participation in this decision-making; the kind of partnerships that are built up between social areas to create a counterweight to decisions based essentially on fiscal arguments; and the type of relationships and negotiations established by the economic authority with social areas (whether bilateral or joint).

This analytical perspective combines elements of formal institutions (what the rules prescribe for the purposes of the budgetary allocation process) and informal ones (practice, customs, organizational memory of these processes). The qualitative character of this information may mean it exceeds the capacity for systematic review, but it is essential for it to be considered in specific studies.

\section{Final remarks}

As this chapter has detailed, approaches to the subject of the social policy institutional framework in the region over recent decades have emphasized one or two dimensions, such as the legal, organizational or operational dimension. In the present case, an attempt has been made to look more closely at these dimensions and open out the analysis to other areas. The starting point was the realization that progress on high-quality (effective, efficient, sustainable and transparent) social programmes requires a complementary and thus comprehensive approach to the different dimensions. This does not mean that with the elements dealt with here the whole analysis is complete. On the contrary, the idea is to encourage further approaches so that the subject is studied more and more exhaustively.

A first element to be highlighted is the thematic scope that is intended when social institutions are discussed. Depending on the reference framework used, they may encompass all social functions or be confined to those most oriented towards poverty eradication and non-contributory social protection. It is essential for this framework to be specified when attempting this type of analysis.

A second important element is geographical scope. A genuine understanding of institutions does not confine them to the national sphere and still less to central government, as is usually done. The latter is certainly very important, but targets, approaches and standards derive from international commitments and mechanisms for discussion and agreement between countries. At the same time, cooperation between different countries' national institutions leads to reciprocal learning and important synergies. Much the same happens with the 
subnational level and the participation of different public and private actors. The linkages between these and their operational capacity are key determinants of public policy.

A third element is the specificity of social policy. This aspect is usually organized at once by sector and by population segment, resulting in numerous areas of overlap and shared mandates. What is highlighted here as in no other policy area is that inter-agency coordination is a structural determinant in the organization and achievements of this policy. At the same time, it strains the significance and legitimacy conferred by different actors on the social authority of each country.

Briefly put, it can be deduced from the analytical proposal set out in this chapter that the legislative and organizational dimensions serve to define the characteristics of a country's social authority, i.e., to establish the body or bodies in the State structure that have the powers and formal mandate to exercise the governance function in the area of social development, determine the legal underpinnings on which this authority rests and analyse the different agencies participating in policy management, their systems of coordination and their operational linkages. These are the foundations and structure upon which policy is to be implemented.

Effective institutional development involves determining the rules, authority, organizational model, mandates and systems of coordination and communication followed. However, these decisions do not usually form part of the design of solutions to optimize impact and efficiency, but of the general framework within which this design is carried out. Being aware of opportunities and limitations in these areas is crucial when the aim is to meet the challenge of inclusive, rights-based social development.

The technical and operational dimension and the financing dimension, meanwhile, supply the analysis of the different types of resources available to the organization for fulfilling its mandates and rules. The operating infrastructure and financing model determine the operational capacity limits for these policies. Without the right procedures, needful information, trained personnel and stable funding, among other things, high-quality policies cannot be developed.

On the basis of the analysis of these elements and their mutual consistency, the next chapter analyses the region's current institutions in the sphere of social development policies. This analysis is carried out by considering the government bodies responsible for the design and implementation of social inclusion and development and poverty reduction strategies. As will be seen, the institutional structures for social policy vary greatly between the different countries. Nonetheless, they have all shown progress in the last three decades, whether in the legal and 
regulatory basis of policies, models of organization and social authority, technical and management tools or resourcing and financing systems. Mandates and coordination mechanisms have expanded. Increasingly, the latter are not restricted to poverty reduction functions but encompass the construction of more integrated social protection systems and guarantees of rights. However, great challenges remain, as well as great opportunities, on the path to high-quality social policies.

\section{Bibliography}

Ackerman, J. (2007), Organismos autónomos y democracia: el caso de México, Mexico City, Siglo XXI.

Acuña, C. H. and F. Repetto (2007), “Un aporte metodológico para comprender (y mejorar) la lógica político-institucional del combate a la pobreza en América Latina", Working Paper, No. 44, Buenos Aires, University of San Andrés.

Bohórquez, E. (2009), "Hacia una nueva arquitectura de la información pública y política social en el Distrito Federal", Ensayos para la Transparencia en el Distrito Federal, No. 9, Mexico City, Federal Institute for Access to Public Information.

Braun, M. and C. E. Vélez (2004), "Retos institucionales para la equidad y sustentabilidad del desarrollo social en América Latina", Washington, D.C., Inter-American Development Bank (IDB).

Cecchini, S. and R. Martínez (2012), Inclusive social protection in Latin America: a comprehensive rights-based approach, ECLAC Books, No. 111 (LC/G.2488-P), Santiago, Economic Commission for Latin America and the Caribbean (ECLAC).

Cohen, E. and R. Martínez (2004), “Manual. Formulación, evaluación y monitoreo de proyectos sociales", Santiago, Economic Commission for Latin America and the Caribbean (ECLAC).

Cunill-Grau, N., F. Repetto and C. Bronzo (2015), "Coordinating sectors and institutions for building comprehensive social protection", Towards universal social protection: Latin American pathways and policy tools, S. Cecchini and others (eds.), ECLAC Books, No. 136 (LC/G.2644-P), Santiago, Economic Commission for Latin America and the Caribbean (ECLAC).

ECLAC (Economic Commission for Latin America and the Caribbean) (2016a), Horizons 2030: Equality at the Centre of Sustainable Development (LC/G.2660/ Rev.1), Santiago.

(2016b), Panorama Social de América Latina 2015. Documento informativo, Santiago.

(2015), Inclusive social development: the next generation of policies for overcoming poverty and reducing inequality in Latin America and the Caribbean (LC/L.4056(CDS.1/3)), Santiago.

Franco, R. and M.Székely (2010), "Institucionalidad social en América Latina”, Project Documents (LC/W.312), Santiago, Economic Commission for Latin America and the Caribbean (ECLAC).

Gargarella, R. (2013a), “Dramas, conflictos y promesas del nuevo constitucionalismo latinoamericano", Anacronismo e Irrupción. Revista de Ciencia y Filosofía Política, vol. 3, No. 4.

(2013b), Latin American Constitutionalism, 1810-2010: The Engine Room of the Constitution, New York, Oxford University Press. 
Irarrázaval, I. (2006), “Institucionalidad de la política social en Chile. Propuestas para los nuevos desafíos", La nueva realidad de la pobreza en Chile, Santiago, Liberty and Development Foundation.

Kaufmann, J., M. Sanginés and M. García Moreno (2015), Building Effective Governments: Achievements and Challenges for Results-Based Public Administration in Latin America and the Caribbean, Washington, D.C., Inter-American Development Bank (IDB).

Machinea, J. L. and G. Cruces (2010), “Instituciones de la política social: objetivos, principios y atributos", Institucionalidad social en América Latina, R. Franco and M. Székely (coords.), Project Documents (LC/W.312), Santiago, Economic Commission for Latin America and the Caribbean (ECLAC).

Mainwaring, S. and C. Welna (2003), "Introduction", Democratic Accountability in Latin America, Oxford University Press.

Martínez, R. (2015), "Monitoring and evaluation of social protection policies and programmes", Towards universal social protection: Latin American pathways and policy tools, Simone Cecchini and others (eds.), ECLAC Books, No. 136 (LC/G.2644-P), Santiago, Economic Commission for Latin America and the Caribbean (ECLAC).

O'Donnell, G. (2003), "Horizontal accountability: the legal institutionalization of mistrust", Democratic Accountability in Latin America, vol. 1, Scott Mainwaring and Christopher Welna, Oxford University Press.

PAHO/WHO (Pan American Health Organization/World Health Organization) (2015), Intersectoral Action and Health Equity in Latin America: An Analytical Approach, Washington, D.C.

Repetto, F. (2004), “Capacidad estatal: requisito necesario para una mejor política social en América Latina", INDES Working Paper, I-52, Washington, D.C., InterAmerican Development Bank (IDB).

Repetto, F. and F. Potenza (2015a), "Documento final de consultoría. Institucionalidad social y autoridad social en América Latina y el Caribe. Abordaje conceptual, avances y desafíos de la institucionalidad de la política social y de la protección social". (2015b), "Institucionalidad social y autoridad social en América Latina y el Caribe: abordaje conceptual, avances y desafíos de la institucionalidad de la política social y de la protección social", unpublished.

Sepúlveda, M. (2014), "The rights-based approach to social protection in Latin America: from rhetoric to practice", Social Policy series, No. 189 (LC/L.3788), Santiago, Economic Commission for Latin America and the Caribbean (ECLAC).

Stein, E. and others (eds.) (2008), Policymaking in Latin America: How Politics Shapes Policies, Washington, D.C., Inter-American Development Bank (IDB).

Székely, M. (2015), "Cambios en la institucionalidad de la política de protección social en América Latina y el Caribe: avances y nuevos desafíos", Technical Note, No. 810, Washington, D.C., Inter-American Development Bank (IDB). (2010), "Midiendo el nivel de institucionalidad de las políticas sociales en América Latina", Institucionalidad social en América Latina, R. Franco and M. Székely (eds.), Project Documents (LC/W.312), Santiago, Economic Commission for Latin America and the Caribbean (ECLAC). 
Chapter II

\title{
Social development and social protection institutions in Latin America and the Caribbean: overview and challenges
}

\author{
Rodrigo Martínez ${ }^{1}$ \\ Carlos Maldonado Valera ${ }^{2}$
}

\section{Introduction ${ }^{3}$}

In view of the dimensions identified in the first chapter, this one describes the key features, achievements and challenges faced by Latin American and Caribbean countries in developing an institutional framework that delivers a high-quality social policy (one that is effective, efficient, sustainable and transparent), with a view to overcoming poverty and achieving social development and inclusion. The first part of the chapter provides an overview of the legal and regulatory frameworks that characterize the region. It offers both an international and a national perspective, to develop a scenario beyond national frameworks and to describe the differences and similarities between individual countries. It also highlights the

Senior Social Affairs Officer of the Social Development Division of the Economic Commission for Latin America and the Caribbean (ECLAC).

2 Social Affairs Officer of the Social Development Division of the Economic Commission for Latin America and the Caribbean (ECLAC).

3 The authors thank Social Affairs Officer, Guillermo Sunkel, and consultants Gabriel Kattan, Matías Salces and Fabiana Pierre, all of the Social Development Division of ECLAC, for their collaboration in the collection, systematization and analysis of information on social institutions in Latin America and the Caribbean. 
particularities of the region in terms of the State commitments assumed under various international legal instruments of major importance for social development and progress made in guaranteeing rights. Secondly, it studies the organizational dimension of social policy institutions, by considering the key features of regional forums dedicated to social development, and also the organizational characteristics and key social authorities at the national level. It describes the mandates and features of ministries of social inclusion and development, along with the governmental mechanisms in charge of certain key segments of the population and the institutional affiliation of conditional cash transfer and social pension programmes. This twin approach highlights how a social agenda has been built at the regional level, with a number of recurring themes, in the form of a dialogue in various forums between the national and regional levels. It also points up some common difficulties in terms of coordination. Thirdly, this chapter provides an overview of the region's main policy and management instruments within the social sector, with a view to showcasing both the advances of recent decades and the challenges that remain. Fourthly, it considers the financing of social policy institutions, focusing on total social spending, broken down into its main functions and the budget of the ministries of social inclusion and development in the region as a share of total public expenditure, to give an idea of the budgetary importance of such entities. The closing section offers comments and reflections on the preceding discussion.

\section{A. International, regional and national legal and regulatory frameworks}

The legal basis of each country's social policy has different reference points and components. The initial level consists of the mandates and objectives proposed in cooperation and integration instruments and in various international forums, which impose a commitment on the States that adhere to them. These are in addition to the rights established in the constitution and in the different national legal instruments and regulations existing in each country.

\section{International framework}

The international instruments that frame social policies at the global and regional levels include the Universal Declaration of Human Rights of 1948, followed by the conventions of the International Labour Organization (ILO), in particular the Equal Remuneration Convention, 1951 (No. 100), the Social Security (Minimum Standards) Convention, 1952 (No. 102), the Discrimination (Employment and Occupation) Convention, 1958 (No. 111) and the Indigenous and Tribal Peoples Convention, 1989 (No. 169); the 
International Covenant on Economic, Social and Cultural Rights (ICESCR), of 1966, as well as the American Convention on Human Rights and the Additional Protocol to the American Convention on Human Rights in the Area of Economic, Social and Cultural Rights (San Salvador Protocol), both signed within the framework of the Organization of American States (OAS), in 1969 and 1988, respectively. The international instruments that have served as a benchmark for national legislation include the Beijing Declaration and Platform for Action (1995) on gender equality, signed by 31 of the region's countries, or the Durban Declaration and Programme of Action (2001), to combat racism, racial discrimination, xenophobia and related intolerance at the national, regional and international levels, signed by 28 countries. ${ }^{4}$ In addition, the Programme of Action of the International Conference on Population and Development, adopted in 1994 at the International Conference on Population and Development in Cairo, attended by 31 countries of the region, has been highly valuable in guiding social policies and fostering the adoption of a rights approach.

Although some of these instruments may seem somewhat remote in time, they have had a fundamental influence on social policy in this century. With the momentum given by the Copenhagen Declaration on Social Development of 1995, and the Millennium Declaration of 2000 and its Millennium Development Goals, they have made it possible to give greater importance to combating poverty and reducing inequalities in health, education, work, housing and discrimination on the grounds of gender and race or ethnicity. These efforts have been given renewed momentum today with the 2030 Agenda for Sustainable Development, which imposes new commitments and challenges on all countries and on the social policy framework at the national and regional levels.

As shown in figure II.1, 29 of the 33 countries of Latin America and the Caribbean, have affiliated (explicitly or implicitly) to the International Covenant on Economic, Social and Cultural Rights (ICESCR). Nonetheless, only in 14 of them has this instrument been signed and ratified by the legislature. Meanwhile, the Protocol of San Salvador on Economic, Social and Cultural Rights has only been acceded to by 16 countries. The specific international conventions with greatest adherence in the region are the Convention on the Rights of the Child and the Convention on the Elimination of All Forms of Discrimination against Women, which have received ratification or accession from all 33 countries. In addition, 32 countries have ratified or acceded to the International Convention on the Elimination of All Forms of Racial

Approved, respectively, at the Fourth World Conference on Women, held in Beijing in 1995, and at the World Conference against Racism, Racial Discrimination, Xenophobia and Related Intolerance, held in Durban (South Africa) in 2001. See [online] http://www.un.org/ womenwatch/daw/beijing/pdf/Beijing\%20full\%20report\%20S.pdf and http://www.un.org/ en/events/pastevents/cmcr /aconf189_12.pdf. 
Discrimination. The figure also shows that the recent 2006 Convention on the Rights of Persons with Disabilities has been ratified by or acceded to by 30 countries. ${ }^{5}$

Figure II.1

Latin America and the Caribbean (33 countries): signature and ratification or accession of agreements, conventions and conventions related to economic, social and cultural rights (Number of countries)

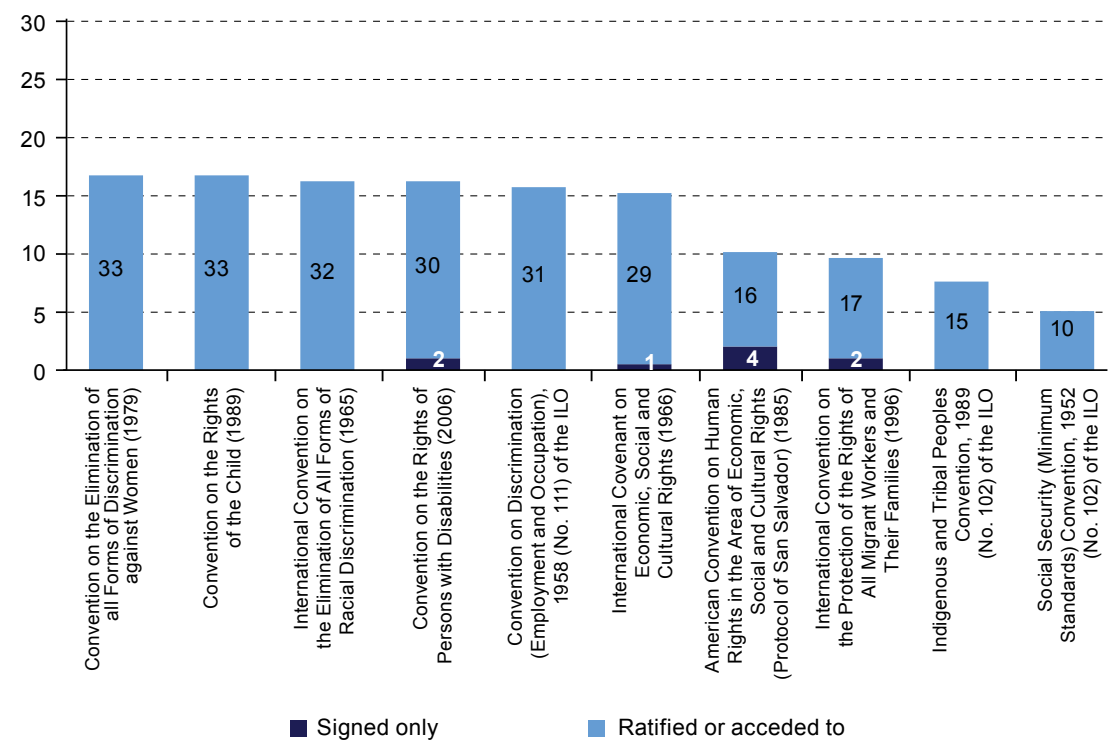

Source: Economic Commission for Latin America and the Caribbean (ECLAC), on the basis of official information from the respective countries.

In the labour domain, the ILO Discrimination (Employment and Occupation) Convention, 1958 (No. 111), has been ratified by the vast majority of countries in the region. This is considered to be the first international instrument on discrimination and protects all workers against discrimination based on race, colour, gender, religion, political opinion, national extraction, social origin and any other criterion that each State may define. Moreover, upon ratification, countries assume the commitment to develop policies to promote equality of opportunities and treatment in these areas.

Other ILO conventions on social protection have gained a lower level of ratification in the region. These include the Social Security (Minimum Standards) Convention, 1952 (No. 102), which

Ratification or accession implies acceptance of the legally binding nature of these instruments, whereas signature only represents acceptance in principle, to be followed by ratification as a final act. 
has been ratified by just 10 countries, along with the Maternity Protection Convention (Revised), 1952 (No. 103) and the Maternity Protection Convention, 2000 (No. 183), both of which were ratified by just nine countries. With respect to specific population segments, 15 out of 33 countries have ratified the Indigenous and Tribal Peoples Convention, 1989 (No. 169), which seeks, among other provisions, to overcome discriminatory practices affecting these peoples, based on the fundamental principles of consultation and participation. The Domestic Workers Convention, 2011 (No. 189) has also gained broad acceptance in the region, which accounts for 12 of the 22 ratifications worldwide. Nonetheless, 21 of the region's countries have not yet ratified it.

The above shows that Latin American and Caribbean countries display a high level of adherence to international agreements on human rights, thereby producing a propitious scenario for the development of social policies based on this approach. Yet this is not enough to ensure the adoption of such measures let alone their results. The legal progress made on this by individual countries is described below.

\section{National regulatory frameworks for social development}

In recent decades, national regulatory frameworks have undergone significant development in the region. Social legislation has reflected a sectoral dynamic, in which the social functions of traditional social policy sectors, such as education, health, social security and labour, played a leading role. Since the 1990s, however, and alongside the development of new international frameworks, national regulations have also evolved. This has raised new issues and refined others, such as social development and the rights and welfare of specific population segments.

From the conceptual standpoint, population segments can be distinguished according to specific stages of the life cycle, especially childhood and adolescence, youth and old age. It is also feasible to disaggregate each stage further to identify specific needs in the design of policies and programmes. For example, this is applicable to early childhood and also the first 1,000 days of life, as crucial stages in personal development. Different cross-cutting populations can also be distinguished, including women (who are a majority of the population, but historically discriminated against) and people with disabilities, persons of African descent and indigenous peoples, whose condition of subordination, marginalization and discrimination has been included on the social agenda in most countries (see diagram II.1). Other cross-cutting groups, such as migrants, have enjoyed comparatively less visibility, at least at the regulatory level, even though they pose a serious and growing challenge for public policies and the effective guarantee of human rights in the region. 
Diagram II.1

Selected segments of the target population in social policy regulatory frameworks
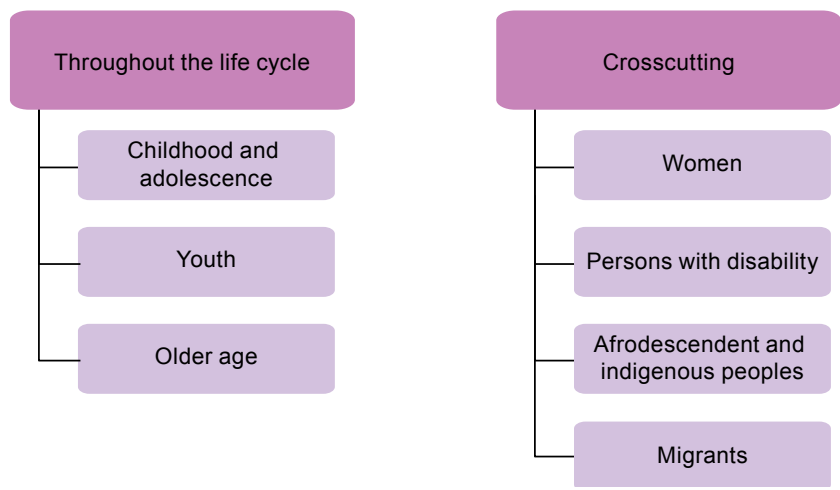

Source: Prepared by the authors.

In the case of national laws, and considering the different functions of the social area, 22 of the region's 33 countries have constitutions that explicitly mention the right to education. Twenty of these also mention the right to work and to social security, while 19 refer to the right to health -areas in which the vast majority have specific legislation. The right to housing appears less frequently, in 15 constitutions. Thirty-two countries have specific regulations on labour and social security and 24 have laws on the right to housing. In contrast, of the 33 cases analysed, the concept of social development is mentioned in just one constitution, and only nine countries have specific legislation on that subject. This reflects the historical evolution of social institutions in the region, in terms of increasing thematic and functional specialization. This is consistent with a diversification of the State's capacities and its technical and fiscal resources, and of the agenda and priorities of its social policy.

In terms of the rights of specific population segments, children and adolescents are explicitly mentioned in the constitutions of 17 countries; followed by older persons (16 countries), people with disabilities (15 countries), and Afrodescendent and indigenous peoples (12 countries). Fewer constitutions mention the rights of women (10 countries) and young people (7 countries). Twenty-nine countries have specific laws on the rights of children and adolescents, 23 on persons with disabilities, 20 on young people and women, and 19 on persons with disabilities (see table II.1). ${ }^{6}$

6 If the observation criteria included indirect mentions in the constitutions of the region's 33 countries, the number of constitutions with contents that refer to protection of the main social rights and of specific population groups would be larger. For example, when reference is made to guaranteeing rights or non-discrimination on the grounds of gender, race, ethnicity or age, among other distinctions. 
Table II.1

Latin America and the Caribbean (33 countries): existence of constitutional and specific laws on sectoral social issues and references to specific segments of the population (Number of countries)

\begin{tabular}{|c|c|c|c|c|}
\hline \multirow[b]{2}{*}{ Pillar } & \multirow[b]{2}{*}{ Category } & \multicolumn{2}{|c|}{ Constitutional provision } & \multirow{2}{*}{$\begin{array}{l}\text { Specific } \\
\text { law }^{a}\end{array}$} \\
\hline & & $\begin{array}{l}\text { (Total excluding } \\
\text { indirect mentions) }\end{array}$ & $\begin{array}{l}\text { (Total including } \\
\text { indirect mentions) }\end{array}$ & \\
\hline \multirow[t]{5}{*}{ Sectoral issues } & Education & 22 & 23 & 27 \\
\hline & $\begin{array}{l}\text { Employment protection } \\
\text { and social security }\end{array}$ & 20 & 23 & 32 \\
\hline & Health & 19 & 21 & 28 \\
\hline & Housing & 15 & 16 & 24 \\
\hline & Social development & 1 & 8 & 9 \\
\hline \multirow{6}{*}{$\begin{array}{l}\text { Population } \\
\text { groups or } \\
\text { segments }\end{array}$} & Children and adolescents & 17 & 18 & 29 \\
\hline & Youth & 7 & 11 & 20 \\
\hline & Older adults & 16 & 16 & 19 \\
\hline & Women & 10 & 14 & 20 \\
\hline & Persons with disabilities & 15 & 17 & 23 \\
\hline & $\begin{array}{l}\text { Afrodescendent and } \\
\text { indigenous peoples }\end{array}$ & 12 & 13 & 14 \\
\hline
\end{tabular}

Source: Economic Commission for Latin America and the Caribbean (ECLAC), based on an analysis of constitutions and a review of the main national legislations on social issues.

a The figures refer to constitutions that explicitly evoke rights in respect of each topic or population segment. For example, with the exception of Chile and Costa Rica, all constitutions refer to persons with disabilities in at least one dimension, nearly always in terms of non-discrimination at work and disability pensions; but only 15 constitutions refer explicitly to this population segment or provide details of the rights and protection in question. National regulations were reviewed to determine the existence of laws on various social-sector issues (education, health, housing and development, social assistance and protection); those targeting specific population groups throughout the life cycle (children, youth and older adults) and cross-cutting issues (gender, indigenous peoples and people with disabilities).

One way to analyse the thematic contents of national regulations on social issues is to examine cases in which there is general legislation devoted to the key sectoral themes of social development, and targeting some of the main population segments prioritized by social policies. For this purpose, identification of the main regulations that address sectoral issues in terms of guaranteeing the main social rights was adopted as a criterion. Of the 33 cases observed, among sectoral issues with general laws, organic laws or codes, the largest number corresponds to the protection of work and social security, in which 32 regulations are identified. This is followed by health with 28, education with 27 , and housing with 24 . Only nine countries have legislation on social development. With respect to specific groups or segments of the population, at the regional level, children and adolescents are covered by regulations in 29 countries, followed by people with disabilities in 23 cases, youth in 20, women in 20, older adults in 19 and, lastly, Afrodescendent and indigenous people in 14 cases. 
In terms of the degree of fulfilment of rights according to the classification of the Office of the United Nations High Commissioner for Human Rights, the Latin America and the Caribbean region scores highly in terms of structural indicators related to the passing of legislation and the ratification of international instruments. Nonetheless, effective implementation is significantly lower (the process that translates the formal commitments made by States into policy design and implementation) and the achievement of concrete progress and results that support compliance with the national and international instruments remains in question. Thus, beyond legal and regulatory progress, the challenge of fostering institutional quality (that is, institutions that are effective, efficient, sustainable and transparent) persists, particularly in relation to the other dimensions through which social institutions are analysed.

\section{B. Organizational characteristics and social authority}

This section describes two important elements in terms of the organizational dimension. The first of these are regional forums devoted to social development that are playing an increasing role in the region and have helped generate a regional agenda in this area. The second element considers the main features of the organizational structure of current social policy in Latin American countries. ${ }^{7}$

\section{Regional mandates and forums dedicated to social development in Latin America and the Caribbean}

A key component of the social policy framework consists of the intergovernmental forums in which Latin American and Caribbean governments have been building a social agenda with specific features and commitments. Their institutional relevance is related to the legal and regulatory framework, as they are deliberation mechanisms that generate objectives and define mandates. They are particularly coordinated with organizational characteristics, since they express the mechanisms and modalities through which countries generate agreements and facilitate regional policy coordination.

Thus, the forums are the organizational expression of international mandates in the social area; and they allow countries to coordinate efforts to improve social policy and its institutions. They enable the exchange of experiences, the search for consensus around common positions, the promotion of cooperative relations and progress in the construction of a regional social agenda. They may also have other objectives, such as following up on mandates or generating information, analysing proposals

The information is up to June 2017. See [online] dds.cepal.org/bdips. 
to establish social policy priorities and drawing up plans of action. For all of the foregoing reasons, the forums provide a very rich and relevant source for policies that are implemented both regionwide and nationally.

Nonetheless, the existence of multiple mechanisms pursuing the same or similar aims poses risks. These include duplication of tasks and efforts, fragmentation and potential dispersion of commitments, and competition between the different forums to become the authoritative voice on the social issue in question, which can hinder the construction of a shared and coherent regional agenda.

To contribute to the analysis of this important process, this section attempts to classify and organize the various intergovernmental forums that explicitly aim to progress the social agenda in the region. Two aspects are considered: their evolution, distinguishing the main types; and their contents, specifying the areas in which commitments and targets have been established.

An outstanding feature of the recent period in Latin America and the Caribbean has been the multiplicity of intergovernmental mechanisms (conferences, meetings, forums and councils) that explicitly aim to advance the social agenda in the region. Without considering those that are sectorspecialized, ${ }^{8}$ the region has 15 intergovernmental forums on development and social inclusion, of which only one was created before $2000 .{ }^{9}$

These are intergovernmental bodies linked to sectoral social policies, such as those of health, education, work and housing or others. In the health domain, the Pan-American Sanitary Conference of the WHO Regional Committee for the Americas and the Andean Health Organization, which is responsible for implementation of the Hipolito Unanue Agreement, should be considered. Educational bodies include the Ibero-American Conference on Education of the Organization of Ibero-American States for Education, Science and Culture (OEI), which is held as part of the Ibero-American Summits (see [online] http://www.oei.es/cumbres. $\mathrm{htm}$ ), and the Regional Education Project for Latin America and the Caribbean (PRELAC) of the United Nations Educational, Scientific and Cultural Organization (UNESCO) and the Organization of the Andrés Bello Agreement for Educational, Scientific, Technological and Cultural Integration (CAB). In the labour area, the American Regional Meeting of the International Labour Organization (ILO), of a tripartite nature (composed of representations of governments, employers and workers' organizations of the Americas), and the Inter-American Conference of Ministers of Labour, under the auspices of the Organization of American States (OAS). Regional or Latin American social security mechanisms include the Ibero-American Social Security Organization (OISS) and the Ibero-American Conference of Ministers and Senior Managers of Social Security. It should be noted that the OISS, in the framework of the IberoAmerican Summit, is responsible for implementation of the Multilateral Agreement on Social Security, which is proposed as the first international instrument at the Ibero-American level that protects the economic benefit rights of millions of migrant workers and their families and workers in multinationals, by coordinating national legislations on pensions, as a guarantee of economic security in old age, disability or death, protected under the social security schemes of the different Ibero-American States (see [online] http://www.oiss.org/Que-es,5335.html). Intergovernmental conferences aimed at improving the social conditions of certain population segments are not considered in the analysis, because, even though the topics in question are obviously part of social development, they focus on constructing a more specific agenda around the rights of women, youth, children or indigenous and Afrodescendent populations.

9 The Council for Human and Social Development of the Caribbean Community (CARICOM), created in 1973. 
The number of forums currently in existence shows the need for and interest in deepening collaboration among countries in the social area and coordinating efforts to improve social policy and its institutions; sharing objectives, achievements and difficulties in the development of social policy, and sharing analytical and methodological approaches to advance the measurement and understanding of the main social problems. It also demonstrates the growing importance of the social dimension in the countries' development agenda in recent decades. These bodies also complement (or could complement) international agreements on development, thereby contributing to the regional adaptation of goals and objectives set in the global agenda, or following up on their compliance. They can also serve as a platform to highlight the region's own social challenges, such as its high level of inequality.

A first attempt at classification reveals two types of forum in terms of their origin, in other words the institution in which they were created and from which they operate (see table II.2). Twelve of them are part of intergovernmental integration processes, either regional or subregional. The condition that make it possible to incorporate the social dimension in this type of structure is a change in the regional integration agenda which, together with trade-related issues, is embracing new topics (Dabène, 2012). There are also three intergovernmental forums in the field of social development attached to United Nations agencies: the Forum of Ministers of Social Development, of the United Nations Educational, Scientific and Cultural Organization (UNESCO); the Ministerial Forum for Development in Latin America and the Caribbean, of the United Nations Development Programme (UNDP), and the Regional Conference on Social Development of Latin America and the Caribbean, a subsidiary body of the Economic Commission for Latin America and the Caribbean (ECLAC). ${ }^{10}$

Regardless of the organization to which they are attached, the forums are distinguished by the orientation with which they were created and the objectives they pursue. Three types are distinguished: those that are designed as vehicles for debate; those that perform analyses and formulate proposals, and those that mainly aim to follow up regional mandates and commitments. ${ }^{11}$ Of the 15 forums identified,

10 This Conference was established by virtue of resolution $682(\mathrm{XXXV})$, adopted at the thirty-fifth session of ECLAC held in May 2014. The first of the Regional Conference on Social Development in Latin America and the Caribbean took place in Lima in November 2015 and was organized jointly by ECLAC and UNDP. Then, in November 2016, the first meeting of the Presiding Officers of the Regional Conference on Social Development in Latin America and the Caribbean was held in Santo Domingo. Other subsidiary bodies of ECLAC that play an important role in the development and follow-up of agendas that are highly relevant for social development include the Regional Conference on Women in Latin America and the Caribbean and the Regional Conference on Population and Development in Latin America and the Caribbean.

11 The forums have been classified according to the main function they perform, as specified in their mission statement; but this does not mean that a forum of a certain type does not perform other functions. 
four are mainly vehicles for debate, or mechanisms that allow for the exchange of experiences, seek consensus to adopt common positions, promote cooperation and make progress in the construction of a regional social agenda. The forums created with this objective are the UNDP Ministerial Forum for Social Development in Latin America and the Caribbean, the Ibero-American Conference of Ministers and Senior Managers of Social Security of the Ibero-American General Secretariat (SEGIB), the Meeting of Social Development Ministers and Authorities of the Southern Common Market (MERCOSUR) and the Council of Ministers for Social and Human Development of the Organization of Eastern Caribbean States (OECS).

Table II.2

Latin America and the Caribbean: intergovernmental forums on social development, by type of institution to which they are attached, 2015

\section{A. United Nations agencies}

\begin{tabular}{|c|c|c|c|c|}
\hline Institution & Forum & $\begin{array}{l}\text { Year of } \\
\text { creation }\end{array}$ & $\begin{array}{l}\text { Periodicity of } \\
\text { meetings }\end{array}$ & Type of forum \\
\hline $\begin{array}{l}\text { Economic Commission } \\
\text { for Latin America and } \\
\text { the Caribbean (ECLAC) }\end{array}$ & $\begin{array}{l}\text { Regional Conference on } \\
\text { Social Development of } \\
\text { Latin America and } \\
\text { the Caribbean }\end{array}$ & 2015 & Biennial & $\begin{array}{l}\text { Mechanism for } \\
\text { analysis and } \\
\text { proposals }\end{array}$ \\
\hline $\begin{array}{l}\text { United Nations } \\
\text { Development } \\
\text { Programme (UNDP) }\end{array}$ & $\begin{array}{l}\text { Ministerial Forum for } \\
\text { Development in } \\
\text { Latin America and } \\
\text { the Caribbean }\end{array}$ & 2007 & Annual & $\begin{array}{l}\text { Vehicle for } \\
\text { discussion }\end{array}$ \\
\hline $\begin{array}{l}\text { United Nations } \\
\text { Educational, } \\
\text { Scientific and Cultural } \\
\text { Organization (UNESCO) }\end{array}$ & $\begin{array}{l}\text { Forum of Ministers of } \\
\text { Social Development }\end{array}$ & 2001 & $\begin{array}{l}\text { Twice a year } \\
\text { (but has been } \\
\text { irregular) }\end{array}$ & $\begin{array}{l}\text { Mechanism for } \\
\text { analysis and } \\
\text { proposals }\end{array}$ \\
\hline
\end{tabular}

\section{B. Regional intergovernmental forums}

\begin{tabular}{|c|c|c|c|c|}
\hline Institution & Forum & $\begin{array}{l}\text { Year of } \\
\text { creation }\end{array}$ & $\begin{array}{l}\text { Periodicity of } \\
\text { meetings }\end{array}$ & Type of forum \\
\hline $\begin{array}{l}\text { Community of Latin } \\
\text { American and Caribbean } \\
\text { States (CELAC) }\end{array}$ & $\begin{array}{l}\text { Meeting of Ministers and } \\
\text { Authorities Responsible } \\
\text { for Social Development } \\
\text { and Hunger and Poverty } \\
\text { Eradication }\end{array}$ & 2013 & $\begin{array}{l}\text { Every two years } \\
\text { (most recently in } \\
2015 \text { ) }\end{array}$ & $\begin{array}{l}\text { Mechanism for } \\
\text { analysis and } \\
\text { proposals }\end{array}$ \\
\hline \multirow{2}{*}{$\begin{array}{l}\text { Organization of } \\
\text { American States } \\
\text { (OAS), Latin American } \\
\text { Integration Association } \\
\text { (LAIA) }\end{array}$} & $\begin{array}{l}\text { Inter-American } \\
\text { Committee on Social } \\
\text { Development (CIDES) }\end{array}$ & 2010 & $\begin{array}{l}\text { When deemed } \\
\text { necessary (no } \\
\text { fixed periodicity) }\end{array}$ & Mandate follow-up \\
\hline & $\begin{array}{l}\text { Meeting of Ministers } \\
\text { and Authorities of Social } \\
\text { Development }\end{array}$ & 2008 & Biennial & Mandate follow-up \\
\hline $\begin{array}{l}\text { Ibero-American General } \\
\text { Secretariat (SEGIB) }\end{array}$ & $\begin{array}{l}\text { Meeting of Ministers of } \\
\text { the Social Area of the } \\
\text { LAIA Member Countries }\end{array}$ & 2009 & $\begin{array}{l}\text { When deemed } \\
\text { necessary (no } \\
\text { fixed periodicity) }\end{array}$ & $\begin{array}{l}\text { Mechanism for } \\
\text { analysis and } \\
\text { proposals }\end{array}$ \\
\hline $\begin{array}{l}\text { Community of Latin } \\
\text { American and Caribbean } \\
\text { States (CELAC) }\end{array}$ & $\begin{array}{l}\text { Ibero-American } \\
\text { Conference of Ministers } \\
\text { and Senior Managers of } \\
\text { Social Security }\end{array}$ & 2000 & $\begin{array}{l}\text { Biennial since } \\
2015\end{array}$ & $\begin{array}{l}\text { Vehicle for } \\
\text { discussion }\end{array}$ \\
\hline
\end{tabular}


Table II.2 (concluded)

\section{Subregional intergovernmental forums}

\begin{tabular}{|c|c|c|c|c|}
\hline Institution & Forum & $\begin{array}{l}\text { Year of } \\
\text { creation }\end{array}$ & $\begin{array}{l}\text { Periodicity of } \\
\text { meetings }\end{array}$ & Type of forum \\
\hline $\begin{array}{l}\text { Organization of Eastern } \\
\text { Caribbean States (OECS) }\end{array}$ & $\begin{array}{l}\text { Council of Ministers } \\
\text { for Social and } \\
\text { Human Development }\end{array}$ & 2014 & Annual & $\begin{array}{l}\text { Vehicle for } \\
\text { discussion }\end{array}$ \\
\hline $\begin{array}{l}\text { Southern Common Market } \\
\text { (MERCOSUR) }\end{array}$ & $\begin{array}{l}\text { Meeting of Social } \\
\text { Development } \\
\text { Ministers and } \\
\text { Authorities of } \\
\text { MERCOSUR }\end{array}$ & 2011 & Twice a year & $\begin{array}{l}\text { Vehicle for } \\
\text { discussion }\end{array}$ \\
\hline $\begin{array}{l}\text { Union of South American } \\
\text { Nations (UNASUR) }\end{array}$ & $\begin{array}{l}\text { South American } \\
\text { Council for Social } \\
\text { Development }\end{array}$ & 2009 & Annual & $\begin{array}{l}\text { Mechanism for } \\
\text { analysis and } \\
\text { proposals }\end{array}$ \\
\hline $\begin{array}{l}\text { Central American Social } \\
\text { Integration Secretariat } \\
\text { (SISCA), Social Subsystem } \\
\text { of the Central American } \\
\text { Integration System (SICA) }\end{array}$ & $\begin{array}{l}\text { Council of Ministers } \\
\text { of the Social Area }\end{array}$ & 2008 & Annual & $\begin{array}{l}\text { Mandate follow- } \\
\text { up }\end{array}$ \\
\hline $\begin{array}{l}\text { Bolivarian Alliance for the } \\
\text { Peoples of Our America } \\
\text { (ALBA) }\end{array}$ & $\begin{array}{l}\text { Meeting of the } \\
\text { Ministerial Council } \\
\text { of the Social Area }\end{array}$ & 2004 & $\begin{array}{l}\text { When deemed } \\
\text { necessary (no } \\
\text { fixed periodicity) }\end{array}$ & $\begin{array}{l}\text { Mandate follow- } \\
\text { up }\end{array}$ \\
\hline Andean Community (CAN) & $\begin{array}{l}\text { Andean Council of } \\
\text { Ministers of Social } \\
\text { Development }\end{array}$ & 2004 & Annual & $\begin{array}{l}\text { Mechanism for } \\
\text { analysis and } \\
\text { proposals }\end{array}$ \\
\hline $\begin{array}{l}\text { Caribbean Community } \\
\text { (CARICOM) }\end{array}$ & $\begin{array}{l}\text { Council for } \\
\text { Human and Social } \\
\text { Development }\end{array}$ & 1973 & $\begin{array}{l}\text { When deemed } \\
\text { necessary (no } \\
\text { fixed periodicity) }\end{array}$ & $\begin{array}{l}\text { Mechanism for } \\
\text { analysis and } \\
\text { proposals }\end{array}$ \\
\hline
\end{tabular}

Source: Economic Commission for Latin America and the Caribbean (ECLAC), on the basis of official information from the respective agencies.

There are seven forums that exist primarily to generate information, analysis and proposals and set social policy priorities. These also serve as vehicles for the exchange of experiences that foster debate among public decision-makers and promote cooperative relations. Some of them also follow up mandates. These forums include the UNESCO Forum of Ministers of Social Development, the Meeting of Ministers of the Social Area of the Member Countries of the Latin American Integration Association (LAIA), the Meeting of Ministers and Authorities Responsible for Social Development and Hunger and Poverty Eradication of CELAC, the South American Council for Social Development of UNASUR, the Andean Council of Ministers of Social Development of the Andean Community, the Council for Human and Social Development of the Caribbean Community (CARICOM) and the Regional Conference on Social Development in Latin America and the Caribbean of ECLAC. Among other issues, the latter seeks to foster the improvement of national social development policies, provide technical inputs at the countries' request, undertake research on multidimensional poverty and make progress in the measurement of poverty, inequality and structural gaps.

Lastly, the four forums tasked with following up specific mandates are the OAS Meeting of Ministers and High Authorities of Social Development, for which the technical secretariat is that organization's Department of Economic 
and Social Development (DDES); the Inter-American Committee on Social Development (CIDES) of the OAS, for which the technical secretariat is also DDES; the social subsystem of the Central American Integration System (SICA), which has a Council of Ministers of the Social Area and a Central American Social Integration Secretariat (SISCA); and the Meeting of the Ministerial Council of the Social Area of the Bolivarian Alliance for the Peoples of Our America (ALBA), which aims to implement and monitor social programmes for the benefit of the inhabitants of the region's countries.

Some specialized areas have experiences of institutional development at the regional level, such as subregional organizations geared towards the execution and practical implementation of agreements on social issues in specific sectors. These include the Andean Health Organization, which implements the Hipólito Unanue Agreement, and the Andrés Bello Convention Organization for Educational, Scientific, Technological and Cultural Integration (CAB) (see table II.2).

\section{The social agendas of selected intergovernmental forums}

In the case of the intergovernmental social development forums mentioned, it is interesting to analyse the focus of their agendas, to identify the extent of convergence and complementarity between them and the areas to which the established commitments correspond. A brief overview of the contents of the agendas of seven of these forums is presented in the following paragraphs. ${ }^{12}$ As can be seen in table II.2, the main objective in five cases is to generate information, analysis and proposals, while two focus on following up mandates.

In general, there is a good deal of convergence and complementarity between the agendas of these forums, mainly in terms of overcoming poverty and social inequalities from a rights perspective. Poverty is predominantly conceived as a multidimensional phenomenon that needs to be addressed through comprehensive social policies. Moreover, insofar as several of these forums are linked to integration mechanisms, their agendas more or less explicitly include the notion that regional integration processes can contribute to greater equality and social inclusion.

In addition to overcoming poverty and inequalities, other recurring themes in the forums are food and nutrition security, the importance of developing the institutional framework for social policies and the need to develop comprehensive social policies (see table II.3). Thus, from the thematic point of view, these elements constitute a "hard core" of the agendas of social development forums.

12 Only forums where there is some type of documentation - action plan, mandates or othersare considered, which makes it possible to determine the thematic pillars of the agendas and to specify in which areas commitments and goals have been established. Forums created as vehicles for discussion are not considered. 
Table II. 3

\section{Latin America and the Caribbean: main thematic pillars of selected intergovernmental social development forums}

\begin{abstract}
Intergovernmental forums and publication year of the document in which the pillars are established

Regional Conference on Social Development of Latin America and the Caribbean, of the Economic Commission for Latin America and the Caribbean (ECLAC) (2015)
\end{abstract}

Main thematic pillars

1. Support for countries in strengthening their public-policy evaluation systems

2. Promotion of exchange of experiences between countries and deepening of the integrated analysis of economic and social policies

3. Deepening of analysis of the multiple dimensions of inequality, poverty and vulnerability

4. Organization, maintenance and updating of databases on social investment, non-contributory social protection programmes and youth and social inclusion

South American Council for Social Development, of the Union of South American Nations (UNASUR) (2015)

1. Development with inclusion

2. Food security and the fight against malnutrition

3. Social, solidarity-based or communal economy with productive inclusion and generation of opportunities

4. Social participation

5. Regional cooperation in social policies

Meeting of Ministers and Authorities Responsible for Social Development and Eradication of Hunger and Poverty, of the Community of Latin American and Caribbean States (CELAC) (2013)

Andean Council of Ministers of Social Development of the Andean Community (CAN) (2011)

\section{Strengthening of food security}

2. Universalization of health care

3. Universalization of education

4. Literacy programme
1. Overcoming poverty and inequalities

2. Ownership and guarantee of rights

3. Identity and sense of belonging

4. Overcoming territorial asymmetries

5. Social investment guarantee

6. Prevention of the social impacts of climate change and natural disasters

1. Protection and social inclusion

2. Generation of employment for vulnerable populations

3. Poverty reduction

4. Food and nutrition security

Social Development (CIDES), of the Organization of American States (OAS) (2010)

Meeting of Ministers of the Social Area of the Member Countries of the Latin American Integration Association (LAIA) (2009)

Council of Ministers of the Social Area, of the Secretariat of the Central American Social Integration (SISCA) (2008)
1. Cooperation as a support tool for social inclusion

2. Productive integration as a tool of social inclusion

3. Deepening and facilitation of trade in support of social inclusion

1. Strengthening of social institutions in Central America

2. Effective provision of basic social services

3 . Social welfare and human development

Source: Economic Commission for Latin America and the Caribbean (ECLAC), on the basis of Latin American Integration Association (LAIA), "Plan de acción priorizado para el desarrollo de la dimensión social del proceso de integración" (LAIA/CR/Resolución 360), 16 December 2009; Community of Latin American and Caribbean States (CELAC), "Plan of Action of Public Policies on Social Issues of CELAC", 2013; Union of South American Nations (UNASUR), "Plan of Action 2015-2017"; Andean Community (CAN), "Andean Social Development Objectives (OANDES)", Lima, 2011; Central American Social Integration Secretariat (SISCA), "Social Strategic Agenda", 2008; Organization of American States (OAS) [online] http://www.oas.org/en/sedi/ddse/pages/ cpo_cides.asp; ECLAC, "Resolution 1(l)", Regional Conference on Social Development in Latin America and the Caribbean, Lima, 2015.

There is also thematic diversity, since each forum has its specific features; and the respective plans of action identify areas that are only present in the agenda of one or two initiatives. Among the forums that 
are linked to regional integration processes, LAIA highlights the social dimension of the integration process and considers productive integration and trade facilitation as specific thematic pillars in support of social inclusion. CELAC and SISCA include the universal provision of social services (education and health) among their main thematic pillars, while the specific issues proposed by UNASUR include social participation and the social economy, with productive inclusion and generation of opportunities.

The agenda of the Inter-American Committee on Social Development (CIDES) of the OAS includes two issues that are crucial for eradicating poverty and inequalities: social protection and job creation for vulnerable populations. ${ }^{13}$

Lastly, the mandates of the Regional Conference on Social Development in Latin America and the Caribbean emphasize the production of information, analysis and technical assistance. In particular, in 2015, ECLAC was asked to organize databases and keep them up to date in three key areas: (i) social investment, (ii) non-contributory social protection programmes, and (iii) youth and social inclusion. In terms of research, it is tasked with deepening the analysis of the multiple dimensions of inequality, poverty and vulnerability, paying particular attention to women, indigenous and Afrodescendent populations, the life cycle and territory. ECLAC is also encouraged to delve further into the integrated analysis of economic, productive and social policies and the protection of employment and promotion of decent work, stressing the importance of exchanging experiences among countries and promoting South-South cooperation. On technical assistance, it is asked to help countries strengthen their public policy evaluation systems and promote the exchange of experiences.

The common and specific themes of the agendas of the intergovernmental social development forums make a significant contribution to the formulation of a regional social development agenda, which should be informed by the interests and concerns of the countries in each particular regional or subregional scenario. A consideration of the thematic priorities of these forums and the dialogue they seem to have with the social pillar of the 2030 Agenda for Sustainable Development is also central.

\section{Modalities of social authority}

Various modalities of social authority coexist in the region and can be distinguished by the place they occupy in the general State structure, the origin of their delegation and their make-up: ${ }^{14}$

13 See [online] http://www.oas.org/en/sedi/ddse/paginas/cpo_cides.asp.

14 The modalities described are ideal types, which do not necessarily exist in pure form in each country and are not mutually exclusive. For example, in the same country, a modality centered on the Office of the President of the Republic can coexist with a coordinating social development ministry and a social cabinet. Moreover, the proliferation of mandates that imply duplications or the successive creation of new mechanisms can lead to the coexistence of several modalities. 
- Appointed by the Office of the President or Vice-President: specialized technical mechanism operating at a central level of the executive branch, with authority usually formalized by a government decree.

- Family members of the executive: this mechanism is typically the responsibility of the first lady, as coordinator of social assistance programmes.

- National planning agencies: their hierarchical location and functions make it possible to coordinate intersectoral relations, but they may lack the required level of technical expertise in social matters.

- Ministry of Development or Social Inclusion: ministry or secretariat specialized in the fight against poverty and in non-contributory social protection. It often has coordination responsibilities, even when the overlapping of functions, disparity of resources and history hinder its consolidation as the coordinating authority of social policy as a whole.

- Coordinating Ministry: agency appointed to mediate and coordinate the set of key mechanisms in the social area, either from central government or from other government levels. The best-known case is that of Ecuador, which had this modality for the entire government structure between 2008 and 2017. ${ }^{15}$

- Intersectoral collegial entities: social cabinets or economic and social councils, normally composed of ministers from the social area and specialized service directorates, headed by the President, a Vice President or a minister designated as coordinator, with a technical secretariat that is either collegial or based in the planning area.

Among the region's 33 countries for which official information is available, collegiate entities are present in 22 cases. Thus, rather than a unique model or alternative to the others, they represent a complementary mechanism, in which authority over social policy is distributed across the different government departments (see table II.4). These councils or offices are mostly coordinated by the President or Vice President, whereas ministries of social development (or equivalent) only fulfil this function in seven cases. This reflects a disconnect between the formal authority and the real authority of the ministries tasked with coordinating social policy. ${ }^{16}$ At the same time, rather than adopting a specific model, a body with this form of leadership needs the mandates, resources and capacity for inter-institutional coordination in social matters.

15 This model was altered when the Government of President Lenin Moreno took office on 24 May 2017 and eliminated the coordinating ministries in Ecuador.

16 Table II.A1.2 of annex II.A1 reports the detailed composition of each country's collegial bodies for intersectoral coordination in the social area. 
Table II.4

\section{Latin America and the Caribbean (22 countries): type of authority that coordinates} the social cabinet or the main intersectoral collegial entity of the social area

\begin{tabular}{|c|c|c|c|c|c|}
\hline Country & $\begin{array}{c}\text { Office of the } \\
\text { President or } \\
\text { Vice-President, or } \\
\text { Presidential Delegate }\end{array}$ & $\begin{array}{l}\text { Ministry of } \\
\text { Development } \\
\text { or Social } \\
\text { Inclusion }\end{array}$ & $\begin{array}{c}\text { Family or } \\
\text { conjugal circle } \\
\text { of members of } \\
\text { the Government }\end{array}$ & $\begin{array}{l}\text { Ministry } \\
\text { of Other } \\
\text { Portfolio }\end{array}$ & $\begin{array}{l}\text { Ministry } \\
\text { Coordinator } \\
\text { of Social } \\
\text { Affairs }\end{array}$ \\
\hline $\begin{array}{l}\text { Antigua and } \\
\text { Barbuda }\end{array}$ & $x$ & & & & \\
\hline Argentina & & $x$ & & & \\
\hline Belize & $x$ & & & & \\
\hline $\begin{array}{l}\text { Bolivia } \\
\text { (Plurinational } \\
\text { State of) }\end{array}$ & $\mathrm{x}$ & & & & \\
\hline Brazil & & $\mathrm{x}$ & & & \\
\hline Chile & & $x$ & & & \\
\hline Colombia & & & & $x$ & \\
\hline Costa Rica & $x$ & & & & \\
\hline $\begin{array}{l}\text { Dominican } \\
\text { Republic }\end{array}$ & $\mathrm{x}$ & & & & \\
\hline Ecuador $^{\mathrm{a}}$ & & & & & $x$ \\
\hline El Salvador ${ }^{b}$ & & & & $x$ & \\
\hline Guatemala & $x$ & & & & \\
\hline Haitic & & & $x$ & & \\
\hline Honduras & $x$ & & & & \\
\hline Mexico & & $x$ & & & \\
\hline Nicaragua $^{d}$ & & & $x$ & & \\
\hline Panama & & $x$ & & & \\
\hline Paraguay & $x$ & & & & \\
\hline Peru & $x$ & & & & \\
\hline $\begin{array}{l}\text { Trinidad and } \\
\text { Tobago }\end{array}$ & & $x$ & & & \\
\hline Uruguay & & $x$ & & & \\
\hline $\begin{array}{l}\text { Venezuela } \\
\text { (Bolivarian } \\
\text { Republic of) }\end{array}$ & $x$ & & & & \\
\hline Total & 10 & 7 & 2 & 2 & 1 \\
\hline
\end{tabular}

Source: Economic Commission for Latin America and the Caribbean (ECLAC), on the basis of official information from the countries.

a In Ecuador, when the Government of President Lenin Moreno took office in May 2017, a major reform was launched in relation to the coordinating ministries. The Coordinating Ministry of Social Development, which chaired the Sectoral Social Development Council up to that time (as established in Decree No. 117-A of February 2007), became the Technical Secretariat of the Toda una Vida (Whole Life) Plan, attached to the Office of the President and with ministerial rank. In addition, Decree No. 34 of June 2017 established new Sectoral Councils, coordinated by a counsellor, minister or authority designated by the President. The Technical Secretariat of the Toda una Vida Plan coordinates the Sectoral Council for Social Development.

b In El Salvador, the Office of Social Management and Inclusion is coordinated by the Ministry of Health, by presidential decision.

c In Haiti, the National Commission to Combat Hunger and Malnutrition was created in 2012, led by the First Lady of the Republic. In 2017 this mechanism seems to be inactive, but there is no official information that establishes its formal dissolution or the creation of new mechanisms.

d In Nicaragua, the Government appoints the head of the coordinating entity of the intersectoral body (Communication and Citizenship Council of the Presidency of Citizen Power). 
In recent years, collegiate entities have also emerged for specific issues (poverty, social protection, malnutrition and food and nutrition security, care, discrimination, gender and others) or targeting certain segments of the population. The latter can be cross-cutting (such as national mechanisms for the advancement of women and the promotion of racial equality, or bodies that promote the rights of persons with disabilities, among others). Others focus on promoting rights and the well-being of segments of the population in a specific stage of the life cycle (such as childhood, youth or old age).

\section{Ministries and secretariats of development and social inclusion}

Ministerial-rank bodies in the areas of education, health and work have a long history in the countries of the region. In contrast, as shown in figure II.2, ministries (or secretariats) of development and social inclusion only appear for the first time in the late twentieth century and, above all, during the twenty-first.

Figure II.2

Latin America and the Caribbean (22 countries): year of creation of ministries or other mechanisms devoted to social development ${ }^{a}$

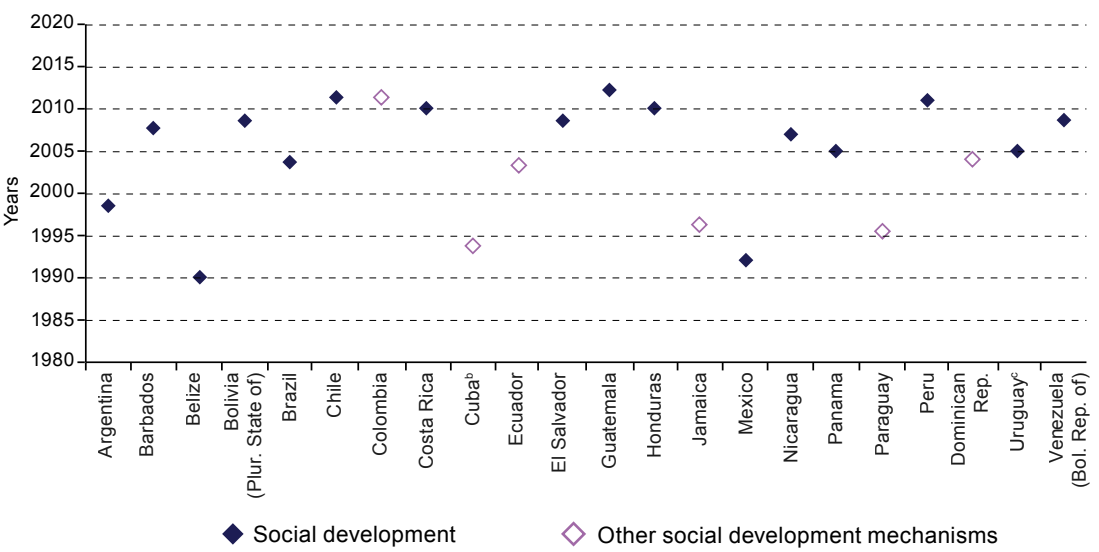

Source: Economic Commission for Latin America and the Caribbean (ECLAC), on the basis of official information from the countries.

a Countries not included in the figure are those for which the founding year of the Ministry of Social Development was not identified (Antigua and Barbuda, Bahamas, Dominica, Grenada, Guyana, Haiti, Saint Kitts and Nevis, Saint Vincent and the Grenadines, Saint Lucia, Suriname, and Trinidad and Tobago).

b The Ministry of Labour and Social Security of Cuba was created in 1994, through Decree Law No. 147 for the reorganization of the agencies of Central State Administration. In 2001, the National Social Security Institute was created, which makes the work of the Ministry more complex; and, under Agreement No. 7335 of the Council of Ministers of 19 December 2012, it was given the mission of proposing, directing and controlling the policy of the State and Government on issues of work, protection, workplace safety and hygiene, social security and prevention, assistance and social work.

c The Ministry of Housing and Social Promotion of Uruguay was dissolved in 1977. 
Several of these ministries arose from the social investment funds (FIS) created during the 1990s as autonomous and transitional entities dedicated to the development of programmes and projects to combat poverty and promote investment in social service infrastructure, especially health, education and water and sanitation. In this period specifically, discussion on social authority and institutions became part of the debate, in particular promoting social issues with the economic authority and the effectiveness and efficiency of social programmes through organization and tools of evaluation, monitoring and participant registries (Franco and Székely, 2010).

At present, ministries specializing in development and social inclusion policies have become significantly widespread; and most countries have this body or a specific division assigned to the Office of the President or Vice-President, with special attention to the design, implementation and coordination of such policies. Nonetheless, not all countries have a law that protects them, although some are solely based on a presidential administrative decree.

The region thus has a heterogeneous institutional landscape in terms of organizational structure and social authority. In addition to being diverse in terms of the level they occupy in the structure of the State and in their legal status, some of these entities have been formally designated to coordinate development and social inclusion policies. In other cases, they share authority with other departments or mechanisms.

Some of the bodies that exercise authority in social issues have similar objectives, but also have their specific features in the different countries. Thus, an analysis of the mission and mandates of national entities dedicated to social development and the overview of agencies that depend on them help to give an idea of the challenges involved in the intersectoral coordination of non-contributory social protection policies. These challenges mostly focus on policies related to poverty, protection and social inclusion and, to a lesser extent, on the provision of different types of care.

All these entities coexist with a growing number of mechanisms devoted to welfare and guaranteeing the rights of certain segments of the population, such as children and adolescents, older adults, persons with disabilities, indigenous peoples and Afrodescendent populations, among others. In this diverse panorama, institutional modalities can to some degree be associated with their mandates.

The first modality corresponds to cases where ministries of social development are responsible for the needs of the aforementioned population segments. In the 25 countries in the region for which information is available, 15 ministries from the social development area 
are responsible for the bodies devoted to older persons, five are in charge of youth institutes, and eight oversee institutions tasked with ensuring the welfare and rights of children and adolescents.

Seven focus on issues related to women, and nine others deal with persons with disabilities (see figure II.3). In the cases of Chile and Uruguay, the Ministry of Social Development holds the mandate and management of several of these segments.

Figure II. 3

Latin America and the Caribbean (26 countries): main government agencies formally responsible for coordinating services for various population segments (Number of institutions)

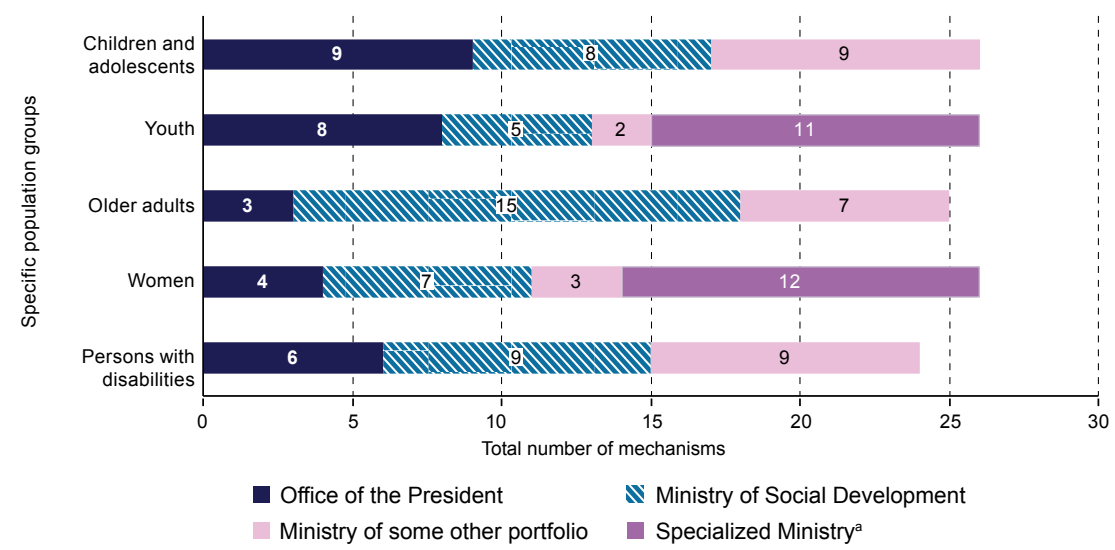

Source: Economic Commission for Latin America and the Caribbean, on the basis of official data from ministries and secretariats of social development.

a Refers to ministries that are explicitly focused on a given segment of the population, but which may also fulfil other mandates targeting other population groups or social problems.

A second modality, which tends to be complementary to the previous one, consists of intersectoral committees formed by various ministries and other entities, usually coordinated by the Office of the President or Vice President. An example are agencies in charge of children's welfare and rights (childhood councils), a modality that exists in nine of the 26 countries. The main challenge is to ensure that these intersectoral bodies have the authority needed to coordinate multiple ministries and other governmental (and even non-governmental) entities. Given that they have extensive mandates (in general, to promote or guarantee a broad set of rights), it is essential that they have the capacity to mobilize resources and coordinate the government entities involved in the implementation of social protection actions.

The third alternative that entails specific coordination challenges is the existence of ministries targeted on specific population segments (see part 3). Such is often the case with national mechanisms created to promote the advancement of women, which generally consist of a ministry 
that addresses women's needs and rights, or an official of ministerial rank to head the mechanism. ${ }^{17}$ In this case, the challenge lies in the capacity of these entities to coordinate with other ministries, especially those tasked with promoting social development. This refers both to the implementation of social protection policies and programmes and to coordination with other central government mechanisms, to ensure that each segment's needs are taken into account by governmental public action as a whole.

The challenge shared by these modalities in the implementation of social protection policies is to ensure that their basic functions (protect and secure income, identify unmet demand and guarantee access to social services and promotion policies, as well as promoting decent work to give access to protection and social welfare) are met for each segment of the population, through either general or specific actions (see figure II.3).

The intersection of sectoral objectives targeted on population groups or segments poses a challenge that characterizes the ministries of development and social inclusion and distinguishes them from the other government departments. The implementation rationales of policies with population segmentation are complementary but not necessarily synergistic with thematic and sectoral specialization.

Moreover, it is unusual to resort to organizational models with a matrix and "adhocratic" logic to effectively and efficiently attain the different objectives. Instead, there is a tendency to reproduce the structures of (traditional) line ministries and generate mechanisms for specific purposes (by subject or population), in which atomization and competition become a greater risk, and coordination or articulation become increasingly challenging.

In short, there is a wide variety of models and alternatives for social authorities in each segment of the population prioritized or singled out at the institutional level (cross-sectoral commissions, bodies dependent on the Office of the President or Vice-president, ministries, vice-ministries and institutes, among others). The third part of this volume discusses the specific cases of institutions targeting the Afrodescendants, youth and persons with disabilities.

\section{The institutional affiliation of income transfer and non-contributory pension programmes}

Another example of the institutional challenges of non-contributory social protection is the institutional affiliation of conditional cash transfer and social pension programmes. As noted above, the importance of these

17 See the Observatory on Gender Equality in Latin America and the Caribbean, "Ficha técnica: nivel jerárquico de los Mecanismos para el Adelanto de la Mujer (MAM)" [online] at http:// www.cepal.org/oig/ html / niveljerarquico2.html. 
initiatives stems less from their relative fiscal weight and more from their coverage and targeting of lower-income groups.

Table II.5 shows that, of 21 countries in the region that implement at least one cash transfer programme at the national level, in 10 cases this is assigned to the Ministry of Social Development or to an equivalent ministerial entity; in six, to the Office of the President, and in five to some other ministerial portfolio. Among the 19 countries that have a national programme of non-contributory pensions, in eight cases the programme is attached to the Ministry of Social Development or the equivalent ministerial entity; in two, to the Office of the President, and in nine to some other ministerial portfolio. In short, although ministerial entities dedicated to social development are emerging as protagonists of non-contributory social protection and with formal mandates in this area, the governing body of the main programmes, at least those of broader scope, is not always under their wing. This largely reflects the social authority models prevailing in each country, the role given to ministerial entities dedicated to social development, and the existence and institutional affiliation of non-contributory benefits in pension systems. This highlights the need to improve coherence and articulation between models of authority, in the mandates and existing ministerial and programmatic structures, and between these and the multiple actors that participate in social protection systems that are more complex than in the past, as described in the following sections.

\section{The challenges of coordination and articulation between social protection actors}

Greater coordination of social policy generally, and of social protection systems in particular, is needed at various levels and in several dimensions. As has been noted in previous studies, the level of intersectoral coordination represents a continuum that ranges from communication and coordination between various institutional actors to consolidated or integrated action. In this task, faced with the same problem, the actors in question fulfil the phases of the cycle of their policies and programmes in an intersectoral manner, based on common procedures and practices and even sharing resources, responsibilities and actions, along with joint monitoring and evaluation (PAHO/WHO, 2015). Forging high levels of intersectoral coordination involves political, financial, organizational and time costs, so this collaboration is justified when dealing with largescope problems of great complexity (Cunill-Grau, Repetto and Bronzo, 2015; Repetto and Potenza, 2015). Some of the dimensions and challenges involved in the institutional coordination of social protection systems are outlined below. 


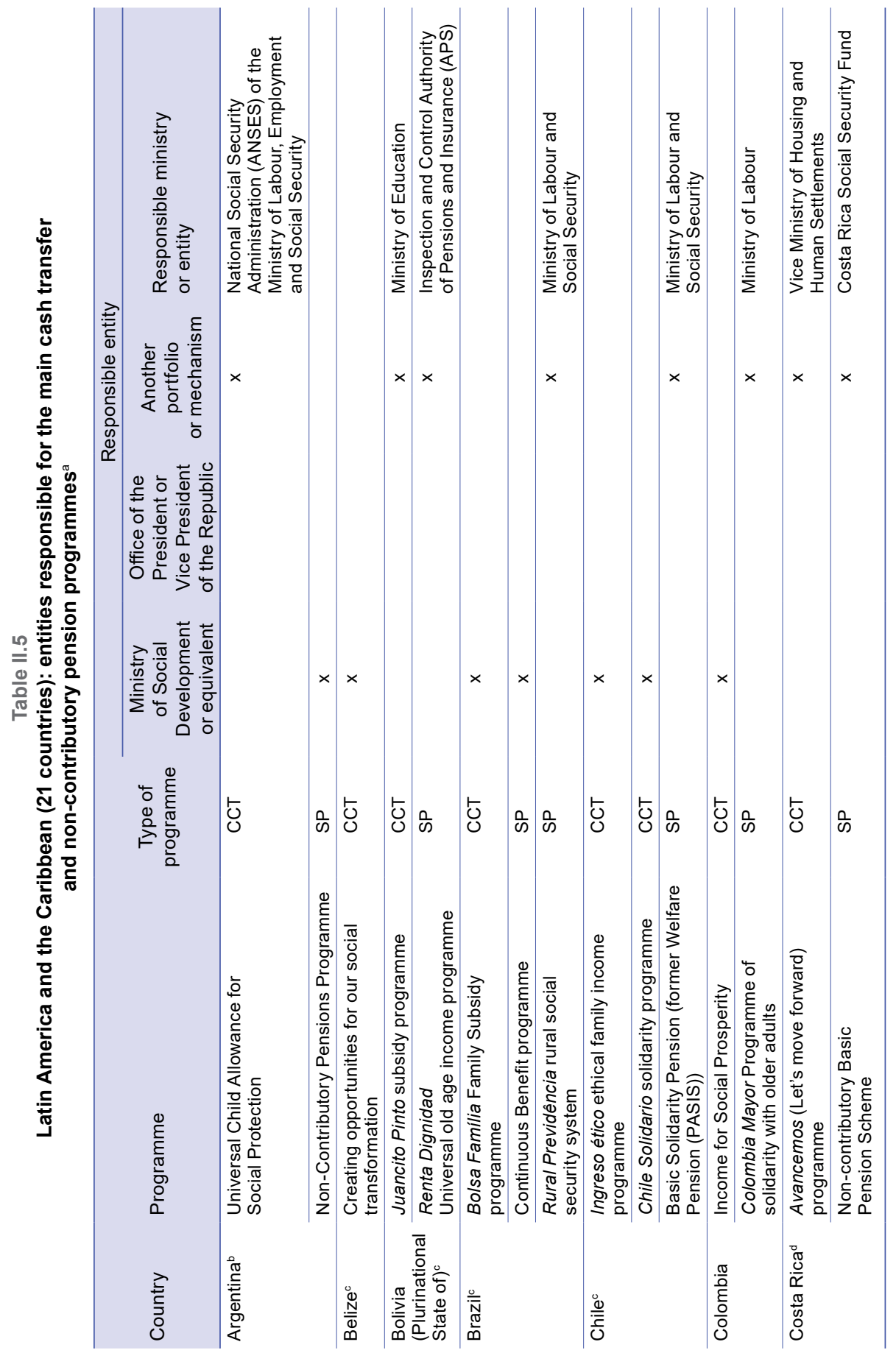




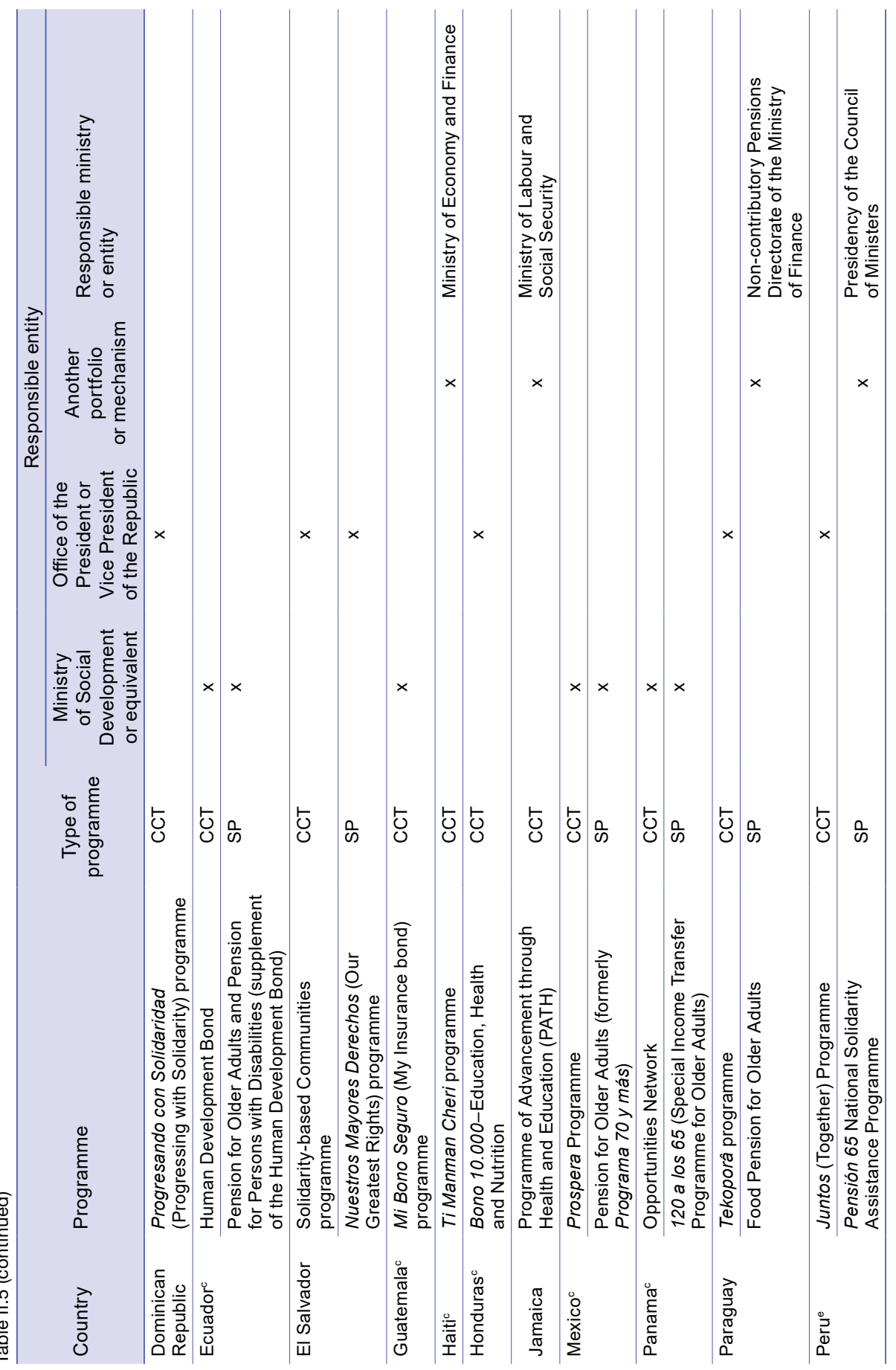




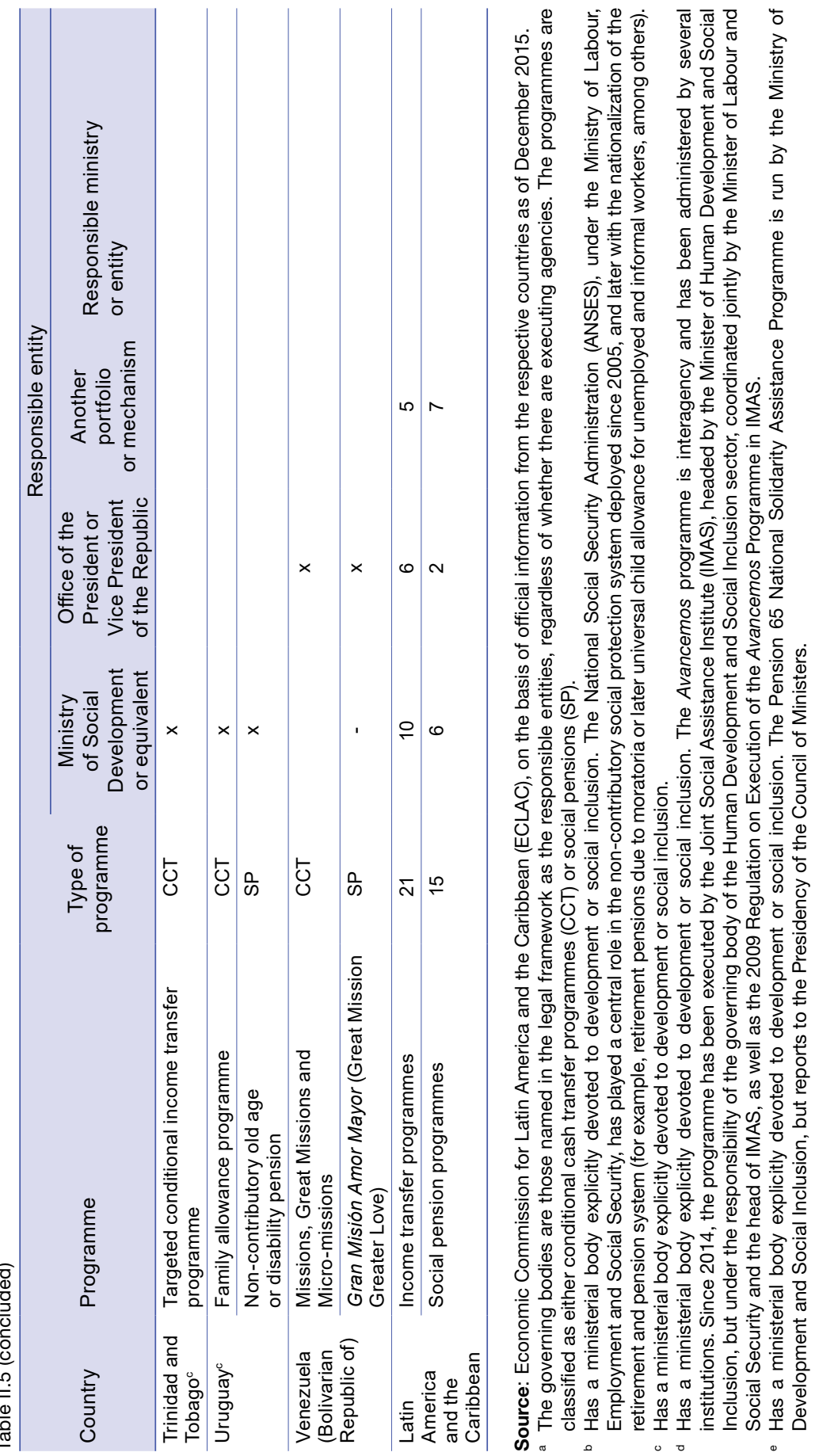




\section{(a) Coordination between the different sectors of social policy}

Sectoral inertias often obstruct the design of social policies and programmes aimed at addressing and producing impacts on various dimensions of well-being. The experience of income transfer programmes was innovative at the time, by combining coordinated and intersectoral actions in the areas of assistance, education, nutrition and health. Currently, most of these programmes are developing greater capacity for linking and coordinating with other sectoral actions targeting employment and productive development. Their common goal is to take better advantage of the years of education achieved within the framework of the programmes themselves, by making labour market participation less precarious and thus contribute to the escape from poverty. Nonetheless, the logic of intersectoral work, which includes joint planning, the establishment of common objectives and an integrating rationale in terms of the budget and evaluation and performance systems, among other elements, still needs to be implemented in most countries.

\section{(b) Coordination between contributory and non-contributory components of social protection}

The existence of social protection systems with high levels of coverage, equity and fiscal sustainability is strongly linked to the possibility that access to this system will be less segmented in the long term, and the contributory and non-contributory components will respond to the same logic of social inclusion and a vocation of universality, with a joint analysis of risk and consistency between incentives and financing. Recently, the noncontributory pillar has expanded autonomously in the region to fill gaps in the coverage of traditional social security. Nonetheless, an outstanding challenge is to expand the latter to sectors that have had little coverage thus far, and to build channels of communication between non-contributory policies and programmes, social security and the formal labour market. Although there is no conclusive evidence of adverse incentives arising from migration from non-contributory programmes to contributory and formal mechanisms, a pending task involves constructing alternatives and institutional mechanisms that establish links between the two.

\section{(c) Coordination between social entities with general mandates and social authorities targeting specific social problems or population segments (cross-cutting or by stages of the life cycle)}

The emergence of thematically focused social authorities stems from the enrichment and growing complexity of the region's social agenda. These entities have focused on providing an intersectoral approach to specific social problems, such as discrimination, inequality, poverty or care, and on promoting the rights and attending to the needs of specific segments of the population (women, persons with disabilities, Afrodescendent 
populations or indigenous peoples) and those related to different stages of the life cycle (childhood, youth and old age). A key institutional challenge is to ensure that the work of these entities, based on their more or less extensive mandates, translates into higher levels of mainstreaming and intersectoral coordination, rather than a fragmentation of the institutional architecture reflected in disperse policies and programmes and more motivated by competition than by collaboration. In the specific case of social protection systems, the mission of these entities is relevant for mainstreaming or articulating the attention of the different components and identifying specific needs and gaps. The experience of care systems (described in chapter V) illustrates these challenges.

\section{Management tools and the technical and operational dimension}

A key factor in an institutional framework that supports quality social policy is to have infrastructure and equipment, instruments, protocols and procedures in place, supported by physical and human resources that allow adequate implementation of government plans in order to achieve policy goals.

A review of the available information from the region's 33 countries shows that currently only 21 have an explicit social development plan or strategy. Although the mere existence of such plans is positive, in many cases they are limited to government cycles and do not represent State policies. This is an institutional weakness, because it puts at risk the sustainability through time that many policies need to be able achieve long-term social objectives. In the areas of health and education, the implementation of such plans dates back a long time, but strategies to combat poverty and promote development and social inclusion are of shorter tradition. In the social investment funds (FIS) of the 1990s, some evaluation and monitoring systems were introduced in an incipient manner, with ex ante evaluation processes. This extended into the present century, accompanied by conditional cash transfer programmes (CCTs), which have brought significant innovations in terms of technical and administrative capacity, along with an expansion of impact evaluations. Thus, in most Latin American and Caribbean countries, tools have been built for the administration of management information and the articulation of social programmes, such as participant registries, totally or partially integrated, and monitoring and evaluation systems for social development programmes.

The key features of the current evaluation models in the region include the fact that they have had a greater tendency towards ex post evaluation, which generates a significant dissemination of experimental and quasi-experimental designs of impact estimation. Their most recurrent limitations include a disconnection from process evaluation and monitoring 
indicators, which reduces the ability to attribute results to the programmes themselves. Nor has cost-effectiveness analysis been sufficiently developed, where results are associated with the costs incurred. Moreover, the models are maintained in a programme logic rather than one of policy, which limits the ability to make decisions on the whole of public management in a given area; for example, the components of protection or strategies to combat poverty and inequality (Martínez, 2015).

In terms of accountability, the existence of formal norms and procedures within the State is essential to control and verify the functioning of social policies and programmes. Monitoring and evaluation systems are crucial in these processes, along with participant registries and operating rules, and the mechanisms (general and sectoral) of the comptroller and audit of public actions. This is complemented by the accountability instruments of the entities that implement social development policies and programmes and the role played by various non-State actors, including programme participants, civil society and its organizations, and the media, among others.

Along with accountability, participation mechanisms play an important role in improving the design and institutionalizing and enhancing the impact and sustainability of policies. These span a range of modalities, from participatory budgeting exercises and sectoral or thematic consultation forums to mechanisms for recipients to participate in the management of the programmes. The National Social Assistance Conferences in Brazil stand out, both for their scope and size, and for their results, in which an extensive process of dialogue and consultation takes place, starting at the municipal level and reaching up to the national level, with the election of delegates in each of these stages and the participation of various governmental bodies coordinated by the Ministry of Social and Agrarian Development, together with civil society organizations and users of the programmes. The National Social Assistance Conferences have achieved very important results such as the creation of the national social assistance system.

As table II.6 shows, if the existence of information, evaluation and transparency systems is used as a proxy, most of the ministerial entities devoted to social development currently have this type of tool. Of the 22 countries for which information is available, 19 have registries of social programme recipients, although in few cases are these integrated and regularly updated systems. With respect to social information systems, nine countries have a sectoral system (that is, attached to the ministerial entity devoted to social development); and, in five, these systems include all the central government's social policies. There are at least 15 countries with bodies dedicated to the evaluation of government programmes, including social programmes, and nine with sectoral evaluation systems. Lastly, in terms of transparency, 16 systems of access to public information were identified, which either depend on the Government or are specific to ministerial entities focused on social development. 


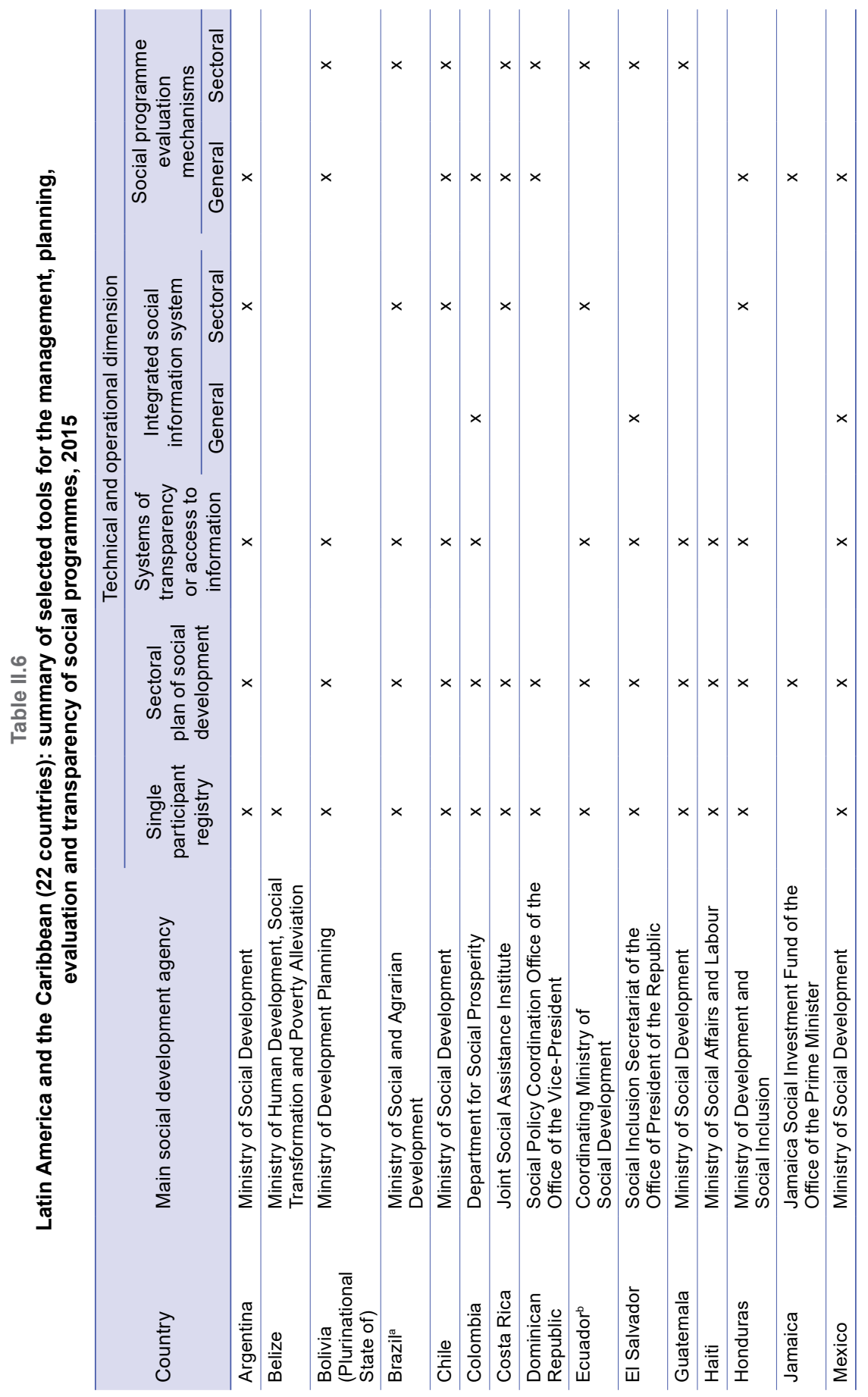



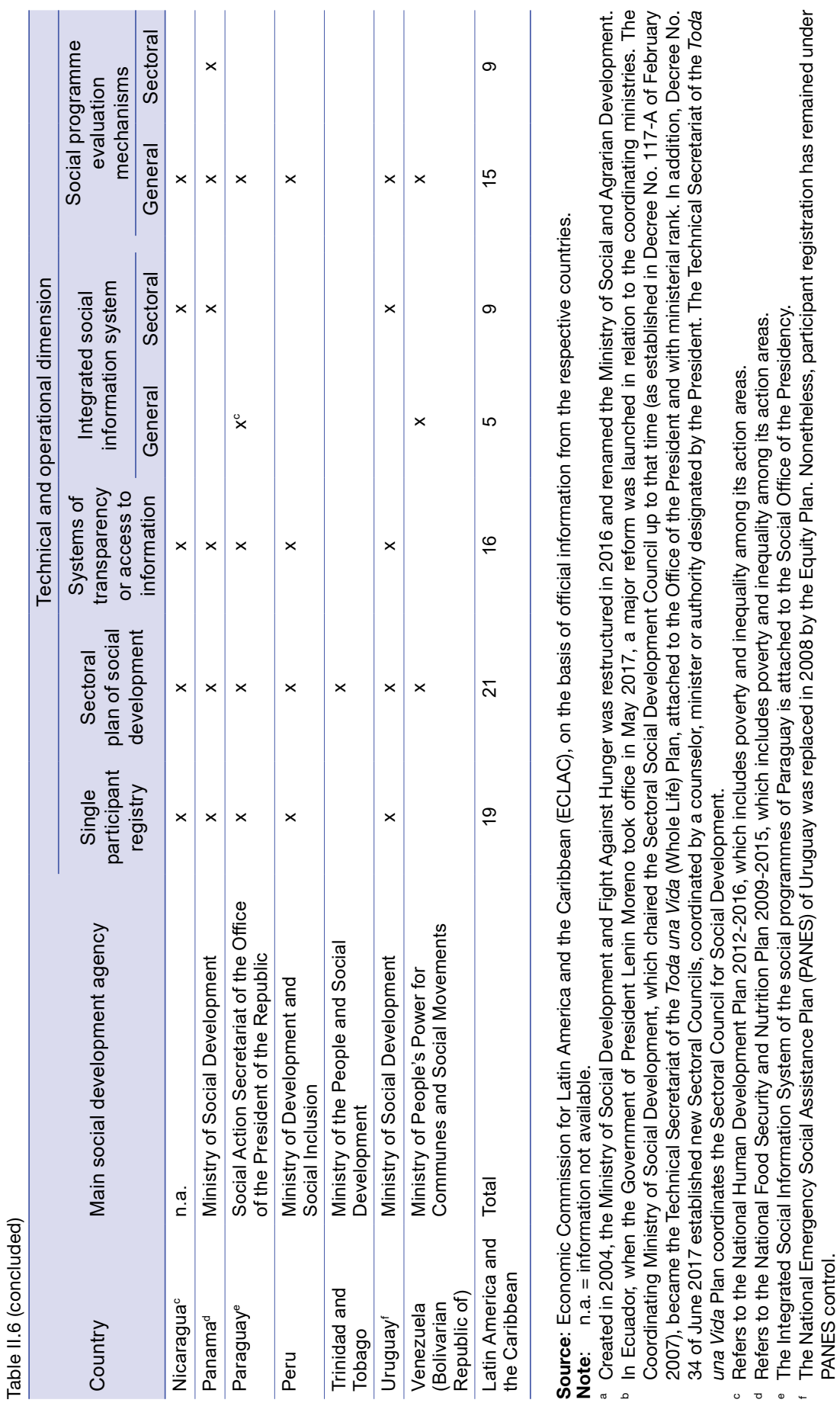


\section{Financing}

The proportion of public funds allocated to each government function is a basic indicator of the latter's political and economic priority; and its volatility in the face of economic cycles shows how context-dependent this allocation is. Thus, increasing resources allocated to social policies relative to gross domestic product (GDP) and their relative stability are fundamental for the sustainability and institutional strengthening of these policies.

The sustained growth of social resources in the region reflects a progressive institutionalization of social policy financing, particularly in terms of social protection and the fight against poverty. Although the growth rate of these resources varies, it has remained positive and was a key source of support when coping with the international crisis in the late 2000s. Nonetheless, regional needs are still very substantial and there are major challenges in terms of resource availability. Funding is still far below the expenditure levels (both absolute and relative) prevailing in the countries of the Organization for Economic Cooperation and Development (OECD) (which average around $27 \%$ of GDP).

A comparison of available resources and their GDP share between different countries shows that the institutional framework is not homogeneous in this regard or in terms of the coverage of existing services in the different policy areas. In general, more needy countries have lower service coverage and fewer resources per capita; and they assign a lower fiscal priority (see table II.7).

The foregoing paragraphs have discussed the contribution of conditional transfer programmes to social institutions, in terms of coordination and management tools. In contrast to their coverage, which is close to $21 \%$ of the population in the region as a whole, the resources of these programmes represented just $0.39 \%$ of GDP around 2013, as a regional average (ranging between $0.01 \%$ and $1.13 \%$ of GDP in the different countries). At the same time, the per capita amounts fluctuated between US\$ 0.51 and US\$ 41.19 per month (ECLAC, 2015). This may be a good indicator of efficiency, but it also reflects the level of priority accorded to these programmes in the different countries.

An indicator of the priority assigned by the region's countries to development and social inclusion policies is the annual budget of the ministries of social development or the equivalent entity relative to the total public sector budget. The proportion varies greatly, but with a different distribution to that shown in table II.7 -ranging from 1.0\% in Nicaragua and Uruguay or $1.1 \%$ in Paraguay, to $5.2 \%$ in Peru and $6.0 \%$ in Argentina (see table II.8). These figures rate these entities' budgetary importance as low to moderate, in contrast to the importance of their tasks. ${ }^{18}$ Although such amounts do not reflect the mobilization of resources from other ministerial bodies that act in coordination, they do give an idea of their relative importance within central government.

18 The values shown correspond to an administrative and non-functional classification of social expenditure. 
Table II.7

Latin America (18 countries): social spending in three groups of countries
with different results in terms of protection and social promotion
(simple average of each group), around 2015
(In constant dollars at 2010 prices and percentages of GDP)

\begin{tabular}{|c|c|c|c|c|c|c|}
\hline \multirow[b]{3}{*}{ Indicator } & \multicolumn{2}{|c|}{ Group 1} & \multicolumn{2}{|c|}{ Group 2} & \multicolumn{2}{|c|}{ Group 3} \\
\hline & \multicolumn{2}{|c|}{$\begin{array}{c}\text { Argentina, Brazil, } \\
\text { Chile, Costa Rica, } \\
\text { Panama and Uruguay }\end{array}$} & \multicolumn{2}{|c|}{$\begin{array}{c}\text { Colombia, Mexico and } \\
\text { Venezuela (Bolivarian } \\
\text { Republic of) }\end{array}$} & \multicolumn{2}{|c|}{$\begin{array}{l}\text { Bolivia (Plurinational State of), } \\
\text { Dominican Republic, Ecuador, } \\
\text { El Salvador, Guatemala, } \\
\text { Honduras, Nicaragua, } \\
\text { Paraguay and Peru }\end{array}$} \\
\hline & $\begin{array}{l}\text { Public } \\
\text { sector }\end{array}$ & $\begin{array}{c}\text { Central } \\
\text { Government }^{\mathrm{b}}\end{array}$ & $\begin{array}{l}\text { Public } \\
\text { sector }^{\mathrm{a}}\end{array}$ & $\begin{array}{c}\text { Central } \\
\text { Government }^{\mathrm{b}}\end{array}$ & $\begin{array}{l}\text { Public } \\
\text { sector }^{\mathrm{a}}\end{array}$ & $\begin{array}{c}\text { Central } \\
\text { Government }^{\mathrm{b}}\end{array}$ \\
\hline $\begin{array}{l}\text { Public social } \\
\text { expenditure, } \\
\text { per capita (US\$ at } \\
2010 \text { prices) }\end{array}$ & $2,101.0$ & $1,445.0$ & $1,131.0$ & 832.0 & 407.0 & 318.0 \\
\hline $\begin{array}{l}\text { Public expenditure } \\
\text { on social protection, } \\
\text { per capita } \\
\text { (US\$ at } 2010 \text { prices) }\end{array}$ & 863.0 & 699.0 & 413.0 & 267.0 & 99.0 & 73.0 \\
\hline $\begin{array}{l}\text { Public social } \\
\text { expenditure } \\
\text { (percentages of GDP) }\end{array}$ & 19.9 & 13.0 & 15.0 & 10.9 & 11.5 & 9.1 \\
\hline $\begin{array}{l}\text { Public expenditure } \\
\text { on social protection } \\
\text { (percentages of GDP) }\end{array}$ & 8.1 & 6.3 & 5.5 & 3.5 & 2.8 & 2.0 \\
\hline $\begin{array}{l}\text { Public expenditure } \\
\text { on education } \\
\text { (percentages of GDP) }\end{array}$ & 5.3 & 3.7 & 4.7 & 4.5 & 4.5 & 4.0 \\
\hline $\begin{array}{l}\text { Public expenditure on } \\
\text { health (percentages } \\
\text { of } G D P \text { ) }\end{array}$ & 4.7 & 2.1 & 3.1 & 1.7 & 2.7 & 2.2 \\
\hline $\begin{array}{l}\text { Public expenditure } \\
\text { on housing and } \\
\text { community services } \\
\text { (percentages of GDP) }\end{array}$ & 1.4 & 0.6 & 1.0 & 1.0 & 0.9 & 0.7 \\
\hline $\begin{array}{l}\text { Public expenditure on } \\
\text { recreational activities, } \\
\text { culture and religion } \\
\text { (percentages of GDP) }\end{array}$ & 0.2 & 0.1 & 0.4 & 0.2 & 0.3 & 0.1 \\
\hline $\begin{array}{l}\text { Public spending } \\
\text { on environmental } \\
\text { protection } \\
\text { (percentages of GDP) }\end{array}$ & 0.2 & 0.1 & 0.2 & 0.1 & 0.4 & 0.1 \\
\hline
\end{tabular}

Source: Economic Commission for Latin America and the Caribbean (ECLAC), on the basis of S. Cecchini and R. Martínez, Inclusive social protection in Latin America: a comprehensive rights-based approach, ECLAC Books, No. 111 (LC/G.2488-P), Santiago, Economic Commission for Latin America and the Caribbean (ECLAC), 2012.

a In the case of the public sector, Panama and the Plurinational State of Bolivia report information for 2014 and the Bolivarian Republic of Venezuela reports for 2009. In the cases of the Bolivarian Republic of Venezuela, Chile, the Dominican Republic, Ecuador, Guatemala, Honduras, Nicaragua, Panama, Paraguay and Uruguay, the data refer to Central Government. The data for Brazil, Colombia and the Plurinational State of Bolivia correspond to General Government; for Argentina, El Salvador and Mexico, they correspond to the non-financial public sector; and for Costa Rica and Peru, they correspond to the public sector.

b In the case of Central Government, Panama reports information for 2014 and the Bolivarian Republic of Venezuela, for 2009. 
Table II. 8

Latin America and the Caribbean (14 countries): budget of the Ministry of Social Development or equivalent entity as a proportion of budgeted primary expenditure, around $2015^{\mathrm{a}}$

(Percentages)

\begin{tabular}{llc}
\hline Country & Ministry of Social Development or equivalent & Percentage \\
\hline Argentina & Ministry of Social Development & 6.0 \\
\hline Brazil $^{\mathrm{b}}$ & Ministry of Social Development and Fight against Hunger & 3.9 \\
\hline Chile & Ministry of Social Development & 1.7 \\
\hline Colombia & Department for Social Prosperity & 2.4 \\
\hline Costa Rica & Ministry of Human Development and Social Inclusion, & 3.3 \\
\hline Ecuador & Joint Social Assistance Institute (IMAS) & \\
\hline Guatemala & Ministry of Economic and Social Inclusion & 3.4 \\
\hline Haiti & Ministry of Social Development & 3.2 \\
\hline Mexico & Ministry of Social Affairs and Labour & 3.1 \\
\hline Nicaragua & Ministry of Social Development & 3.2 \\
\hline Panama & Ministry of Family, Adolescence and Childhood & 1.0 \\
\hline Paraguay & Ministry of Social Development & 2.7 \\
\hline Peru & Secretariat of Social Action & 1.1 \\
\hline Uruguay & Ministry of Development and Social Inclusion & 5.2 \\
\hline $\begin{array}{l}\text { Latin America and } \\
\text { the Caribbean } \\
\text { (simple average) }\end{array}$ & Ministry of Social Development & 1.0 \\
\hline & & 2.8 \\
\hline
\end{tabular}

Source: Economic Commission for Latin America and the Caribbean (ECLAC), on the basis of the budget laws of the countries.

a The values shown are amounts budgeted but not necessarily executed.

b The Ministry of Social Development and Fight Against Hunger was renamed in 2016 as the Ministry of Social and Agrarian Development.

Another element that needs to be considered in this dimension is the quality of the data collection and dissemination processes. Although progress has been made in incorporating the approaches, categories and procedures of functional expenditure analysis, institutional coverage and the classification of social functions remain heterogeneous; as does the consideration of private contributions, whether through the co-financing of services (out-of-pocket expense) or contributions made by foundations and non-governmental organizations (NGOs) or other entities. Moreover, the analytical approach used is still fundamentally one of accounting and budgetary control, and little progress has been made towards viewing spending as an integral part of public policy management and decision making. ${ }^{19}$

19 To improve these measurement systems, the methodological proposals of the Government Statistics manual of the International Monetary Fund (IMF) should be articulated with the System of National Accounts, in the satellite accounts line. It should include data on costs and investment as an integral part of the system of social management analysis, articulated with social information, to promote more rational decision making to maximize the impacts and efficiency of resource use (Martínez and Collinao, 2010; Martínez, 2015). 


\section{E. Final remarks}

This volume has shown that analysis of the legal and regulatory, organizational, technical and operational, and investment and financing dimensions is fundamental for the study of social policy institutions. In this regard, it is important to observe national realities, but also the international and regional panorama. In recent years, the social development agenda in Latin America and the Caribbean has made many positive steps in terms of institutional development in all of these areas, along with different processes of integration, dialogue and exchange between countries. There is a great deal of convergence and complementarity in the agendas of this multiplicity of forums, especially in terms of overcoming poverty and social inequalities from a rights perspective. The fact that poverty is predominantly understood as a multidimensional phenomenon to be addressed through comprehensive social policies is fundamental, since it involves sharing conceptual elements to define a social agenda that is regionally coherent. Moreover, the notion that regional integration processes can contribute to greater equality and social inclusion is also present (more or less explicitly) in the agenda of these forums.

These issues are compatible with the key orientations of the 2030 Agenda for Sustainable Development, which will help coordinate the monitoring of new priorities at the regional level. There are also specific issues that have a prominent place on the agenda of certain mechanisms, which increases their diversity.

With regard to social policy institutions in each country, intersectoral coordination and articulation persists as an area needing further development to promote a systemic and integrated management in the region. This need responds to the multidimensional characteristics of social phenomena and the thematic specialization of the sectors (for example, in ministries of health, education, social development, employment and housing). It also has to do with the specifics of the various segments of the population served, related to the life cycle or to characteristics and determinants of gender, race, ethnicity or disability status.

Another organizational challenge is vertical articulation between the different levels of government (central, subnational and local), as well as the consolidation and expansion of consultation and participation mechanisms. Advancing on these fronts is fundamental for the design and implementation of truly comprehensive and participatory policies.

In terms of management, the region's countries have made major progress in terms of models and instruments. This is reflected in the expansion of programming regulations and participant registration 
systems, along with the incorporation of processes design and ex ante evaluation, monitoring and evaluation of programme impact. This represents an auspicious step forward in terms of the effectiveness, efficiency, transparency and sustainability of social policies. Nonetheless, significant challenges remain, such as evaluation at the level of social policy as a whole (rather than just programmes), the expansion of knowledge and techniques among those who manage the policy and the development of additional accountability mechanisms, which are clearer and involve participation by different actors, among other things.

It is also necessary to advance in terms of guaranteeing sufficient and stable resources to meet social policy challenges, in particular social protection for people living in poverty and indigence. In this process, the identification of alternatives linked to fiscal rules that favour social policy and its association with "green tax reform" initiatives are emerging as possible ways forward.

The institutional fabric of non-contributory social protection is heterogeneous, but faces common challenges. In general, there is a need for coherence and articulation between the institutional models and the existing ministerial and programmatic structures, and also with the multiple actors involved in social protection systems that are more complex today than in the past. For example, income transfer and social pension programmes are not always governed by entities that have a formal mandate to combat poverty or promote social protection, which necessarily entails greater coordination. Another challenge is to balance the objective of promoting social protection for all, with addressing and raising the profile of specific needs in different segments of the population, on which various government entities converge. Thus, a central institutional challenge is intersectoral coordination between the different areas of social protection policy, between the contributory and non-contributory components and systems of care, and between entities with general mandates and those with specific ones.

In summary, the countries of the region have made significant progress in terms of their social policy institutions, which presages substantive improvements in quality, effectiveness, efficiency, transparency and sustainability. In this area there is no single desirable model, but common major challenges that need to be addressed, including the following:

- Consolidate a legal and regulatory base that gives sustainability to social policy as pertaining to the State (rather than to a government administration) and makes it possible to advance towards more structural and long-term objectives that extend beyond government terms of office. 
- Strengthen the capacity for coordination and articulation of policies to overcome poverty with social protection policies, comprehensively defined, with other areas of social policy (education, health, employment, housing) and with the economic, infrastructure and productive development spheres. This need stems from the multidimensional nature of the phenomena of poverty, inequality and social development. It also responds to the thematic specialization of the sectors, and the need to address specific population characteristics, according to stages of the life cycle, gender, race, ethnicity and disability.

- Improve the capacity for articulation and cooperation between the central, regional and local levels of government, focusing on those that are particularly weak and located in the poorest areas; and develop mechanisms for participation by policies' target populations and their organizations, and also by key private players. Heterogeneity in terms of technical capacity and resources (physical, human and financial) at the subnational levels is also a key challenge to be addressed, because these aspects tend to be weaker in areas that are further from the central government and present higher levels of poverty.

- Deepen the capacity of public management on social issues, by formalizing procedures, ranging from the definition of plans to the evaluation of their results, and ensure the availability of reliable and timely information to guide decision making with a view to maximizing impacts and efficiency.

- Have sufficient resources in place to meet the needs of a quality social policy, turning the idea of current spending into social investment, and improving its recording and dissemination, in terms of both financing and execution.

Lastly, spaces of agreement and broad social and political covenants aimed at higher objectives, such as those established in the 2030 Agenda for Sustainable Development (ECLAC, 2015), should be promoted. These agreements provide a crucial foundation for institutionalizing and legitimizing new social protection policies through time. Along with social and political consensus, progress is needed to forge a fiscal pact that ensures sufficient and stable resources to achieve the objectives of poverty eradication, guaranteed rights and a substantive reduction of social inequality in Latin America and the Caribbean. 


\section{Bibliography}

Cecchini, S. and R. Martínez (2012), Inclusive social protection in Latin America: a comprehensive rights-based approach, ECLAC Books, No. 111 (LC/G.2488-P), Santiago, Economic Commission for Latin America and the Caribbean (ECLAC).

Cunill-Grau, N., F. Repetto and C. Bronzo (2015), “Coordinating sectors and institutions for building comprehensive social protection", Towards universal social protection: Latin American pathways and policy tools, S. Cecchini and others (eds.), ECLAC Books, No. 136 (LC/G.2644-P), Santiago, Economic Commission for Latin America and the Caribbean (ECLAC).

Dabène, O. (2012), "Explaining Latin America's fourth wave of regionalism: regional integration of a third kind", paper presented at the International Congress of the Latin American Studies Association, San Francisco, May.

ECLAC (Economic Commission for Latin America and the Caribbean) (2015), Inclusive social development: the next generation of policies for overcoming poverty and reducing inequality in Latin America and the Caribbean (LC/L.4056(CDS.1/3)), Santiago.

Franco, R. and M. Székely (2010), "Institucionalidad social en América Latina", Project Documents (LC/W.312), Santiago, Economic Commission for Latin America and the Caribbean (ECLAC).

IMF (International Monetary Fund) (2014), Government Finance Statistics Manual 2014, Washington, D.C.

Martínez, R. (2015), "Monitoring and evaluation of social protection policies and programmes", Towards universal social protection: Latin American pathways and policy tools, Simone Cecchini and others (eds.), ECLAC Books, No. 136 (LC/G.2644-P), Santiago, Economic Commission for Latin America and the Caribbean (ECLAC).

Martínez, R. and M. P. Collinao (2010), "Gasto social: modelo de medición y de análisis para América Latina y el Caribe", Manuales, No. 65 (LC/L.3171-P), Santiago, Economic Commission for Latin America and the Caribbean (ECLAC).

PAHO/WHO (Pan American Health Organization/World Health Organization) (2015), Intersectoral Action and Health Equity in Latin America: An Analytical Approach, Washington, D.C.

Repetto, F. and F. Potenza (2015), "Documento final de consultoría. Institucionalidad social y autoridad social en América Latina y el Caribe: abordaje conceptual, avances y desafíos de la institucionalidad de la políticas social y de la protección social", unpublished. 


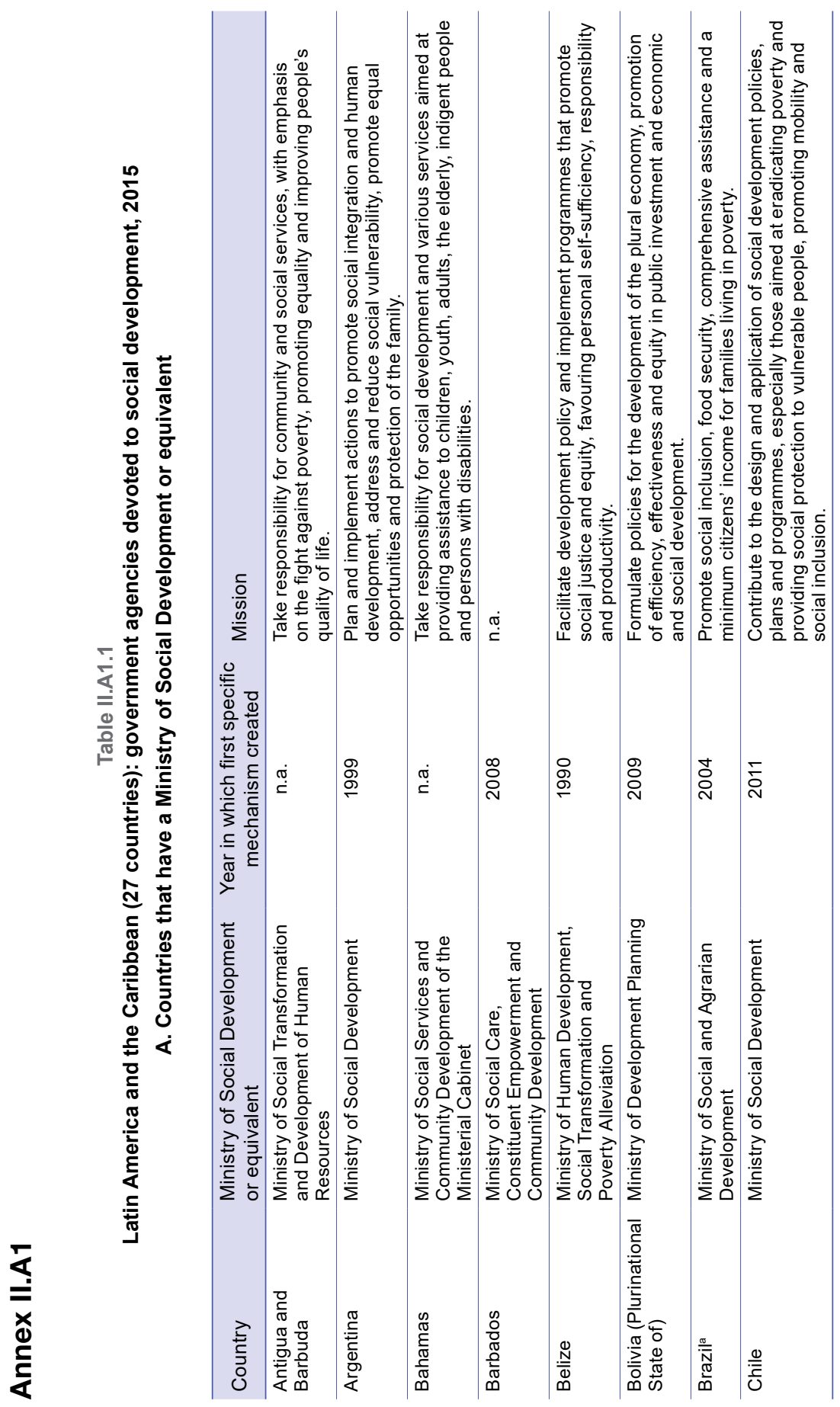




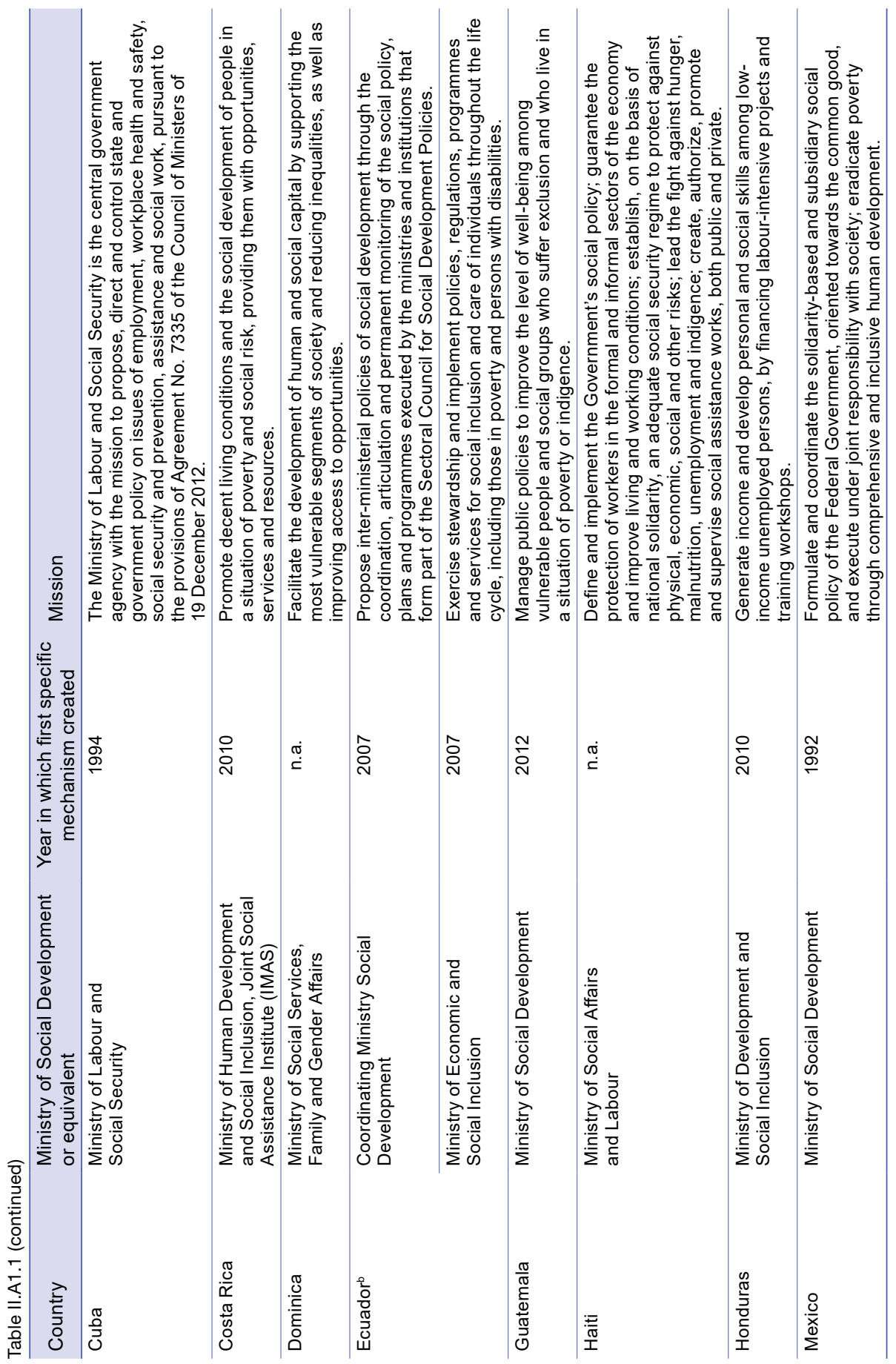




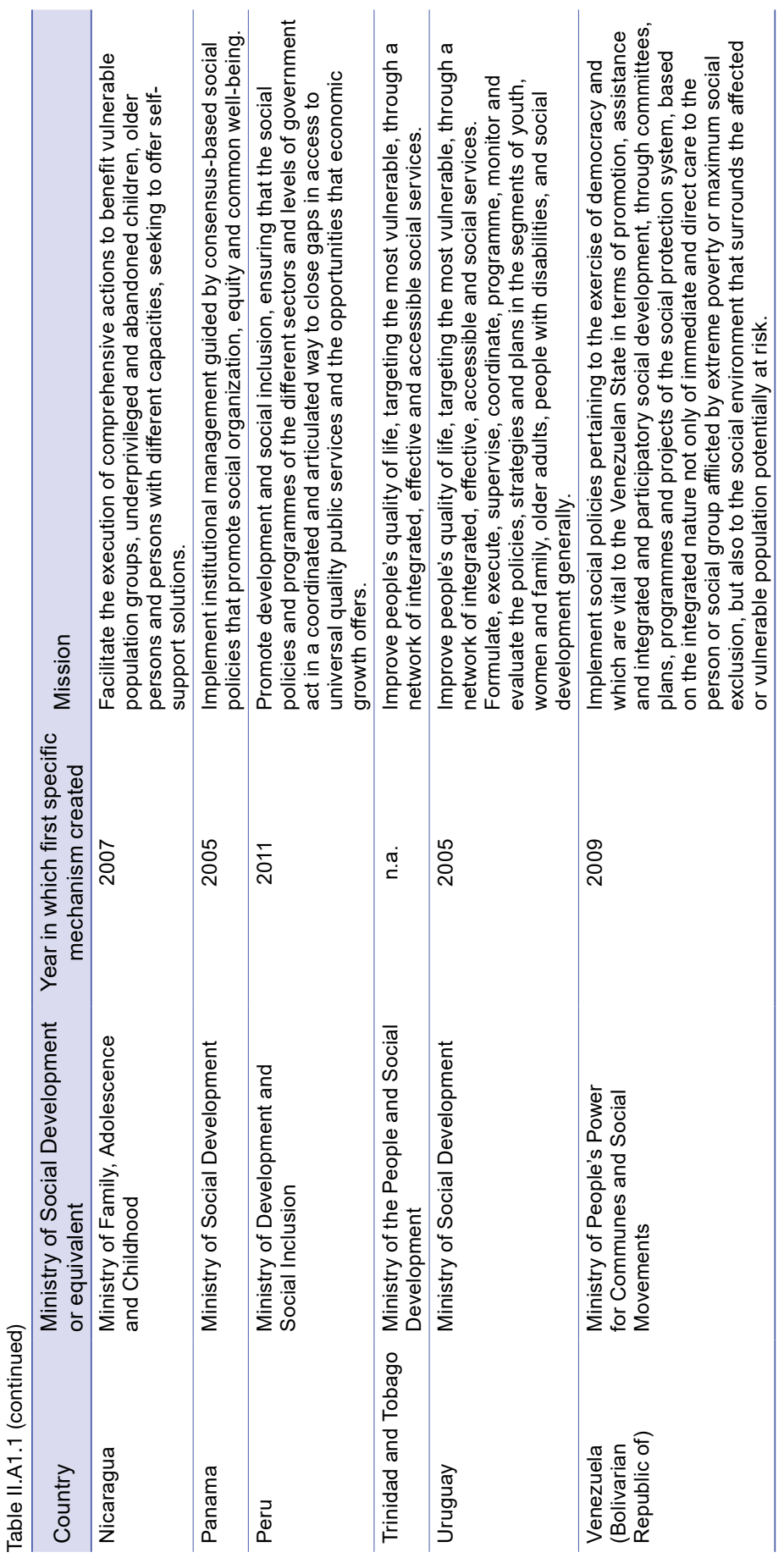




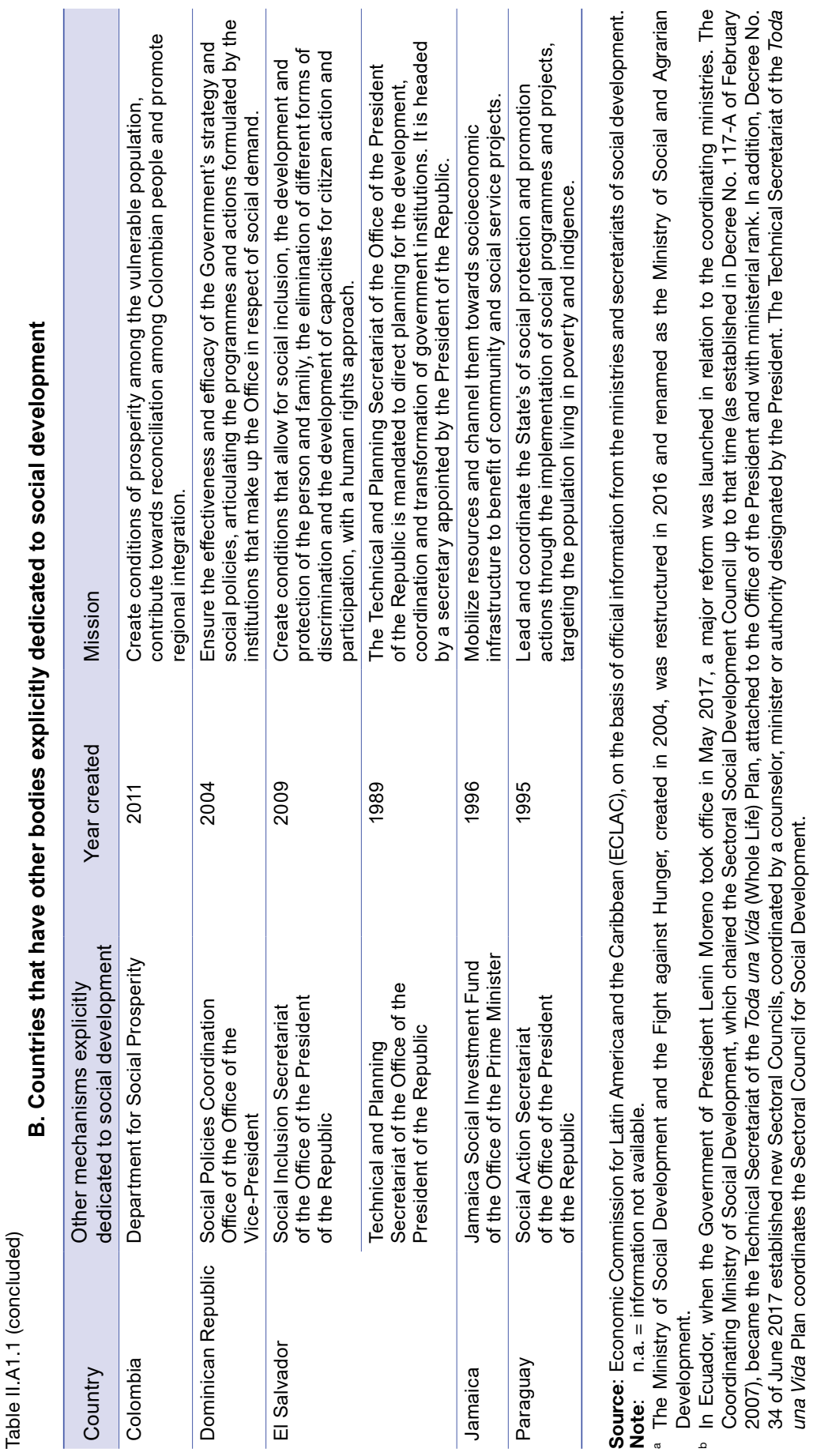




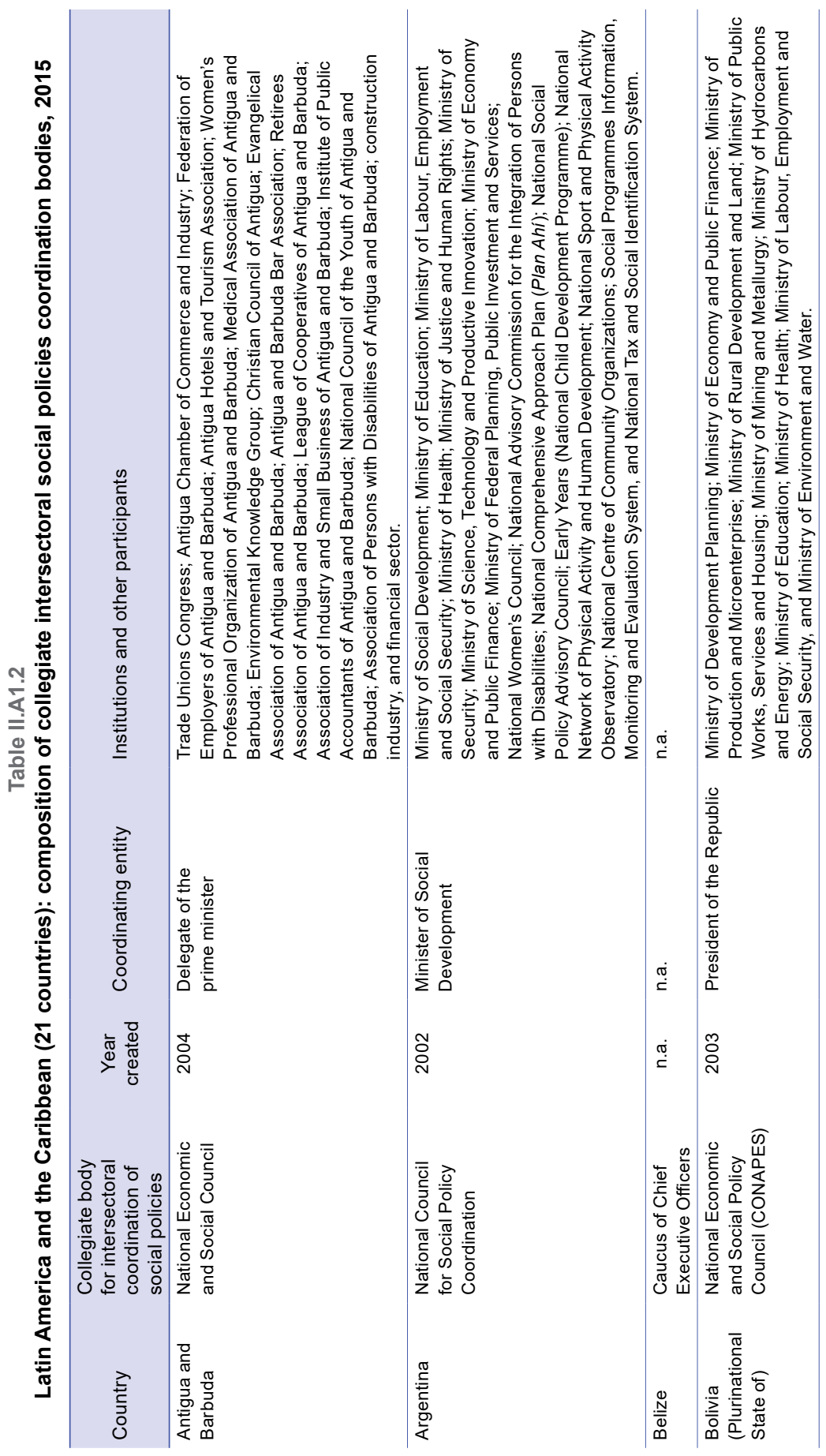




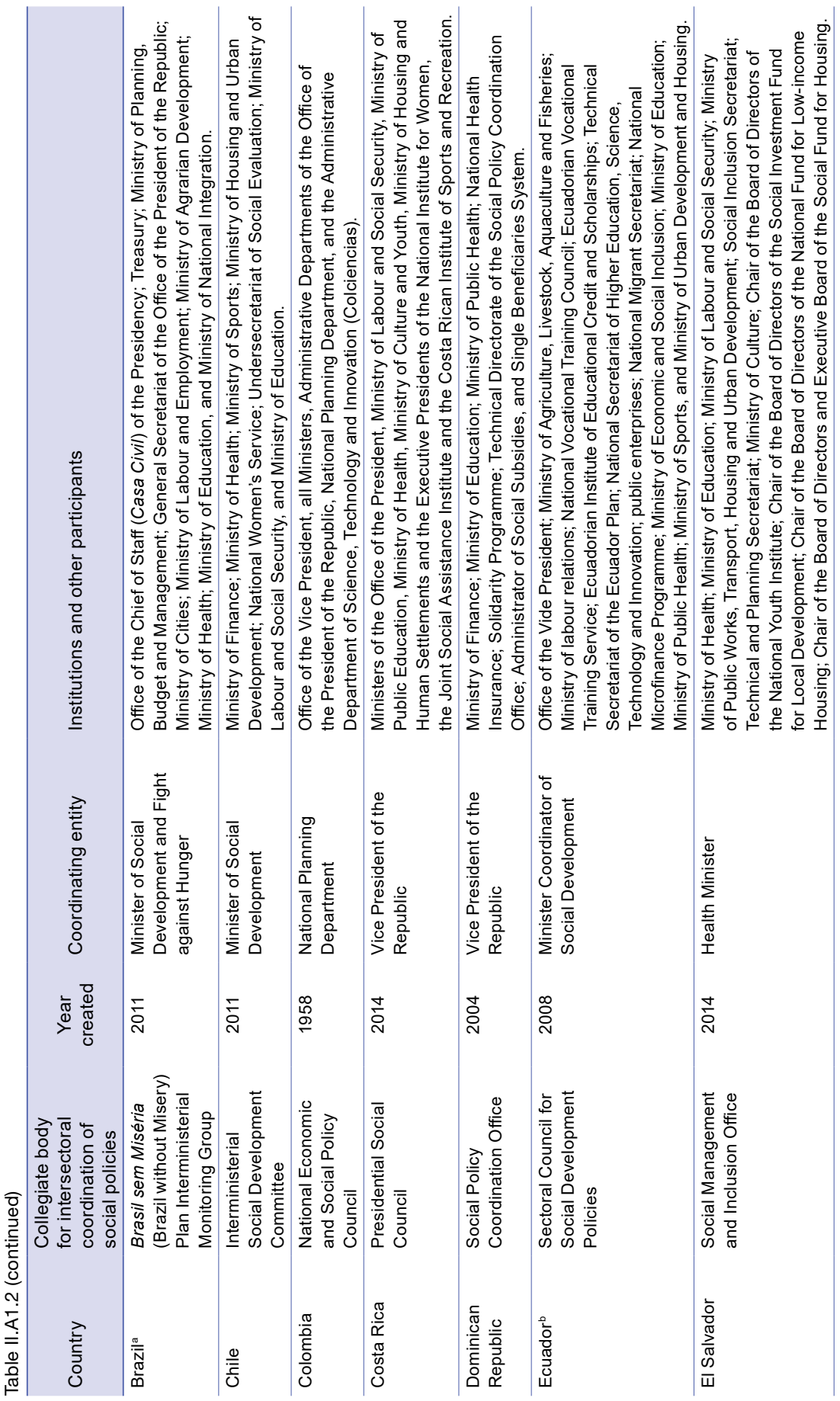




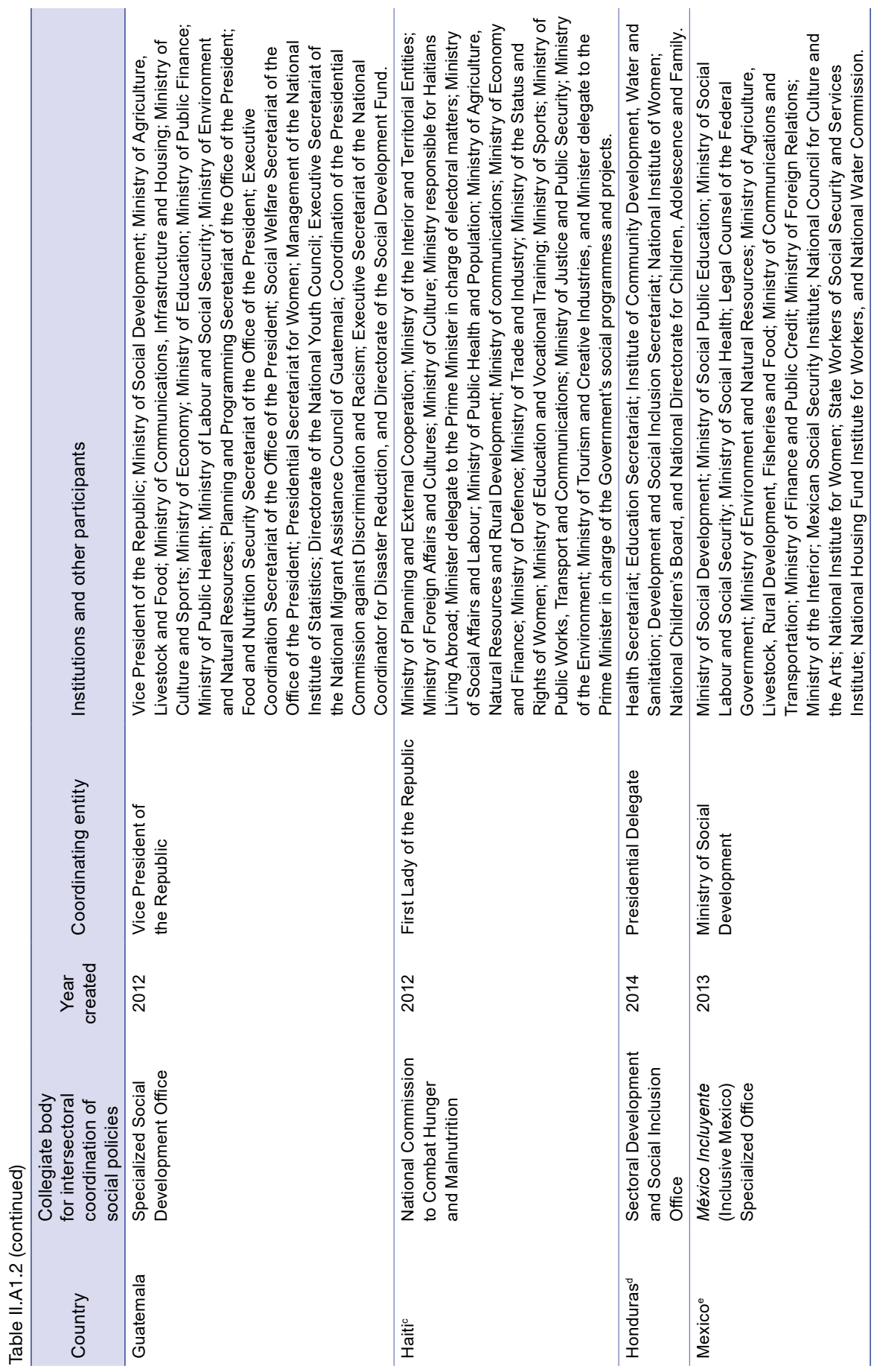




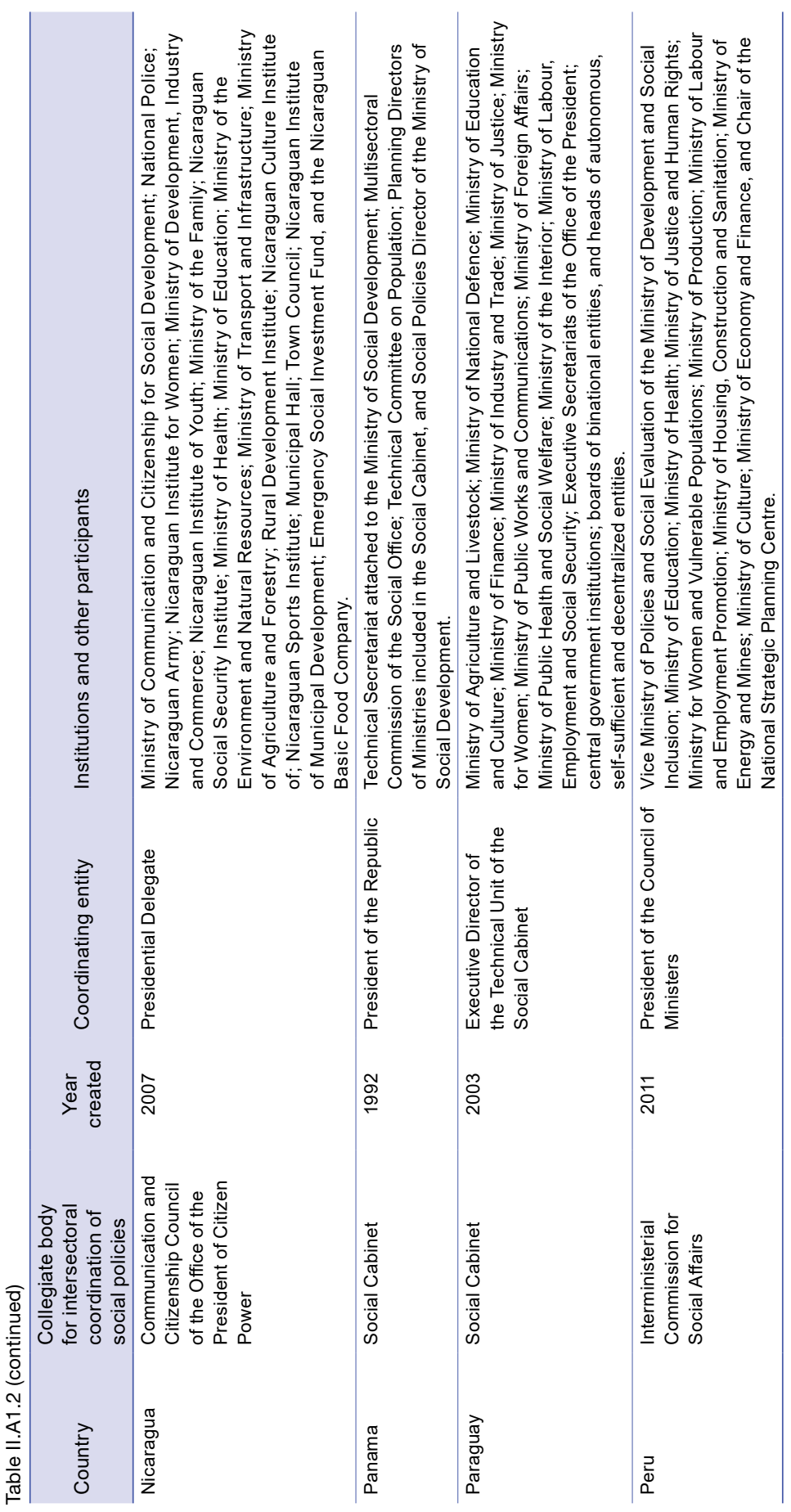




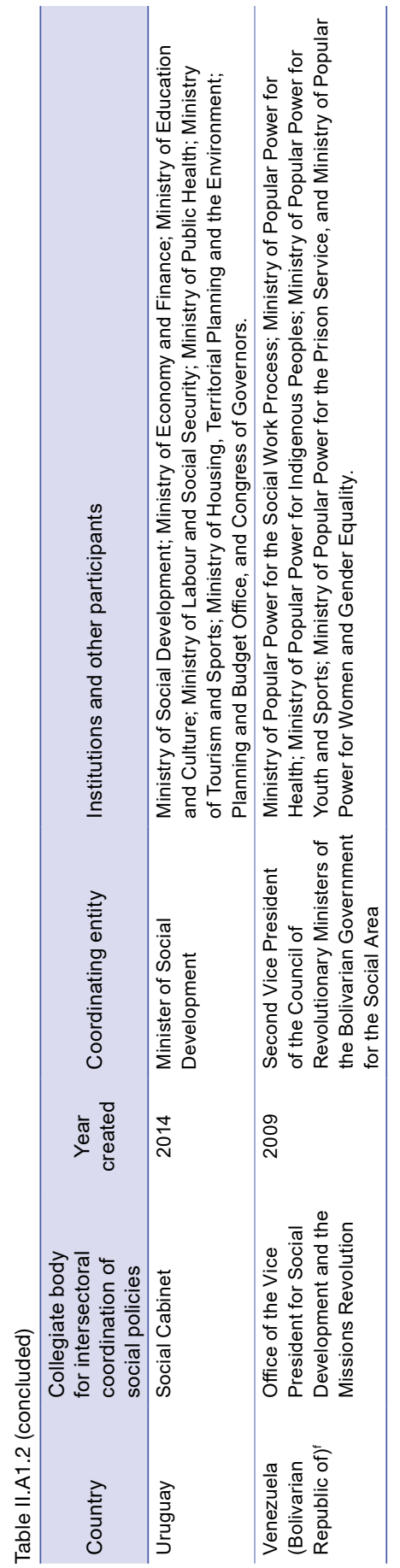

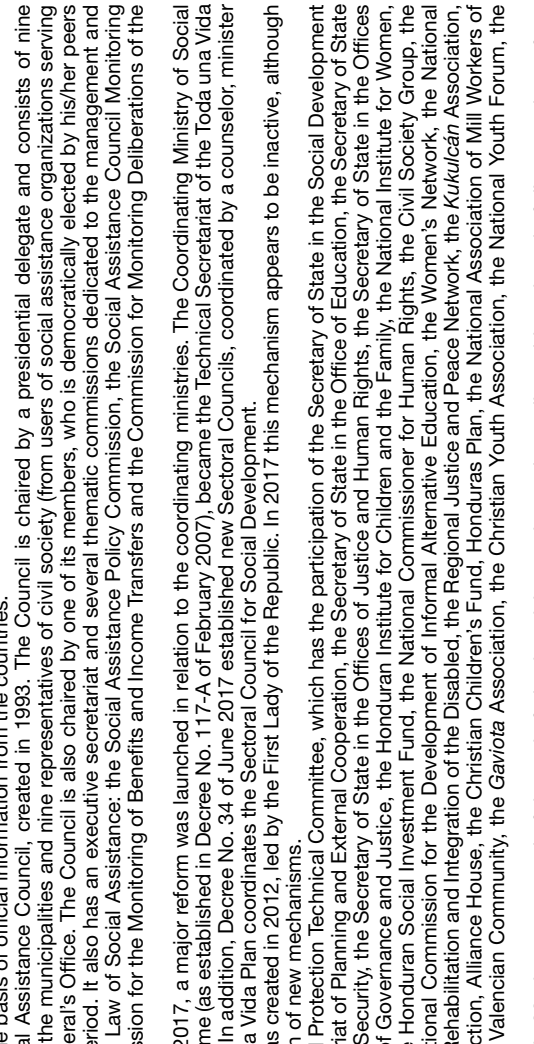

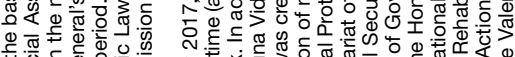

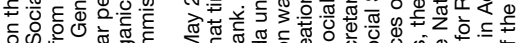

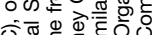

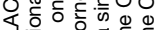

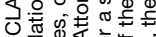

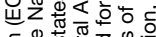

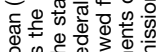

空.

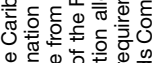

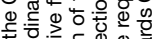

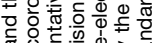

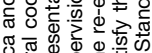

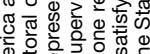

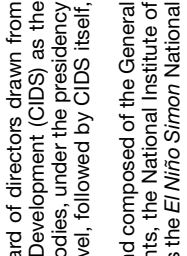

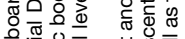

.

तक

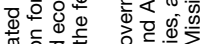

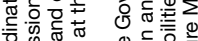

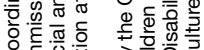

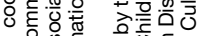

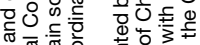

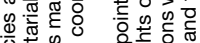

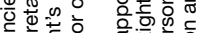

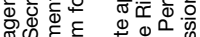

T⿻

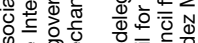

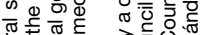

क्षे

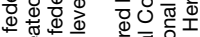

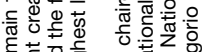

ه

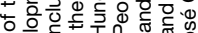
万人.

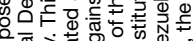
है.

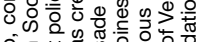

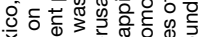

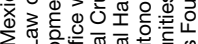

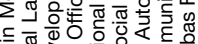

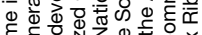

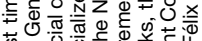
$\leq 0, \overline{0}$

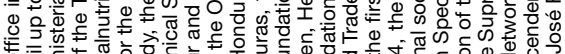

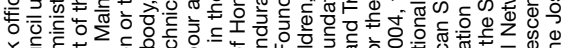

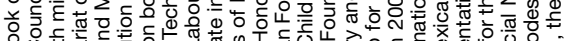

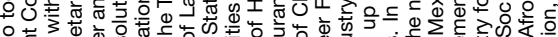

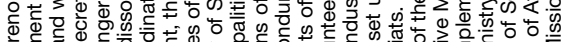

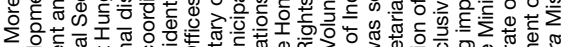

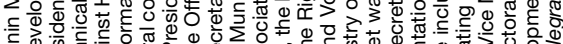

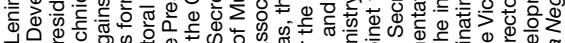

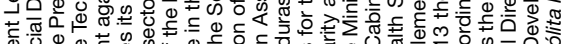

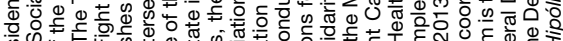

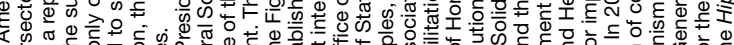
品

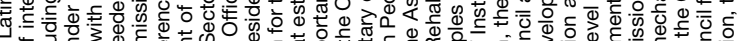

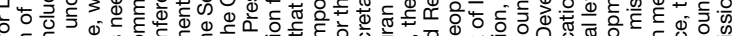

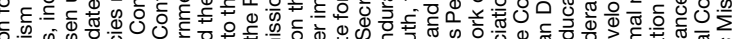
은

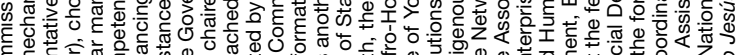
हो

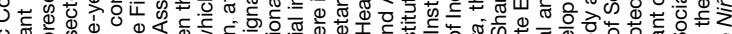

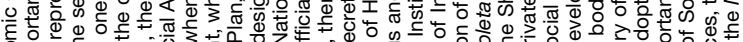

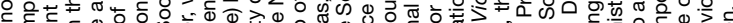

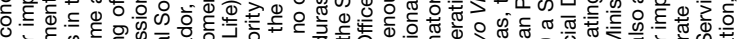

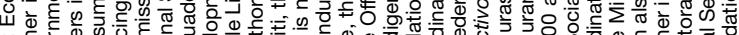

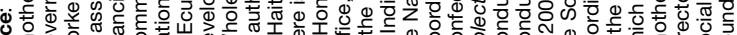

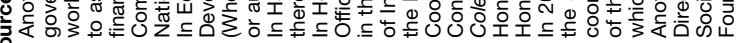


Part 2

Components and institutional framework of social protection 

Chapter III

\section{Labour market regulation and social protection: institutional challenges}

Mario D. Velásquez Pinto ${ }^{1}$

\section{Introduction ${ }^{2}$}

This chapter analyses the institutional framework of labour regulations as a component of social protection -in other words as the set of rules and actions designed to protect decent work and enable social protection to be provided for workers and their dependants.

It starts by discussing the role of labour regulations and the proposals and measures aimed at making the region's labour markets more flexible (through the deregulation of the 1980s and 1990s); and it also considers their negative effects on job quality and the increasing lack of protection and rising poverty. This has enhanced the perceived value of labour regulations as components of social protection, and the design of active policies to improve the functioning of labour markets and strengthen productive participation in them.

Consultant of the Social Development Division of the Economic Commission for Latin America and the Caribbean (ECLAC).

2 This chapter is based on the document Regulación del mercado de trabajo y protección social en países de América Latina, authored by Mario Velásquez with collaboration from Fabiana Pierre and Matías Salces, Research Assistants in the Social Development Division of ECLAC (see Velásquez, 2016). 
The second section analyses the scope of the relationship between labour regulations as components of social protection. The third part puts forward an analytical proposal based on the role played by labour standards in protecting workers against a set of risks that arise during the life cycle -in the pre-active phase, during workforce participation and in old age. Specific labour regulations are identified for each stage and each risk identified.

The fourth section seeks to identify standards and their contents in each country, drawing on three main sources: the ratification of the international conventions of the International Labour Organization (ILO), the fundamental guarantees expressed in the respective national constitutions, and each country's labour codes.

The fifth part of the chapter examines how the institutional framework is designed to ensure compliance with the standards. It considers the design and basic functions of ministries of labour, along with the characteristics of the relevant judicial and administrative mechanisms. In the latter case, the section describes the systems, their functions and their institutional strength, through a set of indicators. It concludes by analysing performance indicators, which measure the degree of protection that exists against the risks described.

The final section reflects on the achievements of Latin American countries and the challenges they face in moving towards a strengthened institutional framework that contributes to the sustainability and effectiveness of labour market regulation, as a key component for universalizing decent work and social protection in the region.

\section{A. Labour regulations and flexibility in Latin America ${ }^{3}$}

Labour market regulations, and compliance with them, are decisive for enabling labour relations to develop under conditions of freedom, equality, security and human dignity. These are the attributes on which the ILO bases its definition of decent work; and they serve as a reference for establishing international standards in this area.

In recent decades, the role and effectiveness of such regulations has been questioned in the region - particularly in the 1990s, in the belief that economic liberalization processes undertaken to facilitate international financial flows and goods and services trade presupposed greater wage flexibility and labour mobility (World Bank, 1995).

This study only refers to paid employment and its regulations. Unpaid work -in other words, the production of goods and services by household members, for which there is no market valuation but which contributes to family and social welfare- is excluded from the analysis. Some of these activities are related to the family's own needs, such as caring for children and adults, cooking, gardening and maintaining the home, or caring for other people, such as friends who are visiting or relatives who live outside the home. 
In order to help countries restructure and adjust as they opened up to greater competition and integrated deeper into the global economy, it was considered necessary to amend regulations on individual and collective labour relations, as well as those governing the social contributions and other taxes levied on wages. These were thought to produce negative effects by favouring individuals with good jobs at the expense of the unemployed and workers in the informal economy. Labour market flexibility was seen as a key factor for the success of reforms that aimed to foster growth in the region. ${ }^{4}$

Vega Ruiz (2005) found that 11 out of 17 Latin American countries analysed had implemented labour reforms that enhanced flexibility between 1990 and 2005. The most profound reforms were undertaken in Argentina and Peru; and four other countries (Brazil, Colombia, Ecuador and Panama) also made significant, but less wide-ranging, changes. Five other countries (the Bolivarian Republic of Venezuela, Chile, ${ }^{5}$ the Dominican Republic, Guatemala and Nicaragua) introduced reforms on a smaller scale.

The reforms were complemented by changes in contributory social protection policies. One of the areas prioritized under this approach was the pensions system (see chapter IV), in which the World Bank encouraged privatization and the creation of a multi-pillar system that would include a compulsory savings-plan component, financed entirely by contributors and managed by private firms (World Bank, 1994). The expectation was that this type of system would encourage economic growth and development of the capital and investment markets. This, in turn, would boost productive employment, which was seen a sine qua non for the development of contributory social security systems.

Fraile (2009) argues that socio-labour policies of this type seldom produced the expected results. More flexible labour markets, the decentralization of collective bargaining, the privatization of pensions and the growing importance of the market in the provision of social welfare, often spawned greater informality and inequalities and undermined social protection, without stimulating employment.

The behaviour of the labour market did not improve significantly after the reforms, so the expectation that liberalization would increase the demand for labour was not fulfilled (Berg, Ernst and Auer, 2006). Moreover, labour instability increased in the region during the 1990s, as the average time spent in a job dropped to 7.6 years by the end of the decade, compared to 10.5 years in the countries of the Organization for Economic Cooperation and Development (OECD) (Tokman, 2007).

See Lora and Pagés (1997); Edwards and Lustig (1997); Heckman and Pagés (2000 and 2004); Kuczynski and Williamson (2003); Singh and others (2005), cited by Fraile (2009).

In Chile, the changes were made before the period covered by the cited study, in particular through the Plan Laboral of 1979. Since 1990, democratic governments have gradually changed some of the latter's provisions. 
Wages were also highly flexible in Latin America between 1980 and 2000; and their share in gross domestic product (GDP) fell by 13 percentage points between 1990 and 2005 across the region as a whole (IILS, 2008).

The open unemployment rate fluctuated, albeit around a rising trend, especially after the economic crises that were a periodic feature of the second half of the 1990s. The main problem was the poor quality of the jobs created. Between 1990 and 2003, six out of ten employed persons worked in the informal economy; and only five out of ten new employees paid social security contributions (ILO, 2004). Thus, the labour flexibility measures did not seem to be effective in reducing informality.

When considering labour market trends, it was not surprising that the privatization of pension systems failed to expand social-security coverage as anticipated. By 2002, coverage, measured as the percentage of the labour force that were active contributors, had declined in the 12 Latin American countries that had started to renew their pension systems in the 1980s (Mesa-Lago, 2004). This experience also showed that precarious and unstable employment jeopardize workers' ability to accumulate sufficient contributions to qualify for a minimum pension at retirement (see chapter IV).

By the end of the period reviewed, scant progress had been made in reducing poverty and income inequality in Latin America. Poverty retreated from $48.3 \%$ in 1990 to $44 \%$ in 2002 , but was still above $40.5 \%$ in 1980. In absolute terms, however, the number of people living below the poverty line had grown by 120 million since 1980 (ECLAC, 2009). Meanwhile, income inequality intensified in the 1990s, when it was well above the international average.

The experience described above highlights the importance of labour regulations as a fundamental component of social protection. In fact, the deregulation of labour standards as a way to increase labour market flexibility fostered the spread of precarious jobs. This affected the potential for increasing productivity associated with stable occupations and decent working conditions; and it contributed to lower levels of social protection for workers and their dependants.

Labour flexibility has two dimensions: (i) the labour market; and (ii) labour as a factor of production (Amadeo and Camargo, 1993). The first can be seen as the ability of the economy or the labour market to return to an optimal equilibrium following an exogenous shock or changes in conditions. It thus reflects the ease with which firms can adjust staffing levels, or how easily workers to move from one segment of the market to another (external flexibility). It also refers to the adaptation of work organization (internal flexibility), which includes the ability to perform various tasks, the adjustment of pay and the redistribution of working hours, among other factors. The second dimension, in contrast, refers to the 
adaptability of the workers themselves, which depends on the suitability of their human capital and potential for productivity growth.

The types of flexibility indicated have significant interdependencies that need to be considered. For example, in economies that have highly flexible wage and employment arrangements, time-limited employment contracts tend to predominate, unemployment is more frequent, and wages tend to vary widely over the cycle - all of which undermines job security and erodes job quality. Conversely, long-term employment contracts contribute to productivity growth, either through promotion incentives and good working conditions, or else through performancebased pecuniary incentives, supported by training opportunities.

The foregoing discussion leads to two main conclusions. The first is that there is an optimal desirable level of flexibility, which is certainly less than the maximum possible. Experience is eloquent in this regard. Secondly, the optimal level of flexibilities requires a framework of labour regulations that help labour markets function efficiently and promote decent work. Striking this balance requires labour regulations that can protect the economic and social rights of workers when dealing with change. This would ensure access to social protection against the risks faced by the worker, both in active life and afterwards, which would also benefit his/her dependants before they themselves enter labour markets.

\section{B. Labour market regulations and social protection}

Social protection seeks to guarantee an income that makes it possible to maintain a minimum quality of life, access social and social promotion services, and to universalize decent work. According to Cecchini and Martínez (2011), three main components are needed to achieve these objectives: (i) non-contributory social protection (social assistance); (ii) contributory social protection (social security); and (iii) labour market regulation. The latter is understood as the set of regulations and standards that aim to promote and protect decent work.

If labour market regulations are viewed as forming a component of social protection, the protection of workers' individual and collective rights can become a critical element in reducing and mitigating the risks associated with the lack of decent work (Barrientos and Hulme, 2008). This scarcity is characteristic of the region, and contributory and noncontributory social protection policies seek to resolve it.

Nonetheless, labour market regulations in Latin America cover only part of the working-age population, since informal employment is widespread and affects just under half of the population of non- 
agricultural workers, as illustrated in figure III.1. ${ }^{6}$ This constitutes a structural barrier to the effective application of labour standards in the region and the scope of the protection derived from them.

According to ILO (2016), the prevalence of informal employment declined from $50.1 \%$ of total non-agricultural employment to $46.5 \%$ in 2009-2014, thanks to a benign economic scenario and the implementation of a set of targeted policies in the region's countries. Nonetheless, the trend reversed in 2015 when the proportion rose again to $46.8 \%$. This percentage was similar to that recorded in 2013 and means that at least 133 million workers were informal in 2015. As the slowdown in regional economic growth has persisted (and some economies have actually shrunk), it is highly likely that informal employment has spread further in 2016.

In terms of the characteristics of informal workers, ILO (2013) reports that $30.5 \%$ of informal employment in 2013 corresponded to employers and self-employed workers, plus wage-earning employees in unregistered informal production units. The latter have few workers, little capital and a small scale of operations, which makes it difficult for them to achieve an adequate level of productivity and sufficient production volumes. Another $11.4 \%$ were employees working in the formal sector, mainly in situations of noncompliance with the regulations, ignorance of the law, economic incapacity or institutional weakness. A third group consisted of workers employed informally in the household sector (mostly domestic workers), representing $4.9 \%$ of total non-farm employment in that year.

A breakdown of these statistics by occupational category (see table III.1) shows that self-employed workers have the highest rates of informality $(82.3 \%)$, followed by domestic workers $(77.5 \%)$ and the

\footnotetext{
The report (ILO, 2014) refers to informal non-agricultural employment, which has specific features that need to be analysed in detail. In Measuring Informality: A statistical manual on the informal sector and informal employment, 2013, the ILO states: "Many countries exclude agricultural and related activities (ISIC, rev. 4, Section A; see UN, 2008c) from the scope of statistics on the informal sector, but some include them. The 15th ICLS resolution recognized that, from a conceptual standpoint, agricultural and related activities would be included in the scope of the informal sector if they are carried out by household unincorporated enterprises and if they meet the criteria of the informal sector definition. For practical data collection purposes, however, the 15th ICLS resolution (ILO, 1993a, paragraphs 16 and 20) provided the option to exclude agricultural and related activities from the scope of informal sector surveys and to measure them separately. The reasoning was that many developing countries have a large agricultural sector, mainly composed of small, unregistered household unincorporated enterprises, and that the inclusion of such enterprises in informal sector surveys would lead to a considerable expansion of survey operations and increase in costs. Moreover, many national statistical offices already have an established system of agricultural surveys whose coverage includes (or can be extended to include) household unincorporated enterprises engaged in agricultural and related activities. In terms of concepts, definitions, classifications, survey content, questionnaire design, reference periods, sampling frames and procedures, organization of field work, etc., agricultural surveys could be well suited to meeting the particular requirements for measuring informal units carrying out agricultural and related activities." That being said, while not all rural activities are agricultural, most of them are rural.
} 
employees of microenterprises with fewer than ten workers $(58.6 \%)$. The latter is over four times the proportion in firms with more than ten workers. These three categories account for $79 \%$ of all informal workers in the countries of the region analysed.

Expanding opportunities for decent work increases the potential to reduce and mitigate the risks and demands for social protection during workers' lives, both in the active phase and in retirement, and to protect their dependants.

Figure III.1

Latin America (14 countries): non-agricultural informal employment, 2009 and 2011-2015

(Percentages)

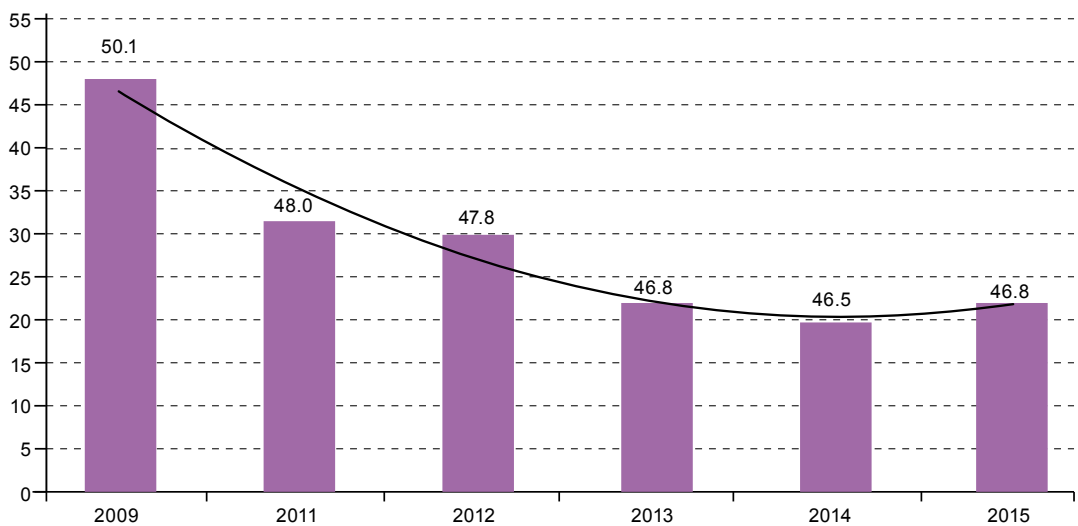

Source: International Labour Organization (ILO), 2016 Labour Review. Latin America and the Caribbean, Lima, ILO Regional Office for Latin America and the Caribbean, 2016.

Table III.1

Latin America (14 countries): rate and composition of non-agricultural informal employment by occupational category, 2013

(Percentages)

\begin{tabular}{lcc}
\hline Occupational category & $\begin{array}{c}\text { Informal employment rate } \\
\text { in each category }\end{array}$ & $\begin{array}{c}\text { Composition of informal } \\
\text { employment }\end{array}$ \\
\hline Total & 46.8 & 100 \\
\hline Wage-earners (including employers) & 33.7 & 52.7 \\
\hline In the public sector & 15.9 & 4.3 \\
\hline In private firms & 32.9 & 38.1 \\
\hline \multicolumn{1}{c}{ with 1-10 workers } & 58.6 & 27.8 \\
\hline \multicolumn{1}{c}{ with more than 10 workers } & 14.4 & 9.4 \\
\hline In households & 77.5 & 10.3 \\
\hline Own-account workers & 82.3 & 40.9 \\
\hline Auxiliary family workers & 100 & 5.3 \\
\hline Others & 96.7 & 1.1 \\
\hline
\end{tabular}

Source: International Labour Organization (ILO), Measuring Informality: A Statistical Manual on the Informal Sector and Informal Employment, Geneva, 2013. 


\section{Risks and labour regulations}

In view of the stated role of labour regulations as a component of social protection, the following paragraphs provide an approach to analysing them. First, it is argued that the link between labour standards and protection is the employed worker. This is because application of the regulations assumes the existence of an employment relationship and makes it possible to protect against certain risks, which: (a) the workers themselves face; (b) their dependants face before they begin working life; and (c) will enable workers to gain protection once they cease active life.

The proposed analysis recognizes the worker and the employment relationship as the channel through which regulations become components of protection against certain risks that require an adequate level of coverage. This is due to their potential effects on the development of decent work, with respect to three related population groups defined in terms of the life cycle: (i) the workers themselves; (ii) their dependants; and (iii) those who leave the workforce. ${ }^{7}$

\section{(a) Prior to active life}

There are two main risks in this stage of the life cycle: lack of protection for the newborn baby and child in his/her initial stages of development; and precarious labour market participation in the form of child labour or unregulated forms of adolescent work.

With regard to the first situation, protection seeks to ensure conditions of well-being for the unborn, newborn and child throughout his/her growth and development process. In this case, the key labour regulations selected are those that establish pre-natal and post-natal rest periods, leave for feeding and caring for children due to illness, and the entitlement crèche services or other alternatives with a similar purpose.

In terms of preventing precarious labour-market engagement, in both childhood and adolescence, the relevant labour standards are mainly those that prohibit child labour and those that regulate the work of adolescents, through the requirement to ensure appropriate working conditions and attention to special cases.

\section{(b) During active working life}

There are three main areas of risk during working life: (i) the absence of employment contracts as a minimum condition for protecting workers' basic rights in the employment relationship; (ii) impediments to

\footnotetext{
Social protection in the specified stages of the life cycle is not the exclusive preserve of labour standards and institutions. For example, the coverage of health-related risks is not confined to the scope of work-related accidents or occupational diseases, as happens with other common or chronic and disabling diseases that may also prevent work activity either temporarily or permanently. In this case, the units of analysis are the health systems and the coverage they provide.
} 
exercising the right to organization and collective bargaining; and (iii) lack of coverage against the risks of work-related accidents and occupational diseases, as well as the possibility of being made redundant.

The main labour regulations that are germane to these risks are the requirement to formalize the individual employment contract and thus recognize the basic obligations of this relationship in terms of hours and days of work and rest, overtime, paid holidays, and the amount and periodicity of pay. They also seek to specify reasons that could justify a rescission of the contract and the consequences that may arise for the parties.

The basic issues regulated in an employment contract include ensuring that a minimum wage is paid. The level of the minimum wage is determined according to the characteristics of each country and aims to guarantee the right of every worker to a basic level of consumption and living standards, irrespective of the work performed and the skill needed for it. It is also especially important to prevent all employment discrimination based on gender, race or social status, or any other ground. This is most frequently expressed through wage differentials that do not reflect the functions performed or the skill levels or work experience of those who perform them.

In the area of collective rights, labour regulations aim to guarantee the right of every worker to organize for the purpose of upholding the rights specified in employment contracts and labour regulations and those relating to working conditions. They also seek to make it easy to report non-compliance and enable unions to represent their members in dealings with the employer, in order to resolve the contingencies that naturally arise in the life of enterprises, and to improve them by taking into account their contribution to the production process.

One of the essential functions of unions is to engage in collective bargaining with employers, with the aim of establishing (in a collective agreement) work and employment conditions appropriate the firms or activity sector in which they operate. These conditions include: (i) pay that rises in real terms through time; (ii) benefits associated with the attainment of goals; (iii) investments in job training; (iv) internal promotion mechanisms, and (v) prevention and monitoring of working conditions.

A third area of interest for the analysis in this stage concerns the firm's fulfilment of its responsibility to guarantee protection against the risk of workplace accidents and occupational diseases and unemployment. In the first case, workers have the right to work in a safe environment; and the employer has a duty to establish preventive or compensatory measures (monetary or services) if such an event materializes. This is independent of the modality used, which may be a direct charge or based on the purchase of insurance for the purpose. 
In the case of redundancy risk, unless the employee breaches the employment contract, the employer is usually required to pay compensation for dismissals without just cause, on bases that are normally defined and regulated in the respective labour codes. Nonetheless, some countries have unemployment insurance, which guarantees an income to workers during the period of unemployment and supports them in their search for a new job. In such circumstances, the employer is required to make contributions to protect against said event.

\section{(c) In old age}

One of the main risks in old age is the absence, or insufficiency, of coverage provided by social security systems (especially pensions and health) to protect income and general conditions of well-being.

From the standpoint of labour regulations and their relationship with protection against old-age risks, entitlement to protection is generally based on payments made to contributory systems during working life. This is directly linked to an employment trajectory pursued under decent working conditions. Otherwise, the protection required will depend on the conditions of access and adequacy of the benefits provided by noncontributory systems.

Regardless of the type of system that provides the required protection, the coverage and sufficiency of the benefits will always be conditional on their financial sustainability. Nonetheless, the dimensions of coverage, sufficiency and sustainability need to be reconciled. If the first two are subordinated to sustainability, there is a greater risk of failing to cover the entire population that requires protection, or that the benefits are not sufficient to alleviate poverty in old age.

Table III.2 illustrates the analytical matrix developed from these considerations. It identifies the main risks and the labour regulations selected to face them, in each stage of the life cycle. Nonetheless, the mere existence of a standard is not a sufficient condition to guarantee the necessary protection, absent the capacity to promote and oversee fulfilment and to sanction eventual non-compliance.

Based on the legal-regulatory and organizational dimensions described in chapter I, the following paragraphs analyse the situation prevailing in the region's countries in terms of institutionalizing labour regulation as a component of social protection, and its capacity to be held accountable for its objectives. This analysis focuses on the promotion of compliance with labour standards, the monitoring of working conditions and the application of penalties for non-compliance. These are three complementary areas that enhance compliance with labour standards. 

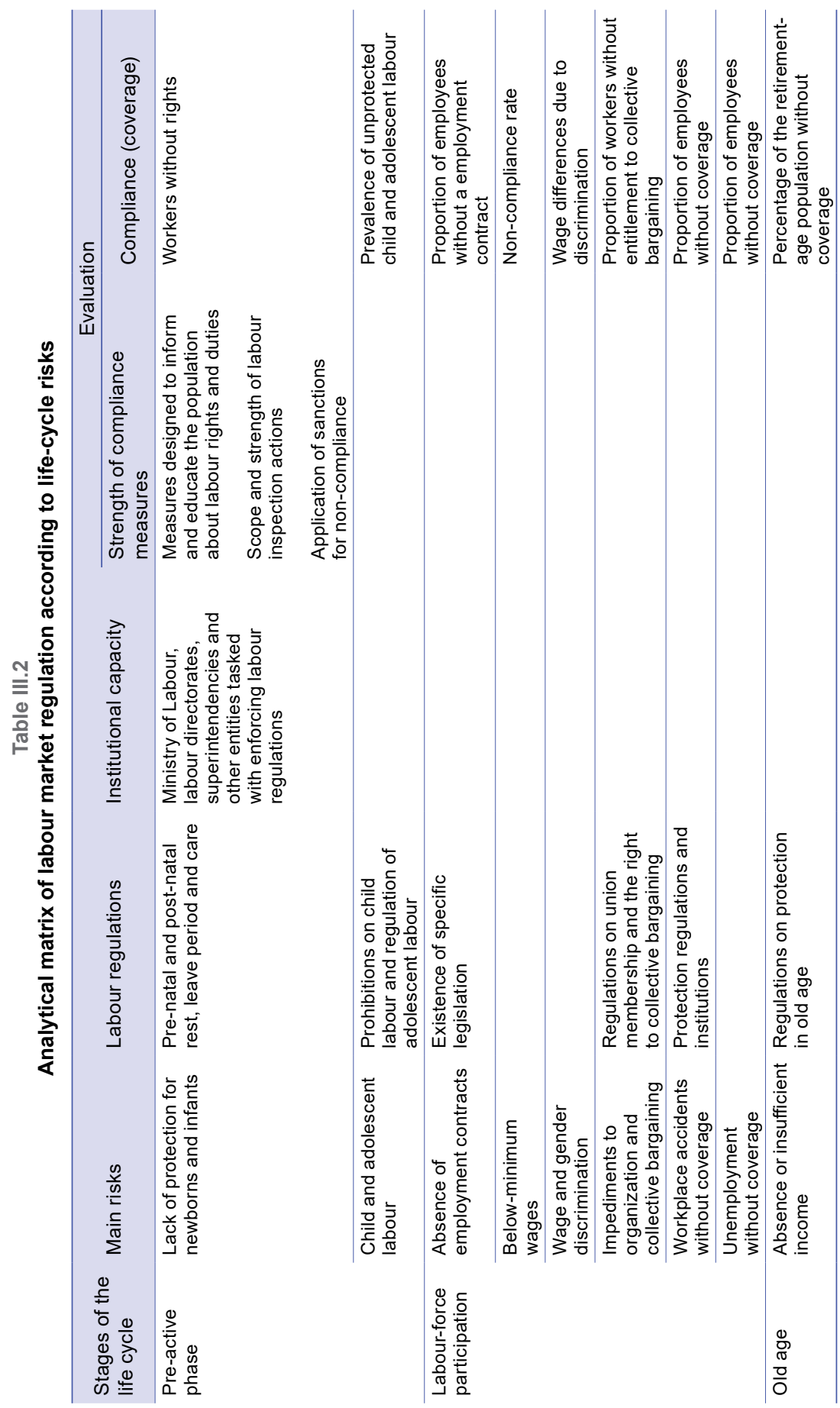

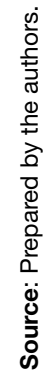




\section{Labour regulations}

In light of the foregoing, two fundamental questions need to be answered to describe the legal-regulatory dimension of the institutional framework of labour market regulation, in its role as part of the social protection system. These questions are: (i) are there rules or regulations in place to protect workers against the identified risks; and (ii) what are their contents? To answer these questions, the different legal sources are examined below, according to their hierarchy - ranging from adherence to, and ratification of, international conventions, in conjunction with constitutional provisions, through to labour codes, special laws and specific decrees.

\section{International conventions}

At the international level, the institutional framework for the regulation of employment and labour relations is further developed than in other areas of social policy (in both breadth and depth) and also in its history and stakeholder participation (governments, employers and workers). The International Labour Organization (ILO) urges its 178 member States to maintain certain labour standards of minimum treatment, based on international conventions, recommendations and resolutions, with the aim of improving living and working conditions. ${ }^{8}$

\section{(a) ILO conventions and protection against risks in the life cycle}

The objectives of labour market regulation as a component of social protection are specified in the fundamental conventions and other technical conventions. The ILO Governing Body has established eight fundamental conventions. ${ }^{9}$ These range from freedom of association and freedom of

8 An ILO convention is an international standard (approved at an international labour conference), and its effectiveness in each country depends on ratification by the competent State authority. If a country ratifies a convention, it generally enters into force there one year after the ratification date. Countries that ratify conventions are obliged to implement them in their national legislation and practices. The application of ILO conventions is overseen through the annual reports that each member State has to submit on compliance, and through direct control, which operates through a system of complaints lodged with the Board of Directors or control bodies by Member States (complaints) or by union representations of workers or employers ("claims"). In order to guarantee the application of the conventions, ILO has a highly developed supervision procedure. ILO recommendations are non-binding proposals addressed to member States, which only oblige them to inform the ILO Director about the state of the respective domestic legislation and the degree to which the recommendation in question is being observed. Resolutions, in contrast, express ILO opinion or judgement on specific issues and, consequently, are not binding. They are usually precursors of future recommendations and conventions, formulated by exhortation or invitation, either to member States, or to the Governing Body, the Director General or to ILO itself.

9 The eight conventions are: the Freedom of Association and Protection of the Right to Organize Convention, 1948 (No. 87); the Right to Organize and Collective Bargaining Convention, 1949 (No. 98); the Forced Labour Convention, 1930 (No. 29); the Abolition of Forced Labour Convention, 1957 (No. 105); the Minimum Age of Admission to Employment Convention, 1973 (No. 138); the Convention on the Prohibition of the Worst Forms of Child Labour, 1999 (No. 182); the Equal Remuneration Convention, 1951 (No. 100), and the Convention on Discrimination in Employment and Occupation, 1958 (No. 111). 
union membership to the effective recognition of the right to collective bargaining, the elimination of all forms of forced or compulsory labour, the effective abolition of child labour and the elimination of discrimination in employment and occupation. The International Labour Organization launched a campaign in 1995 to achieve universal ratification of these conventions. At present, more than 1,200 ratifications have been registered, representing $86 \%$ of the possible number of ratifications worldwide.

In terms of stages of the life cycle, risks in childhood and adolescence are addressed in various ILO Conventions: the Convention on the Night Work of Minors (Industry), 1919 (No. 6); the Convention on the Protection of Maternity, 2000 (No. 183); the Abolition of Forced Labour Convention, 1957 (No. 105); the Minimum Age of Admission to Employment Convention, 1973 (No. 138) and the Worst Forms of Child Labour Convention, 1999 (No. 182) (see table III.3).

Table III. 3

\section{ILO Conventions in Latin American countries related to the stages of the life cycle}

\begin{tabular}{|c|c|c|c|}
\hline Convention & Year & Fundamental contents & Stage \\
\hline $\begin{array}{l}\text { C006. Convention } \\
\text { concerning the Night } \\
\text { Work of Young Persons } \\
\text { Employed in Industry }\end{array}$ & 1919 & $\begin{array}{l}\text { Young persons under eighteen years } \\
\text { of age shall not be employed during } \\
\text { the night in any public or private } \\
\text { industrial undertaking, or in any } \\
\text { branch thereof. }\end{array}$ & $\begin{array}{l}\text { Childhood and } \\
\text { adolescence }\end{array}$ \\
\hline $\begin{array}{l}\text { C087. Convention } \\
\text { concerning Freedom } \\
\text { of Association and } \\
\text { Protection of the Right } \\
\text { to Organize }\end{array}$ & 1948 & $\begin{array}{l}\text { Workers and employers, without } \\
\text { distinction whatsoever, shall have the } \\
\text { right to establish and, subject only to the } \\
\text { rules of the organization concerned, to } \\
\text { join organisations of their own choosing } \\
\text { without previous authorization. }\end{array}$ & Working age \\
\hline $\begin{array}{l}\text { C098. Convention } \\
\text { concerning the } \\
\text { Application of the } \\
\text { Principles of the Right } \\
\text { to Organize and to } \\
\text { Bargain Collectively }\end{array}$ & 1949 & $\begin{array}{l}\text { Workers shall enjoy adequate } \\
\text { protection against acts of anti-union } \\
\text { discrimination in respect } \\
\text { of their employment. }\end{array}$ & Working age \\
\hline $\begin{array}{l}\text { C100. Equal } \\
\text { Remuneration } \\
\text { Convention }\end{array}$ & 1951 & $\begin{array}{l}\text { Ensure the application to all workers } \\
\text { of the principle of equal remuneration } \\
\text { for men and women workers for } \\
\text { work of equal value. }\end{array}$ & Working age \\
\hline $\begin{array}{l}\text { C102. Convention } \\
\text { concerning Minimum } \\
\text { Standards of Social } \\
\text { Security }\end{array}$ & 1952 & $\begin{array}{l}\text { Guarantee medical assistance, income } \\
\text { support for sickness, unemployment, } \\
\text { old age, workplace accident and } \\
\text { occupational disease, and family, } \\
\text { maternity, disability and } \\
\text { survivor benefits. }\end{array}$ & $\begin{array}{l}\text { Working age } \\
\text { and old age }\end{array}$ \\
\hline $\begin{array}{l}\text { C105. Convention } \\
\text { concerning the Abolition } \\
\text { of Forced Labour }\end{array}$ & 1957 & $\begin{array}{l}\text { Suppress and not make use of any } \\
\text { form of forced or compulsory labour. }\end{array}$ & $\begin{array}{l}\text { Childhood and } \\
\text { adolescence and } \\
\text { working age }\end{array}$ \\
\hline $\begin{array}{l}\text { C111. Convention } \\
\text { concerning } \\
\text { Discrimination in } \\
\text { Respect of Employment } \\
\text { and Occupation }\end{array}$ & 1958 & $\begin{array}{l}\text { Declare and pursue a national policy } \\
\text { designed to promote, by methods } \\
\text { appropriate to national conditions and } \\
\text { practice, equality of opportunity and } \\
\text { treatment in respect of employment and } \\
\text { occupation, with a view to eliminating } \\
\text { any discrimination in respect thereof. }\end{array}$ & Working age \\
\hline
\end{tabular}


Table III.3 (concluded)

\begin{tabular}{|c|c|c|c|}
\hline Convention & Year & Fundamental contents & Stage \\
\hline $\begin{array}{l}\text { C131. Convention } \\
\text { concerning Minimum } \\
\text { Wage Fixing }\end{array}$ & 1970 & $\begin{array}{l}\text { Establish a system of minimum wages } \\
\text { which covers all groups of wage } \\
\text { earners whose terms of employment } \\
\text { are such that coverage would } \\
\text { be appropriate. }\end{array}$ & Working age \\
\hline $\begin{array}{l}\text { C138. Convention } \\
\text { concerning Minimum } \\
\text { Age for Admission } \\
\text { to Employment }\end{array}$ & 1973 & $\begin{array}{l}\text { Pursue a national policy designed to } \\
\text { ensure the effective abolition of child } \\
\text { labour and to raise progressively } \\
\text { the minimum age for admission } \\
\text { to employment or work to a level } \\
\text { consistent with the fullest physical and } \\
\text { mental development of young persons. }\end{array}$ & $\begin{array}{l}\text { Childhood and } \\
\text { adolescence }\end{array}$ \\
\hline $\begin{array}{l}\text { C155. Convention } \\
\text { concerning Occupational } \\
\text { Safety and Health and } \\
\text { the Working Environment }\end{array}$ & 1981 & $\begin{array}{l}\text { In the light of national conditions and } \\
\text { practice [...] formulate, implement } \\
\text { and periodically review a coherent } \\
\text { national policy on occupational safety, } \\
\text { occupational health and the } \\
\text { working environment. }\end{array}$ & Working age \\
\hline $\begin{array}{l}\text { C158. Convention } \\
\text { concerning Termination } \\
\text { of Employment at the } \\
\text { Initiative of the Employer }\end{array}$ & 1982 & $\begin{array}{l}\text { Establishes the principle that the } \\
\text { employment of a worker shall not be } \\
\text { terminated unless there is a valid } \\
\text { reason for such termination connected } \\
\text { with the capacity or conduct of the } \\
\text { worker or based on the operational } \\
\text { requirements of the undertaking, } \\
\text { establishment or service. }\end{array}$ & Working age \\
\hline $\begin{array}{l}\text { C161. Convention } \\
\text { concerning Occupational } \\
\text { Health Services }\end{array}$ & 1985 & $\begin{array}{l}\text { Establishment of occupational health } \\
\text { services at the enterprise level. }\end{array}$ & Working age \\
\hline $\begin{array}{l}\text { C182. Convention } \\
\text { concerning the } \\
\text { Prohibition and } \\
\text { Immediate Action for the } \\
\text { Elimination of the Worst } \\
\text { Forms of Child Labour }\end{array}$ & 1999 & $\begin{array}{l}\text { Take immediate and effective } \\
\text { measures to secure the prohibition and } \\
\text { elimination of the worst forms of child } \\
\text { labour as a matter of urgency. }\end{array}$ & $\begin{array}{l}\text { Childhood and } \\
\text { adolescence }\end{array}$ \\
\hline $\begin{array}{l}\text { C183. Maternity } \\
\text { Protection Convention }\end{array}$ & 2000 & $\begin{array}{l}\text { Establishes a period of maternity leave } \\
\text { of not less than } 14 \text { weeks. }\end{array}$ & $\begin{array}{l}\text { Childhood and } \\
\text { adolescence }\end{array}$ \\
\hline $\begin{array}{l}\text { C187. Convention } \\
\text { concerning the } \\
\text { promotional framework } \\
\text { for occupational safety } \\
\text { and health }\end{array}$ & 2006 & $\begin{array}{l}\text { Promote a preventative safety and } \\
\text { health culture with a view to the } \\
\text { progressive achievement of a safe } \\
\text { and healthy working environment. }\end{array}$ & Working age \\
\hline $\begin{array}{l}\text { C189. Convention } \\
\text { concerning decent work } \\
\text { for domestic workers }\end{array}$ & 2011 & $\begin{array}{l}\text { Take measures to ensure the effective } \\
\text { promotion and protection of the human } \\
\text { rights of all domestic workers. }\end{array}$ & Working age \\
\hline
\end{tabular}

Source: Prepared by the author, on the basis of International Labour Organization (ILO), "Ratification by convention", NORMLEX Information System on International Labour Standards, 2015 [online] http://www.ilo.org/dyn/normlex/en/f?p=NORMLEXPUB:12001:0::NO.

The conventions that protect working conditions during working age include the following: the Termination of Employment Convention, 1982 (No. 158); the Workmen's Compensation Convention, 1925 (No. 17); the Workmen's Compensation (Occupational Diseases) Convention (Revised), 1934 (No. 42); the Freedom of Association and Protection of the Right to Organize Convention, 1948 (No. 87); the Right to Organize and 
Collective Bargaining Convention, 1949 (No. 98); the Equal Remuneration Convention, 1951 (No. 100); the Discrimination (Employment and Occupation) Convention, 1958 (No. 111); the Minimum Wage Fixing Convention, 1970 (No. 131), and the Social Security (Minimum Standards) Convention, 1952 (No. 102), which also addresses risks in old age.

Conventions to protect workers bound by an employment relationship include the Employment Relationship Recommendation, 2006 (No. 198). This requires member States to formulate and implement a national policy that includes measures giving guidance on how to determine the existence of an employment relationship and on the distinction between waged and independent workers, together with measures to combat covert employment relationships (ILO, 2015d).

The ILO Hours of Work (Industry) Convention, 1919 (No. 1), is also included in this category, in order to limit hours of work and provide adequate rest periods for workers. The fact that nearly 100 years have passed since its approval is testament to a long history of institutional development in this area. Currently, ILO standards expand and specify this regulatory framework in several aspects in relation to the promotion of decent work (ILO, 2015e). The concerns of the ILO include ensuring access to adequate and regular wages, regular payment of wages, the fixing of minimum wage levels, and payment of wages owed in the event of employer insolvency (ILO, 2015e).

In the area of collective relations, there are two fundamental conventions that regulate protection of the exercise of the rights of unionization and collective bargaining (the Freedom of Association and Protection of the Right to Organize Convention, 1948 (No. 87) and the Right to Organize and Collective Bargaining Convention, 1949 (No. 98)). Such protection is seen as a necessary requirement for robust collective bargaining and social dialogue (ILO, 2015k).

In addition, international conventions have been selected that regulate the protection of workers' access to social security, especially in the field of occupational safety and health: the Occupational Safety and Health Convention, 1981 (No. 155), and the Protocol of 2002 to the Occupational Safety and Health Convention, 1981; the Occupational Health Services Convention, 1985 (No. 161), and the Promotional Framework for Occupational Safety and Health Convention, 2006 (No. 187).

Lastly, given its importance in the stage of old age, it is necessary to consider the Social Security (Minimum Standards) Convention, 1952 (No. 102), which establishes the minimum standard for the level of social security benefits and conditions for accessing them. It comprises the nine main branches of social security, namely, medical care, sickness, unemployment, old age, occupational accidents and occupational diseases, family, maternity, disability and survivor benefits. 
States are offered the possibility of ratifying this Convention by initially accepting at least three of the nine parts and then complying with the obligations derived from the others, thereby progressively attaining all the objectives set in the Convention. The minimum benefits level can be determined relative to the wage level of the country concerned (see table III.A1.1 in the annex). Temporary exceptions may also be granted for countries whose economy and medical services are insufficiently developed. This would allow them to restrict the scope of the Convention and the coverage of the benefits granted.

Closely linked to Convention No. 102 is the Social Protection Floors Recommendation, 2012 (No. 202), which provides guidelines for establishing and maintaining social security floors. It also provides guidance on implementing social protection floors in the framework of strategies to extend social security, to higher levels for the largest possible number of people, pursuant to the guidelines of the ILO standards in this area.

\section{(b) Ratifications and implementations}

Table III.4 lists the conventions that have been ratified and put into effect by the countries of Latin America and, therefore, form part of national legislations. As can be seen, the fundamental conventions are applied in practically all of the countries analysed. Those with the fewest ratifications are the Convention Concerning Termination of Employment at the Initiative of the Employer) (ratified only by the Bolivarian Republic of Venezuela). Similarly, the Maternity Protection Convention, 2000 (No. 183), has only been ratified by Cuba, although previous instruments, such as the Maternity Protection Convention (Revised), 1952 (No. 103), are still in force in Brazil, Chile, Ecuador, the Plurinational State of Bolivia and Uruguay (ILO, 2015b).

If the most recently approved agreements, such as the Promotional Framework for Occupational Safety and Health Convention, 2006 (No. 187), are considered, the degree of ratification by the countries is less, although the Workers Compensation Convention, 1925 (No. 17) has been ratified by Argentina, Colombia, Mexico, Nicaragua, Panama and Plurinational State of Bolivia; and the Occupational Diseases Convention (Revised), 1934 (No. 42) has been ratified by Argentina, Brazil, Cuba, Honduras, Mexico, Panama and the Plurinational State of Bolivia. In contrast, the Domestic Workers Convention, 2011 (No. 189), has experienced a relatively faster ratification process. In the case of the Social Security (Minimum Standards) Convention (No. 102), just under half of the countries considered have ratified and implemented it.

Lastly, of the 16 conventions selected, the largest number of ratifications pertain to Chile and Uruguay. Most countries have ratified between nine and 11 conventions; Honduras, Paraguay and Peru have ratified half of them; and the Dominican Republic has only ratified seven. 


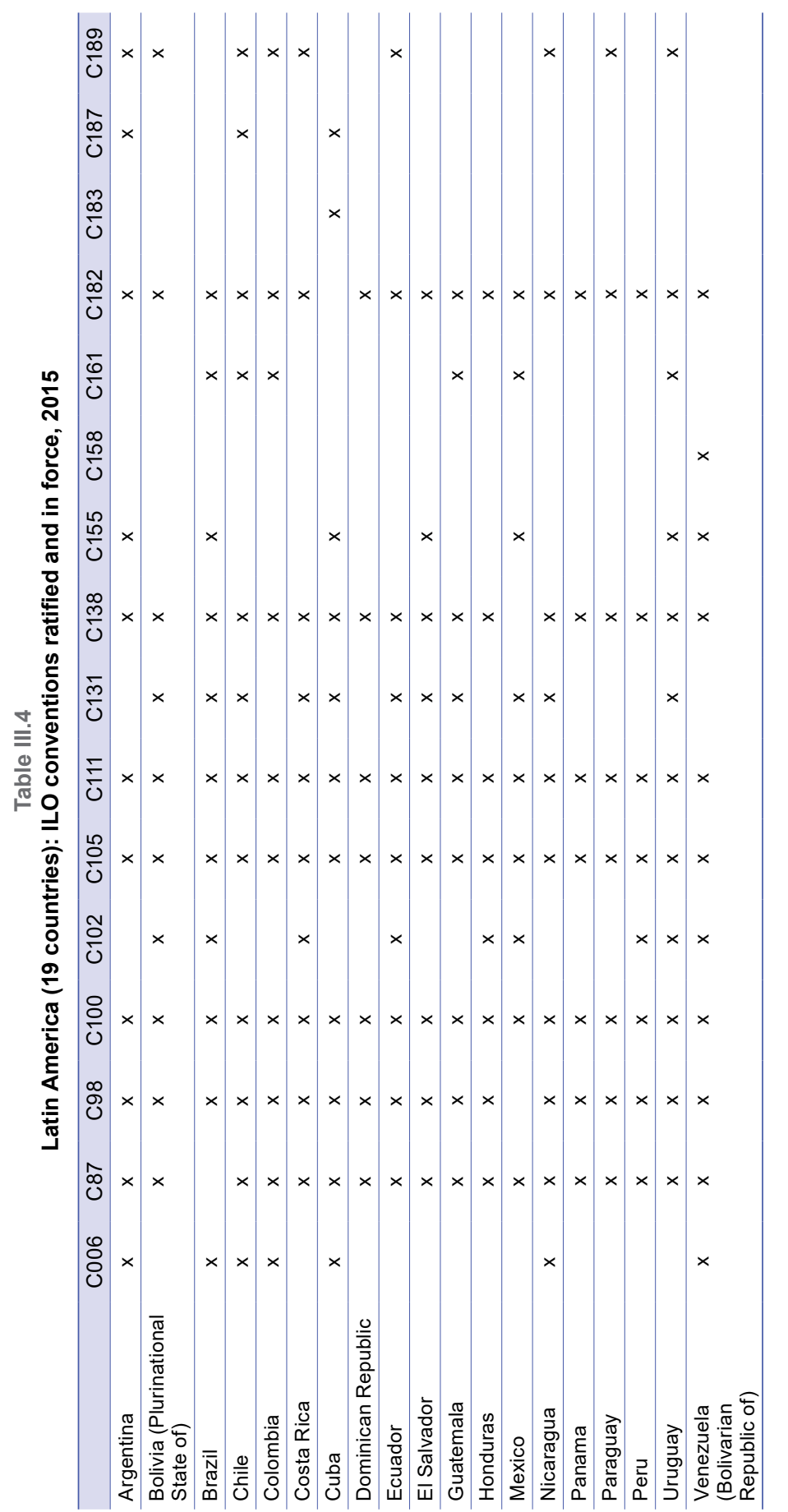

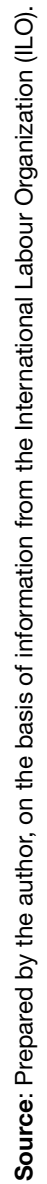




\section{Constitutional guarantees}

A second legal source of labour standards can be found in each country's national constitution. As shown in table III.5, all of the countries considered have constitutional articles that make explicit mention of paid work. In most cases, this right is included in the concept of freedom of work (Chile and Costa Rica) or social function (El Salvador). The obligation to pursue full employment is also established, which must be protected and organized under principles of social justice.

In terms of specific subjects, although not all that are of interest for the present analysis are mentioned, they usually include maternity protection, paid leave and breastfeeding, the prohibition of forced and child labour and, in some cases, the regulation of child labour. Nonetheless, despite the fact that some countries include maternity protection in their respective constitutions, many have not ratified or implemented Convention No. 183 or some of the earlier ones on the same subject.

With respect to protection during working life, it is frequent to guarantee a minimum wage and regulated working hours for workers, as well as the entitlement to be covered by social security mechanisms for various contingencies in working life. Protection against unjustified dismissal, equal pay and the right to a healthy and safe working environment are also recurrent themes of the guarantees offered in the different countries of the region. Nonetheless, seven countries have not ratified the Minimum Wage Fixing Convention, 1970 (No. 131), and none has ratified the three selected occupational safety and health conventions. There is less uniformity among constitutional guarantees in this area and also, although less intensively, in relation to protection in old age and in the degree of ratification of the Social Security (Minimum Standards) Convention No. 102.

\section{Labour codes}

The next level of the legal sources for labour standards consists of each country's labour code - a systematized set of rules that regulate relations between employers and workers. These are regulatory frameworks designed specifically to guarantee a set of rights and obligations emanating from the employment relationship. 


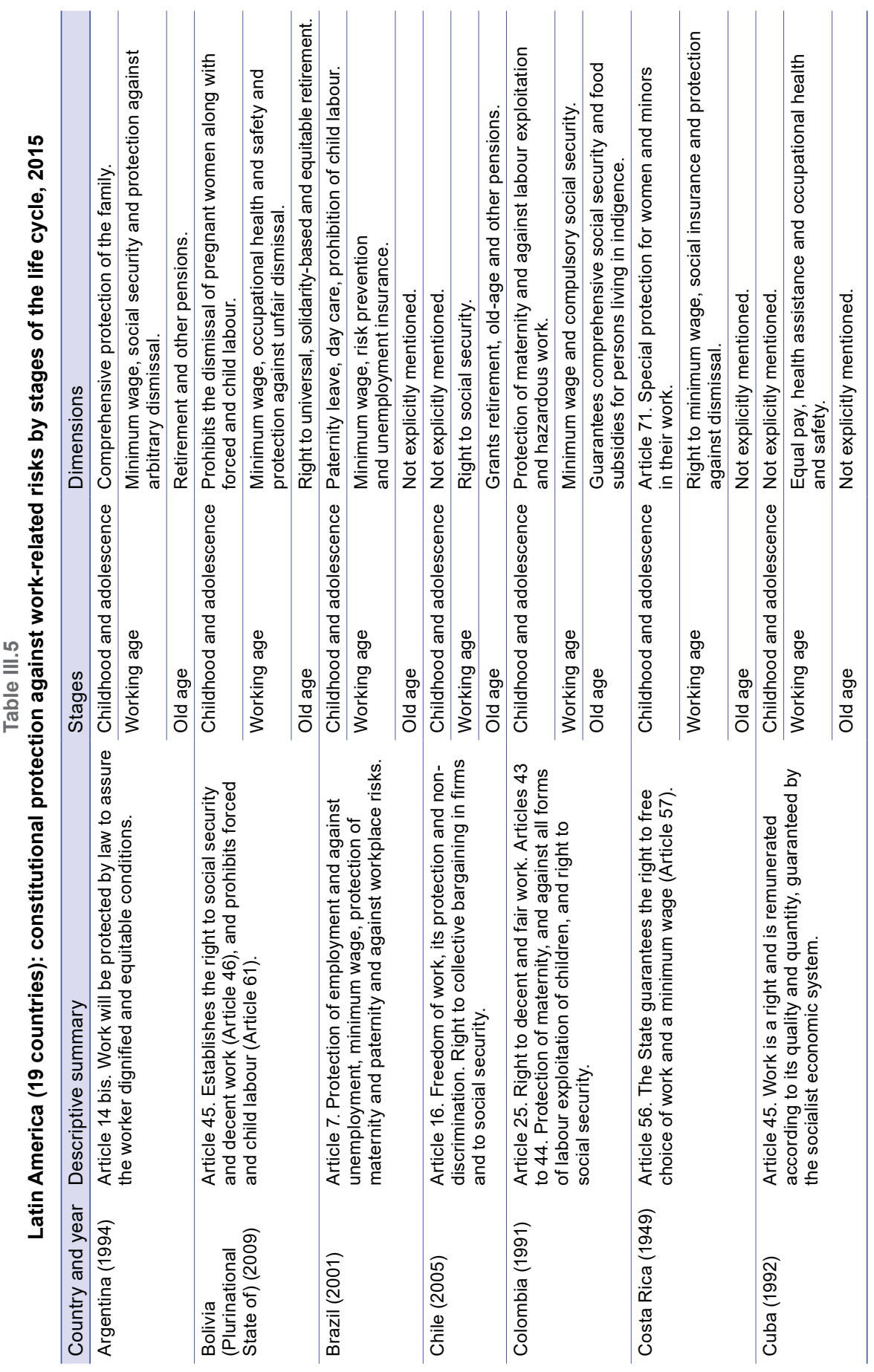




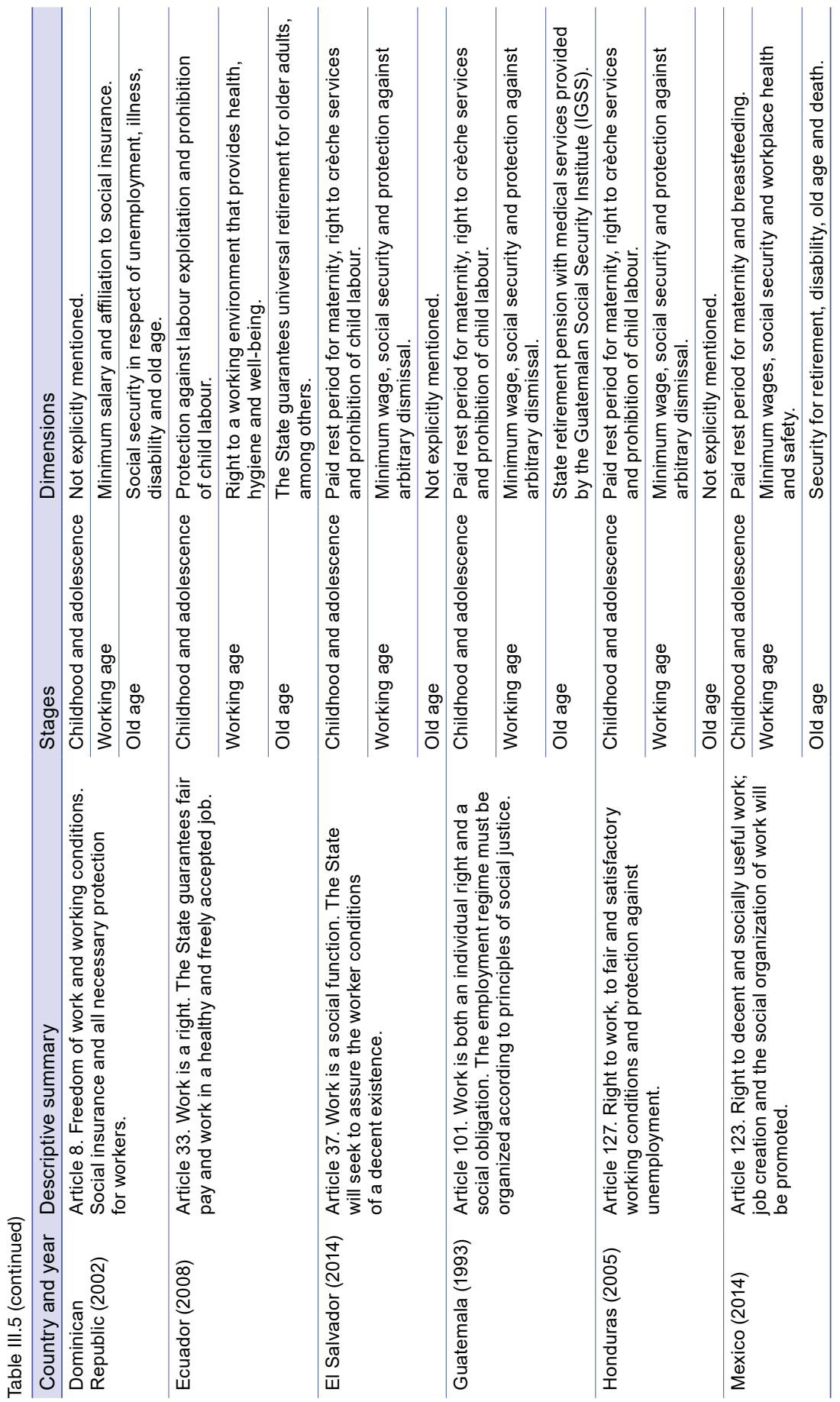




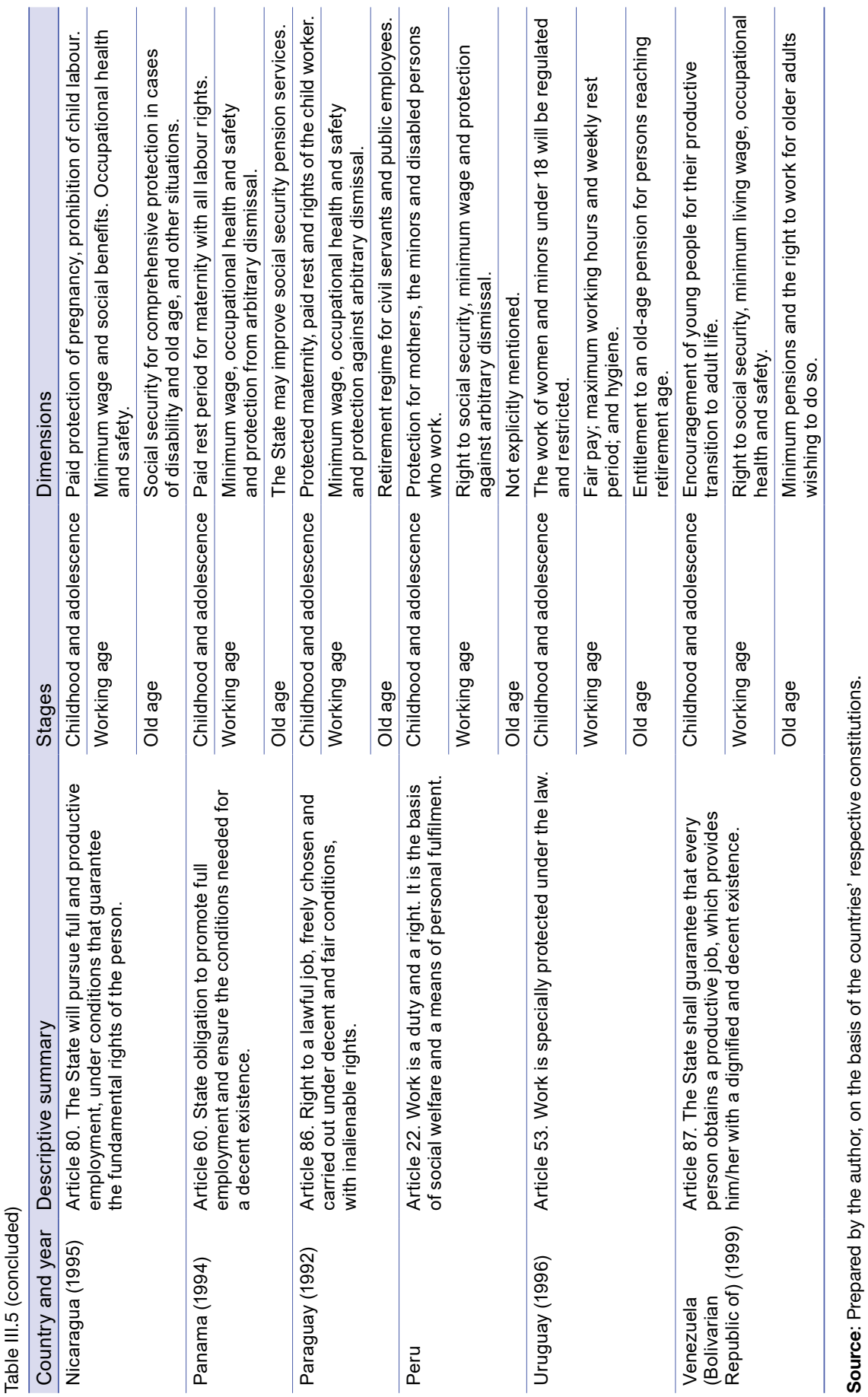


Table III.6 shows information on the existence of labour regulations in Latin American countries, drawing on the most recent versions. Labour codes usually contain rules that regulate the individual contract on specific aspects of child labour, working hours, pay and their protection, along with leave and holiday periods, as well as special contracts for certain groups of workers. There are chapters that develop standards on the protection of maternity and family life, employment discrimination and protection against the risks of workplace accidents and occupational diseases, among other issues. Lastly, they usually include norms on the setting up and functioning of union organizations, together with regulations on collective bargaining processes and affiliation to social security systems.

Although the matrix of labour regulations prevailing the region's countries was altered in the 1980s and 1990s to make labour markets more flexible, as described above, the trend has partially reversed since then. As Bensusán (2013) notes, the relaxing of regulations did not solve the problems of the labour market, but aggravated them, since it widened the gap between workers and spawned new inequalities. ${ }^{10}$ In response, some of the region's countries revived state intervention, strengthened unions and promoted public policies aimed at generating quality jobs and providing greater social protection.

Weller (2009) states that, in the decade of 2000, there were generally no far-reaching flexibility reforms and that the period coincided with the assumption of a more cautious attitude towards proposals for radical deregulation (Freeman, 2005) in the international debate. The author clarifies that measures of this type were concentrated in microenterprises and small business, or else in specific sectors, such as agro-exports in Peru.

The author also notes that the most recent reforms have focused on revising collective labour relations with a view to aligning them to ILO standards, strengthening collective bargaining and, in some cases, extending this to new groups of workers. On the other hand, reforms in the field of individual labour relations have had a protective bias. Governments have also adopted corrective measures to discourage precarious employment and address deficiencies in social protection. For example, the minimum wage has been raised (Argentina, Brazil, Chile and Uruguay), temporary contracts have been restricted (Argentina and the Plurinational State of Bolivia) and subcontracting has been regulated (Chile, Colombia, Peru and Uruguay).

10 See also Tokman (2007 and 2011) and Fitoussi and Rosanvallon (1997). 


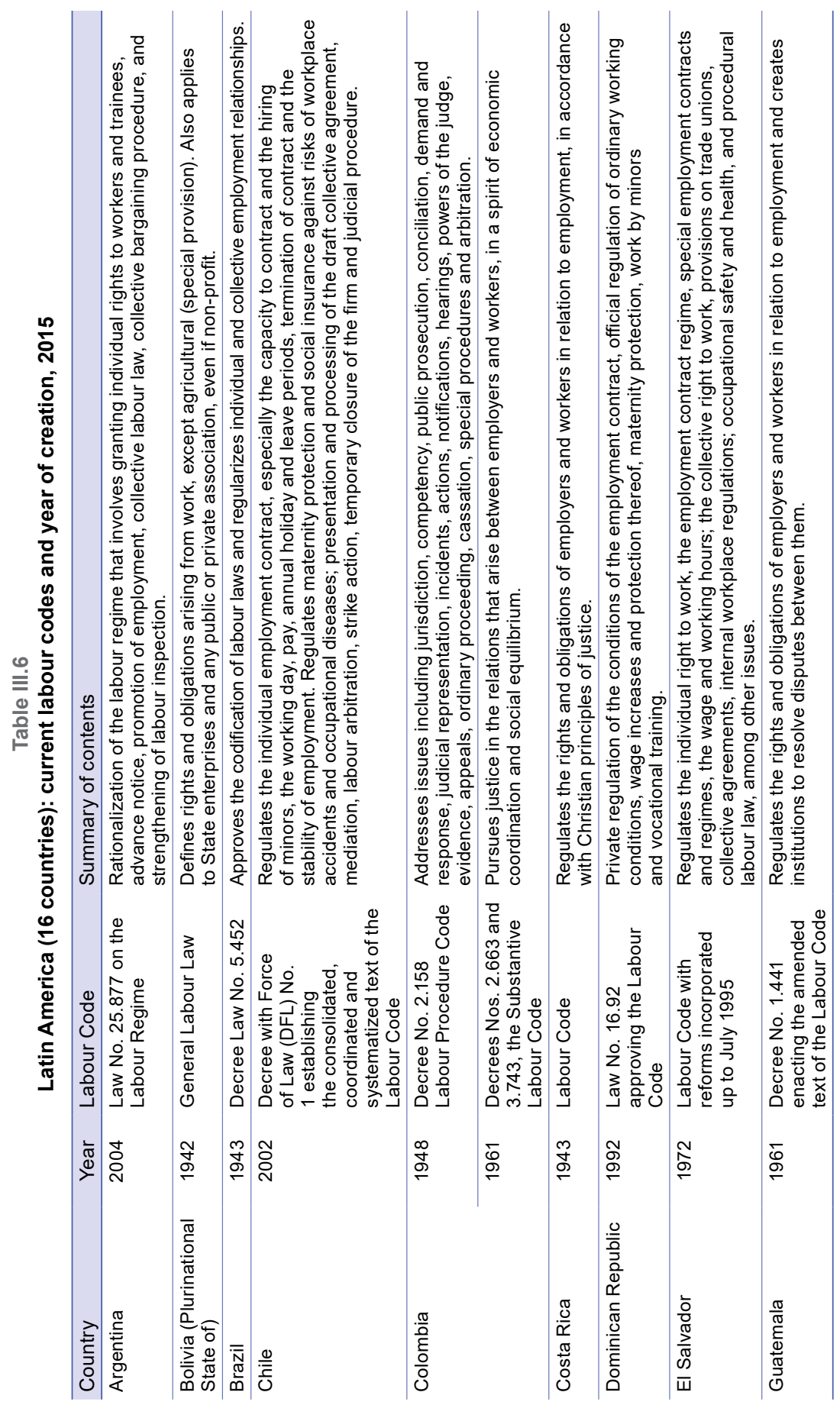




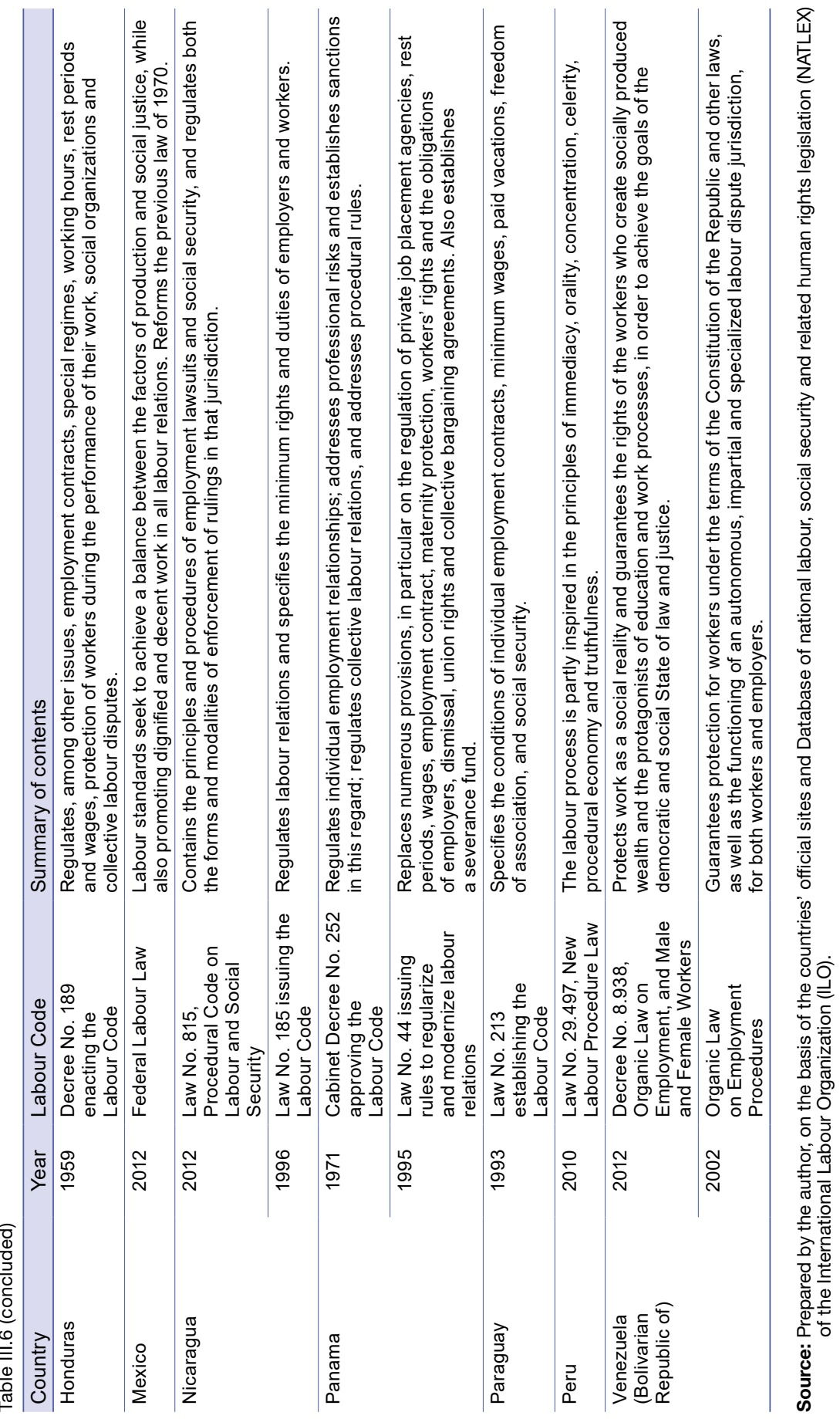


When considering protection for the newborn child and the risks of early precarious participation in the labour market, it is important to note the regulations on maternity protection, which guarantee compulsory paid leave. Examples include an outright ban on restricting employment contracts for reasons of marriage or pregnancy in Brazil, Ecuador and El Salvador. In Panama, on the other hand, this is conditional, since a pregnant woman can be dismissed, but only for just cause and with prior judicial authorization. There are also many regulations on the right to pre-natal and post-natal rest, for example, in Chile (six and 12 weeks respectively), the Dominican Republic (six weeks in both cases) and the Bolivarian Republic of Venezuela (six and 20 weeks), among others.

There are also provisions that oblige the employer to set up care, breastfeeding and feeding facilities in firms, under various modalities of crèches, nurseries or pre-school units. This objective is achieved in Brazil through public institutions. Colombia has comprehensive early childhood care centres for pre-school children under the age of seven, which are open to the families of public and private employees; and Mexico has established the Mexican Social Security Institute (IMSS). Other modalities operate within firms, which may be required to offer this type of facility, depending on the number of female workers they have: over 20 in the Bolivarian Republic of Venezuela, Chile and Honduras; more than 30 in Costa Rica and Guatemala and over 50 in Colombia.

There are also provisions that prohibit work by children or minors and regulate the work of adolescents, although the age limit varies between countries. For example, the employment of minors under 18 years of age in hazardous activities is prohibited in Chile, and there are fines for employers who hire minors without observing the compulsory legal safeguards. Similar provisions apply in Ecuador and Nicaragua, or for the work of children under 18 years of age in Honduras, under 15 in Paraguay and under 14 in Guatemala. The work of adolescents is also regulated in the Plurinational State of Bolivia through apprentice contracts; and in Brazil, work by children under 14 is prohibited. There are similar restrictions in El Salvador, Mexico and Paraguay, with other age limits and requirements for a legal representative.

For the working-life stage, there is a wide range of regulations designed to guarantee adequate working conditions to address the risks of precariousness and lack of protection. Firstly, there are norms that guarantee the right to receive a minimum wage, set according to the 
special modalities of each country. All countries regulate access and recognize the obligation to protect the worker from workplace accidents and occupational diseases. This responsibility always rests with the employer, and it is not limited to guaranteeing compensation in event of accident or occupational disease (which can be implemented by contracting insurance). Steps are taken to ensure employers have the adequate security conditions in place to prevent such situations. For example, in Argentina, work is suspended in situations of serious or imminent risk. In most cases, there are fines for non-compliance with the regulations.

The employer is also required to enrol employees in social security systems. All countries have regulations to protect the worker against arbitrary dismissal, which guarantee a payment to compensate for breach of contract by the employer, or when there is no justified reason for the dismissal.

In addition, the respective labour codes include provisions to ensure the right to protection through social security systems. In the case of old age, this involves providing the corresponding protection after working life, under conditions that vary from country to country.

Along with the obligation to register workers in social insurance schemes, information must be provided on the contributions made, as is done in Argentina. On the other hand, it is often considered justified to terminate an employment contract if the worker starts to receive a retirement or other pension, as in Colombia, Costa Rica, Guatemala, Honduras and El Salvador. In many cases, monetary compensation is established, either as an amount equivalent to severance as in the Dominican Republic, or an additional wage payment in Nicaragua or to contributions made to the Workers' Housing Fund in Mexico.

There are also special situations, such as the forced retirement of those over 65 years of age in the Plurinational State of Bolivia, except for permanency agreements that do not exceed three years. Another special situation arises in El Salvador, where workers who have served continuously or discontinuously for 25 years are entitled to a retirement pension from their employers.

Table III.7 presents a detailed list of the contents of labour regulations, by stages of the life cycle and main risks of lack of protection. 


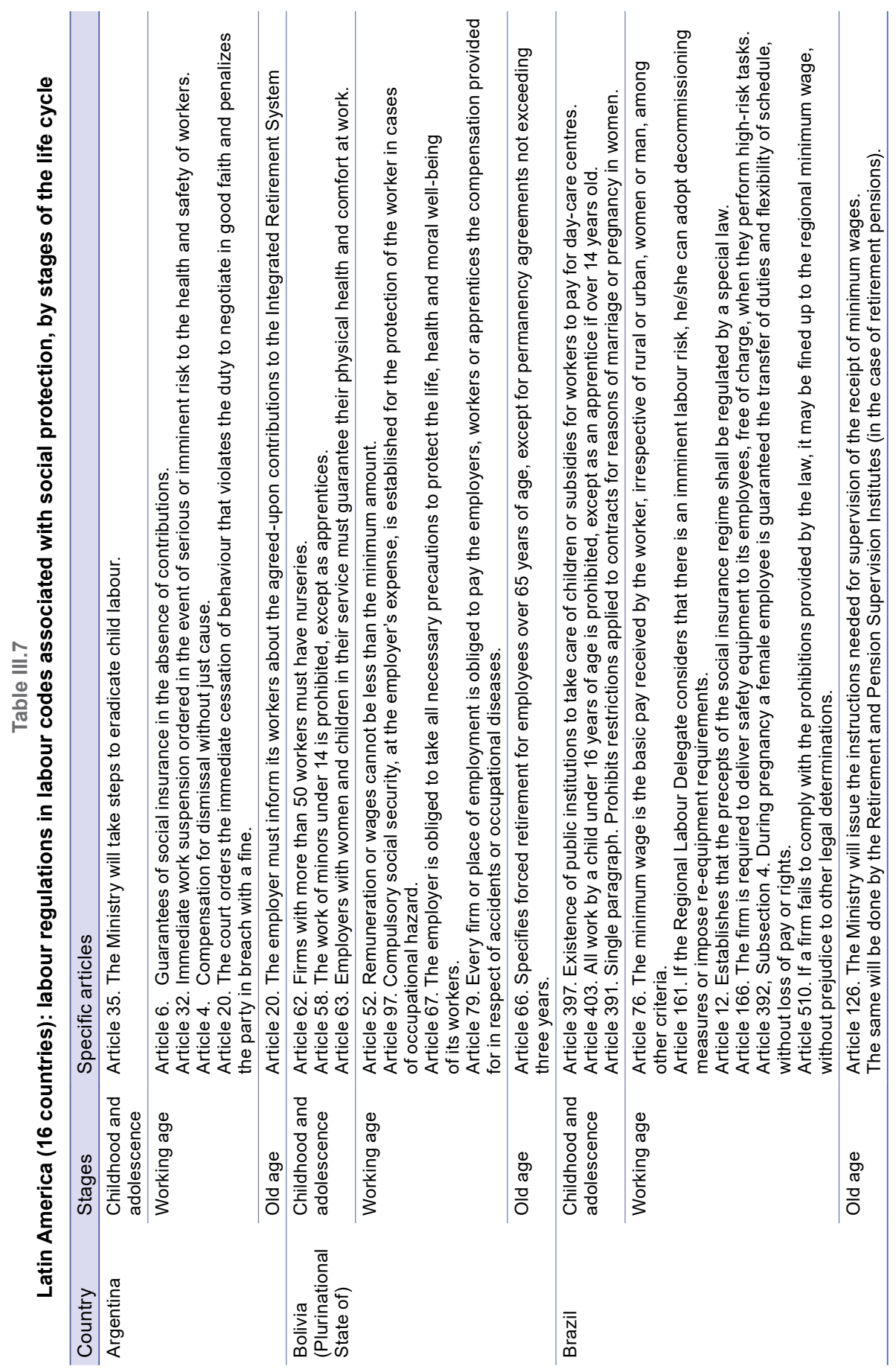




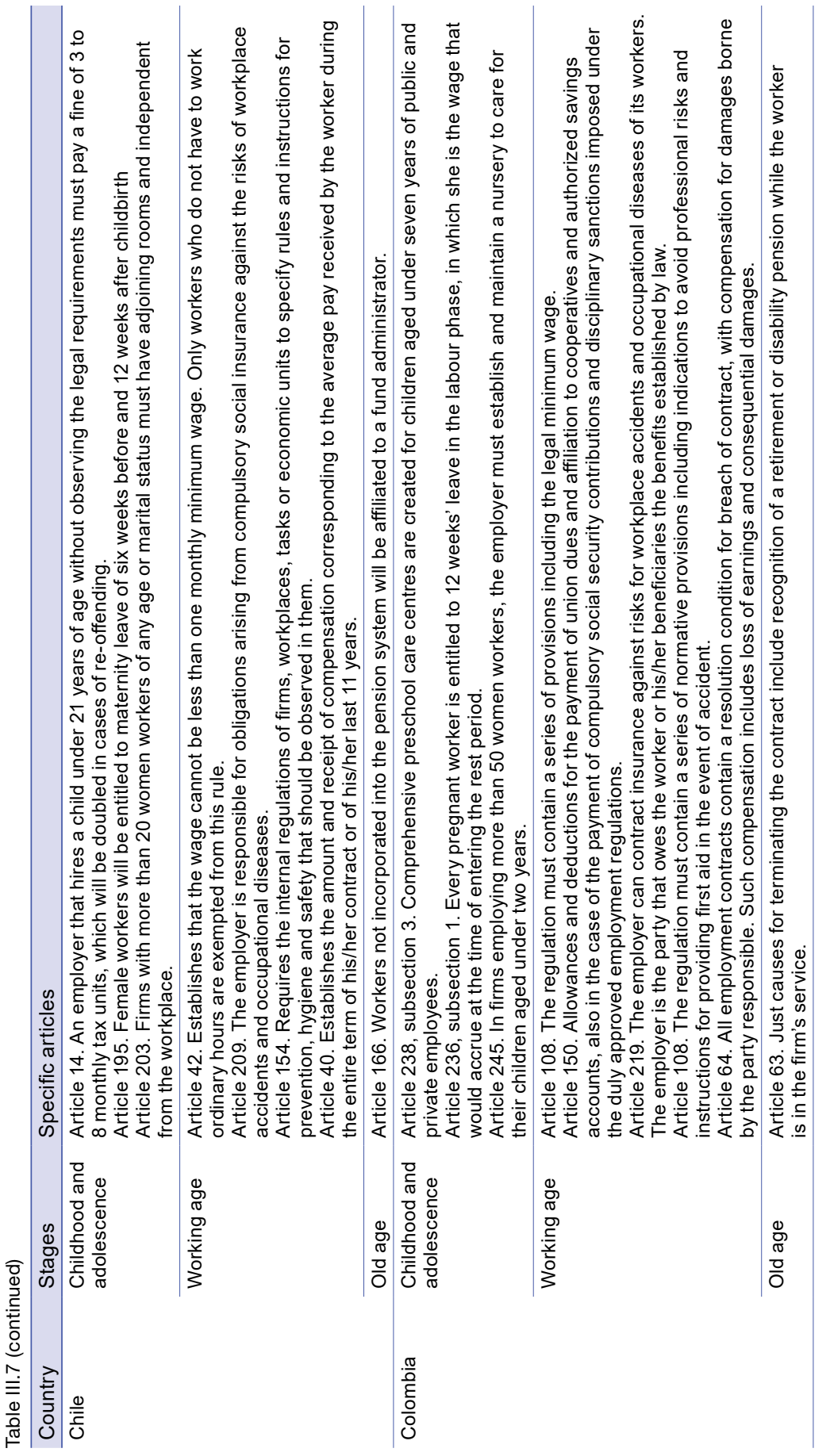




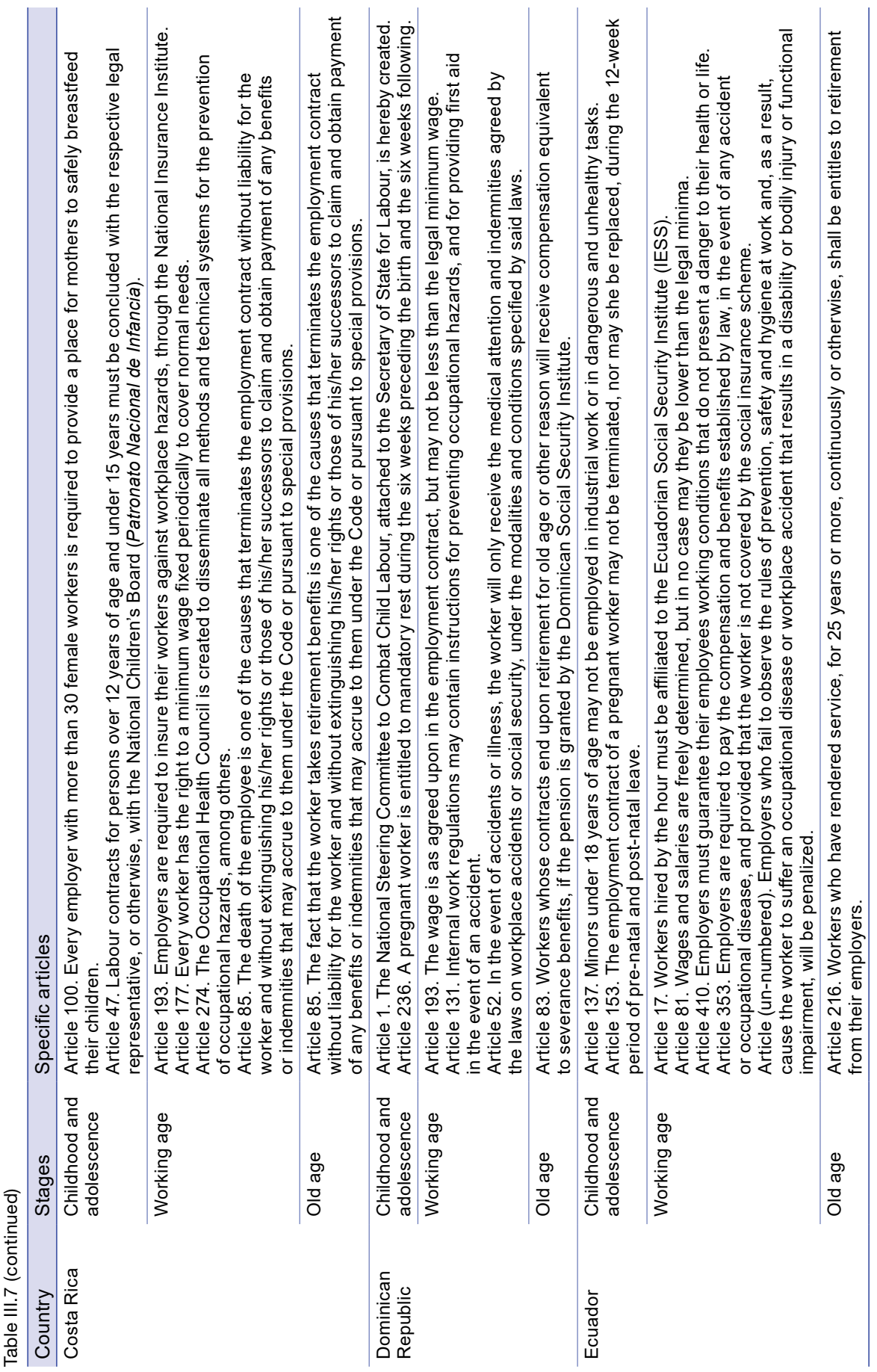




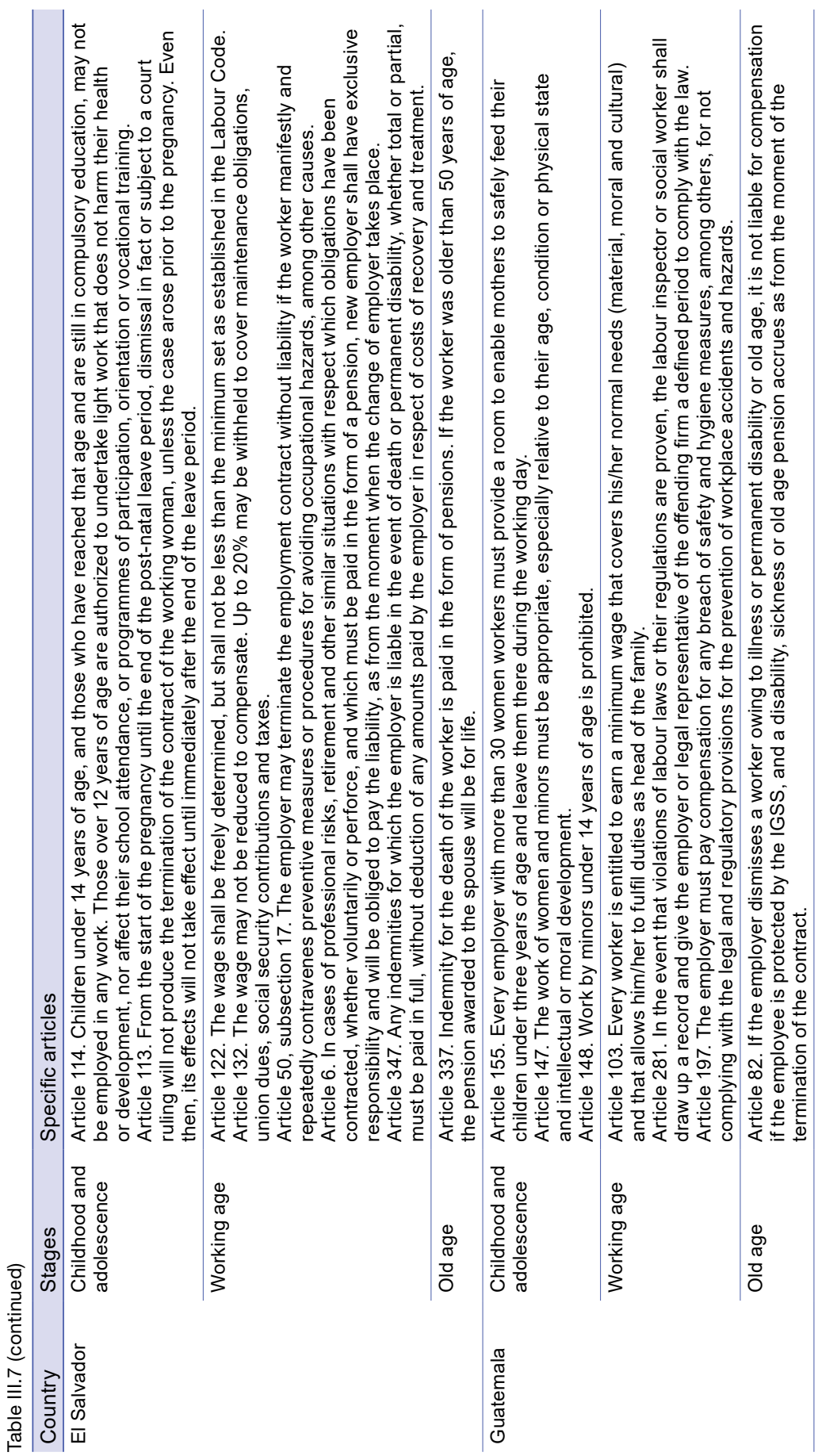




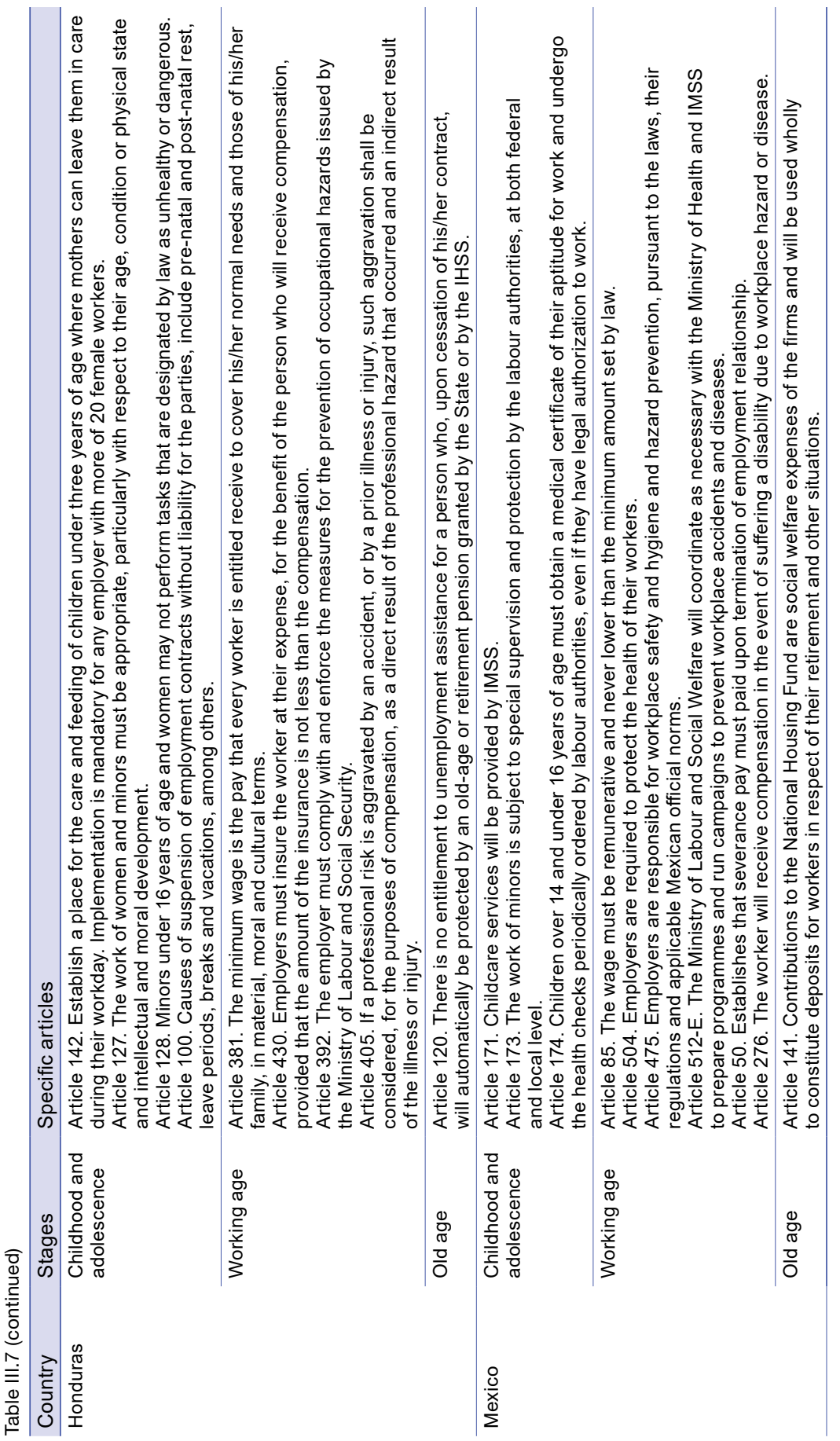




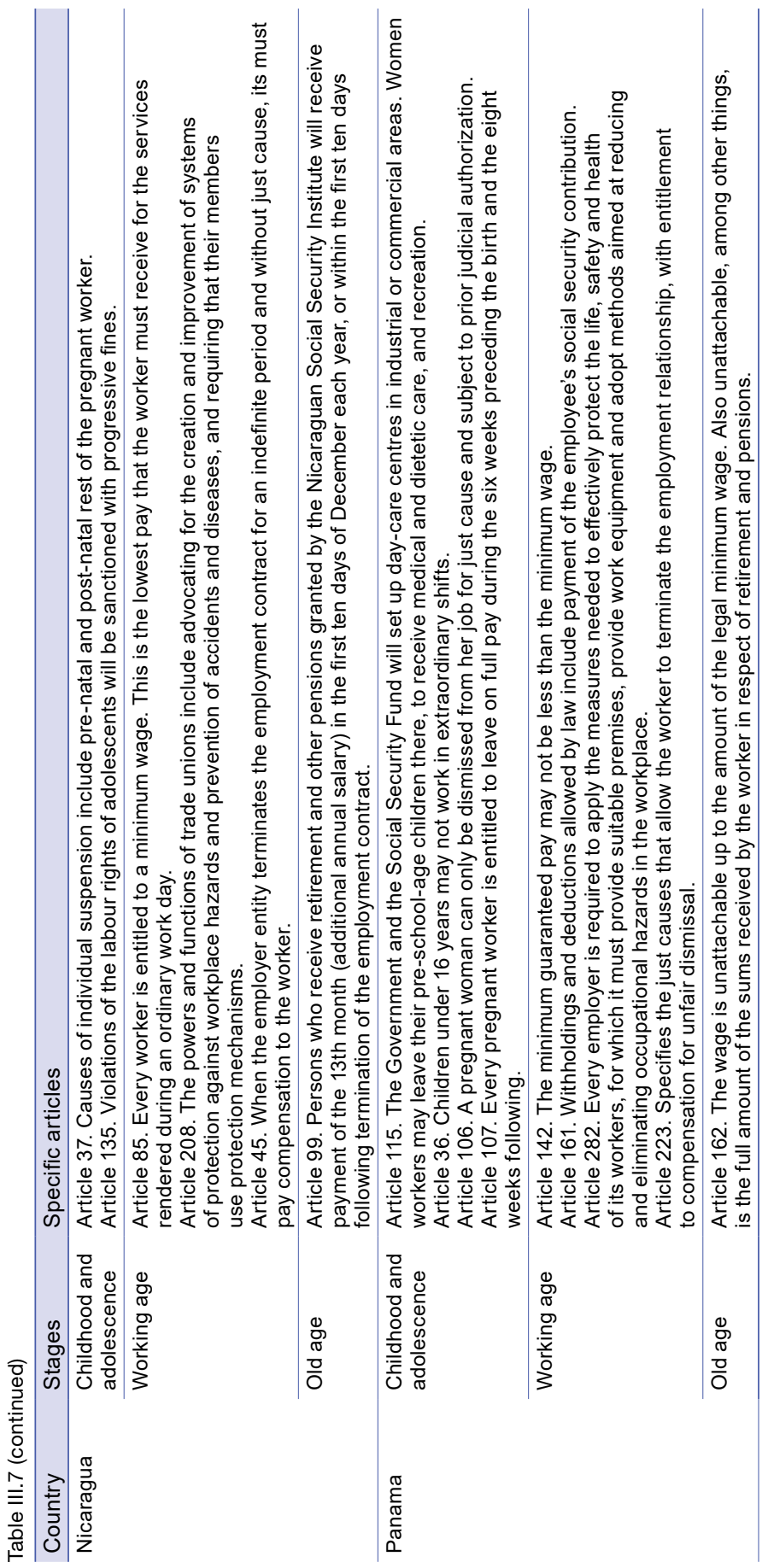




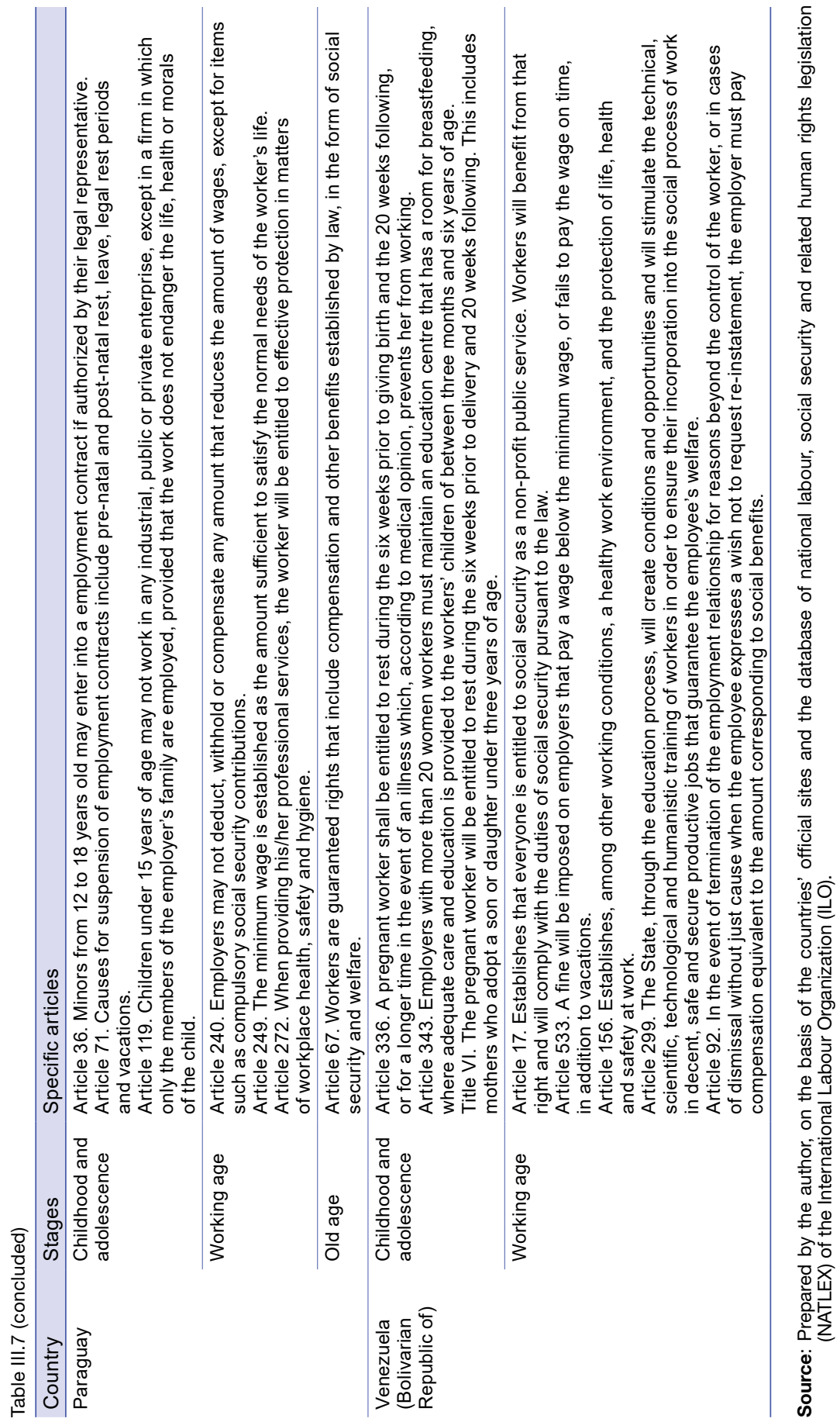




\section{Organizational dimension for regulatory compliance}

As noted in chapter I, the mere existence of regulations is not enough to ensure the desired effects in terms of social protection during the life cycle. The institutional strength of the authority responsible for the policies, and of the different actors that comprise the organization in charge of implementing them, is crucial for ensuring compliance with the regulatory matrix. ${ }^{11}$

This section describes the main government agencies responsible for the generation, application and monitoring of compliance with the set of labour standards and regulations analysed.

\section{Labour administration}

Labour administration as a sphere of governance dates back to the second half of the nineteenth century. ${ }^{12}$ The objective was to regulate labour markets through systematic and continuous government intervention, in order to improve working conditions and preserve the balance between employers' and workers' interests. The chief motivation of governments was to maintain social peace and avoid major social conflicts. Institutions were created gradually, from the first labour inspectorates and employment offices to labour ministries.

The International Labour Organization identifies three main models for the structure and organization of a ministry of labour, which are not mutually exclusive and are often combined in the same country: (i) direct management (most of the activities are the responsibility of the ministry and its departments); (ii) indirect management (through decentralized departments), and (iii) delegated management (recourse to existing or new independent bodies, for which the ministry is responsible). Whatever the chosen model or combination, a ministry of labour generally consists of units that can be grouped into three main categories: (i) technical departments; (ii) management support services, and (iii) general administrative services, as illustrated in diagram III.1.

11 Institutional capacity or strength can be thought of as the ability of ministries to perform their labour-administration functions, and to mobilize and adapt their resources for policy making. This identifies the administrative components at the micro level of human resources, in terms of their adequacy and relevance for the fulfilment of institutional tasks; and also at the meso level, which refers to organizational design and consistency with organizational objectives. There is a further political component, which relates to the ability to promote the organization's objectives, considering the environment of relations with political actors, the State and other individuals or groups that operate in the area of public affairs. For a discussion on this concept, see Velásquez (2011).

12 Based on ILO (2011). 
Diagram III.1

Classical organizational structure of a labour ministry

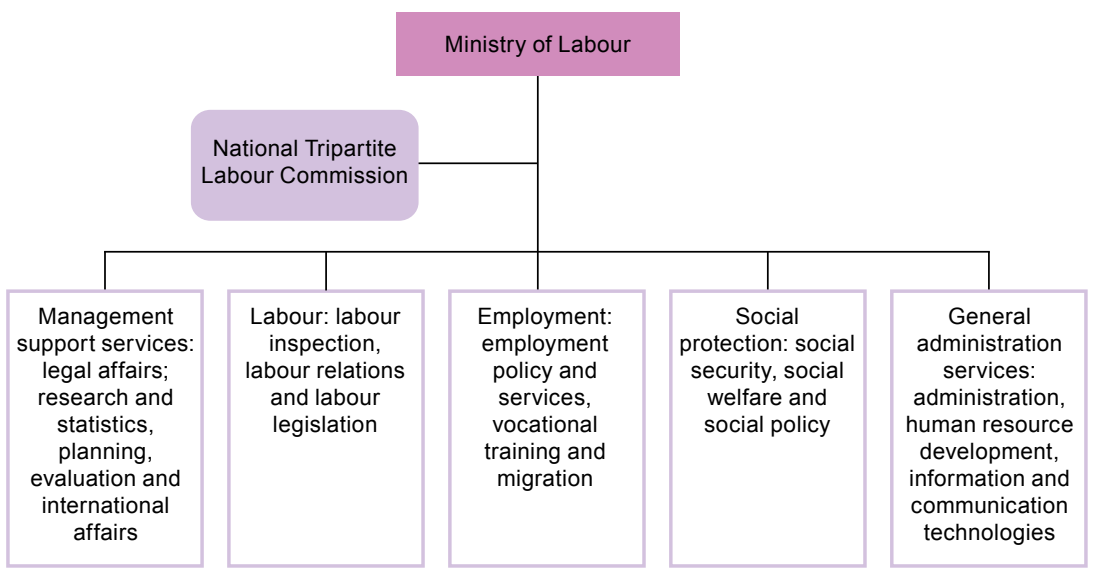

Source: International Labour Organization (ILO), "Labour administration and labour inspection", International Labour Conference, 100th session, 2011 [online] http://www.ilo.org/wcmsp5/ groups/public/---ed_norm/---relconf/documents/meetingdocument/wcms_153918.pdf.

Administrative support services are responsible for managing human, material and financial resources. Management support is vitally important to ensure proper functioning and usually covers the areas of planning, programming, evaluation, legal advice, legal drafting, international relations, research and statistics. These play a key role in the formulation of ministry policies, plans and programmes and require well-trained and experienced staff with knowledge that extends beyond the labour domain.

In most ministries, the technical units are in charge of thematic areas, such as labour relations, legislation, employment, social security, labour inspection and working conditions. They are responsible for supervising the administration and application of labour policies and legislation, drafting new policies and legal texts, and providing advice and reporting on their application. They also usually deal with the statistical analysis of data and prepare descriptive field reports; create and maintain national databases; prepare annual reports; and hold direct consultations with employers' and workers' organizations. A specific function of a labour ministry is to support cross-professional or intersectoral social dialogue, promote collective bargaining and mediate between the parties in labour disputes. The ministry usually has a specific department in charge of labour relations, which provides assistance in collective bargaining and mediation, among other areas. 
Over time, the function of the ministries of labour developed from their original focus on protection, application and sanction, to one that involved a greater role in the economic development of the countries, especially in the fields of employment policy and social protection. Thus, within the traditional functions of protection through the regulation of working conditions, in which labour inspection plays a leading role, in recent decades the employment component has become more important (formulate employment policies and passive or active market policies) and social security.

The configuration of labour administration systems and their institutions varies according to the characteristics of each country, although there are also similarities. While the authority in national systems of labour administration is usually the Ministry of Labour, some related policies are often an exclusive responsibility or shared with other ministries, such as those of social affairs or social development, economics, finance, education, health, the interior or youth.

It is also common for the provision of services to be delegated to parastatal bodies. For example, this can be divided among agencies specialized in job placement, vocational training, health and safety at work, mediation and arbitration, or administration of the various social protection schemes, whether in terms of pension funding or unemployment. Nonetheless, these bodies have different degrees of autonomy in terms of management, financing and service provision. Even though functions are delegated to these entities, it is essential that the ministry continues to fulfil its role in steering and formulating policies; and it is important to ensure that this does not imply a weakening of its technical functions, due to the emigration of qualified personnel which tends to happen in such cases.

The available information shows that the main responsibility for the generation, application and enforcement of labour regulations among Latin American countries rests with the ministries or secretariats of labour (see table III.8). These, in turn, are organized by areas of functional specialization of employment and social security. In relation to these branches, there are vice-ministries (Colombia, Ecuador, Guatemala, Panama, Paraguay and Peru), general directorates (Plurinational State of Bolivia, El Salvador, Honduras and Uruguay) or secretariats (Argentina, Brazil, Chile and Mexico). These directorates also have general directorates, sub-directorates or under-secretariats, respectively, with higher degrees of specialization in their respective functional areas. 


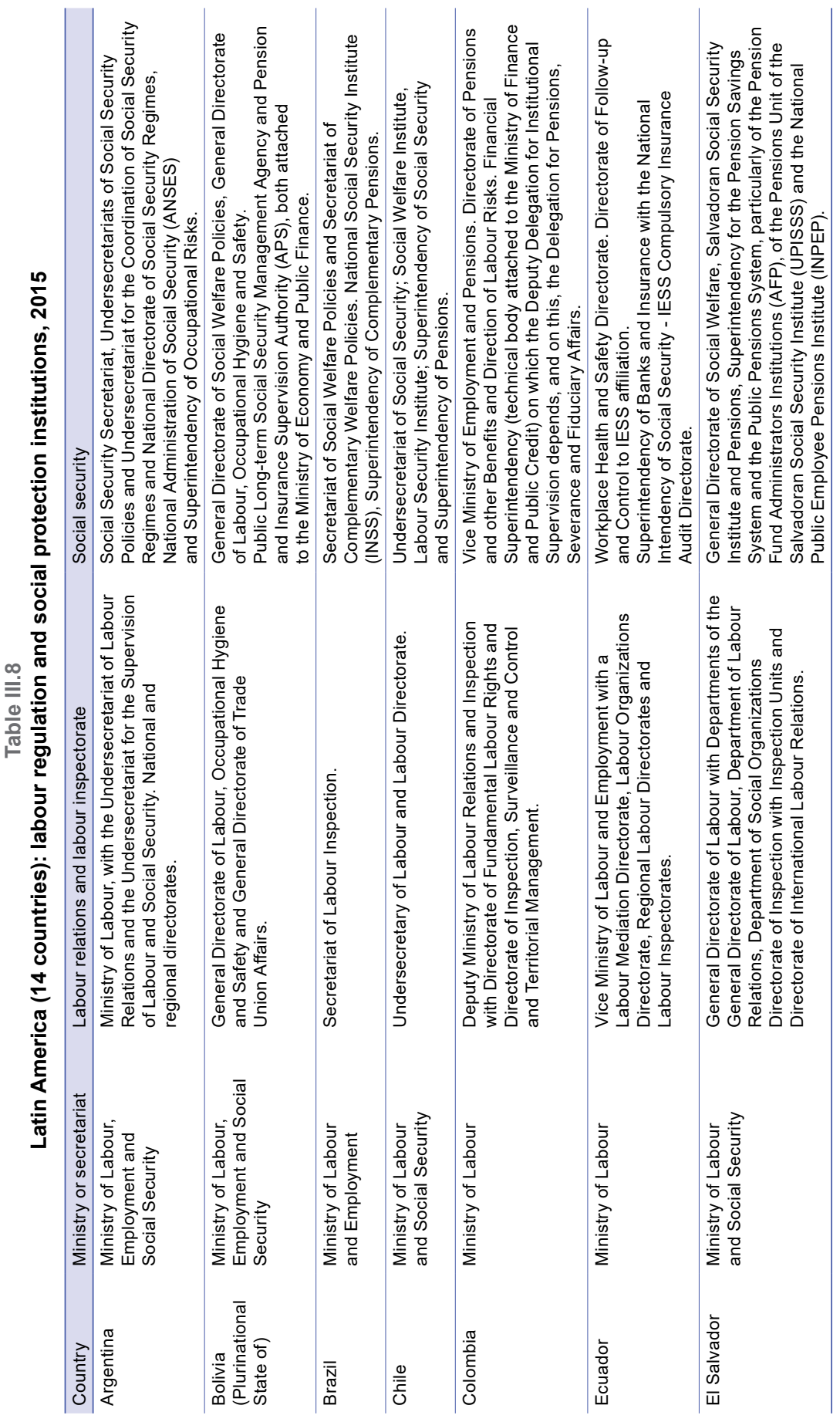




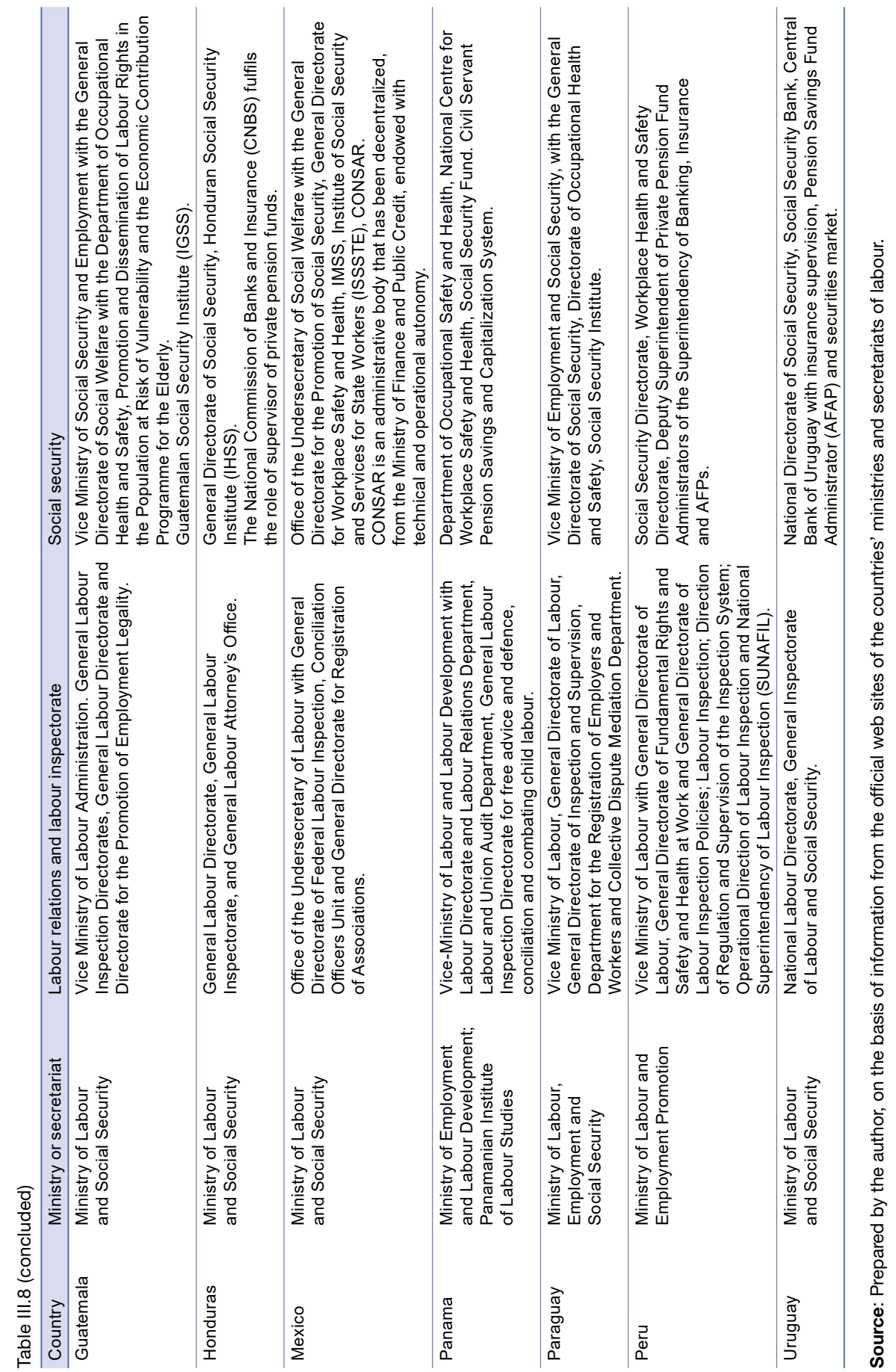


In the labour domain, subdivisions in the levels indicated usually involve labour directorates focused on the enforcement of labour standards. There may also be specialized units in the labour inspectorates (with branches across the country), in labour relations (social organizations) and for mediation in labour disputes.

Most of these functions are fulfilled in the different countries of the region, albeit with varied institutional designs. The main differences are that, in some cases, the work area includes issues related to occupational health and safety conditions (Argentina, Peru, Plurinational State of Bolivia and Uruguay), which reflects a decision to coordinate actions on employment and job security within a single directorate. Other countries have specialized units that fulfil promotion and advocacy functions for compliance, as in Guatemala (Directorate of Labour Legality Promotion), Honduras (Attorney General's Office) and Panama (Free Advisory and Advocacy Service), which illustrates the idea of deploying a variety of actions to promote compliance with the rules, apart from inspection and sanctions for non-compliance. Nonetheless, mention of these specific experiences does not mean that such actions are absent in the other countries, but that they are usually subsumed in the existing labour inspection modalities.

The National Superintendency of Labour Inspection (SUNAFIL) was created in Peru in 2014 with the aim of providing a specialized service for monitoring compliance with standards. It reports directly to the responsible vice ministry and requires close coordination with the Regulation and Supervision Directorate of the Inspection System. The monitoring and evaluation of this new institutional design in the medium term are of special interest for analysing the effectiveness of compliance with standards and their effects on social protection.

In the social security area, the ministries in question usually have a structure similar to their counterparts in the labour domain, particularly in terms of design and generation of standards and policies. Occupational health and safety directorates and social security directorates form part of the line agencies of many ministries or secretariats of labour. However, as noted above, this area, and especially in the pensions domain, have superintendencies and specialized and autonomous entities within labour ministries, with the exclusive mission of supervising the administration of the various systems that operate in it.

Perhaps the best example of this organizational design is Chile, where there are two superintendencies: (i) the Pensions Superintendency, whose purpose is to protect the assets of individuals who pay into the pension fund administrators, and to supervise the operation of the pensions solidarity pillar and the operation of unemployment insurance; and (ii) the Superintendency of Social Security, which oversees the performance of entities that provide insurance against workplace accidents and occupational diseases, among other risks. 
Both maintain attachment to the Ministry of Labour and Social Welfare, and to the Undersecretariat for Social Welfare in terms of design and generation of the regulations governing the different supervised systems.

A situation such as described can be observed in most of the countries for which information on the pensions area has been collected (see table III.8). In practice, the regularity displayed reflects whether there is a superintendency (commission or bank) created to supervise pension fund administration, which does not depend on the Ministry of Labour.

Examples are the Long-term Public Social Security Management Agency and the Pension and Insurance Supervision Authority (APS), both attached to the Ministry of Economy and Public Finance in the Plurinational State of Bolivia; the Financial Superintendency in Colombia (attached to the Ministry of Finance and Public Credit), to which the Pensions Delegation reports; the Superintendency of Banks and Insurance with the National Social Security Administration- Audit Directorate of Compulsory Insurance of IESS in Ecuador; the Superintendency of Pensions for the Pensions Savings System and the Public Pension System in El Salvador; the National Commission of Banks and Insurance (CNBS) in Honduras; the National Commission of the Retirement Savings System (CONSAR), under the Ministry of Finance and Public Credit in Mexico; the Deputy Superintendency of Private Pension Fund Administrators of the Superintendency of Banking, Insurance and AFPs in Peru, and the Central Bank of Uruguay, which supervises insurance, pension fund managers (AFAPs) and the stock market.

In general, the situations mentioned above have been justified by their designers in terms of the institutional weaknesses that characterize the functioning of ministries of labour and, in particular, the financial management of pension funds. Nonetheless, this is a potential area of interagency tensions, since the governing body of the system, and its design and regulations, remain in the labour and social welfare ministries, and these ministries need capacity-strengthening in this area.

\section{The administrative channel}

The labour-market police or labour inspectorate is the State entity responsible for enforcing labour and social security regulations and for punishing violations. The nature of its work is to monitor employer behaviour, which may involve criminal offences against their workers. ${ }^{13}$ Inspection is thus crucial to the effectiveness of existing labour standards (Vega, 2009).

\section{(a) Key factors and characterization of the systems}

The following section examines some of the features of labour inspection systems with a view to identifying key conditions for their

13 When the labour inspectorate detects violations that lead to criminal offences, these are usually linked to human trafficking and child labour, as has happened in Argentina and Brazil. 
operation..$^{14}$ The systems in question can be general or specialized, depending on whether or not responsibilities are distributed between the different inspection services. General systems are responsible, for example, for overseeing labour and employment conditions, along with issues related to the work environment and labour relations. In some cases, they are also responsible for vocational training, migration and social security. In contrast, specialized systems are targeted toward specific contents and are usually supervised by one or more central units. Between these two categories, there are systems based on interdisciplinary teams, in which a single inspector has the professional competencies needed to provide a multifunctional service in each local labour inspection service.

In many countries, inspection services have responsibilities in dispute resolution, participation in the negotiation of collective agreements at the initiative of the parties, compilation and upgrading of socioeconomic data and technical reports for labour authorities, and other administrative registration and enforcement functions. Some include the monitoring and implementation of collective rights, or else they are assigned powers in relation to dismissals, as in the Bolivarian Republic of Venezuela, Chile and Colombia; while others exclude or restrict this possibility (Bensusán, 2009). The range of functions attributed is highly varied and reflects different national cultures and traditions.

The foregoing shows that the labour inspectorate is a multi-purpose institution. It supervises application of the law, while also providing information, training and consultation services. The inspectorate is a specialized public body that brings the reality of the labour market in contact with the labour administration. In some countries it becomes institutionalized as a consultation body for the planning of social policy and legislation.

The inspectorate prevents, informs and acts without always having to resort to suppression or punishment. It prevents disputes at their origin and resolves labour problems de facto, without a court ruling. Moreover, the ability to sanction according to their own judgement means that their action has the potential to be doubly effective.

In addition to exercising general control over legal provisions strictly related to working conditions and worker protection, the inspection task also includes a preventive dimension that involves averting labour hazards. While its essential function is to enforce the rules and provide technical advice and information on the subject, the preventive role also forms part of that task. In most countries, inspectors articulate preventive and repressive approaches de facto, since their action tends not so much to look for infringements and sanction them, but rather to achieve respect for and application of the regulation.

$14 \quad$ Based on Loyo and Velásquez (2015) and ILO (2011). 
The control and advisory functions are complementary, since they pursue objective application of the legal provisions. This does not mean that advice replaces the control function. Warnings or recommendations are fundamental and, in many countries, serve as an intermediate stage between advice and sanction, which makes them a key part of the administrative process.

To perform effectively, inspectors need to have unfettered access to workplaces and any other location where it can reasonably be assumed that labour activity takes place. They must also be able to conduct the tests, examinations and investigations they consider pertinent and, in particular, to question the interested parties, either alone or in the presence of witnesses, on the application of the legal provisions. Moreover, they must be professional and independent public officials, recruited on the basis of proven skills under stable conditions of employment.

Labour inspection is currently viewed as a support for the labour administration, one of the tripartite pillars. In its twin roles of representing the State and acting directly in labour relations, it is the most appropriate institution to support the small- and medium-scale development of the multiple dimensions of social dialogue and labour relations. Tripartite inspection not only creates a sense of ownership of the process, but also provides the parties with a form of direct intervention and understanding of ways to achieve the desired ends (Erikson, 2005).

The education of social actors on the legal provisions and their application, together with risk prevention to guarantee the health or life of individuals, makes the inspection more efficient, with participation by all parties in the employment relation. In this dimension, tripartite labour advisory councils provide a privileged vehicle for transmitting information to employers and workers' organizations.

As an example, table III.9. outlines the labour inspection systems that operate in Brazil and Chile (which are among the most developed in the region), based on ILO guiding principles. Notwithstanding the specific cases of Brazil and Chile, the general panorama in the region displays clear institutional weaknesses, in a variety of dimensions. These include limitations that prevent ministries from having effective legal powers to oversee and enhance the work of inspectors, and from having the operational capacity and human resources needed to fulfil this function effectively. It is also necessary to develop mechanisms for coordination with other specialized sectoral entities in supervisory tasks and in promotion of participation by labour-market players in the design, monitoring and evaluation of such actions, with the aim of expanding the range of subjects observed and the need to cover various productive sectors and geographical areas (Loyo and Velásquez, 2015). 


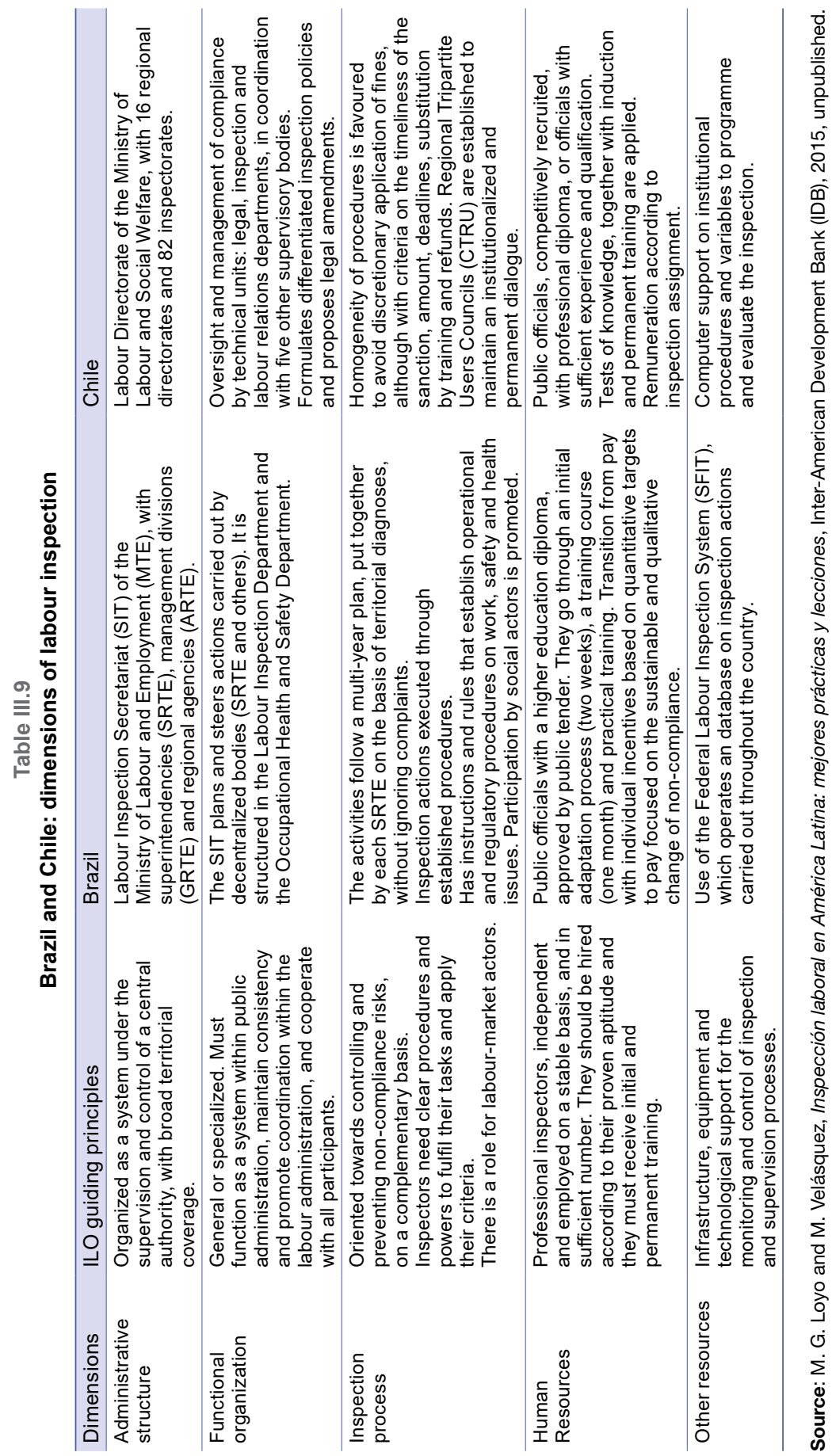




\section{(b) Institutional strength}

Along with the issues of design, organizational structure and complementary functions already observed, the analysis needs a vision of the institutional strength (management capacity) of labour inspection services.

Table III.10 presents a set of selected indicators. The second column reports the absolute number of labour inspectors in each country. The third shows the share of inspectors in the total number of public-sector employees, as an indirect measure of the importance that each State attaches to these functions. Chile, Colombia, Panama and Uruguay are in the lead, measured as a simple average, although these are not large proportions compared to the comparison parameter. The lowest ratios are found in the Bolivarian Republic of Venezuela, Mexico and Paraguay. The next column reports the ratio between the number of labour inspectors and the total number of private-sector employees. This gives an idea of the average potential coverage, considering that the ILO standard is one inspector for every 40,000 workers $(0.0025 \%)$ in relatively less developed countries. Most countries exceed this standard (especially Chile, Panama and Uruguay), although Mexico, Paraguay and Bolivarian Republic of Venezuela do not.

Table III.10

Latin America (14 countries): strength of labour inspection, selected indicators

\begin{tabular}{|c|c|c|c|c|c|}
\hline Country & $\begin{array}{c}\text { Total } \\
\text { inspectors } \\
\text { (number of } \\
\text { persons) }\end{array}$ & $\begin{array}{c}\text { Inspectors/ } \\
\text { public } \\
\text { employees } \\
\text { (percentages) }\end{array}$ & $\begin{array}{l}\text { Inspectors/ } \\
\text { private-sector } \\
\text { wage-earners } \\
\text { (percentages) }\end{array}$ & $\begin{array}{c}\text { Visits per } \\
\text { inspector } \\
\text { (annual } \\
\text { average) }\end{array}$ & $\begin{array}{c}\text { Employers } \\
\text { inspected } \\
\text { (percentages) }\end{array}$ \\
\hline Argentina & 402 & 0.02 & 0.004 & 338.8 & 31 \\
\hline Brazil & 2775 & 0.02 & 0.005 & 99.8 & 12 \\
\hline Chile & 1282 & 0.15 & 0.027 & 84.9 & 32 \\
\hline Colombia & 462 & 0.05 & 0.005 & 26.8 & 1 \\
\hline Costa Rica & 96 & 0.03 & 0.008 & 132.6 & 17 \\
\hline $\begin{array}{l}\text { Dominican } \\
\text { Republic }\end{array}$ & 147 & 0.03 & 0.009 & 376.2 & 36 \\
\hline Ecuador & 169 & 0.03 & 0.005 & 141.4 & 12 \\
\hline Mexico & 376 & 0.01 & 0.001 & 131.6 & 2 \\
\hline Nicaragua & 95 & & & 141.5 & 10 \\
\hline Panama & 217 & 0.09 & 0.025 & 369.8 & 70 \\
\hline Paraguay & 22 & 0.01 & 0.002 & 17.5 & 0 \\
\hline Peru & 386 & 0.03 & 0.007 & 161.0 & 0 \\
\hline Uruguay & 125 & 0.05 & 0.013 & 166.0 & 26 \\
\hline $\begin{array}{l}\text { Venezuela } \\
\text { (Bolivarian } \\
\text { Republic of) }\end{array}$ & 125 & 0.00 & 0.003 & 112.4 & 4 \\
\hline Simple average & 477.1 & 0.04 & 0.005 & 164.3 & 18 \\
\hline
\end{tabular}

Source: Prepared by the author, on the basis of International Labour Organization (ILO), ILOSTAT Database. 
To measure the intensity of the inspectors' action, the average annual number of visits to workplaces is also recorded for each country. This is highest in the cases of Argentina, Panama and the Dominican Republic, and lowest in Colombia and Paraguay.

In terms of the coverage of the population inspected each year, expressed as the ratio between the number of annual visits made with respect to the total number of employers, the regional average (14 countries considered) is $18.1 \%$. This means that, in theory, all firms will have been inspected in a five-year period. Argentina, Chile, the Dominican Republic, Panama and Uruguay are above average in this regard, while Colombia, Mexico, Paraguay and Peru have the lowest coverage rates.

In short, from the standpoint of the strength of labour inspection services, there is a direct relationship between the supply of inspectors and the potential protected population. This can be seen the cases of Chile and Panama, and the group comprising the Bolivarian Republic of Venezuela, Mexico and Paraguay, in which it is impossible to overcome the restrictions of a small team of inspectors with more effective inspections, which finally results in a smaller share of the population being protected. On the other hand, it also highlights the capacity demonstrated by Argentina and the Dominican Republic, which report a high percentage of employer inspections, despite not having a particularly large staff for these functions.

\section{(c) Main findings on risk coverage}

Using the matrix of analysis proposed for this study, the following paragraphs analyse the findings obtained on various areas of worker protection, considering the main risks confronted over the life cycle.

Table III.11 reports a set of indicators that have been selected to illustrate the status of the protection derived, among other factors, from the labour regulations analysed. The second column shows the proportion of informal employment with respect to total nonagricultural employment, as previously defined, in which the simple average among the countries considered is $52.6 \%$. This information is particularly germane to this analysis, since informality in employment represents a structural barrier that excludes over half of the region's workers from the protection provided by labour regulations. According to the information presented, informal employment is most prevalent in the Central America countries and also in Paraguay and Peru. The smallest proportions are found in Costa Rica and Uruguay, although in each case informality encompasses just over one third of all nonagricultural workers. 


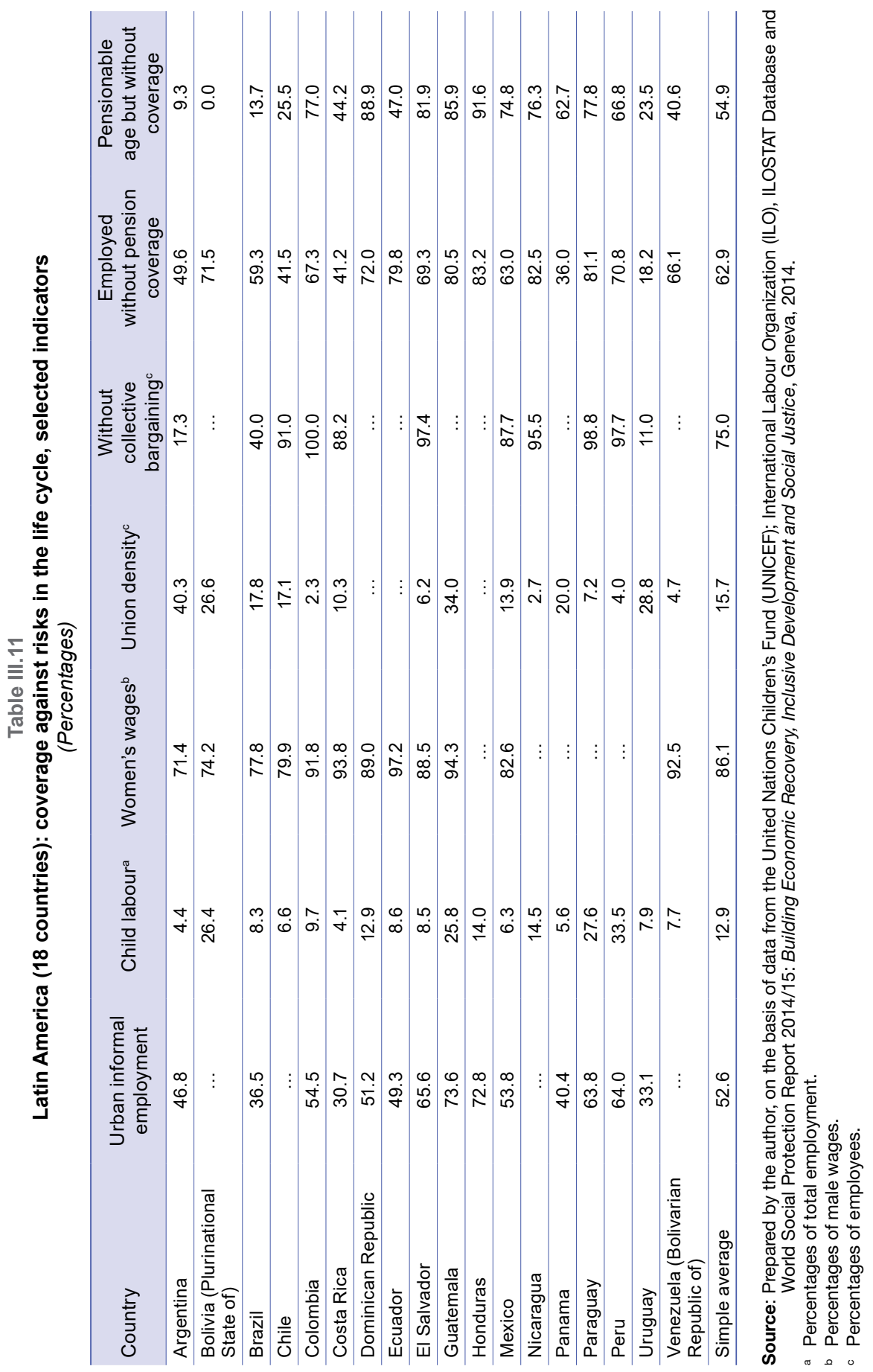


When considering the stages of the life cycle, the key issue in the pre-active stage is the prevalence of child labour, defined as the percentage of children between five and 14 years of age who work under such conditions. ${ }^{15}$ The average of the countries considered is $12.9 \%$. This highlights the fact that, despite the decision adopted by ILO members to abolish this type of practice, there is still a lack of protection for children and adolescents, especially in Guatemala, Paraguay, the Plurinational State of Bolivia and Peru.

For the active-life phase, four indicators can be used. Firstly, wage discrimination in employment between women and men is illustrated by the ratio between the average pay of women and men, which averages $86.1 \%$ among the countries for which information is available. The disparity is significant, and particularly large in Argentina and the Plurinational State of Bolivia. Nonetheless, the construction of that indicator needs to be refined with more granular data to control for occupation type.

Collective rights can be assessed through information on union density. This is measured by the proportion of workers who are affiliated to a trade union organization relative to the total number employed, and the proportion of those who cannot participate in collective bargaining. The two indicators are related, since a low rate of unionization is usually associated with poor coverage of collective bargaining. Nonetheless, the relationship is not strictly proportional, since it depends on the specific content of the regulations on the subject - for example, whether the benefits obtained by unionized collective bargaining can be extended to non-unionized workers and whether negotiations extend beyond the firm.

The results obtained indicate that relatively low union density persists among the countries, with an average on the order of $15.7 \%$; but the figures are even lower in the Bolivarian Republic of Venezuela, Colombia, El Salvador, Nicaragua, Paraguay and Peru. On the other hand, a high proportion of employed workers are excluded from the right to bargain collectively ( $75 \%$ on average), with even higher proportions in Chile, Colombia, El Salvador, Mexico, Paraguay and Peru. These indicators need to be refined to consider the relevant population in each case, in other words the unionized population or the population that is in a position to negotiate.

15 The information on child labour (UNICEF, 2015) refers to work done by a child who has not attained the minimum age specified for the type of occupation in question (as determined by national legislation and in accordance with international standards) and which, consequently, impedes education and the full development of the child. Child labour is also considered to be any work that endangers the physical, mental or moral well-being of the child, either by the nature of the work or as a result of the conditions under which it is carried out. It is referred to as dangerous work. Unquestionably, the worst forms of child labour are those defined internationally as slavery, human trafficking, debt bondage and other forms of forced labour, as well as the forced recruitment of children for use in armed conflicts, prostitution, pornography and other illegal activities. 
With regard to the risk of not having income in old age, data exist on the proportion of employed persons who have not been registered in pension systems during their active life, and the percentage who do not have such coverage despite reaching retirement age. In the case of the employed, coverage is $62.9 \%$ of the total and even higher in countries of Central America, where it exceeds $80 \%$. In contrast, in Panama the rate is $36 \%$ and in Uruguay (the lowest) just $18.2 \%$. This wide dispersion of results needs to be analysed in greater detail, both in terms of the importance of wage-earning employment and informal employment, as well as the replacement rate and the absolute value of pensions, among other factors.

Lastly, the proportion of adults of pensionable age who do not have pension coverage averages $54.9 \%$ among the different countries. This degree of lack of protection stems from the aforementioned gap in active-life coverage and means that non-contributory systems will have to provide an income for their subsistence in old age.

\section{The judicial channel}

According to Ciudad (2014), it is ideal to have disputes settled directly inside the firm and through the conflict resolution systems established in collective agreements. Otherwise, the labour justice administration is called on to enforce the law and the rule of law, and to grant protection to citizens. Nonetheless, the same author notes that the administration of labour justice in most of the countries of Latin America needs in-depth revision, modernization and strengthening; for, although progress has been made in the sphere of labour justice in various countries, institutions remain weak and inefficient. It has not always been possible to guarantee a streamlined and thorough respect for human rights related to employment or labour rights generally, or to provide citizens who work with the essential elements of security (Ciudad, 2009).

Several countries have implemented reforms in this area, which is why the author suggests learning from good practices observed in Chile, Colombia, Nicaragua and Uruguay, among other countries. ${ }^{16}$ One of the issues that Ciudad considers particularly important is to strengthen judicial conciliation, increasing the powers of the judge in this area and also the preceding administrative conciliation under the Ministry of Labour, to which the parties can submit voluntarily. The author also proposes that the judge should have wide-ranging investigative powers,

16 In the case of Chile in 2013, the information available on a total of 282,247 cases admitted and terminated in the country's labour courts shows that $59.6 \%$ were the subject of a compromise agreement or conciliation, or else monitoring was accepted. See INE (2014). 
and may exceptionally call for additional evidence. To this end, the right of defence of the parties must be respected and duplication of hearings avoided. In Costa Rica, for example, a single conciliation and trial hearing is established, except in particularly complex cases in which two hearings are warranted.

Ciudad proposes to establish an oral statement of defence and to innovate in the system of appeals or challenges, through which the judicial resolutions, the abbreviated procedures for small claims, the special modalities for the protection of fundamental rights and the collective legal conflicts are reviewed. ${ }^{17}$ Moreover, as the oral hearings system provides better-quality justice, but at the same time is more demanding, dynamic and complex, it requires a level of preparation and skill that can only be provide by lawyers who are not just labour lawyers, but specialists in oral litigation. Hence the need to strengthen the system of pro bono legal defence for low-income workers and employers, as is done in Chile with the labour defence system, under the Ministry of Justice. ${ }^{18}$

Faced with the various challenges posed, it is also necessary to provide training for all legal operators, and have professionalized and efficient systems for the management and organization of court offices. They must be provided with the resources and infrastructure required by a system of oral trials, namely, additional judges, hearing rooms, audiovisual recording media, and more robust administrative and management support than in the case of the written system.

It is important to include the effectiveness dimension of labour justice in the analysis. Nonetheless, its study in the region has not been included in this chapter, given its breadth and complexity, as well as the scarcity and dispersion of information sources for comparative analysis, which are normally found within the Ministries of Justice.

17 Costa Rica and Nicaragua have incorporated special modalities for the protection of fundamental labour rights, in accordance with the ILO Declaration on Fundamental Principles and Rights at Work (freedom of association and collective bargaining, equality and non-discrimination, abolition of forced labour and elimination of child labour). All forms of discrimination are included - gender, moral harassment, sexual harassment and others.

18 The Labour Justice Reform has been gradually brought into force throughout Chile since 2009, with 26 labour courts, 84 specialist judges and 136 labour advocates, who provide pro bono representation in court proceedings for workers who need it. The targeting criteria are intended to ensure access to labour justice for the largest number of workers who require it but cannot afford it. In line with the above, the Labour Defence Offices (ODLs) guarantee a maximum coverage of $97.52 \%$ to employees in the first three income quintiles and of $83.61 \%$ to all wageearning employees in the country. Since their creation, ODLs have handled 64,505 cases. Of these, $18,737,29 \%$ of all cases handled, have required claims to filed in the courts. See Ministry of Justice (2011). 


\section{E. Final remarks}

The analysis performed here on the institutional framework of labour market regulation in Latin American countries gives rise to a set of reflections on the progress made and the challenges for its future development.

In terms of the legal-regulatory dimension of the main results of labour regulations in respect of life-cycle risks, the degree of ratification and enforcement of international agreements is generally quite high, especially in the case of the fundamental conventions. This is not true of those applicable to the sphere of occupational safety and health, however, or of the commitment to offer minimum guarantees in the different branches of social security. Nonetheless constitutional guarantees, as a fundamental framework, generally recognize and provide for protection of the rights analysed. Yet there are situations in which a right is protected by the Constitution, but the relevant convention has not been ratified. Lastly, labour codes usually address each of the risks indicated with specific rules, although the contents vary from one country to another.

Studying the organization and capacity of countries to achieve effective compliance with the standards is more complex. The traditional avenue for resolving labour disputes and non-compliance with labour legislation is generally considered to be the judicial one, involving specialized labour courts. This is an area in which the necessary information is not always available, except in some countries where labour justice reforms have been implemented, usually based in the ministries of justice or organizations in the sector.

Making progress in this dimension is vitally important, since labour justice is a key element for compliance with the standards, dispute settlement and the achievement of effective protection. Accordingly, the contents and results of the labour justice reforms undertaken in the region should be considered and integrated into the analysis.

The administrative route as an element for enforcing labour standards is a constituent part of labour administration systems in the various countries that have specialized agencies, such as labour inspectorates. Nonetheless, the evidence reveals major shortages of inspectors to cover the relevant population. There are also weaknesses in physical and technological support infrastructure, the ability to undertake inspection processes that link prevention and punishment actions, faculties for development of the inspection function in all workplaces and the existence of skilled human resources for this. Nonetheless, a complete picture of the capacity and institutional strength of the administrative channel would require more quantitative data, in addition to impact assessments. This would make it possible to classify countries by degree of institutional strength and, on that basis, analyse the results that are ultimately obtained on compliance and protection. 
An analysis of the results in terms of the degree of compliance or coverage of the relevant population in a situation of risk or lack of protection shows that there is less non-compliance in relation to child labour and wage discrimination. Nonetheless, protection is sparser in terms of the characteristics of jobs (52.6\% of employment is informal), the exercise of collective rights (just $15.7 \%$ of those employed belong to a union, and $75 \%$ are not covered by instruments derived from collective bargaining). A similar situation pertains in relation to the risk of not having an income in old age $(62.9 \%$ of employed persons are not registered in pension systems during active life, and $54.9 \%$ of the over-65s do not have pension coverage). This situation is particularly serious for women, who have significant gaps in income and protection relative to men.

Based on the preliminary analysis undertaken and its comparison with the available results, it is not yet possible to definitively explain the extent to which lack of protection is due to non-compliance or nonobservance of labour standards. On the other hand, it is possible to describe some of the elements that should be considered in any new development stages of this conceptual and methodological base:

- Further progress is needed in terms of measuring the effectiveness of a regulation. That is, the mere existence of a regulation is not a sufficient condition to ensure compliance or achievement of the desired effect in terms of protection. A detailed study is needed of each regulation and its variations from one country to another; and the practical effects of its implementation need to be ascertained (evasion, avoidance or other effects not considered). This is particularly important in the context of the region's high rate of labour informality.

- The validity of a regulation must be compared to a relevant standard. For example, even if all of a country's wage-earners were paid at least the minimum wage, it would be necessary to determine whether that guaranteed minimum would enable them to finance a basic shopping basket for themselves and their dependants.

- To complete the proposed analysis, the employment dimension considered by ministries of labour should be taken into account, in each case, along with the regulation of labour relations (employment area) and social security regulations and policies (social security area), regardless of whether their effect on social protection is supposed to be indirect. As noted above, the effects of labour justice reforms should also be included, where relevant.

- Lastly, new information sources are needed to make it possible to construct a larger number of indicators on the various risks that are considered fundamental. Given the existence of high rates of informal employment, a distinction must always be made between the total population and the population covered by labour inspection services. 


\section{Bibliography}

Amadeo, E. and J. Camargo (1996), "Labor flexibility, productivity and adjustment", Las instituciones laborales frente a los cambios en América Latina: contribuciones a un seminario (Santiago de Chile, mayo de 1993), J. Figueiredo (ed.), Geneva, International Institute for Labour Studies (IILS), International Labour Organization (ILO).

Barrientos, A. and D. Hulme (eds.) (2008), Social Protection for the Poor and Poorest. Concepts, Policies and Politics, Basingstoke, Palgrave Macmillan.

Bensusán, G. (2013), "Reforma laboral, desarrollo incluyente e igualdad en México", Studies and Perspectives series, No. 143 (LC/L.3624), Mexico City, ECLAC subregional headquarters in Mexico.

(2009), "La inspección del trabajo en América Latina: teorías, contextos y evidencias", Estudios Sociológicos, vol. 27, No. 81, Mexico City, El Colegio de México.

Berg, J., Ch. Ernst and P. Auer (2006), Meeting the Employment Challenge: Argentina, Brazil and Mexico in the Global Economy, Boulder, Colorado, Lynne Rienner.

Bertranou, F. and G. Pérez (2006), "Normas internacionales del trabajo, seguridad social y pensiones", OIT Notas, No. 2, Santiago, International Labour Organization (ILO).

Cecchini, S. and R. Martínez (2012), Inclusive social protection in Latin America: a comprehensive rights-based approach, ECLAC Books, No. 111 (LC/G.2488-P), Santiago, Economic Commission for Latin America and the Caribbean (ECLAC).

Chahad, J. (2009), "Flexibilidad y seguridad en el mercado de trabajo: en busca de alternativas para mejorar la protección social de los trabajadores brasileños", El nuevo escenario laboral latinoamericano. Regulación, protección y políticas activas en los mercados de trabajo, J. Weller (ed.), Buenos Aires, Siglo XXI.

Ciudad, A. (2014), "Avances en la modernización de la justicia laboral peruana y desafíos para el futuro inmediato", Revista de Derecho del Trabajo y Seguridad Social, year 1, No. 1, Lima, University City of San Marcos [online] https:// tallerdelaboral.files.wordpress.com/2015/01/revista-de-derecho-laboral-yseguridad-social.pdf.

(2009), "Modernización de la justicia laboral en América Latina", Managua [online] http:/ / www.poderjudicial.gob.ni/pjupload/laboral/pdf/dradolfo.pdf.

Directorate of Labour (2015), “Código del Trabajo", Santiago [online] http:/ / www.dt. gob.cl/legislacion/1611/articles-95516_recurso_2.pdf.

ECLAC (Economic Commission for Latin America and the Caribbean) (2009), Social Panorama of Latin America, 2008 (LC/G.2402-P), Santiago.

Edwards, S. and N. Lustig (eds.) (1997), Labor Markets in Latin America: Combining Social Protection with Market Flexibility, Washington, D.C., Brookings Institute Press.

Erikson, B. (2005), "Shared interests: unions and labour inspection", Labour Education, vol. 3-4, No. 140-141, Geneva, International Labour Organization (ILO).

Filgueira, F. and others (2006), “Universalismo básico: una alternativa posible y necesaria para mejorar las condiciones de vida", Universalismo básico: una nueva política social para América Latina, C.G. Molina (dir.), Washington, D.C., InterAmerican Development Bank (IDB).

Fitoussi, J.-P. and P. Rosanvallon (1997), La nueva era de las desigualdades, Buenos Aires, Editorial Manantial. 
Fraile, L. (2009), “Lessons from Latin America's neo-liberal experiment: an overview of labour and social policies since the 1980s", International Labour Review, vol. 128, No. 3, Geneva, International Labour Organization (ILO).

Freeman, R. (2005), "Labour market institutions without blinders: the debate over flexibility and labour market performance", NBER Working Paper, No. 11286, Cambridge, Massachusetts, National Bureau of Economic Research (NBER).

Goldin, A. (2009), "Flexibilidad laboral y seguridad del trabajador: una perspectiva argentina", El nuevo escenario laboral latinoamericano. Regulación, protección y políticas activas en los mercados de trabajo, J. Weller (ed.), Buenos Aires, Siglo XXI.

Heckman, J. and C. Pagés (2004), Law and Employment: Lessons from Latin America and the Caribbean, Chicago, Chicago University Press.

(2000), "The cost of job security regulation: evidence from Latin American labour markets", Working Paper, No. 430, Washington, D.C., Inter-American Development Bank (IDB).

IILS (International Institute for Labour Studies) (2008), World of Work Report 2008: Income Inequalities in the Age of Financial Globalization, Geneva, International Labour Organization (ILO).

ILO (International Labour Organization) (2016), 2016 Labour Review. Latin America and the Caribbean, Lima, ILO Regional Office for Latin America and the Caribbean. (2015a), "Ratification by convention", NORMLEX Information System on International Labour Standards [online] http: / / www.ilo.org/dyn/normlex/ en $/ f ? p=N O R M L E X P U B: 12001: 0:: N O$.

(2015b), "International labour standards on maternity protection", Labour Standards [online] http://www.ilo.org/global/standards/subjects-coveredby-international-labour-standards/maternity-protection/lang--en/index.htm. (2015c), "International labour standards on child labour", Labour Standards [online] http://www.ilo.org/global/standards/subjects-covered-by-internationallabour-standards/child-labour/lang--en/index.htm.

(2015d), "International labour standards on employment promotion", Labour Standards [online] http://www.ilo.org/global/standards/subjectscovered-by-international-labour-standards/employment-promotion/lang-en/index.htm.

(2015e), "International labour standards on working time", Labour Standards [online] http://www.ilo.org/global/standards/subjects-covered-by-internationallabour-standards/working-time/lang--en/index.htm.

(2015f), "International labour standards on wages", Labour Standards [online] http://www.ilo.org/global/standards/subjects-covered-by-internationallabour-standards/wages/lang--en/index.htm.

(2015g), "C131-Minimum Wage Fixing Convention, 1970 (No. 131)" [online] http://www.ilo.org/dyn/normlex/en/f?p=NORMLEXPUB:12100: 0::NO::P12100_ILO_CODE:C131.

(2015h), "International labour standards on employment security", Labour Standards [online] http://www.ilo.org/global/standards/subjects-coveredby-international-labour-standards/employment-security/lang--en/index.htm. (2015i), "International labour standards on equality of opportunity and treatment", Labour Standards [online] http://www.ilo.org/global/ standards/subjects-covered-by-international-labour-standards/equality-ofopportunity-and-treatment/lang--es/index.htm. 
(2015j), "International labour standards on other specific categories of workers", Labour Standards [online] http:/ / www.ilo.org/global/standards / subjects-covered-by-international-labour-standards/specific-categories-ofworkers/lang--en/index.htm.

(2015k), "International labour standards on freedom of association", Labour Standards [online] http:/ / www.ilo.org/global/standards/subjects-covered-byinternational-labour-standards/freedom-of-association/lang--en/index.htm.

(2015l), "International labour standards on occupational safety and health", Labour Standards [online] http://www.ilo.org/global/standards/subjectscovered-by-international-labour-standards/occupational-safety-andhealth/lang--en/index.htm.

(2015m), “Databases and subjects", ILOSTAT Database [online] http:// www.ilo.org/ilostat/faces/help_home/data_by_subject?_adf.ctrl-state= 24er6ate8_252\&_afrLoop=1235234311911441.

(2015n), "ILOSTAT Database” [online] http://www.ilo.org/ilostat/ faces/oracle/ webcenter/portalapp/pagehierarchy/Page131.jspx?_afrLoop =673213457537053 \&_adf.ctrl-state $=18 \times 51$ xol1b_86\&clean $=$ true\#\%40\%3F_afrLoop $\% 3 D 67321345753$ 7053\%26clean\%3Dtrue\%26_adf.ctrl-state\%3Dxqgct6rx6_2993.

(2014a), Thematic Labour Overview 1. Transition to Formality in Latin America and the Caribbean, Lima, Regional Office for Latin America and the Caribbean. (2014b), World Social Protection Report 2014/15: Building Economic Recovery, Inclusive Development and Social Justice, Geneva.

(2013), Measuring Informality: A Statistical Manual on the Informal Sector and Informal Employment, Geneva.

(2011), "Labour administration and labour inspection", International Labour Conference, 100th session [online] http://www.ilo.org/wcmsp5/groups/public/--ed_norm/---relconf/documents/meetingdocument/wcms_153918.pdf.

(2004), 2004 Labour Overview. Latin America and the Caribbean, Lima, ILO Regional Office for Latin America and the Caribbean.

(1993), "Resolution concerning statistics of employment in the informal sector, adopted by the Fifteenth International Conference on Labour Statisticians (Januart 1993)" [online] http://www.ilo.org/wcmsp5/groups/public/--dgreports /---stat/documents/normativeinstrument/wcms_087484.pdf.

INE (National Institute of Statistics) (2014), “Justicia”, Informe anual 2013, Santiago [online] http://www.ine.cl/canales/menu/publicaciones/calendario_de publicaciones/ pdf/completa_justicia_2013.pdf.

Kuczynski, P. P. and J. Williamson (eds.) (2003), After the Washington Consensus: Restarting Growth and Reform in Latin America, Washington, D.C., Institute for International Economics.

Lora, E. and C. Pagés (1997), "Legislación laboral en el proceso de reformas estructurales de América Latina y el Caribe", Working Paper, No. 4065, Washington, D.C., Inter-American Development Bank (IDB).

Loyo, M. G. and M. Velásquez (2015), “Inspección laboral en América Latina: mejores prácticas y lecciones", Inter-American Development Bank (IDB), unpublished.

Mesa-Lago, C. (2004), "An appraisal of a quarter-century of structural pension reforms in Latin America", CEPAL Review, No. 84 (LC/G.2258-P), Santiago, Economic Commission for Latin America and the Caribbean (ECLAC). 
Ministry of Justice (2011), “Cuenta sectorial" [online] http://2010-2014.gob.cl/ media/2010/05/JUSTICIA.pdf.

Office of the Minister-Secretary General of the Presidency (2005), "Chile. Constitución (1980). Fija el texto refundido, coordinado y sistematizado de la Constitución Política de la República de Chile" Santiago, 17 September [online] http://www.leychile.cl/Navegar?idNorma=242302.

Singh, A. and others (2005), "Stabilization and reform in Latin America: a macroeconomic perspective on the experience since the early 1990s", Occasional Paper, No. 238, Washington, D.C., International Monetary Fund (IMF).

Tokman, V. (2011), "Informalidad en América Latina: balance y perspectivas de políticas", Revista Internacional de Estadística y Geografía. Realidad, Datos y Espacio, vol. 2, No. 3, Mexico City, National Institute of Statistics and Geography (INEGI).

(2007), "The informal economy, insecurity and social cohesion in Latin America", International Labour Review, vol. 146, No. 1-2, Geneva, International Labour Organization (ILO).

(2004), Una voz en el camino. Empleo y equidad en América Latina: 40 años de búsqueda, Santiago, Fondo de Cultura Económica.

UNICEF (United Nations Children's Fund) (2015), “Definiciones conceptuales para un sistema integral de protección a la infancia", Los Derechos de los Niños, una Orientación y un Limite series, No. 4, Santiago.

Vega Ruiz, M. L. (2009), “La inspección de trabajo en Europa: retos y logros en algunos países seleccionados aún en tiempos de crisis", Working Paper, No. 3, Geneva, International Labour Organization (ILO).

(2005), La reforma laboral en América Latina: 15 años después. Un análisis comparado, Lima, ILO Regional Office for Latin America and the Caribbean [online] http://www.oit.org/wcmsp5/groups/public/---americas/---rolima/---ilo-buenos_aires/documents/publication/wcms_bai_pub_2.pdf.

Velásquez, M. (2016), “Regulación del mercado de trabajo y protección social en países de América Latina", Social Policy series, No. 218 (LC/L.4244), Santiago, Economic Commission for Latin America and the Caribbean (ECLAC). (2011), "Diagnóstico y análisis institucional de ministerios de trabajo en América Latina. Aplicación a los casos de Chile, Colombia, Paraguay y Perú", Technical Notes, No. IDB-TN-349, Washington, D.C., Inter-American Development Bank (IDB).

(2009), "Flexibilidad, protección y políticas activas en Chile", El nuevo escenario laboral latinoamericano. Regulación, protección y políticas activas en los mercados de trabajo, J. Weller (ed.), Buenos Aires, Siglo XXI.

Weller, J. (2009), "Avances y retos para el perfeccionamiento de la institucionalidad laboral en América Latina", El nuevo escenario laboral latinoamericano. Regulación, protección y políticas activas en los mercados de trabajo, J. Weller (ed.), Buenos Aires, Siglo XXI.

World Bank (1995), World Development Report 1995: Workers in an Integrating World, Oxford, Oxford University Press.

(1994), Averting the Old-Age Crisis. Policies to Protect the Old and Promote Growth, New York, Oxford University Press. 


\section{Annex III.A1}

Table III.A1.1

\section{Benefits provided for in ILO Convention No. 102 and in subsequent conventions ${ }^{a}$}

\begin{tabular}{|c|c|}
\hline Branch & Contents \\
\hline Medical assistance & $\begin{array}{l}\text { Convention No. 102: provides for preventive and general medical } \\
\text { care, including home visits, specialist care, the supply of essential } \\
\text { pharmaceutical products as prescribed, and pre-natal and post-natal } \\
\text { care provided by a medical practitioner or a qualified midwife, as well } \\
\text { as hospitalization where necessary. } \\
\text { Convention No. } 130 \text { : establishes the same benefits as Convention } \\
\text { No. } 102 \text {, plus dental care and medical rehabilitation. }\end{array}$ \\
\hline Sickness benefits & $\begin{array}{l}\text { Convention No. 102: periodic payments corresponding to at least } \\
45 \% \text { of previous earnings. } \\
\text { Convention No. } 130 \text { : periodic payments of at least } 60 \% \text { of previous } \\
\text { earnings. Also the payment of funeral expenses in the case } \\
\text { of the death of the beneficiary. }\end{array}$ \\
\hline Unemployment benefits & $\begin{array}{l}\text { Convention No. 102: periodic payments corresponding to at least } \\
45 \% \text { of previous earnings. } \\
\text { Convention No. 168: periodic payments of at least } 50 \% \text { of previous } \\
\text { earnings. Possibility of applying special calculation rules after the } \\
\text { qualifying period. The set of benefits to which the unemployed may } \\
\text { be entitled must guarantee healthy and reasonable living conditions } \\
\text { in accordance with national standards. }\end{array}$ \\
\hline Old-age benefits & $\begin{array}{l}\text { Convention No. 102: periodic payments corresponding to at least } \\
40 \% \text { of previous earnings. Obligation to review the rates of the relevant } \\
\text { benefits following substantial changes in the general level of earnings } \\
\text { or in the cost of living. } \\
\text { Convention No. } 128 \text { : periodic payments corresponding to at least } \\
45 \% \text { of previous earnings. The same conditions as Convention } \\
\text { No. } 102 \text { in relation to the review of rates. }\end{array}$ \\
\hline $\begin{array}{l}\text { Benefits in the event of a } \\
\text { workplace accident and } \\
\text { occupational disease }\end{array}$ & $\begin{array}{l}\text { Convention No. 102: medical assistance, periodic payments } \\
\text { corresponding to at least } 50 \% \text { of previous earnings in cases of } \\
\text { incapacity for work or disability; benefits for widows or dependent } \\
\text { children in case of the death of the breadwinner, with periodic } \\
\text { payments corresponding to at least } 40 \% \text { of previous earnings. } \\
\text { Possibility of commuting periodic payments into a lump sum, under } \\
\text { certain conditions. Except in the case of inability to work, the periodic } \\
\text { payment rates will be reviewed following substantial changes } \\
\text { in the cost of living. } \\
\text { Convention No. } 121 \text { : same as Convention No. 102, plus several types of } \\
\text { assistance in the workplace. Periodic payments corresponding to at least } \\
60 \% \text { of previous earnings in cases of incapacity for work or disability, } \\
\text { benefits for widows or for dependent children, in case of the death of the } \\
\text { breadwinner, with periodic payments corresponding to at least } 50 \% \text { of } \\
\text { previous earnings. Obligation to prescribe a minimum amount for these } \\
\text { payments, possibility of commuting payments into a lump sum under } \\
\text { certain conditions and complementary benefits for disabled persons } \\
\text { requiring the constant help or attendance of another person. }\end{array}$ \\
\hline Family benefits & $\begin{array}{l}\text { Convention No. 102: periodic payments or provision of food, clothing, } \\
\text { housing, holidays or domestic help, or a combination thereof. }\end{array}$ \\
\hline
\end{tabular}


Table III.A1.1 (concluded)

\begin{tabular}{ll}
\hline Branch & Contents \\
\hline Maternity benefits & Convention No. 102: medical care which must include, at least, \\
pre-natal, confinement and post-natal care provided by a medical \\
practitioner or a qualified midwife, as well as hospitalization where \\
necessary; periodic payments corresponding to at least \\
45\% of previous earnings. \\
Convention No. 183: medical benefits that must include pre-natal, \\
confinement and post-natal care, as well as hospitalization where \\
necessary; cash benefits at a level that ensures that the woman can \\
maintain herself and her child in proper conditions of health and with \\
a suitable standard of living. At least two thirds of previous earnings, \\
or a comparable amount. \\
Convention No. 102: periodic payments corresponding to at least \\
40\% of previous earnings; obligation to review the amounts of the \\
relevant benefits, following substantial changes in the general level \\
of earnings or in the cost of living. \\
Convention No. 128: periodic payments corresponding to at least \\
Disability benefits \\
substantial changes in the general level of earnings or cost of living. \\
Obligation to provide rehabilitation services and take measures to \\
further the placement of disabled persons in suitable employment. \\
Convention No. 102: periodic payments corresponding to at least \\
40\% of previous earnings; obligation to review these amounts following \\
substantial changes in the general level of earnings or cost of living. \\
Convention No. 128: periodic payments corresponding to at least \\
$\begin{array}{l}45 \% \text { of previous earnings; obligation to review these amounts } \\
\text { following substantial changes in the general level of earnings } \\
\text { or in the cost of living. }\end{array}$ \\
\hline Survivor benefits
\end{tabular}

Source: Prepared by the author, on the basis of International Labour Organization (ILO), "Ratification by convention", NORMLEX Information System on International Labour Standards, 2015 [online] http://www.ilo.org/dyn/normlex/en/f?p=NORMLEXPUB:12001:0::NO::.:.

a This information does not include provisions on the duration of the benefits or on entitlement conditions. Nor does it cover the exceptions allowed under these instruments or higher benefit levels in the relevant recommendations. 



\section{Chapter IV \\ Institutional aspects of Latin America's pension systems}

Andras Uthoff ${ }^{1}$

\section{Introduction ${ }^{2}$}

United Nations Secretary-General Ban Ki-moon said that addressing demographic change, in particular the rising number of older persons in the world, is an obligation. He called for the barriers restricting the full participation of older people in society to be lifted and for their rights and dignity to be afforded protection.

Deciding how to design and implement pension systems to sustain quality pensions over the long term is an issue of common interest across the world. The solution, however, depends on the context in which the system is to operate and on the institutional framework that supports it. This chapter addresses those issues.

Consultant with the Social Development Division of the Economic Commission for Latin America and the Caribbean (ECLAC).

2 This chapter is based on the document "Aspectos institucionales de los sistemas de pensiones en América Latina", prepared by Andras Uthoff with assistance from Fabiana Pierre, both of whom are consultants with the ECLAC Social Development Division; see Uthoff (2016). 
Pension systems are part of the social security component of social protection policy ${ }^{3}$ (also called welfare or social insurance). ${ }^{4}$ Their purpose is to even out consumption over the life cycle, to provide income following invalidity or the death of a breadwinner and to alleviate poverty in old age. Such systems must adapt to various contexts that differ, essentially, in terms of their demographics, their members' working conditions, the role assigned to the State in collecting and managing funds and the level of economic and institutional development attained by the country in question. In designing them, countries must choose from various alternatives as regards: (i) their sources of funding, (ii) the financial management model used, (iii) how their benefits are defined, (iv) how the system is managed, and (v) the redistribution of resources to the most needy. They require institutions to deliver benefits, to regulate them and to oversee the sustainability of their operations over time.

In line with the contents of chapter I, which dealt with the four dimensions of the institutional framework, this chapter analyses the institutional developments that pension systems require. Examining them is intended to ensure that the performance of each system reconciles the logic of its funding with that of the principles of social security and guarantees that, over the course of several generations, the risks to which the system's functioning is vulnerable (arising from funding, demographic change, economic and financial crises) can be overcome.

The evidence examined herein shows that in all the progress made, the dimensions of the institutional framework are not exclusive and must be combined. It concludes that an ongoing effort is needed both to ensure the system's solvency and sustainability over time and to guarantee universal access to decent ${ }^{5}$ and accessible benefits. ${ }^{6}$

In addition to this introduction, the work is divided into three sections. The first describes the challenges facing the design of a pension system and the options that exist. The second highlights the importance of the institutional developments adopted and how they respond to future challenges. The third section, containing final comments, is intended as a conclusion.

A concept used in political and economic science to define a political proposal or general model of the State and of how society is organized, according to which the State provides services in fulfilment of social rights to all the country's inhabitants.

4 According to the International Labour Organization (ILO), social insurance or social welfare is the protection that society extends to its members, by means of a series of public measures, to counter economic and social privations that would otherwise lead to the disappearance of income, or a significant reduction thereof, on account of sickness, maternity, workplace accidents, occupational illnesses, unemployment, invalidity, old age and death. It also provides protection in the form of medical care and assistance for families with children.

5 This refers to the right of access to a level of benefits that the system grants to a citizen and that society establishes for compliance with civic duties and for addressing the demands of retirement, invalidity or survivorhood.

6 This means that they can be attained or secured through the way in which the system works. 


\section{A. Pension system and social security}

Public pension systems are a part of a country's contributory social protection or social security framework. ${ }^{7}$ They are designed to guarantee social benefits in the form of pensions in the event of: (i) worker disability, (ii) the death of workers who were their families' breadwinners, in order to provide for their dependants, (iii) workers reaching the age when society has decided they are eligible to stop working and to live on a pension associated with their employment histories, and (iv) people affected by old age and invalidity who are without the incomes needed for sustenance (poverty relief).

As part of social security, public pension systems are based on foundations that create an organization, an institution or an ideal based on six principles without which it would lose its identity and its reason for existence: universality, equality, solidarity, integrity, unity and financial sustainability (see box IV.1).

Box IV.1

Fundamental principles of social security

\section{Universal coverage}

Universality may be interpreted from two perspectives: a subjective perspective whereby everyone must be covered by social security, a principle that arises from its nature as a basic human right; and an objective one whereby social security must cover all the contingencies (risks) faced by a person living in society.

This principle is related to the current focus of social security: the lack of coverage for certain contingencies faced by citizens.

\section{Equality, equity or uniform treatment}

This principle, which is not exclusive to social security, means that all persons must enjoy equal protection from a given contingency. Taking social and economic inequalities into account, the treatment given must be such that the benefit provided adequately covers the risk in question, regardless of any inequality that may exist.

It can also be defined as equality of treatment, in that it means that all humans, as such, have the right to social security and prohibits all discrimination on the grounds of race, colour, sex, language, religion, political or any other opinion, national or social origin, economic status or any other factor.

\section{Solidarity and income redistribution}

This principle is essential in distinguishing between a social security system and private insurance. All persons contribute to the social security system according to their capacity to contribute and receive benefits in accordance with their needs. This is an essential tool in meeting the central objective: redistributing wealth with social justice. 
Box IV.1 (concluded)

Solidarity can be that of the healthy towards the sick, of the young towards the elderly (intergenerational or horizontal) and also between people with different incomes, from those who have more to those who have less (intragenerational or vertical). Geographical solidarity also exists, between those regions that have more resources and others that are poorer.

\section{Integrity and adequacy of benefits}

The benefit provided must cover the contingency in a full and timely fashion: it must respond to the actual needs of the sector for which it is intended, with dignity, timeliness and effectiveness.

\section{Unity, State responsibility, efficiency and participatory management}

Unity, State responsibility and efficiency imply a system in which all official, semi-official and private institutions involved in the field of social welfare implemented by the State act with a degree of unity or coordination in order to prevent duplications of efforts and administrative inefficiencies.

Participation means that society is involved in the administration and leadership of social security through its representative organizations and also through its funding. The ILO Social Security (Minimum Standards) Convention of 1952 (No. 102) deals with participation by workers' representatives and possibly by employers. In broad terms, participation (informative, consultative, advisory or administrative) means that the opinions of all those affected by social security in any way are heard.

\section{Financial sustainability}

The social security plan must be financially viable in accordance with the country's economic capacity. It must also be implemented by stages, but as part of a general plan, indicate the priorities in its implementation and make progress when resources are available.

Source: Prepared by the author, on the basis of conventions and recommendations of the International Labour Organization (ILO).

It is interesting to note that the regulatory framework governing the principles of social security includes the solvent and sustainable funding of its benefits. That requires the reconciliation of its social objectives with the economic demands of its funding; in particular, the design of direct and indirect taxation mechanisms that, essentially:

- Attain their social objective of providing decent benefits for old age, invalidity and survivorhood, and

- Are in tune with macroeconomic policy, in that they do not bring pressure to bear on the competitive capacity of the workforce, do not increase the country's fiscal burden beyond what is authorized by its agreements governing fiscal responsibility and do not distort the demand for financial instruments. 
This creates a public-policy challenge. Given the enormous inequalities and budgetary constraints that still characterize the economies of Latin America, the design of a pension system must be grounded on a broad social contract. That compact must serve to reconcile the principle of equivalence (in other words, it must be actuarially solvent over time) with the principles of universality and solidarity (it must include cross subsidies from those able to save to those who cannot) in order to ensure access to decent benefits for all. This is not a new task. It can be seen in a series of agreements that, over the course of time, have been suggested in response to the choices made by the authorities among the options that exist for designing a pension system.

\section{Pension system design options}

Systems designed to provide pension benefits and uphold rights are the result of choices among at least five relevant issues. These are listed below, and all involve major institutional developments.

(i) Participation of the affiliate in funding: whether or not citizens must contribute funds to participate in the system. Three models exist:

- In a contributory system, affiliates must make regular contributions.

- In the non-contributory model, affiliates are not required to contribute directly to the system, which is instead funded from other sources.

- A combination of those two models.

(ii) Financial management of resources. The funds accumulated by the system and that are used to pay for pensions can be managed in two opposing ways:

- Pay-as-you-go: a compact between generations in which the economically active contribute to the system to pay for the pensions of those who have already retired and for the accumulation of an intertemporal reserve fund. It equates to a collective fund that accrues with a general or tiered average premium and is assigned by means of predetermined benefit rules.

- Funded: a savings account is established for every active worker affiliated to the system, in which their contributions are deposited and capitalized on for their personal use upon retirement. The pension is then determined by the amount accumulated 
(principal and interest) and other parameters. ${ }^{8}$ This alternative is actuarially fair for the individual but lacking in solidarity. To remedy that, it must be supplemented with other mechanisms.

(iii) Rules for the granting of benefits. The benefits established by the system must be determined in some way. Two extreme alternatives exist:

- The defined benefit plan establishes a rule for determining benefits based on clear standards related to the worker's employment history. Thus, the benefit is determined by a formula that uses a range of factors, including the worker's salary, years of service and retirement age. ${ }^{9}$

- In a defined contribution plan, the contributions made for each affiliate (by the employee, the employer or both) are predetermined, but the amount of the pension is unknown until it is calculated upon retirement. Under a typical defined contribution agreement, contributions are deposited in an account that grows through investments in authorized financial instruments. Upon retirement, workers have an accrued fund in accounts that they own, which can be used to purchase a pension. The accrued funds are generally portable, so they can be voluntarily moved between different fund administrators. The cost of a defined contribution plan is easy to calculate, but the plan's benefits depend on the balance in the worker's account when he or she decides to make use of the funds. The invested contributions follow economic cycles (recessions and depressions, expansions, booms, slumps and decelerations), and so the benefit cannot be calculated in advance. Under a regime of individual financial savings accounts (such as the Chilean model), all risks are assumed by the contributors themselves. Under a virtual (notional) funded regime, the sponsor (the State) assumes those risks (for example, in the Swedish model).

(iv) Public or private administration. Although a public pension system is the responsibility of the State, its management can be entrusted to third parties, such as industry associations, private administrators or other entities. There are two extreme alternatives for system management, but the State invariably bears final responsibility.

Funding is full, but individual. It is used as an mandatory savings scheme for retirement, but it does not cover contingencies. The worker must have additional insurance for invalidity and death and, at the end of the savings period, the amount saved is used to purchase a lifelong annuity or a programmed withdrawal.

9 Those factors can be used as adjustment criteria for updating the benefit to cover inflation, including social security services or incentives for early retirement, or continuing to work. 
- State administration, when the State itself or some dependent body handles the system's functioning.

- Private administration, when a private third party manages the system, an arrangement that requires a high level of State regulation and oversight.

(v) Distribution mechanisms. When workers find themselves facing invalidity, death (with the survival of a dependant) or old age, it is possible that they have not yet met the requirements for receiving a pension or are in a situation of poverty. In such cases, two options exist:

- Distributive, when the system has a cross-subsidy component or receives funds from other sources to relieve poverty in cases of invalidity, survivorhood and old age.

- Non-distributive, when the system is not equipped with a poverty relief component and people have to make use of welfare policies.

Box IV.2 details the different pay-as-you-go mechanisms used in pension systems.

Box IV.2

Different pay-as-you-go mechanisms

The term "pay-as-you-go" is used when pensions are paid for with current revenue. Nevertheless, when referring to the funding mechanism, that revenue feeds into a fund from which future pensions are paid. It is therefore useful to distinguish between:

- Pay-as-you-go pensions: Those paid for (usually by the State) from current tax income and not from an accumulated fund.

- Collectively funded pay-as-you-go schemes: Defined benefit regimes in which benefits are paid for through an intergenerational compact. The active generation contributes premiums that pay for the benefits of the generation that is already retired and to build a reserve fund for future contingencies. Such systems are said to operate on the basis of indebtedness between generations, with each successive generation of young people committed to contribute for current retirees. The scheme operates with a technical reserve through which contributions can be determined, with two extreme alternatives:

- General average premium: A constant contribution rate is set from the onset, which enables its financial viability to be assured indefinitely. The premium is set at a level necessary for the current value of all likely future income to be equal to the current value of all probable future costs. During an initial phase (several decades), income outstrips expenditure, and the surplus goes into the technical reserve. In the future, when costs exceed premiums (expenditure outstrips revenue from contributions), earnings and part of the reserve are used to cover the difference. 
Box IV.2 (concluded)

- Staggered average premium: Equilibrium periods of between 10 and 15 years are used, on the basis of which premiums are modified. This is a pay-as-you-go regime where premiums change as actuarial evaluations demand adjustments to adapt to increased spending as a result of new cases, increased years of coverage, greater life expectancy or unforeseen readjustments. It is a mid-point between simple pay-as-you-go and general average premiums, in that: (a) it defines equilibrium periods during which premiums remain unchanged, (b) it guarantees financial balance during individual periods before moving on to the next step, (c) funds accrue, but to a lesser extent than in general average premium systems, and (d) the interest earned by the reserve is used to fund spending.

- Simple collectively funded pay-as-you-go schemes: A simple payas-you-go regime entails yearly assessments of the cost of benefits and establishing the level of funding needed to cover them, with the additional possibility of providing a reserve for contingencies.

- Pay-as-you-go schemes using individual accounts and notional funding: A defined contribution regime that is funded by contributions from active workers and uses a social compact to determine how pay-as-you-go contributions are capitalized. In such models: (a) the individual is not guaranteed a specific level of benefit, (b) records of contributions for retirement are kept, but rather than being invested they are accrued in accordance with indicators of the economy's performance (real wage increases, productivity increases or others), (c) at the end of the period, the capitalized amount is used to provide a lifelong or temporary benefit and (d) complementary insurance for invalidity and death must be acquired. This alternative is actuarially fair for the individual and the readjustment formula can be modified to establish mechanisms to ensure solidarity, so that productivity gains are redistributed among all.

Source: Prepared by the author.

\section{Classification of pension systems}

Customarily, the models for organizing, funding and determining benefits are classified into four groups according to their historical origins.

- The first is social insurance, called Bismarckian. ${ }^{10}$ It involves a system of tripartite contributions (from the workers, their employers and the State), managed by a State-administrated pay-as-you-go regime with defined benefits. In the absence of a poverty relief component, that goal is attained by means of welfare policies. This is the predominant system in Latin America, but with low rates of coverage on account of the high levels of informality in the labour market.

10 Named for first person to implement such a system, German Chancellor Otto von Bismarck. 
- The second type is Beveridgean social security. ${ }^{11}$ This is a non-contributory system, funded solely by general revenue, administered by the public budget (transfers), with defined benefits, managed by the State and with a poverty relief component. Such systems have been limited in Latin America on account of low tax bases and revenues available to fund them.

- The third, the individual account funded model, was promoted by international financial institutions in the 1990s. Faced with the imminent prospect of demographic change, the shortage of long-term financial saving and the political and demographic risks threatening pay-as-you-go systems, those institutions suggested modifying the financial management methods of the original contributory systems. This is done through the accrual of funds in individual accounts on the basis of defined contributions. ${ }^{12}$ Administration is private, although regulated and supervised by the State, and there is no poverty relief component. The functioning of this model has failed due to obstacles in addressing informal economic activities and the absence of cross-subsidies to support those with a low capacity for saving (low levels of taxable income and limited density of contributions). In addition, a series of conflicts have arisen in the regulation and the oversight of fund administration companies.

- The fourth type is the mixed or multipillar scheme, which arose in response to the lessons learned with each of the earlier models. With this goal, and to solve the problems of exclusion (inequality), inefficiency and insolvency, combinations of the different alternatives have been suggested. There are systems that combine contributory and non-contributory mechanisms and pay-as-yougo with funding, deliver pensions based on both defined benefits and defined contributions, are managed financially through capitalization and the management of the State budget and work for a suitable blend of State and private administration (and, by so doing, strengthen competitive mechanisms) and redesign the poverty relief component by encouraging work and saving.

Table IV.1 shows examples of countries that, in one way or another, have adopted one of these categories. ${ }^{13}$

From Lord Beveridge, who introduced it in the United Kingdom.

Only the contribution is defined, and the benefit is the result of the final accrued funding of each individual account.

13 Although each option is presented in a binary form, intermediate solutions are also possible. 
Table IV.1

Options for the design of a pension system

\begin{tabular}{|c|c|c|c|c|c|}
\hline Options & $\begin{array}{l}\text { Beveridge } \\
\text { Universal } \\
\text { pension }\end{array}$ & $\begin{array}{l}\text { Bismarck } \\
\text { Public pay- } \\
\text { as-you-go }\end{array}$ & $\begin{array}{l}\text { Individual } \\
\text { funded }\end{array}$ & $\begin{array}{l}\text { Mixed or } \\
\text { parallel }\end{array}$ & $\begin{array}{l}\text { Notional } \\
\text { funding }\end{array}$ \\
\hline \multicolumn{6}{|c|}{ Participation in funding } \\
\hline Contributory & & $x$ & $x$ & $x$ & $\mathrm{x}$ \\
\hline Non-contributory & $\mathrm{x}$ & & & $x$ & \\
\hline \multicolumn{6}{|c|}{ Financial management } \\
\hline Pay-as-you-go & $x$ & $x$ & & $x$ & $x$ \\
\hline $\begin{array}{l}\text { Saving and } \\
\text { capitalization }\end{array}$ & & & $x$ & $x$ & \\
\hline \multicolumn{6}{|l|}{ Benefits } \\
\hline Defined benefits & & $\mathrm{x}$ & & $\mathrm{x}$ & \\
\hline $\begin{array}{l}\text { Defined } \\
\text { contributions }\end{array}$ & & & $x$ & $x$ & $x$ \\
\hline \multicolumn{6}{|l|}{ Administration } \\
\hline State & $\mathrm{x}$ & $x$ & & $\mathrm{x}$ & $\mathrm{x}$ \\
\hline $\begin{array}{l}\text { Private, regulated } \\
\text { and supervised }\end{array}$ & & & $x$ & $x$ & \\
\hline \multicolumn{6}{|l|}{ Redistributive role } \\
\hline $\begin{array}{l}\text { Guaranteed } \\
\text { minimum (GM) }\end{array}$ & $x$ & $\mathrm{x}$ & $x$ & $x$ & $x$ \\
\hline $\begin{array}{l}\text { GM plus poverty } \\
\text { relief }\end{array}$ & & & $\mathrm{x}$ & & $\mathrm{x}$ \\
\hline Examples & $\begin{array}{l}\text { New Zealand } \\
\text { and rural } \\
\text { Brazila }^{\mathrm{a}}\end{array}$ & $\begin{array}{l}\text { Ecuador, } \\
\text { Nicaragua, } \\
\text { Bolivarian } \\
\text { Republic of } \\
\text { Venezuela, } \\
\text { and Brazil } \\
\text { (Special } \\
\text { Social Welfare } \\
\text { Regime } \\
\text { (RPPS)) }\end{array}$ & $\begin{array}{l}\text { Plurinational } \\
\text { State of } \\
\text { Bolivia, Chile, } \\
\text { El Salvador, } \\
\text { Mexico, } \\
\text { Dominican } \\
\text { Republic } \\
\text { and Brazil } \\
\text { (complementary } \\
\text { pension) }\end{array}$ & $\begin{array}{l}\text { Argentina } \\
\text { (before } \\
2008), \\
\text { Colombia, } \\
\text { Peru, } \\
\text { Uruguay, } \\
\text { Costa } \\
\text { Rica and } \\
\text { Panama }\end{array}$ & $\begin{array}{l}\text { Sweden, } \\
\text { Brazil } \\
\text { (General } \\
\text { Social Welfare } \\
\text { Regime } \\
\text { (RGPS), } \\
\text { adaptation) }\end{array}$ \\
\hline
\end{tabular}

Source: Prepared by the author.

a Assistance Programme for Rural Workers (PRORURAL)/Assistance Fund for Rural Workers Rural (FUNRURAL), which provides pensions - albeit precarious ones - to rural workers, fishers and mineral prospectors (garimpeiros) aged 65 years and over. However, the pension is exclusively for the head of the household with a ceiling of one multiple of the minimum wage.

b General Social Welfare Regime, using the logic of the Welfare Calculation Rule, which correlates the amount collected from contributions with the pension.

\section{B. Institutional challenges}

As a State policy that transcends individual governments, a pension system must be based on constitutional values and be adaptable to the obstacles that reality invariably places on the achievement of its objectives. Accordingly, the institutional framework built on the basis of the options outlined above presupposes the implementation of a system based on the principles of social security. Since universal access 
to decent benefits as a way of ensuring ownership of social rights is the rationale pursued by social protection policy, one fundamental question arises: how can access to decent pensions for people with a low capacity for saving be permanently guaranteed in a financially sustainable system?

In earlier works, ECLAC has underscored the importance of solidarity, such as when it stated: "The structural changes reflected in the current situation call for a fresh approach to social protection within a framework of integral solidarity that combines contributory and non-contributory mechanisms. A new social covenant must therefore be formed in which social rights are seen as the normative horizon and existing inequalities and budgetary restrictions are the limiting factors to be addressed. In other words, the ethical imperatives that underpin a social-rights-based covenant must be reconciled with existing financial constraints. Emphasis must also be placed on efficient resource use with a view to expanding the coverage and raising the quality of services, especially for the lowest-income sectors of the population." (ECLAC, 2006, p. 12.)

Thus, two kinds of institutional development needs arise. First of all, to achieve the fundamental objectives of the system: reconciling efficiency and solidarity and protecting the system from the risks that could affect its functioning and its results. Then, to address the four dimensions of the institutional framework (see chapter I): (i) the legal and regulatory, emphasizing a legal framework that can support the entire social security structure (contributory and non-contributory pillars), (ii) the organizational, aimed at establishing a pensions authority that can interconnect and converse with all government agencies and system participants, (iii) the technical and operational, in which transparency, civic participation and accountability are the main management tools for shifting the institutional framework of the pension system in a more democratic and inclusive direction, and (iv) the funding dimension, to ensure solvency and fiscal balance in the face of demographic change, investment risks and the economic cycle.

\section{Elements for resolving the conflict between efficiency and solidarity}

Assessing a pension system is matter of both regulations and method. First of all, systems must be fair and promote equity along their two dimensions (vertical and horizontal). From the viewpoint of vertical equity, a case could be made for subsidizing people who face economic problems and are unable to contribute. In contributory systems, however, 
contributions must be encouraged, which must be done by maintaining a degree of equivalence between how much is contributed and how much is received. From the viewpoint of horizontal equity, two individuals with similar work and welfare histories should receive the same benefits.

Secondly, once the regulatory framework has been decided on, the chosen methods work for efficiency by attaining the goals set at the lowest cost to contributors. That means a system that protects the individual in the best way possible from risks that could affect its operation.

As regards this challenge, pension systems as a component of social protection policy are at a critical juncture that demands a new approach. That requires acknowledging that those solidarity-based mechanisms established for social protection and based exclusively on the labour market (Bismarckian social insurance models) have failed in guaranteeing inclusiveness. The creation of formal, stable, decent work and the levels of contribution attained have not succeeded in reaching the levels of funding needed to ensure universal coverage.

Tables IV.2 and IV.3 indicate areas of commonality in all the experiences reported by the International Federation of Pension Funds Administrators (FIAP) in which contributions were encouraged by emphasizing the defined contributions argument and the concept of contribution ownership. For example, although enrolment by a significant percentage of the economically active population (EAP) was achieved, only a fraction of that population contributes regularly. ${ }^{14}$ In Latin America, high rates of poverty, unemployment and underemployment (associated with informality), together with the scant existence of countercyclical social protection policies (in particular, unemployment insurance) mean that large sectors of the economically active population spend lengthy periods of their working lives underemployed or unemployed and, as a result, unable to contribute. Consequently, the members of those sectors have welfare histories with low contribution densities, which constrains their ability to self-fund their pensions. This is compounded by the incompatibility of roles among those who work in the home and perform care duties and their potential within the labour market, a factor that generally has a discriminatory impact on access to contributory social protection by women. It can therefore be expected that over the course of their working lives, many affiliates in contributory systems experience major welfare shortcomings that prevent them from saving enough to self-fund their pensions.

14 Comparisons of membership numbers must be conducted with care. In some countries, defined contribution (DC) systems are not mandatory, except for high-income persons with stable jobs (for example, in Uruguay and Costa Rica, which have mixed systems). In others, members choose between defined contribution (DC) and defined benefit (DB) plans (Peru and Colombia, which have parallel systems). 
Table IV.2

Latin America and the Caribbean (10 countries): coverage indicators for defined contribution systems, by affiliated members

(Affiliated members as a percentage of the economically active population)

\begin{tabular}{lrrrrr}
\hline $\begin{array}{l}\text { Compulsory systems } \\
\text { in Latin America }\end{array}$ & 2011 & 2012 & 2014 & 2015 & $\begin{array}{c}\text { Variation between } \\
\text { 2011 and 2015 }\end{array}$ \\
\hline Bolivia (Plurinational State of) & 34.53 & 28.17 & 29.14 & 31.48 & 3.05 \\
\hline Chile & 110.20 & 113.09 & 114.29 & 115.35 & 5.15 \\
\hline Colombia & 43.59 & 46.57 & 52.44 & 54.34 & 10.75 \\
\hline Costa Rica & 94.57 & 97.78 & 112.81 & 118.34 & 23.77 \\
\hline Dominican Republic & 51.72 & 55.13 & 58.32 & 60.99 & 9.27 \\
\hline El Salvador & 100.19 & 107.24 & 94.53 & 98.07 & -2.12 \\
\hline Mexico & 85.75 & 87.30 & 89.28 & 88.80 & 3.05 \\
\hline Panama & 24.40 & 24.20 & 15.41 & 15.91 & -8.49 \\
\hline Peru & 22.84 & 24.01 & 34.93 & 36.37 & 13.53 \\
\hline Uruguay & 64.54 & 68.53 & 73.84 & 76.50 & 11.96 \\
\hline $\begin{array}{l}\text { Simple average for } \\
\text { Latin America }\end{array}$ & 63.23 & 65.20 & 67.50 & 69.62 & 6.39 \\
\hline
\end{tabular}

Source: International Federation of Pension Funds Administrators (FIAP), Los sistemas de pensiones multipilares: invirtiendo en el futuro, Santiago, 2016.

Note: Values above $100 \%$ are because double membership is possible and persons already receiving benefits are included.

Table IV.3

Latin America and the Caribbean (8 countries): coverage indicators for defined contribution systems, by contributing members

(Contributing members as a percentage of the economically active population)

\begin{tabular}{lrrrrc}
\hline $\begin{array}{l}\text { Mandatory systems } \\
\text { in Latin America }\end{array}$ & 2011 & 2012 & 2014 & 2015 & $\begin{array}{c}\text { Variation between } \\
\text { 2011 and 2015 }\end{array}$ \\
\hline Chile & 61.61 & 63.89 & 59.73 & 64.54 & 2.87 \\
\hline Colombia & 18.81 & 18.91 & 22.04 & 20.83 & 2.02 \\
\hline Costa Rica & 42.19 & 41.89 & 48.94 & 50.74 & 8.65 \\
\hline Dominican Republic & 24.49 & 25.50 & 27.95 & 29.45 & 4.96 \\
\hline El Salvador & 27.38 & 28.44 & 23.62 & 24.26 & -3.12 \\
\hline Mexico & 28.49 & 29.29 & 29.91 & 30.00 & 1.51 \\
\hline Peru & 9.90 & 11.37 & 15.37 & 15.79 & 5.89 \\
\hline Uruguay & 40.69 & 43.26 & 45.88 & 42.22 & 1.53 \\
\hline $\begin{array}{l}\text { Simple average for } \\
\text { Latin America }\end{array}$ & 31.70 & 32.82 & 34.18 & 34.74 & 3.04 \\
\hline
\end{tabular}

Source: International Federation of Pension Funds Administrators (FIAP), Los sistemas de pensiones multipilares: invirtiendo en el futuro, Santiago, 2016.

Regardless of the need for policies to create more and better jobs, it is unlikely that the short or medium term will see enough employment to serve as a mechanism for protecting the majority of the population from the risks of insufficient income, health care and ageing. For that reason, a combination of the three methods described is essential. 
Consequently, several countries embarked on structural reforms that changed the way their systems were funded, how those funds were managed and the way in which the rights and obligations of affiliates were correlated..$^{15}$ Although the importance of the options described in this document was highlighted, the major challenges facing the systems in reconciling efficiency with equality was also made apparent.

The institutional developments needed to ensure access to decent pensions for all, including people with a low capacity for saving, have followed three paths:

- The interconnection of contributory and non-contributory funding;

- The organization of cross-subsidies, either implicitly or explicitly, from persons or economic agents with a high capacity for savings to those with lower capacities; and

- The definition of decent benefits in response to the rights arising from being a citizen or having contributed financially to the system.

\section{(a) The interconnection of contributory and non-contributory funding}

Social protection responds to two sets of logic, according to the type of relationship existing between its funding model and its benefits: one that correlates the retirement amount due to each participant in the system with the contributions made during the active stage, and one that makes use of taxes or cross-subsidies.

In the first instance, the individual expects a clear correlation between what he or she contributes to the social security system and the benefits received from it. What it entails, therefore, is contributory funding and access to benefits in line with the contributions made. The extreme case is a mandatory individual savings account.

The second case involves non-contributory funding and access to a benefit that bears no relation to the contributions made. That allows progress to be made towards equitable benefits. The most tangible expression of this is social assistance. Taxpayers contribute through general taxation, and the benefits bear no direct relation to contributions. This model works as a redistribution mechanism: that is, by channelling transfers from those who have the most to those with lower incomes.

15 During the 1990s, the main reforms involved changing from a pay-as-you-go pension system to the total or partial introduction of individual funded systems, and that was the path chosen, for example, in Argentina, the Dominican Republic, Chile (in 1981), El Salvador, the Plurinational State of Bolivia and Uruguay. At that juncture the new paradigm was instituted, with the support of the international financial institutions under the conditions set by those countries' debt renegotiation programmes. 
Specifying which rights are assured and to what extent -and, consequently, what risks society is willing to assume as a collective responsibility - leads to the explicit definition of the public goods over which the State assumes irreplaceable and non-transferable responsibility. That definition is independent of whether the provision of those goods is entrusted to a public institution or to a private one.

Within that framework, a social contract or compact that stipulates the acceptable standards of social protection for all citizens will always assume a position along a line running between the extremes of individual equity (understood as a direct correlation with the contributions made by each individual) and social equality (in other words, the social optimization of benefits from the entire universe of contributions). The ideal balance, which interconnects contributory and non-contributory funding, is one that allows the efficient mobilization of a maximum amount of resources to ensure access to decent levels of pensions for all.

\section{(b) The organization of cross-subsidies}

There are two broad categories of subsidies that ensure decent pensions during old age for people with low incomes and a low capacity for saving. These are explicit subsidies on the benefits received and implicit cross-subsidies. They can operate simultaneously or separately.

Explicit subsidies are cash transfers to persons with a low capacity for saving. During the contributory stage, they can take the form of coupons, tax exemptions, tax credits and employers' contributions. During the passive stage, income transfers can be made to the system's potential or actual beneficiaries who are facing poverty. Subsidies can be organized by the system's sponsor (usually, the State), so that their origin and funding is known, and they can be focused on addressing specific situations.

The system can also be designed in a way that implicitly creates subsidies from those with a high capacity for saving to those with low levels of savings. This generally requires careful regulation of the defined benefits formula.

\section{(c) Decent benefits from citizen and contributory rights ${ }^{16}$}

A pension system based on social citizenship requires an inclusive institutional framework that guarantees all persons the same opportunities to participate in its benefits, in its duties and in the decisions taken regarding its orientation. In other words, through

16 Based on ECLAC (2015, ch. I). 
the deliberate action of the State, the enforced entitlement to rights is demanded by means of a process of participation and inclusion and a brake on economic inequalities.

Given that ensuring entitlement to economic, social and cultural rights requires resources, institutions and public capacities, its enforcement can only be shaped and increased over time, and it varies from one society to another. In addition, it requires a system that gradually improves its institutions, expands the provision of resources and assets and makes progress with the processing of social demands. A permanent definition of what the social rights of persons with disabilities, senior citizens and survivors translate into is needed. In other words, the range of benefits and access to which all potentially eligible persons can aspire on account of their status as citizens must be known, as must the deadlines set by society for achieving full entitlement.

This demands progress in the different fields of intervention in the political arena, such as social policy, tax structures, the size and focus of social public spending and its effects in terms of redistribution and expanded opportunities for a decent life during old age. Progress is also needed in mitigating social costs through the application of countercyclical policies to counteract economic volatility, and in administrative efficiency to optimize the effects of social protection and inclusion policies and programmes on the population living in or vulnerable to poverty. Policies to ensure protection of the family, the care of the elderly and increased possibilities for women to enter the job market must be established.

\section{(d) Practical experiences}

Various ongoing reforms seek to adapt the institutional designs of pension systems to the challenge of reconciling financial sustainability with the solidarity needed to ensure decent benefits for all. Table IV.4 provides an overview of some recent experiences with reform processes. It shows that, on the basis of the three paths described, this concern is a reality in the region.

It is interesting to note that the different experiences with pension system design intended to produce a broader approach to social security combine these paths through the construction of pillars, levels or regimes that are not always well interconnected or integrated. 
Table IV. 4

Initiatives to reconcile equivalence between contracts and solidarity

\begin{tabular}{|c|c|c|c|}
\hline & $\begin{array}{l}\text { Through interconnecting } \\
\text { contributory and non- } \\
\text { contributory funding }\end{array}$ & $\begin{array}{l}\text { Through the } \\
\text { organization of } \\
\text { cross-subsidies }\end{array}$ & $\begin{array}{l}\text { Through decent citizen } \\
\text { and contributory } \\
\text { benefits }\end{array}$ \\
\hline $\begin{array}{l}\text { Legal and } \\
\text { regulatory } \\
\text { dimension }\end{array}$ & $\begin{array}{l}\text { Nature of the benefit: } \\
\text { - Individual contracts } \\
\text { - Mandatory (Chile, } \\
\text { Dominican Republic, } \\
\text { El Salvador, Mexico and } \\
\text { Plurinational State } \\
\text { of Bolivia) } \\
\text { - Voluntary (Brazil) } \\
\text { - Optional (Colombia } \\
\text { and Peru) } \\
\text { - Social contracts (Brazil, } \\
\text { Colombia, Costa Rica, } \\
\text { Ecuador, Panama } \\
\text { and Peru) }\end{array}$ & $\begin{array}{l}\text { Role of the State: } \\
\text {-Active (funds } \\
\text { and provides) } \\
\text { - Rights (Brazil, Costa } \\
\text { Rica and Uruguay) } \\
\text { - Welfare (Chile) } \\
\text { - Subsidiary (Chile) }\end{array}$ & $\begin{array}{l}\text { - Poverty relief (Brazil, } \\
\text { Chile (1981), Costa } \\
\text { Rica, United States } \\
\text { and Uruguay) } \\
\text { - Right to a guaranteed } \\
\text { minimum through } \\
\text { seniority and situation } \\
\text { of poverty or inequality } \\
\text { (Chile (1981 and 2008), } \\
\text { Costa Rica and } \\
\text { United States) }\end{array}$ \\
\hline $\begin{array}{l}\text { Organizational } \\
\text { dimension }\end{array}$ & $\begin{array}{l}\text { - Government ministries } \\
\text { (Argentina, Brazil, } \\
\text { Ecuador, Honduras } \\
\text { and Nicaragua) } \\
\text { - Regulation and public- } \\
\text { private interconnections } \\
\text { (Chile, Colombia, } \\
\text { Costa Rica, Dominican } \\
\text { Republic, El Salvador, } \\
\text { Mexico, Panama, Peru, } \\
\text { Plurinational State of } \\
\text { Bolivia and Uruguay) } \\
\text { - Regulation with private } \\
\text { initiative (Brazil and } \\
\text { United States) }\end{array}$ & $\begin{array}{l}\text { Growing interconnections } \\
\text { between ministries } \\
\text { of social development, } \\
\text { health, labour and social } \\
\text { welfare (Argentina, } \\
\text { Brazil, Chile, Colombia, } \\
\text { Costa Rica, Mexico and } \\
\text { Uruguay) }\end{array}$ & $\begin{array}{l}\text { - Provided through a } \\
\text { welfare network (Brazil, } \\
\text { Chile (1981), Costa } \\
\text { Rica, United States } \\
\text { and Uruguay) } \\
\text { - Provided by the system } \\
\text { itself (Chile (2008), } \\
\text { Costa Rica and } \\
\text { United States) }\end{array}$ \\
\hline $\begin{array}{l}\text { Technical and } \\
\text { operational } \\
\text { dimension }\end{array}$ & $\begin{array}{l}\text { Permanent actuarial analysis } \\
\text { between rights and: } \\
\text { - Contributions (all) } \\
\text { - Employers' contributions } \\
\text { (eliminated in some) } \\
\text { - Fiscal contributions } \\
\text { (different) } \\
\text { - Tax reform (viability) }\end{array}$ & $\begin{array}{l}\text { - Welfare policy } \\
\text { - Targeting instrument } \\
\text { or criterion } \\
\text { - Static or integrated } \\
\text { pillars }\end{array}$ & $\begin{array}{l}\text { - Ceiling, guarantees } \\
\text { and legally established } \\
\text { quotas (Brazil, Chile, } \\
\text { Costa Rica, United } \\
\text { States and Uruguay) } \\
\text { - Regulated levels } \\
\text { with incentives for } \\
\text { contributions }\end{array}$ \\
\hline $\begin{array}{l}\text { Funding } \\
\text { dimension }\end{array}$ & $\begin{array}{l}\text { Fiscal responsibility law } \\
\text { - Items to guarantee } \\
\text { contingent liabilities } \\
\text { - Welfare deficits } \\
\text { - Funding for regulatory } \\
\text { and structural institutional } \\
\text { developments }\end{array}$ & $\begin{array}{l}\text { - From general taxation } \\
\text { for the eligible population } \\
\text { according to targeting } \\
\text { criteria (Chile, Costa } \\
\text { Rica, United States } \\
\text { and Uruguay) } \\
\text { - From an item of the } \\
\text { national budget (Brazil) } \\
\text { - From high to low income } \\
\text { or contributions (Brazil } \\
\text { and United States) } \\
\text { - From agricultural } \\
\text { companies to poor rural } \\
\text { populations (Brazil) }\end{array}$ & $\begin{array}{l}\text { - Budgetary laws } \\
\text { increasingly guided } \\
\text { by fiscal responsibility } \\
\text { laws (Chile, Costa Rica, } \\
\text { United States } \\
\text { and Uruguay) } \\
\text { - State budget laws } \\
\text { (Brazil) }\end{array}$ \\
\hline
\end{tabular}

Source: Prepared by the author. 
For example, the Brazilian system achieves this through three pillars: ${ }^{17}$

(i) The first pillar regulates contributions, defines benefits and is based on mandatory membership.

(ii) The second pillar rewards the capacity for saving and involves what is known as complementary individual or corporate welfare.

(iii) The third pillar is a subsidized form of social assistance and grants non-contributory pensions to senior citizens living below the poverty line. There is a special subsidy to cover the costs of the pension for rural poverty relief, which makes use of tax revenues from agricultural exports.

In the case of Chile, recent history involves two different phases.

(i) Prior to 2008, three pillars were used:

- The first pillar: contributory, mandatory and using defined contributions, but with a minimum guaranteed pension after 20 years of contributions and self-financing of a benefit below a minimum level.

- The second pillar: voluntary and using defined contributions to increase the self-financed pension.

- A non-contributory welfare pension (PASIS), unrelated to the previous pillars, subject to fiscal leeway and allocated on a quota basis.

(ii) Following the 2008 reforms, subsidies were incorporated into the system through a new solidarity-based pillar:

- The first pillar remained mandatory and with defined contributions. The minimum guaranteed pension after 20 years of contributions was eliminated.

- The second pillar remained unchanged.

- A solidarity-based pillar was introduced to replace the minimum guaranteed pension and the PASIS, in order to redesign the mechanism for determining the guarantee of a minimum pension with subsidies in inverse proportion to the capacity for saving (minimum guaranteed coverage). First, an item from the general budget is established to

17 The information indicated herein does not include the changes that began in 2016. 
finance solidarity-based actions (Solidarity Fund) and, second, pension rights for the poorest $60 \%$ of the population, funded by contributions from general revenue (solidaritybased fund). People without savings (Basic Solidarity-based Pension (PBS)) and with savings (Solidarity-based Welfare Contribution (APS)) are targeted.

Costa Rica designed an integrated pension system consisting of four components:

(i) The Basic Pensions Regime, managed by the Costa Rican Social Insurance Fund (CCSS). The amount of the old-age pension of the Invalidity, Old Age and Death Regime of the CCSS is a basic proportion of the average wage, calculated on the basis of the most recent 240 contributions made by the member and indexed to inflation.

(ii) The Labour Capitalization Fund (FCL) is a savings fund established with the employer's contribution of $3 \%$ of the worker's wage reported to the CCSS. Those contributions are credited to individual accounts belonging to each worker, which are managed by the Complementary Pensions Operator (OPC).

(iii) The Voluntary Complementary Pensions Regime is an acquired pension plan that, as provided for in Law No. 7523, can be transferred to another operator, in which case seniority alone will be recognized, whereas the remaining conditions are to be governed by the terms of the Worker Protection Act.

(iv) Non-contributory pensions have two components: the Noncontributory Basic Amount Pensions Regime (RNC) and the Minimum Pension (PM) of the Invalidity, Old Age and Death Regime.

In the United States, efforts have been made to promote solidarity within the system through the following mechanisms:

- In the contributory social security system, implicit crosssubsidies are established by setting a ceiling and a benefits rule that is in proportion to income.

- A welfare pension is offered for poverty relief in old age.

- Markets for private welfare savings external to the system are promoted by means of tax incentives. 
In turn, Uruguay has a mixed system that involves three components. For subsidies to apply, within the different regimes the following levels of individual monthly income are determined, provided that they represent calculable allocations.

- First level (intergenerational solidarity retirement regime). This regime covers all members on the basis of their calculable allocations, or portions thereof, up to 5,000 Uruguayan pesos. This creates benefits that are funded through contributions made by employers, workers and the State.

- Second level (individual mandatory savings retirement regime). This regime covers the range of calculable allocations from 5,000 to 15,000 Uruguayan pesos, which creates benefits that are funded solely with personal contributions. It is managed by public institutions, including the Social Insurance Bank, or by private organizations and individuals (article 92 of the Social Security Act).

- Third level (voluntary savings). For the range of calculable allocations in excess of 15,000 Uruguayan pesos, the worker can contribute, or not, to any of the fund management agencies referred to in the previous section.

In addition to these three levels, there are non-contributory pensions for poverty relief in old age (see table IV.5).

\section{Elements for sustainability associated with the ageing process}

Institutional developments within pension systems can also be assessed in terms of their ability to address the risks that affect their functioning over generations.

This second challenge is the result of the imminent ageing of the population. Associated with this, changes in the age structure of the total population and in life expectancy as a result of falling mortality affect the context in which pension systems operate, as do political, social, economic and financial events.

The population is ageing at different rates in different countries, as well as within individual countries, chiefly as a result of the transition from high to low levels of fertility and the permanent reductions in mortality that prolong people's lifespans (see table IV.6). 


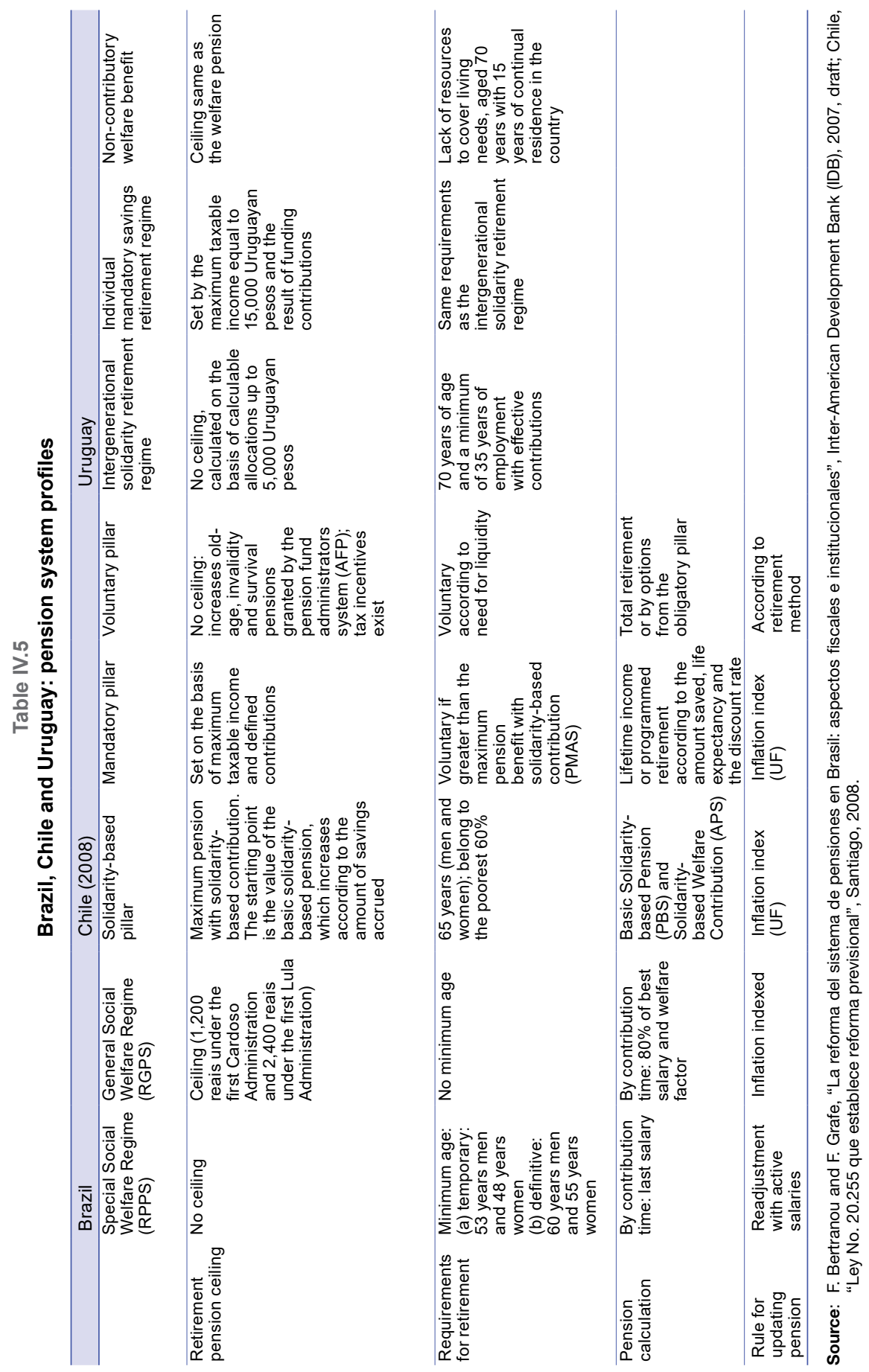




\section{Table IV.6}

\section{Latin America and the Caribbean (19 countries): different transitions in fertility and mortality}

\begin{tabular}{|c|c|c|c|c|c|c|}
\hline \multirow[t]{2}{*}{ Country } & \multicolumn{3}{|c|}{ Global fertility rate } & \multicolumn{3}{|c|}{$\begin{array}{l}\text { Life expectancy at birth } \\
\text { (years) }\end{array}$} \\
\hline & 1950-1955 & 2010-2015 & $2045-2050$ & $1950-1955$ & $2010-2015$ & $2045-2050$ \\
\hline $\begin{array}{l}\text { Bolivia } \\
\text { (Plurinational } \\
\text { State of) }\end{array}$ & 6.8 & 3.1 & 1.8 & 40.4 & 67.0 & 76.5 \\
\hline Guatemala & 7.0 & 3.7 & 1.8 & 42.0 & 71.3 & 78.1 \\
\hline Honduras & 7.5 & 2.9 & 1.7 & 41.7 & 72.8 & 78.6 \\
\hline Nicaragua & 7.2 & 2.5 & 1.7 & 42.3 & 72.7 & 78.4 \\
\hline Paraguay & 6.5 & 2.7 & 1.7 & 62.7 & 72.3 & 77.3 \\
\hline Colombia & 6.8 & 2.4 & 1.9 & 50.6 & 73.8 & 79.0 \\
\hline Costa Rica & 6.7 & 1.7 & 1.7 & 57.3 & 79.1 & 82.0 \\
\hline $\begin{array}{l}\text { Dominican } \\
\text { Republic }\end{array}$ & 7.6 & 2.5 & 1.9 & 46.0 & 72.7 & 77.8 \\
\hline Ecuador & 6.7 & 2.6 & 1.8 & 48.6 & 75.5 & 81.4 \\
\hline El Salvador & 6.3 & 2.1 & 1.8 & 45.1 & 72.3 & 78.1 \\
\hline Mexico & 6.7 & 2.2 & 2.0 & 50.7 & 76.6 & 81.3 \\
\hline Panama & 5.8 & 2.5 & 1.9 & 56.8 & 77.3 & 82.6 \\
\hline Peru & 6.9 & 2.4 & 1.8 & 43.9 & 74.0 & 79.1 \\
\hline $\begin{array}{l}\text { Venezuela } \\
\text { (Bolivarian } \\
\text { Republic of) }\end{array}$ & 6.5 & 2.4 & 1.8 & 55.2 & 74.5 & 79.6 \\
\hline Brazil & 6.2 & 1.8 & 1.7 & 51.0 & 73.2 & 79.5 \\
\hline Chile & 5.0 & 1.8 & 1.6 & 54.8 & 79.0 & 82.1 \\
\hline Argentina & 3.1 & 2.2 & 1.8 & 67.2 & 76.0 & 80.7 \\
\hline Cuba & 4.2 & 1.5 & 1.6 & 59.4 & 79.2 & 82.1 \\
\hline Uruguay & 2.7 & 2.0 & 1.7 & 66.1 & 80.0 & 81.6 \\
\hline
\end{tabular}

Source: Latin American and Caribbean Demographic Centre (CELADE)- Population Division of ECLAC, "Population estimates and projections", Santiago, Economic Commission for Latin America and the Caribbean (ECLAC), 2011.

a The global fertility rate (GFR) is the average number of children that would be born to a woman belonging to a hypothetical cohort of women who during their fertile lives had children in accordance with the fertility rate by age over a specific study period (normally one given year) and were not exposed to mortality risks from the time of their births to the end of their childbearing years. Life expectancy is the average number of years lived by a given absolute or total population over a specific period.

A population's ageing profile is generally illustrated by means of three indicators: (i) the ageing index, which measures the ratio of older persons (in this case, aged over 60) to young people (aged under 15), (ii) the median age of the population, and (iii) the potential support ratio, which measures the relationship between the working-age population (from 15 to 60 years of age) and older people (see figure IV.1). ${ }^{18}$

18 Cut-off ages typically vary from one country to the next. This document uses those applied by the Latin American and Caribbean Demographic Centre (CELADE)-Population Division of ECLAC to generate data and indicators on ageing. 
Figure IV.1

Latin America (18 countries): ageing indicators, 1950-2100

A. Potencial support ratio (population aged 15-59/population aged $>60$ )

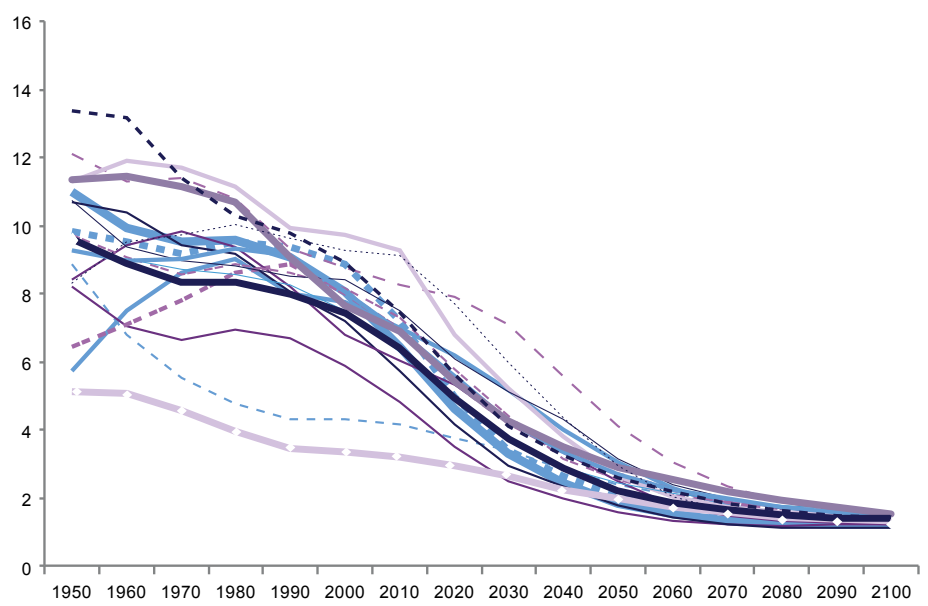

B. Ageing index (population aged $>60 /$ population aged $<15$ ) $^{\star} 100$

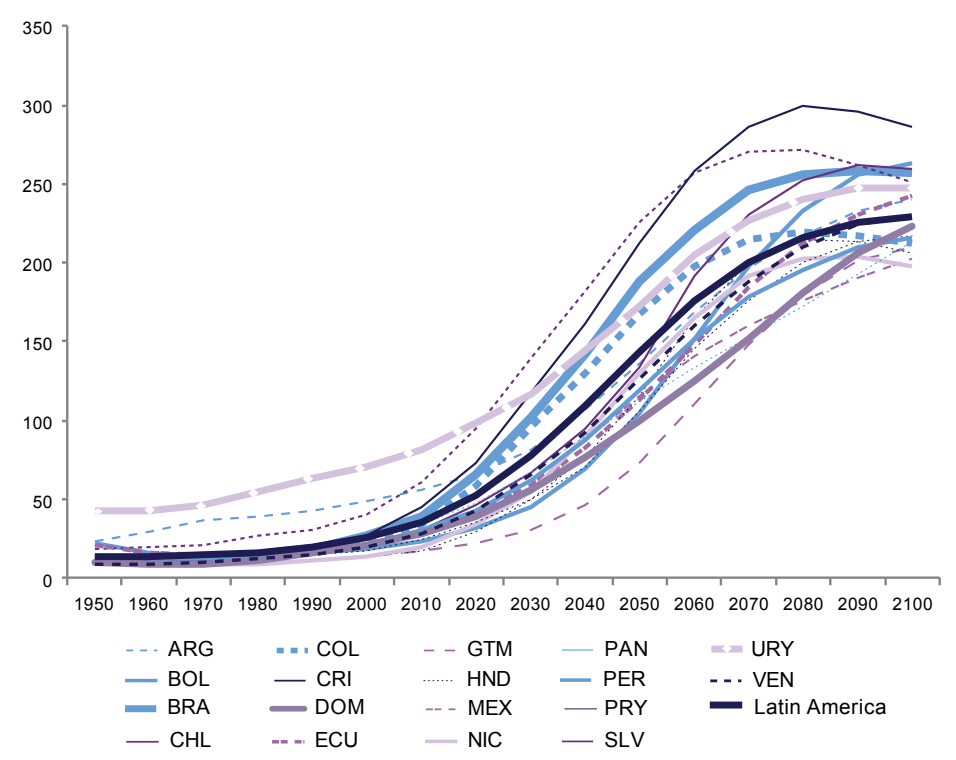


Figure IV.1 (concluded)

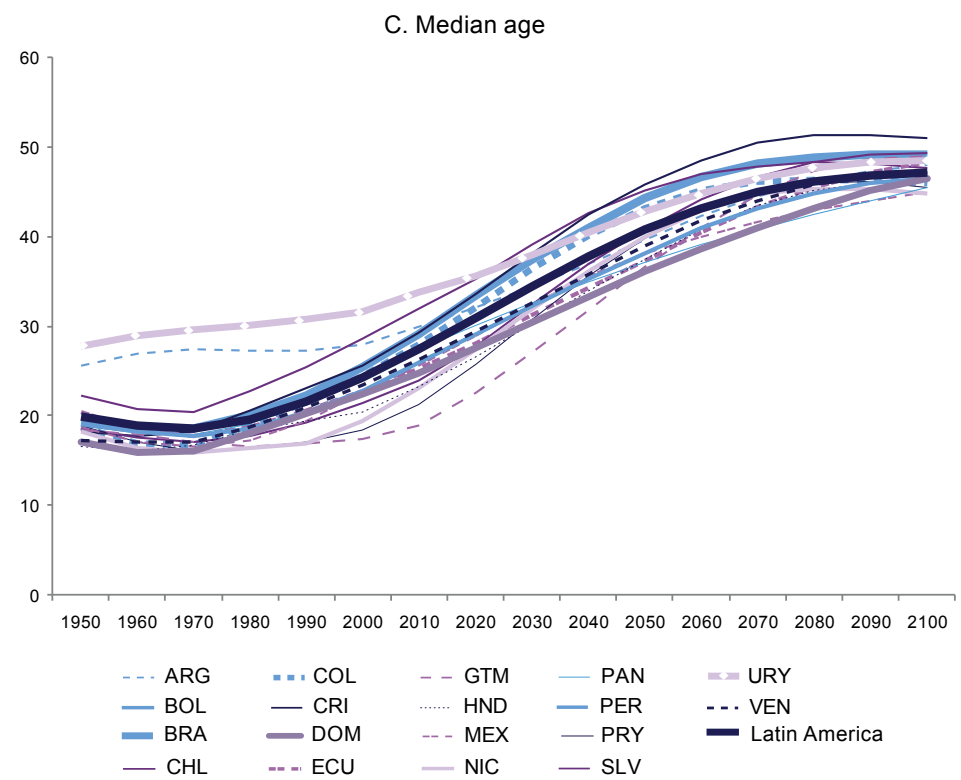

Source: Latin American and Caribbean Demographic Centre (CELADE)-Population Division of ECLAC, "Population estimates and projections", Santiago, Economic Commission for Latin America and the Caribbean (ECLAC), 2015.

Note: Ageing index $=$ (population aged 60 and over / population aged 14 and under ${ }^{*} 100$. Potential support ratio $=$ (population aged 15 to 59 ) $/$ (population aged 60 and over).

In the Latin America of 1950, for each 100 young people there were 13.6 older people; by 2015, that figure had risen to 42.8 and, by 2040, it will reach 106. The median age was 19.9 years in 1950, had risen to 28.9 in 2015 and will be over 37 in 2040 . The potential support ratio indicates that in 1950, for each older person there were 9.7 people of working age. By 2015 that figure had been almost halved (4.9) and it will be a mere 2.6 in 2040. Chile and Brazil (along with Argentina, Cuba and Uruguay) are among the Latin American countries where fertility is declining fastest and that are showing the most pronounced signs of ageing.

Ageing has significant implications for the design and sustainability of pension systems. If the demographic base that sustains a pay-as-yougo pension system is weakened, ${ }^{19}$ the potential $^{20}$ sustainability ratio falls.

19 Pay-as-you-go is a system in which the contributions of today's active workers fund the pensions of today's retirees, in the understanding that future generations will do the same. Accordingly, as the ratio between potential assets and liabilities falls - and unless a reserve fund exists or changes are made to parameters such as the contribution rate, the replacement rate or the retirement age - the pension funding mechanism weakens (see table IV.2).

20 It is qualified as "potential" because it is a purely demographic ratio, in that it does not take into consideration actual developments with work and savings among the working-age population. 
That indicator already stands at values below 4 in Argentina, Cuba and Uruguay. It will reach that level in Chile in five years' time and within a decade in Brazil. Life expectancy upon retirement is also increasing, which affects the benefits of systems based on the administration of individual savings accounts. Life expectancy beyond the age of 60 in the countries of Latin America will increase from 20.2 to 21.1 years among men and from 23.4 to 24.4 years among women. In Chile, the figure will rise from 20.9 to 21.6 years for men and from 25.0 to 25.9 years for women (CELADE, 2011).

The main concern to the authorities is the financial effect of these changes. For example, assuming a guaranteed universal pension and reasonable assumptions for gross domestic product (GDP) growth, it can be shown that the cost of its funding will increase if the retirement age is maintained. Hypothetically, assume that each country establishes a universal pension costing $10 \%$ of its per capita GDP ${ }^{21}$ for those aged over 60 . The total cost in 2010 would exceed $1.4 \%$ of GDP in the countries where the ageing process is most advanced and, over the following 30 years, would amount to more than $2.2 \%$ of GDP. Under the same conditions and over the same period, in Chile the cost would rise from $1.3 \%$ to $2.7 \%$ of GDP and, in Brazil, from $1.0 \%$ to $2.4 \%$. Table IV.7 shows the cost as a percentage of GDP for each country of a transfer to all their older persons aged 60,75 or 80 equal to $10 \%$ of per capita GDP. ${ }^{22}$

Funding a non-contributory system with a universal guarantee becomes a stable component of the fiscal budget. It rises as the proportion of the eligible population grows, increasing as the level of the guaranteed universal benefit rises. ${ }^{23}$ The weight of those transfers within the fiscal budget is in direct proportion to the number of beneficiaries as percentage of the total population. ${ }^{24}$ In the case of an old-age pension, that proportion will increase as younger people are included as beneficiaries and as the general population ages. The value of the benefit is an administrative decision subject to political debate and budgetary constraints, generally adopted during the debate on the public sector budget. All these elements must be taken into account in a social agreement regarding this type of system. A technical and political discussion on these parameters (retirement age and benefit) is therefore essential.

21 In Chile, the Basic Solidarity-based Pension (PBS) is equal to some US\$ 120 a month (much lower than the minimum wage, which exceeds US\$ 350) and its relative value is equal to $10 \%$ of per capita GDP.

22 The calculations were made using the value of the Chilean PBS as a reference; however, some countries, such as Colombia, do not allow pensions worth less than the minimum wage.

23 The generosity of a universal guarantee is measured by the ratio between the monetary benefit and per capita GDP.

24 Additionally, so is the generosity of the transfer expressed as a percentage of per capita GDP. 
Table IV.7

Latin America and the Caribbean (19 countries): simulated cost of universal pensions as a percentage of national GDPa

\begin{tabular}{|c|c|c|c|c|c|c|c|c|c|}
\hline \multirow{2}{*}{ Country } & \multicolumn{3}{|c|}{2010} & \multicolumn{3}{|c|}{2025} & \multicolumn{3}{|c|}{2040} \\
\hline & $P>60$ & $\mathrm{P}<75$ & $P>80$ & $P<60$ & $\mathrm{P}<75$ & $\mathrm{P}>80$ & $P>60$ & $\mathrm{P}>75$ & $P<80$ \\
\hline $\begin{array}{l}\text { Bolivia } \\
\text { (Plurinational } \\
\text { State of) }\end{array}$ & 0.71 & 0.16 & 0.07 & 0.97 & 0.24 & 0.11 & 1.39 & 0.39 & 0.20 \\
\hline Guatemala & 0.65 & 0.18 & 0.09 & 0.74 & 0.22 & 0.12 & 1.03 & 0.30 & 0.17 \\
\hline Honduras & 0.62 & 0.18 & 0.09 & 0.87 & 0.23 & 0.13 & 1.35 & 0.39 & 0.22 \\
\hline Nicaragua & 0.62 & 0.18 & 0.10 & 0.97 & 0.24 & 0.14 & 1.52 & 0.46 & 0.26 \\
\hline Paraguay & 0.77 & 0.20 & 0.11 & 1.09 & 0.29 & 0.15 & 1.47 & 0.47 & 0.27 \\
\hline Colombia & 0.86 & 0.21 & 0.11 & 1.41 & 0.34 & 0.17 & 1.96 & 0.65 & 0.36 \\
\hline Costa Rica & 0.95 & 0.27 & 0.15 & 1.66 & 0.41 & 0.23 & 2.35 & 0.84 & 0.47 \\
\hline $\begin{array}{l}\text { Dominican } \\
\text { Republic }\end{array}$ & 0.86 & 0.25 & 0.13 & 1.29 & 0.34 & 0.19 & 1.80 & 0.60 & 0.34 \\
\hline Ecuador & 0.86 & 0.25 & 0.13 & 1.27 & 0.34 & 0.19 & 1.81 & 0.60 & 0.34 \\
\hline El Salvador & 0.94 & 0.29 & 0.16 & 1.20 & 0.39 & 0.24 & 1.65 & 0.55 & 0.32 \\
\hline Mexico & 0.88 & 0.24 & 0.13 & 1.30 & 0.36 & 0.20 & 1.96 & 0.60 & 0.35 \\
\hline Panama & 0.97 & 0.27 & 0.15 & 1.41 & 0.41 & 0.24 & 2.01 & 0.69 & 0.41 \\
\hline Peru & 0.88 & 0.23 & 0.11 & 1.27 & 0.34 & 0.19 & 1.86 & 0.57 & 0.32 \\
\hline $\begin{array}{l}\text { Venezuela } \\
\text { (Bolivarian } \\
\text { Republic of) }\end{array}$ & 0.86 & 0.21 & 0.11 & 1.34 & 0.34 & 0.17 & 1.85 & 0.61 & 0.34 \\
\hline Brazil & 1.02 & 0.27 & 0.15 & 1.66 & 0.44 & 0.24 & 2.40 & 0.84 & 0.48 \\
\hline Chile & 1.31 & 0.38 & 0.21 & 2.06 & 0.59 & 0.33 & 2.65 & 1.05 & 0.61 \\
\hline Argentina & 1.46 & 0.47 & 0.26 & 1.73 & 0.57 & 0.32 & 2.18 & 0.76 & 0.46 \\
\hline Cuba & 1.71 & 0.54 & 0.30 & 2.67 & 0.83 & 0.50 & 3.61 & 1.45 & 0.78 \\
\hline Uruguay & 1.85 & 0.67 & 0.39 & 2.13 & 0.76 & 0.46 & 2.53 & 0.99 & 0.61 \\
\hline
\end{tabular}

Source: Prepared by the author.

a Cost (as a percentage of GDP) of providing an annual universal pension (equal to $10 \%$ of per capita GDP) to all older people $(P>60, P>75$ and $P>80)$.

The institutions responsible for the financial management of members' contributions to contributory pension systems must work to ensure their long-term sustainability.

The four dimensions of institutional developments can be classified by the way in which they tackle the challenges posed by the ageing of the population. To wit:

(i) adjustments to adapt to changes in the age structure and in life expectancy at retirement;

(ii) policies to improve labour market inclusion;

(iii) regulation of the assigned destination of pension funds (to transfer them within a generation or to other generations); and

(iv) prudent regulation to guarantee their profitability in financial markets. 


\section{(a) Adjustments to adapt to changes in the age structure and in life expectancy at retirement}

The ability to fund pensions for a large group of beneficiaries depends on the amount of the pension, but also on the number of members contributing to the system and the size of their contributions. To address these changes, systems that operate under this financial administration regime (solidarity-based compacts between generations) must modify their parameters. This implies a major political debate about whether to raise the retirement age, increase the rate up to which active generations contribute, reduce the ratio between the pensions received by beneficiaries and the salaries of the active workers contributing to the system, or complement the system with defined-contribution private pensions. ${ }^{25}$

In turn, the funded mechanism must address increases in life expectancy after retirement age. One way to achieve this would be to convince members to contribute more (in a way similar to pay-as-you-go, with a higher rate or longer period of contributions). Another way would be to reduce benefits through the mechanisms through which the system correlates savings with the amount and continuity of payments (lifelong annuity or scheduled retirement).

From the organizational perspective, it is important to identify a sponsor of the system to take responsibility for its results and functioning. That sponsor must ensure that, in accordance with the law, the benefits offered to members are funded in both pay-as-you-go and funded systems. In the former, this is because the potential support ratio changes and compromises the sponsor's capacity to provide the defined benefits. In the latter, it is because increases in life expectancy at retirement age determine the pension levels for the same level of savings, which affects the member individually. ${ }^{26}$

It should be recalled that the pay-as-you-go mechanism is based on solidarity between generations, under a compact in which the active generations fund the pensions of the retired cohorts. The funded mechanism, meanwhile, is based on proper financial regulation and supervision by the (public or private) administrators of pension funds and on the establishment of rules for equivalence between contributions and benefits.

25 The effect of these demographic changes can be mitigated if pay-as-you-go systems begin the adequate management of reserve fund during the years when they have a high potential support ratio.

26 Neither do systems based on funding in individual accounts escape the effects of demographic changes. On the contrary, constant increases in life expectancy at retirement age mean that the amount saved for self-financed pensions must cover a greater number of years, and so the only effect is to reduce the pension. The difference in this case is that in order to avoid lower pensions, the decision to postpone retirement and to save more depends on the individual and not on public policy. 
The State participates directly in the provision of non-contributory pensions and represents the sponsor of final resort and the promoter of reforms with fiscal costs. For those reasons, it must assume a key technical and operational role in monitoring demographic changes and in providing funding to cover the impact of those changes on the non-contributory funds needed to adapt the system to them.

As regards funding, the management of pension funds must not exert future pressures on fiscal accounts in order to ensure their sustainability. For that reason, their management demands actuarial models that ensure that their parameters (contribution rate, retirement age and replacement rate) are adapted to the structure of demographics and the labour market and to the changes therein that could affect its effective sustainability ratio (active members contributing or passive members entitled to benefits). The fiscal cost of the State's explicit guarantees to cover the needs of older people within the system is affected by ageing. The non-contributory nature of a system does not completely avoid demographic risk, since ageing necessarily leads to two phenomena. First, each year a greater proportion of the population reaches retirement age, which changes the age structure and increases the proportion of older people covered by welfare and assistance policies. Second, survival rates among older people rise, which requires larger budgetary transfers to cover an unchanged pension (see table IV.8).

\section{(b) Adjustments to changes in the quality of employment in the labour market}

The risks of the economic cycle affect all contributory systems, regardless of their financial management. Through their effects on the quality of people's jobs, those risks determine the ability of members to make regular contributions. In the case of non-contributory systems, economic cycles can require governments to constrain their budgets, affecting their ability to maintain coverage levels and the adequacy of the guaranteed benefits.

In the regulatory framework, defining a system as contributory implies determining the tax requirements for participation, which have to do with the contribution rate and the legal retirement age. It also requires clear rules to bind compliance with those demands with benefits offered by the system, all within the framework of other benefits afforded by labour laws. In non-contributory systems, fiscal responsibility legislation constrains the margin available for revising the coverage and adequacy of those guarantees within the national budget. 


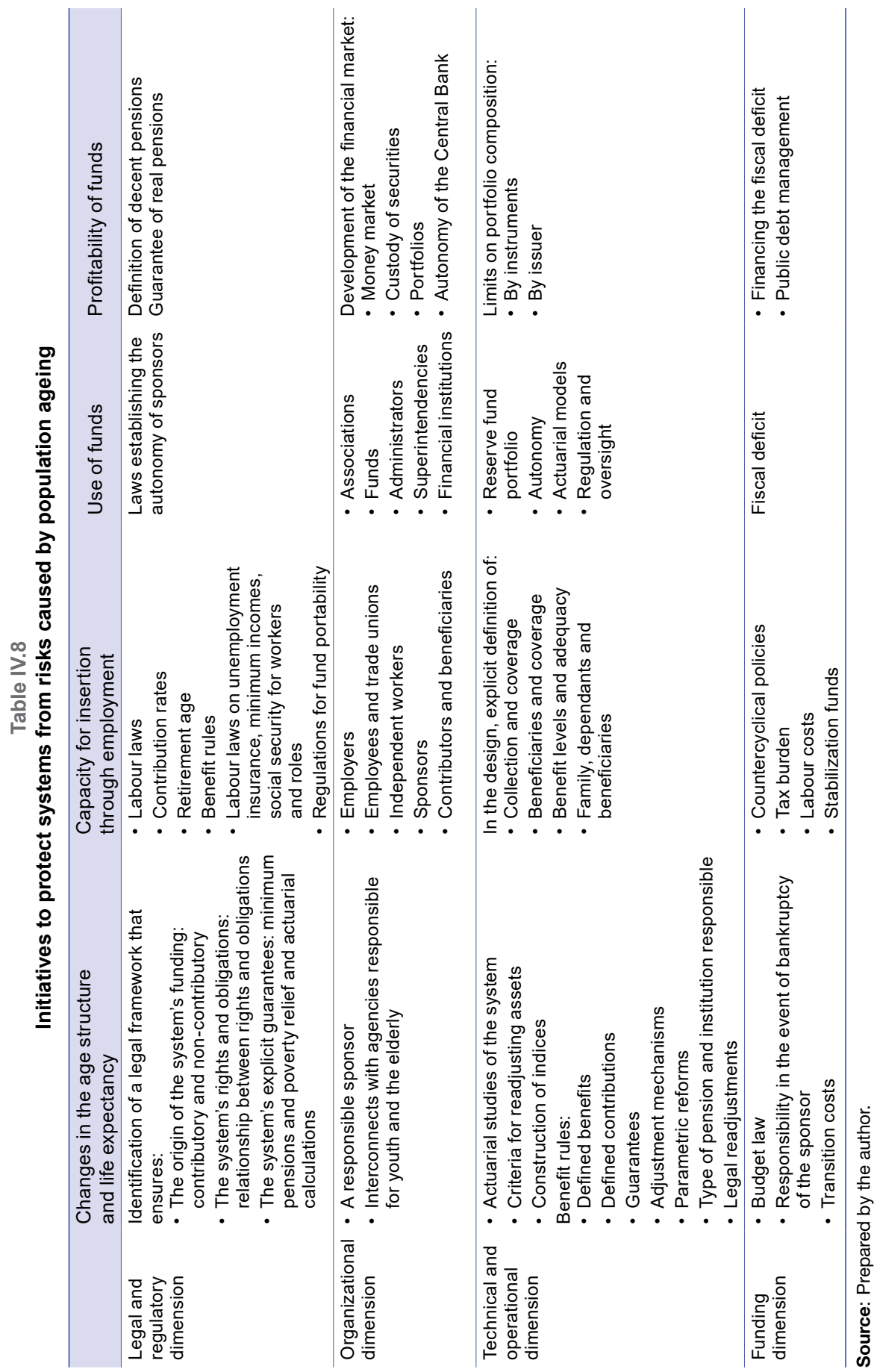


The density of contributions in contributory systems -in other words, the frequency with which a member can make contributions to the system- becomes an issue of fundamental importance. This depends on the extent to which the actors and their representatives are able to ensure the continuity and quality of employment. The non-standardized nature of the labour market, defined by segmentation between formal and informal employment and by worker mobility between those categories, impacts the sponsor's ability to ensure the continuity of contributions. For that reason, at the organizational level, a vital role is played by the management of labour relations between employers and workers, and by support for entrepreneurship and workers' rights, in that they contribute to the formalization of employment.

During workers' active lives (between the ages of 15 and 65), they can join contributory systems if they participate in economic activities, secure employment and contribute. This is dependent on their ability to obtain formal employment and on the capacity of the economy to create such jobs. As a result, systems are sensitive to whether or not a country's economic growth has enabled the job market to become an instrument of social inclusion for the majority of the population. This is a weakness of Latin American development that affects both funded and pay-as-you-go systems, where the ability to contribute to the system determines the right of members to receive benefits. For that reason, ECLAC has recommended systems that combine contributory and non-contributory funding (Cecchini and Martínez, 2012).

Within the non-contributory pillar there are no problems with contribution density, and so the labour market and the incompatibility of roles are overcome by means of the criterion of universal entitlement under which pensions are assigned. However, since welfare spending is a component of the budget, it must be analysed in the annual budget debate, unless rules for the long-term allocation of welfare resources and for fiscal responsibility are in place.

Given the vulnerability of the system's collections during economic cycles, there are direct and indirect developments that address:

- The existence or otherwise of macroeconomic countercyclical policies, for either funding or unemployment insurance.

- The monitoring of family structures and strategies during the cycle, ensuring that:

- Active members continue to contribute.

- Passive members continue to receive benefits.

- The system's incentives structure is not affected by the potential repercussions of the economic cycle on other household decisions. 
In particular, the full range of policy instruments must be coherent with the logic of how the system is funded and must ensure the coverage and adequacy of its benefits.

Within the fiscal dimension there is a clear interplay between the funding method, the design of the system and countercyclical policies. The recognition of explicit guarantees must be clearly demarcated, in both non-contributory and contributory models, in order to address the deficiencies caused by different contribution densities. As a result, systems usually set very strict eligibility rules for benefits. Membership must be flexible enough to allow worker mobility between different job options and to ensure that contribution rates maintain a correlation with both the adequacy of benefits and the competitiveness of labour in the context of globalization. These macroeconomic considerations address the essence of the relationship with the fiscal sphere and, in the most extreme cases, have led to the creation of stabilization funds for dealing with contingencies.

\section{(c) Regulating the destination and use (ownership) of pension funds}

One concern in connection with the use of pension funds (in reserves or individual accounts) is keeping them out of the reach of actors with interests other than funding the members' pensions. A fund is at risk of political use when the administration system is controlled by the government. Historically, this risk has been associated with the management of public pay-as-you-go models. ${ }^{27}$ Nevertheless, funds can also be controlled by economic interest groups, a risk that is heightened in funded models.

The authorities must ensure that the administration of those funds is not affected by conflicts of interest with the management of the companies in which they invest or with the groups that manage them. The creation of a funded system to replace original pay-as-you-go systems is also affected by the political decision on how to finance the cost of the transition away from the original pay-as-you-go system. Legislation is also needed to ensure the manager and the sponsor are autonomous and that the assets of the workers and the manager are kept separate.

Within the organizational dimension, the structure and nature of the corporate governance responsible for managing the fund on the sponsor's behalf must be clearly established. This entails a great dilemma in that, on the one hand, the governing body is its representative and, on the other, it must be guided by strict criteria on behalf of the welfare

27 Argentina's 2010 experience with reform shows that as long as the funded component of a pension system is not consolidated as a key element in the welfare system and in the functioning of the money market, it will never be safe from the political risk of the State assuming control of its funds. 
interests of the members and not those of the sponsor. The financial and intangible nature of the management's results make it very difficult to determine how that autonomy is to be created. At the organizational level, conflicts of interest exist when:

- The financial administration is in the hands of an industry, for which a superintendency charged with the prudent organizational regulation of the industry must be established.

- The sole administrator of those funds is the State or one of its dependent agencies. In the latter case, the administration of the pensions fund must be kept separate from the management of the fiscal budget. This is to ward against the political risk of pension fund liquidity being used for the purposes of servicing the public debt. This is frequently justified on the grounds of social profitability, but not on those of financial profitability, which is what produces long-term growth in pension funds. Nevertheless, another political risk that exists is the use of funds on alternatives that are less profitable from the welfare perspective, when groups outside the government control how the funds are administrated in their own interests.

The implementation of a pension system must increase the transparency of how its funding connects with the fiscal budget and with investment alternatives in the country. The aim is to prevent the system, at times of budget deficit, from acting as a lender of last resort, or permanently denying other investors access to the fund. This relates to both the operational and fiscal dimensions of the institutional framework.

As the Argentine experience shows, funding in individual accounts and their administration by State-regulated private companies does not guarantee that this problem can be averted. Following the adoption of a series of measures intended to improve coverage and freedom of choice within both retirement regimes (payment facilities for autonomous workers and non-structural legislative amendments presented as improvements to the pre-existing mixed system), pressure on the system led to a radical, structural change that ultimately eliminated the funded pillar. After 14 years with a mixed regime, it was replaced with the Integrated Argentine Welfare System (SIPA). The country returned to a publicly administrated pay-as-you-go regime under the National Social Security Administration (ANSES), the largest social security management agency (created in December 2008 by means of Law No. 26.425). ${ }^{28}$

28 Within this process, the tendency towards litigiousness was brought to an end. The Sustainability Guarantee Fund, administrated by ANSES, was established, in accordance with investment rules similar to those to which the Retirement and Pension Fund Administrators were subject, and a Legislative Supervisory Committee was also created in 2008. 
In the fiscal dimension, there must be actuarial models that determine the State's explicit guarantee of the guarantees offered by the system. One interesting aspect of the region's experience has been the way in which the countries that changed their pay-as-you-go regimes for funded models managed the costs of the transition that affected the welfare deficit and the pressure on public finances. In Chile, the dictatorship adjusted the fiscal accounts through reductions in other spending (see box IV.3), but the remaining countries were unable to carry out similar adjustments. The long-term effect has been greater fiscal pressure on pension fund resources for the payment of pensions or other spending, with which private investment has been displaced. One extreme case is that of El Salvador, where the costs of the transition have not been funded. The consequence of this has been increased public indebtedness with the system and the payment of very low pensions that require subsidies.

\section{Box IV.3}

Chile: funding the transition towards the individual funded model (extract from the report of Chile's recent Presidential Advisory Commission)

As regards fiscal sustainability, the analysis of the costs arising from the transition that began in 1981 is separated from the additional costs of the 2008 reforms, particularly that of the Solidarity-based Pension System. The spending caused by the transition that began in 1981 (recognition bonds, operational deficit and State guaranteed minimum pension) accounted for almost $5 \%$ of annual GDP in 1984. This spending has fallen as most of the costs associated with the change in the system have been paid off. At present values, the cost of the transition was estimated at 136\% of 1981 GDP and was assumed by the State through a combination of tax reforms, spending cuts and debt emission. Spending to cover the operational deficit stood at $1.6 \%$ of GDP in 2012 (Public Finance Report, 2014), and transitory spending is expected to fall to $1 \%$ of GDP by 2025 , according to DIPRES forecasts. The total cost of the structural reform transition is forecast as $2.7 \%$ of GDP in 2025 and will not disappear until 2050: that is, it will take 70 years to be met, which is longer than the original projections (Mesa-Lago and Bertranou, 2015).

The fiscal discipline implicit in Chile's transition has two repercussions in comparison with other international experiences with switching from a mostly pay-as-you-go system to an individual funded model. First, the fiscal savings needed to absorb expenses that accounted for almost $5 \%$ of GDP and that are still being paid have no comparison in Chilean budget debates held under democracy. Second, these fiscal savings were what prevented the State from displacing, through debt instruments, other alternative investments in which pension funds could be placed, and this, in turn, allowed the development of the money market.

For that reason, this experience was unique: it was in response to a special situation, and its funding is to be covered by the generation that experienced it and by those that still have to experience the effects of the fiscal adjustment, in addition to self-financing their pensions.

Source: Presidential Advisory Commission on the Pension System, Informe final, Santiago, 2015, pages 57 and 58. 


\section{(d) Prudent regulation to counter financial vulnerability}

Pension funds based on funding or on the reserve funds of pay-asyou-go systems represent long-term financial savings and must include a component of liquidity so that pensions can be paid out as the system requires. Their financial management is vulnerable to fluctuations in the financial markets where they are invested. This financial risk must be subjected to strict regulatory provisions and prudent oversight.

Financial risks are more sensitive to the funded models (be they individual or public with reserves). Countries that replace their pay-asyou-go pension systems with funded models and use public debt to fund the transition costs face a very particular situation. ${ }^{29}$

To ensure that their benefits provide for real consumption at a decent level, the accrued value of these funds is reported in real terms, given that they should be able to grow faster than inflation, so that the funds increase in real terms. Managing the inflationary risk, when the values are not indexed, and the exchange-rate risk, when the fund has been diversified into foreign financial market assets, constitute other factors of vulnerability.

In practice, what can be seen are two major trends. In the short run, the portfolio returns are volatile. In the long term, the pension fund returns are highly sensitive to the system's maturity. During the early stages, greater returns are achieved, but each successive cohort participating in the system sees its fund returns decrease.

As regards regulations, the rapid growth of pension funds poses the challenge of equipping the money market with a solid institutional framework for channelling those resources into uses that allow the funding of decent pensions. This could be accomplished by means of a series of financial institutions and instruments subject to prudent regulations.

In the organizational arena, institutional development is vital for the correct administration of pension funds. Distinctions must be drawn between pension funds, their managing agencies and the superintendencies charged with regulating and overseeing those agencies. This allows updating and fine-tuning the rules and regulations governing different aspects of a rapidly expanding money market: open stock companies, securities transactions, market transparency, risk classification of securities offered to the public, progressive expansion of the investment alternatives available to pension funds, redefinition of the role of securities and insurance oversight agencies, etc.

For example, in El Salvador, the fact that it was impossible to include an item in the national budget to pay for the welfare deficit caused by the transition led to a gradual increase in the State's welfare debt with the system. 
In operational terms, regulations must be established that take into account the concentration of pension funds in shares of stock companies that provide public services and the scarcity of financial instruments. Oversight is also required for the new institutional regulatory needs related to foreign investment by pension funds, improvements in the life insurance industry (which pays pensions in the form of lifelong annuity plans) and the regulation of financial conglomerates in light of the expansion of banks into various segments of the credit and capital markets. Since they represent mandatory savings made by the workers themselves, intended to be their main source of income during their retirement years, pension funds and their administrating agencies must be subject to tight regulation and prudent oversight.

If the pension fund management is privatized, the management company's own assets must be completely separated from those of the pension fund. Each company must manage just one fund and ensure a minimum level of profitability for its portfolio. The rules governing funds' asset portfolios state that all instruments and securities must undergo rigorous risk evaluations and be classified as low risk. Those portfolios must reflect a broad diversification of financial instruments and issuers. They are subject to continuous appraisals at market prices and to the custody of their constituent instruments and securities in the Central Bank.

As regards fiscal matters, pension tax contributions must be allowed to make a large, direct impact on national savings, even though their net effect on the latter is difficult to determine, particularly owing to their substitution by or complementation with other forms of savings. Accordingly, the relationship between public savings and pension tax contributions may help explain their positive net effect on national savings. This indicates that the relationship between public finances and the pension system is essential if the channelling of contributions into the new pension system is to contribute to national savings. Its effect should not be limited to the payment of pensions by the public sector, be it as guarantees, as an operational deficit arising from a transition or on account of the bankruptcy of an actor within the system.

\section{Some experiences with reforms to address ageing}

Various experiences have tried to improve systems in terms of protecting the members against the risks of old age, invalidity and death, and in terms of the systems' inherent deficiencies. Most countries have maintained Bismarckian models by adjusting their parameters, while others have undertaken structural reforms. 
As pension systems are implemented, irrespective of their nature, they must be adjusted to update their parameters and frameworks of reference and to adapt those changes to new socioeconomic demands. As can be seen, financial imbalances in pension systems are one of the main variables for which reforms are needed, be they structural (substitutive or mixed) or just parametric.

\section{(a) Parametric reforms}

In the absence of structural reforms, countries undertake parametric reforms. Table IV.9 summarizes the main parametric changes made within public pay-as-you-go programmes in recent years.

Based on the experience of Sweden, Brazil chose to maintain financial management, under the pay-as-you-go regime, but to make progress towards defining benefits based on a pension benefit calculation formula similar to the defined contributions mechanism. These systems are known as notional models, in which the financial management is based on pay-asyou-go but pensions are defined according to defined contribution plans. In turn, these are capitalized at a discount rate agreed on by society, taking into account various criteria relating to the functioning of the economy.

In 2015, Ecuador adopted its Labour Justice Act, which amended the country's labour code. Three of the act's provisions refer to pensions. First, the coverage of the public pay-as-you-go system was extended to unwaged female homemakers. These women affiliates contribute according to their households' income, as a percentage of the basic unified wage (SBU), which currently stands at US\$ 354 a month. They are entitled to an old-age pension upon reaching 65 years of age provided they have made at least 240 contributions (20 years' membership). The requirements for receiving an invalidity pension vary according to age: women aged between 15 and 25 must have made a minimum of six monthly contributions, compared to at least 60 for those over 46 years of age. Second, the reform eliminated the $40 \%$ that the government was required to contribute to old age, invalidity and survival insurance. Instead, the government will only contribute when the Ecuadorian Social Security Institute (IESS) does not have sufficient resources to meet its social security benefit payment obligations. This measure in particular has fuelled intense debate in the country, in that it undermines the financial sustainability of the public pay-as-you-go system. The proposals for covering the shortfall caused by the elimination of the State's contribution include raising the retirement age, increasing workers' and employers' contribution rates and reducing the level of benefits. Finally, the new law changed the method used to index-link benefits. Since 2010 , the adjustments have ranged from $4.31 \%$ to $16.6 \%$, depending on the level (retirees with lower incomes received larger adjustments). Henceforth, benefits will be adjusted exclusively in line with the previous year's average inflation rate (Social Security Administration, 2015). 


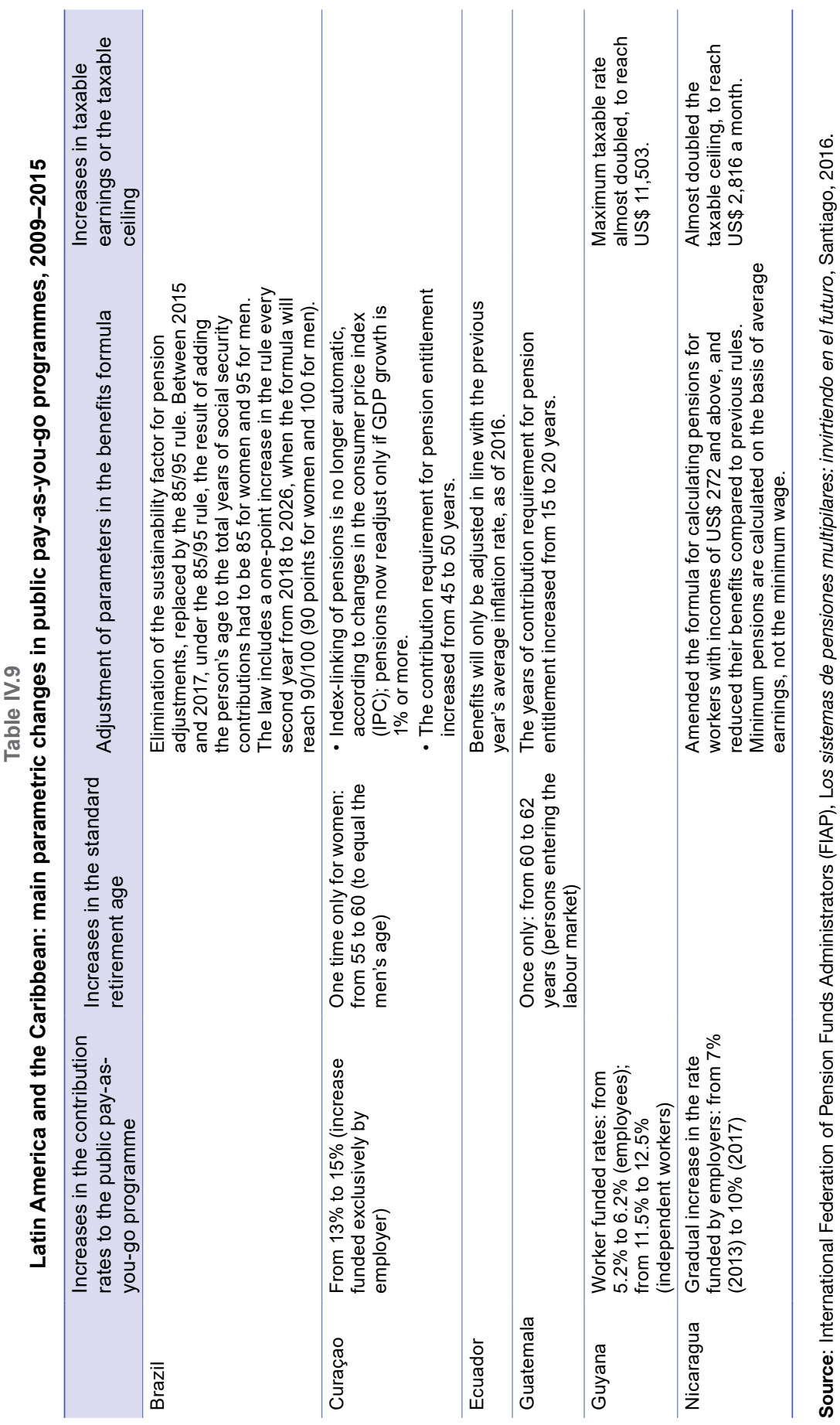


Guatemala modified its public pay-as-you-go system in 2011. The changes included an increase in the minimum retirement age for new entries into the labour market from 60 to 62 years, and an increase in the minimum number of contribution years needed to qualify for a pension from 15 to 20 years. On a temporary basis, the option of retirement at age 60 was maintained for all those workers who were covered by the system in 2010. Nevertheless, in that case the minimum number of contribution years required for pension entitlement was to be increased annually, to reach 20 years in 2015 (Social Security Administration, 2011).

In 2013, Guyana adopted parametric reforms to its worker-funded contributions to the public pay-as-you-go system. The rate was increased by one percentage point, from $5.2 \%$ to $6.2 \%$ of earnings for employed workers, and from $11.5 \%$ to $12.5 \%$ of earnings for independent workers (the employer-funded contribution rate was kept unchanged at $7.8 \%$ ). In addition, in order to protect lower-income workers, the government is to subsidize the hike in the contribution rate for workers earning less than 50,000 Guyanese dollars (US\$ 243) a month (Social Security Administration, 2013).

Also in 2013, Nicaragua published Executive Decree No. 39-2013, amending the Nicaraguan Social Security Institute (INSS) Act, which sets the legal framework for the country's public pay-as-you-go system. The plan includes a gradual increase in the rate of employers' contributions, rising from 7\% in 2013 to 10\% in 2017 (1 percentage point in 2014 and 2015, and 0.5 percentage points in 2016 and 2017). Although the rate for workers' contributions was to remain at $4 \%$ until 2015, the reform almost doubled the taxable ceiling of monthly contributions, for workers and employers alike, which rose to 72,140 cordobas (approximately US\$2,816). Starting in 2016, the INSS will adjust the taxable ceiling in line with the average earnings of all INSS-affiliated workers. Another change was made to the formula for calculating the benefits granted to almost 25\% of INSSaffiliated workers (who earn more than 7,000 cordobas -approximately US\$ 272-a month).

The changes in Nicaragua's formula will yield fewer benefits than those obtained under the previous rules (analysts estimate that an additional eight years of work will be needed to maintain the same level of benefits). At the same time, the minimum pensions are calculated on the basis of average earnings and not the minimum wage (studies indicate that the $135 \%$ hike in the minimum wage over the previous five years increased pressure on the resources of the INSS for the coming years). The government hopes that with all these measures, the INSS will assure its sustainable existence until at least 2036. The government did not propose increases in the retirement age — which currently stands at 60 years - or in the weeks 
of contribution needed (750). The International Monetary Fund (IMF) has suggested that Nicaragua increase its retirement age from 60 to 65 and double the contribution weeks from 750 to 1,500 (in other words, from 14.4 to 28.84 years). It has also called for informality in the labour market, which stands at $70 \%$, to be reduced. According to official figures, the informal segment receives low wages, has no access to social security and remains below the poverty threshold (Social Security Administration, 2014).

\section{(b) Structural reforms}

In 1981, under the military regime and following market-favourable options, Chile reformed its pension system: it abandoned a system based on numerous pay-as-you-go funds in favour of a single system using mandatory contributions to individual savings accounts. In addition:

- The contributory regime was kept in place.

- The pay-as-you-go system was replaced by funding in individual accounts.

- Thebenefits defined regime was replaced by defined contributions.

- Fund administration was transferred from parastate funds to private companies.

- State regulation and supervision was strengthened, without an explicit poverty relief component.

- Further reforms were implemented in 2008 to include an explicit poverty relief pillar and improve the competitiveness and efficiency of the private companies. ${ }^{30}$

- A new law was also enacted in 2008 that modified the explicit guarantees of a guaranteed minimum pension and the welfare pension. These were replaced with a solidarity-based pillar that guarantees benefits for $60 \%$ of the poorest families in the shape of the Basic Solidarity-based Pension (PBS) if they have no self-financed pensions and the Solidarity-based Welfare Contribution (APS) to supplement self-financed pensions up to a legally guaranteed minimum.

Following on from the Chilean experience and with the support of international agencies, during the 1990s similar structural reforms were undertaken in the Plurinational State of Bolivia, El Salvador, Mexico (first within the Mexican Social Security Institute (IMSS) and then in the Institute for Security and Social Services for State Workers (ISSSTE)) and the Dominican Republic. In turn, Colombia and Peru maintained parallel

30 See Chile's Law No. 20.255. 
regimes - the original Bismarckian system and mechanisms for funding individual accounts - with contributors allowed to select between the two. Argentina and Uruguay, and later Costa Rica and Panama, opted for a mixed design whereby the Bismarckian system was supplemented, after a certain threshold, with individual funded accounts. In 2010, Argentina abolished the funded component and returned to an exclusive pay-as-you-go system, defined benefits and public administration. ${ }^{31}$ Box IV.4 contains further details on the Chilean case.

\section{Box IV.4}

The Chilean case: funding in individual savings accounts

The foundations of the current Chilean pension system were designed in 1981 under a de facto regime, in the absence of democratic debate and with options that had been selected beforehand. This led to the implementation of a competitive market for the administration of savings accounts in which economics-oriented criteria took precedence over social security considerations. Those guidelines produced an unprecedented underscoring of the contradiction between the principle of equivalence, which facilitated the sale of individual savings contracts by specialized companies, and the principle of solidarity, which ensured universal and affordable access to a decent old age. They also challenged the immunity of contributors from the inherent risks of pension systems that manage long-term savings.

The options selected on that occasion were extreme. The system adopted involved defined contributions, with funding contributed to individual accounts, private management and the State playing a distributive role. Minimum guarantees were established, but the eligibility conditions were highly restrictive. That role was radically changed by the 2008 reform, when the system incorporated a solidarity-based pillar that replaced the guaranteed minimum pension with a combination of four benefits: (i) the basic solidarity-based invalidity pension, (ii) the basic solidarity-based old-age pension, (iii) the solidarity-based invalidity welfare contribution, and (iv) the solidarity-based old-age welfare contribution. The first two benefits were for people who had not contributed, and the second two were intended to boost self-financed pensions up to a minimum level. Both were given to beneficiaries belonging to the country's poorest $60 \%$ of families.

With the return of democracy in 1990, successive governments reviewed the results of the pension system using three criteria: its cost to the treasury, its coverage and its adequacy. In addition, questions were asked about the lack of competition in the market for fund administrators and attention was drawn to the conflicts of interest that arose in connection with the management of the accumulated funds.

31 Looking forward, the available studies show that if reforms are not undertaken, the financial imbalances will continue to grow. In Mexico, prior to the reform, a social security deficit of more than 3\% of GDP was expected in 2017. Similarly, deficits of 3.5\% of GDP in 2015 were forecast for Colombia, and of 5\% of GDP in 2002 for the Plurinational State of Bolivia (Schmidt-Hebbel, 1995; and Von Gersdorff, 1997). 
Box IV.4 (continued)

As described below, in spite of these public finance initiatives to impose a system run by the private sector and the market, the coverage and adequacy results were not good. After the system had been operating for more than 25 years, the government released the figures both for the cost of the transition and for the system's coverage and adequacy. The report of the Marcel Commission - a body made up of experts of different leanings and charged with preparing a diagnostic assessment and proposals for reforming the pension system - states that: "After servicing much of the implicit debt associated with the switch between systems, estimated to be equal to $136 \%$ of GDP at present value, which has meant pension system deficits in excess of $4 \%$ of GDP for several years and which will continue for several years more (Arenas de Mesa, 2006) (...), the system only allowed $45 \%$ of its members to self-finance their pensions and $5 \%$ to qualify for the guaranteed minimum pension, leaving 50\% without protection" (Presidential Advisory Council for Pension Reform, 2006, based on Berstein, Larraín and Pino, 2005).

The main issues to be considered include:

- The conflict between the principles of equivalence and solidarity: the logic of the Chilean system - by being actuarially fair from the individual perspective, with the present value of benefits equal to the present value of contributions - prevents any form of solidarity among members. Therefore, those who for whatever reason have a low capacity for savings over the course of their working lives are ultimately condemned to poverty in old age.

- Risks associated with ageing: questions of contribution density (the frequency with which a member contributes to the system), the amount of those contributions (the mandatory contribution rate), the net profitability obtained (the system's efficiency) and growing life expectancy at retirement age (demographic change) played a fundamental role in determining the benefits received by members. Thus, the system, which seemed immune to the problems of pay-as-you-go systems, caused them to re-emerge with the same strength. The system failed in its ability to avoid welfare shortcomings by failing to consider different working conditions and incentives among its members. Neither did it establish a mechanism for parametric adjustments that would allow pension quality to be assured in the event of low rates of savings, falling fund profitability and demographic change. The system's logic nevertheless blamed the member for not taking the individual, voluntary decision to contribute more over a longer period of time and to choose better investment options. ${ }^{a}$

- Institutional developments. Mention must be made of the efforts undertaken to include citizen participation in the reform discussions. The next step would be to discuss the different dimensions of institutional development, which have come to the forefront in the efforts underway to reconcile efficiency with solidarity and protect the system from the risks affecting it. In order to reconcile the principle of equivalence with solidarity and poverty relief in old age, the following elements were considered: 
Box IV.4 (continued)

- Public participation, promoted by the Marcel and Bravo Commissions. This is perhaps one of the most interesting institutional developments within the Chilean pension system. It entailed convening groups of experts to examine a reform process. It could be classified as organizational, although, paradoxically, it led to the modification of the legal and regulatory framework.

- During both of her Administrations (2006-2010 and 2014-2018), President Michelle Bachelet convened groups of experts to examine the system and suggest improvements. With different variants, the commissions had the following characteristics: they were independent of the government, were chaired by professionals who enjoyed the President's confidence (supported by a government-funded executive secretariat) and their members were convened by means of a decree with a clear mandate. They also comprised multipartite, multidisciplinary teams of specialized professionals who worked on an honorary basis and held consultations with the public and with interest groups that requested hearings. Finally, they adopted non-binding reports that, once approved by the President, were analysed by government technicians with a view to drafting bills for submission to Congress.

- The legal and regulatory dimension of the 2008 reform: universal access and poverty. In light of historic levels of spending on account of the welfare deficit, caused in this case by the transformation of the system, and the harsh evidence of the new system's low rates of coverage and adequacy, the Marcel Commission suggested the creation of a solidarity-based pillar. It was to be integrated into the existing system and allow poverty relief in old age, in that it would subsidize both those not participating in the system and those who had failed to save enough. The main legal and regulatory change that the reform brought about was Law No. 20,255, which amended the existing legal framework and introduced the major changes described above. That change in legislation heightened the importance and permanence of the reform.

- The organizational, technical and operational dimensions of the 2008 reform: multiple parts that must act in coordination. The following diagram shows the new institutional framework for the coordination of the different agencies involved in the structure of the Solidarity-based Pensions System (SPS). Essentially, the institutions and management instruments are strengthened or reformed, or new ones are created, in order to implement four basic functions of Chile's new solidarity-based pension system: the welfare strategy, the administration and operation of the SPS, the regulation and oversight of the system, and public participation and awareness. 
Box IV.4 (concluded)

Institutional framework for solidarity-based pensions

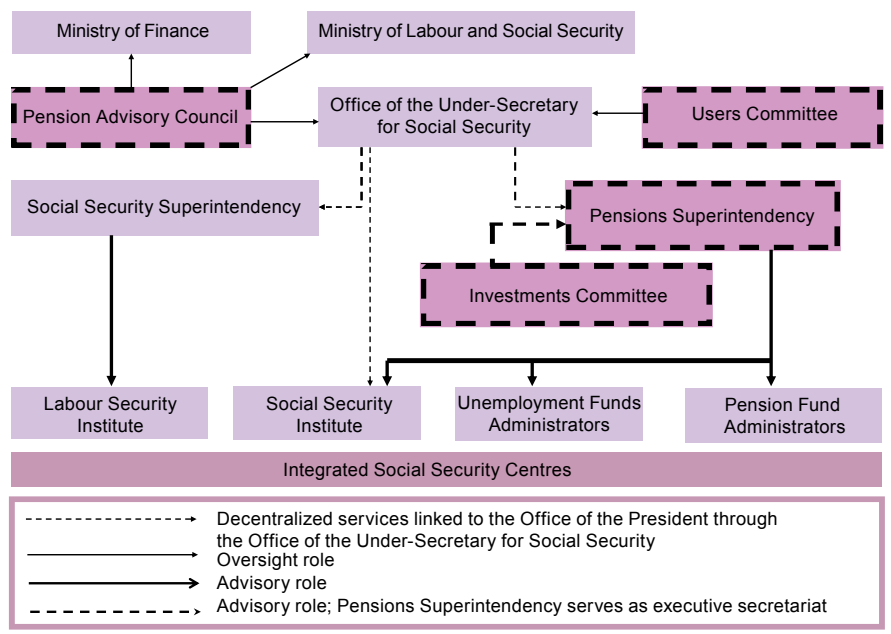

Certain issues related to ageing and contributory and non-contributory funding should be addressed.

- As regards parametric changes for adapting to the demands of ageing, the particularity of the Chilean system is that in order to prevent a drop in pension value, the decision to retire later and save more falls to the individual and is not a matter of public policy. It emphasizes ownership of savings and freedom of choice in supposedly competitive markets.

- The financial management of the contributions made by members to the contributory side of the pension system must be done in such a way to protect the members' rights by properly safeguarding their savings in order to ensure their long-term sustainability. That sustainability remains sensitive to demographic changes, to economic cycles and crises, to fluctuations in the financial market and to the political use of the funds.

- The organizational and operational dimensions. The most important organizational and administrative issues include: the Pension Amount Consultations and Offers System (SCOMP), and the Pensions Superintendency (SUPEN), created by Law No. 20.255 of March 2008 as the successor to and legal continuation of the Pension Fund Administration Superintendency. The new superintendency is a highly professionalized technical control agency, designed to keep strict oversight and control over the SPS (the system managed by the Social Security Institute (IPS)), the Pension Funds Administrators (AFP) and the Retirement Fund Administrator (AFC) (the agency that collects contributions, invests the resources and pays out the retirement insurance benefits).

Source: Office of the Under-Secretary for Social Security, Informe anual 2009, Santiago, Pension Advisory Council, 2010 [online] http://www.previsionsocial.gob.cl/ccp/ documentos/informes/informe-ccp-2009.pdf

a During the past decade, it was decided to create five investment alternatives for contributors (multifunds). The alternatives differ by their levels of risk and expected yield, and according to the investment portfolio of each member. In this way, contributors can select how their savings are to be distributed among the funds. 


\section{Final thoughts}

Pension systems are intended to even out variations in consumption capacity over the course of life. In particular, they should provide income in the event of old age, invalidity and survival following the death of the main breadwinner. They are tools for saving, but also for insurance and transfers. They are guided by principles of social security that seek to ensure access to their benefits by all people, irrespective of their ability to make contributions or pay premiums for the system's funding.

Such systems are therefore subject to vulnerabilities that could hinder the achievement of universal coverage or their own financial sustainability. Their designs are predicated on an institutional framework that can create the conditions for mitigating the risks and vulnerabilities that determine their results. Those institutional developments are classified into the four dimensions described at the beginning of this book. From the cases illustrated, the following issues are worthy of note:

- As regards the legal and regulatory dimension, pension systems require a regulatory framework that sets principles whereby they can be structured around three pillars: contributory, noncontributory and semi-contributory. The goal is to ensure entitlement to rights in the event of old age, disability and death, through a system that combines different ways to interconnect rights and obligations.

- As regards the organizational dimension, extreme solutions do not work. Efforts must be made to avoid creating exclusion through extremes in funding or financial management, in correlations between contributions and benefits and in choosing between public or private administration or between universal or targeted welfare assistance. The rapid process of ageing within the population must be quantified because of the strength of demographic trends and the weak ability of the labour market to promote social inclusion, which create dilemmas and changes in the context in which the systems operate that no paradigm based on exclusion can address. Institutional developments must adapt to the changing, heterogeneous nature of those contexts, allowing articulation between different ministries.

- Regarding the operational and instrumental dimension, there is no single instrument that can assure the objective of guaranteeing all persons dignity in their old age. On the contrary, the absence of inclusive labour markets leads to a low density of contributions over active members' productive life cycles. That, together with the low profitability associated with both the growth of the 
work force and the returns on financial assets, demands new instruments for addressing permanent imbalances between obligations and rights. Countries are discussing the incorporation of instruments that combine criteria of efficiency and equity to deal with those factors. The development of effective mechanisms for democratic management, with high levels of transparency in public accounts, accountability about resource management and decision-making, and civil society participation in the preparation of reform proposals are all essential parts of the technical and organizational implementation needed to ensure effectiveness and equity in systems.

- Finally, as regards the fiscal dimension, the evidence of rapid population ageing, with a labour market that is weak in terms of social inclusion, underscores the need to rethink the mechanisms in place to ensure solidarity and social protection. The labour market has failed to demonstrate a capacity for inclusion through either the creation of decent work or the generation of adequate contribution levels. Notwithstanding the promotion of policies to create more and better jobs, in the short and medium terms employment cannot be expected to represent an adequate source of funding to protect most of the population from risks related to ageing. This situation requires a rethinking of social protection within a framework of comprehensive solidarity that combines contributory and noncontributory mechanisms. As a result, consensus must be built for a fiscal pact and a new social compact where social rights are the regulatory goal and where inequalities and budgetary constraints are assumed as limitations to be recognized and addressed. In other words, the ethical imperatives that underpin a compact focused on social rights must be reconciled with the financial restrictions of each specific context. At the same time, in order to expand coverage and raise service quality -in particular for those sectors with the least resources- efficiency in the use made of those resources must be enhanced (ECLAC, 2006).

As noted by ECLAC (2015), in heterogeneous and unequal societies such as those of Latin America, no single model offers all the answers. As regards pensions, the individual funded system of the Chilean experience (including its solidarity-based pillar) and those of other countries in the region face shared challenges. These are related to the rapid ageing of the population caused by factors including demographic change, low contribution densities caused by labour precarity and structural vulnerability, emergent policies for dealing with the ups and downs of the macroeconomic cycle and the need to establish priorities to address the fragility of long-term fiscal sustainability. 
Faced with the question of how to guarantee everyone affordable access to a dignified old age, regardless of their savings capacity, countries must continue working to combine the following approaches:

- The responsible interconnection of contributory and noncontributory funding.

- The organization of implicit or explicit cross-subsidies from people or economic agents with a high capacity for savings to individuals with low capacities.

- The definition of decent benefits in response to the rights arising from being a citizen or having contributed financially to the system.

- Implicit or explicit parametric adjustments to reconcile financial sustainability with the adequacy of benefits and changes in demographics and the labour market.

- Policies to improve the inclusion capabilities of the labour market.

- Determination of the ownership and destination of pension funds when they exist.

- Prudent regulation to ensure the profitability of those funds on the financial markets.

Pension systems operate in specific contexts that, in Latin America, are characterized by the heterogeneity of their workers' working conditions and by the vulnerability faced by their families. Systems based exclusively on contributory funding and on welfare entitlement through defined contribution regimes lead, in old age, to the replication of the same types of precarity that members suffer during their formative years and working lives. A different situation is found in systems that use higher funding quotas to implement cross-subsidies between their members and beneficiaries: they ensure universal access to a minimum level of dignity in old age but, at the same time, they suffer from weaker financial sustainability.

Social security systems to ensure welfare must address the causes that reproduce, in old age, the inequality seen in the region's societies throughout all stages of the life cycle. This chapter has focused on the institutional developments needed to reconcile the financial sustainability of a pension system from one generation to the next with the amount of solidarity necessary to support those who experienced precarious conditions in earlier stages of the life cycle and were excluded from the benefits of growth. The analysis of the Chilean experience highlights the limitations for this task that are contained in the constitution of explicit regulatory frameworks and public cultural values. The Chilean system, based exclusively on a contributory pillar that uses funding of individual 
savings accounts and a limited network of subsidies that uses a solidaritybased pillar, has been unable to resolve the fragility arising from the realities of the labour market and inequality. The near future may very well see broad discussions and reforms of the four points identified in the previous paragraph. This would help improve the low adequacy of the benefits with which the Chilean system has expanded its coverage, where $79 \%$ of beneficiaries receive pensions below the minimum wage (US\$ 350) and $44 \%$ below the poverty line (US\$127.30).

In order to further the principles of social security, the region's countries must make increasing efforts to: (i) combine sources of funding, (ii) manage those funds with both pay-as-you-go and funded mechanisms, (iii) establish defined levels of minimum benefits and incentives to encourage greater individual saving, and (iv) develop publicprivate partnerships to administrate the system in order to reconcile sustainability and solidarity. Ultimately, what is needed is a State policy with an institutional framework than can assure everyone a dignified old age, by interconnecting the pensions component with other social protection measures.

\section{Bibliography}

Arenas de Mesa, A. (2006) "Gasto público y pensiones: la experiencia chilena", presentation at the XVIII Regional Seminar on Fiscal Policy [online] http:// www.cepal.org/ilpes/noticias/paginas/0/23680/Alberto\%20Arenas.ppt.pdf. (1999) “Efectos fiscales del sistema de pensiones de Chile: proyección del déficit previsional 1999-2037", paper presented at the seminar on fiscal responsibilities of the pension systems, Santiago, Ministry of Finance.

Arenas de Mesa, A. and M. Marcel (1999), "Fiscal effects of social security reform in Chile: the case of the minimum pension", paper presented at the Second APEC Regional Forum on Pension Fund Reforms.

Barr, N. and P. Diamond (2008), Reforming pensions: principles and policy choices, New York, Oxford University Press.

Berstein, S., G. Larraín and F. Pino (2005), "Datos y perspectivas de la cobertura en la reforma de pensiones de Chile", presentation at the AIOS Technical Commissions Meetings in Colombia.

Bertranou, F. M. (2013), "Restrictions, problems and dilemmas of social provision in Latin America: facing challenges from aging and income inequality", Well-Being and Social Policy, vol. 1, No. 1, International Labour Organization (ILO).

Bertranou, F. and F. Grafe (2007), "La reforma del sistema de pensiones en Brasil: aspectos fiscales e institucionales", Inter-American Development Bank (IDB), draft [online] http:/ / www.iadb.org/res/publications/pubfiles/pubCSI-145_esp.pdf.

Budgetary Affairs Bureau (2007), "Fondo de Reserva de Pensiones. Informe trimestral a marzo 2007" [online] http:/ / www.dipres.gob.cl/572/articles-21683_doc_pdf.pdf.

Calvo, E., F. Bertranou and E. Bertranou (2010), "Are old-age pension system reforms moving away from individual retirement accounts in Latin America?", Journal of Social Policy, vol. 39, No. 2, Cambridge University Press. 
Cecchini, S. and R. Martínez (2012), Inclusive social protection in Latin America: a comprehensive rights-based approach, ECLAC Books, No. 111 (LC/G.2488-P), Santiago, Economic Commission for Latin America and the Caribbean (ECLAC).

CELADE (Latin American and Caribbean Demographic Centre-Population Division of ECLAC) (2015), "Population estimates and projections", Santiago, Economic Commission for Latin America and the Caribbean (ECLAC).

(2011), "Population estimates and projections", Santiago, Economic Commission for Latin America and the Caribbean (ECLAC).

Chile (2008), "Ley $\mathrm{N}^{\circ} 20.255$ que establece reforma previsional", Santiago. (1980), “Decreto Ley N ${ }^{\circ} 3.500$ que establece nuevo sistema de pensiones", Santiago.

ECLAC (Economic Commission for Latin America and the Caribbean) (2015), Inclusive social development: the next generation of policies for overcoming poverty and reducing inequality in Latin America and the Caribbean (LC/L.4056(CDS.1/3)), Santiago.

(2014), "Landmarks in the discourse on social protection in Latin America and overview of health and pension system coverage: a synopsis", Social Panorama of Latin America, 2013 (LC/G.2580), Santiago.

(2012), Social Panorama of Latin America, 2011 (LC/G.2514-P), Santiago.

(2006), Shaping the Future of Social Protection: Access, Financing and Solidarity (LC/G.2294(SES.31/3)), Santiago.

FIAP (International Federation of Pension Funds Administrators) (2016), Los sistemas de pensiones multipilares: invirtiendo en el futuro, Santiago.

(2011), Informe Semestral, No. 31, Santiago, June [online] http:// www.fiapinternacional.org/wp-content/uploads / 2016/01/informe_ semestral_n_31-1.pdf.

Filgueira, F. and others (2006), “Universalismo básico: una alternativa posible y necesaria para mejorar las condiciones de vida", Universalismo básico: una nueva política social para América Latina, C. G. Molina (ed.), Mexico City, Inter-American Development Bank (IDB)/Editorial Planeta [online] http://www.iadb.org/ wmsfiles/products/publications/documents/2220408.pdf .

Fultz, E. (2012), "The retrenchment of second-tier pensions in Hungary and Poland: a precautionary tale", International Social Security Review, vol. 65, No. 3.

Hohnerlein, E. M. (2013), "Pension re-reform in Argentina", Zeitschrift für ausländisches und internationales Arbeits- und Sozialrecht (ZIAS), No. 3/2012.

Maldonado, C. and A. Palma (2014), "El caso de la reforma previsional chilena 2005-2008", Social Policy series, No. 183 (LC/L.3665), Santiago, Economic Commission for Latin America and the Caribbean (ECLAC).

Mesa-Lago, C. (2004), "Las reformas de pensiones en América Latina y su impacto en los principios de la seguridad social", Development Financing series, No. 144 (LC/L.2090-P), Santiago, Economic Commission for Latin America and the Caribbean (ECLAC).

Ministry of Social Welfare (2010), "Análisis de seguridad social, 2009".

OECD (Organization for Economic Cooperation and Development), "OECD Pensions Outlook 2012" [online] http://www.oecd.org/finance/privatepensions /50560110.pdf.

Office of the Under-Secretary for Social Security (2016), “Comité de Ministros sobre el Sistema de Pensiones" [online] https://www.previsionsocial.gob.cl/sps/ biblioteca/comite-ministros-sistema-pensiones/. 
(2013a), "Propuestas para mejorar pensiones de vejez" [online] https:// www.fiapinternacional.org/wp-content/uploads/2016/01/estudio_chile_ propuestas_sistema_pensiones.pdf.

(2013b), Consejo Consultivo Previsional. Tercer Informe. Agosto de 2011 hasta diciembre [online] http://www.previsionsocial.gob.cl/ccp/documentos/ informes/informe-ccp-2012.pdf.

(2010), Informe anual 2009, Pension Advisory Council [online] http:/ /www. previsionsocial.gob.cl/ccp/documentos/informes/informe-ccp-2009.pdf.

Pension Advisory Council (2009-2014), Informe anual [online] http://www. previsionsocial.gob.cl/ccp/informes.php.

Peña, M. (2012), "Instrumento técnico de focalización del sistema de pensiones solidarias" [online] http://www.previsionsocial.gob.cl/cu/wp-content/ archivo/2012-01-09-Acta-Ord-32-Adjunto-Instrumento-Tecnico-FocalizacionSPS-MPena.pdf.

Presidential Advisory Commission on the Pension System (2015), Informe final, Santiago [online] http://www.comision-pensiones.cl/Documentos/ GetInforme and https://prensa.presidencia.cl/lfi-content/otras/informescomisiones/InformePensiones.pdf.

Presidential Advisory Council for Pension Reform (2006), El derecho a una vida digna en la vejez. Hacia un contrato social con la previsión en Chile [online] https:/ / www.previsionsocial.gob.clsps/download/estudios-previsionales / comisionpensiones / documentos-interes-general/informe-consejo-asesorpresidencial-reforma-del-sistema-previsional-comision-marcel-2006.pdf.

Rivera, E. (2014), "La reforma previsional de 2008 en Chile. Un análisis desde la política pública", Pactos sociales para una protección social más inclusiva. Experiencias, obstáculos y posibilidades en América Latina y Europa, M. Hopenhayn and others (eds.), Seminars and Conferences series, No. 76 (LC/L.3820), Santiago, Economic Commission for Latin America and the Caribbean (ECLAC).

Rofman, R. and M. L. Oliveri (2011), "La cobertura de los sistemas previsionales en América Latina: conceptos e indicadores", Working Paper, No. 7, World Bank [online] http://siteresources.worldbank.org/INTARGENTINAINSPANISH/ Resources/CoberturaPrevisionalLAC.pdf.

Schmidt-Hebbel, K. (1995), "La reforma pensional colombiana: efectos fiscales y macroeconómicos", Bogota, Colombian Association of Severance Pay and Pension Funds Administrators (ASOFONDOS).

Social Security Administration (2015), "International Update”, May [online] https:/ / www.ssa.gov/policy/docs/progdesc/intl_update/2015-05/index.html.

(2014), "International Update", February [online] https://www.ssa.gov/ policy/docs/progdesc/intl_update/2014-02/2014-02.pdf.

(2013), "International Update", June [online] https:/ /www.ssa.gov/policy/ docs/progdesc/intl_update/2013-06/index.html.

(2011), "International Update", March [online] https://www.ssa.gov/ policy/docs/progdesc/intl_update/2011-03/.

Social Watch (2010), European Social Watch Report 2010. Time for Action: Responding to Poverty, Social Exclusion and Inequality in Europe and Beyond [online] http:// www.socialwatch.eu/wcm/home.html. 
Sojo, A. (2007), "Evolution of the link between selective anti-poverty policies and social sectors policies", CEPAL Review, No. 91 (LC/G.2333-P), Santiago, Economic Commission for Latin America and the Caribbean (ECLAC). (1990), "Nature and selectiveness of social policy", CEPAL Review, No. 41, Santiago, Economic Commission for Latin America and the Caribbean (ECLAC) [online] http://repositorio.cepal.org/handle/11362/11784.

Superintendency for Pensions (n/d) [online] http://www.supen.fi.cr/.

UNDP (United Nations Development Programme) (2011), Human Development Report, 2011. Sustainability and Equity: A Better Future for All, New York.

Uthoff, A. (2016), "Aspectos institucionales de los sistemas de pensiones en América Latina", Social Policy series, No. 221 (LC/L.4282), Santiago, Economic Commission for Latin America and the Caribbean (ECLAC).

(2011), "Reforma al sistema de pensiones chileno", Development Financing series, No. 240 (/LC/L.3422), Santiago, Economic Commission for Latin America and the Caribbean (ECLAC) [online] http://repositorio.cepal.org/ bitstream/handle/11362/5221/1/S1100849_es.pdf.

Von Gersdorff, H. (1997), "Pension reform in Bolivia: innovative solutions to common problems", Policy Research Working Paper, No. 1832, Washington, D.C., World Bank.

World Bank (1994), Averting the Old-Age Crisis, New York, Oxford University Press [online] http://documentos.bancomundial.org/curated/es/1994/09/698030/ averting-old-age-crisis-policies-protect-old-promote-growth. 


\title{
Chapter V
}

\section{Care as a pillar of social protection: rights, policies and institutions in Latin America}

\author{
María Nieves Rico ${ }^{1}$ \\ Claudia Robles ${ }^{2}$
}

\section{Introduction ${ }^{3}$}

Care is a social function, a public good and a basic right, without which it is impossible to conceive of society's existence and reproduction. It evokes the very concept of humanity at a fundamental level: all of us have needed special care during our childhood and we will probably need it when we reach old age, depending on our level of dependency. Moreover, persons who live with a disability or face chronic or terminal illnesses require care, either permanently or more intensively at certain stages of their lives. Awareness of the fact that all people need care changes the perspective from which social responsibilities and interdependency between individuals are

1 Director of the Gender Affairs Division of the Economic Commission for Latin America and the Caribbean (ECLAC).

2 Social Affairs Officer of the Social Development Division of the Economic Commission for Latin America and the Caribbean (ECLAC).

3 This chapter summarizes the key findings of the study titled Politicas de cuidado en América Latina: forjando la igualdad (Rico and Robles, 2016) and new reflections by the authors included in ECLAC (2016a, 2016b and 2017a). The authors thank Gwendoline Peltier for her assistance in systemizing care programmes and laws in Latin America. 
analysed in terms of rights and obligations (Tronto, 1993). Moreover, from the policy standpoint, it is fundamental to consider care as a process in public actions of major impact in the private sphere and in social relations.

Care is a crucial issue for public policies and governments, since it constitutes a precondition for sustainable social and economic development. The conditions under which it is provided are fundamental, for example, to guarantee the comprehensive growth of children, as well as for dignified aging. Another priority is to address the situation of persons who are responsible for providing home-based care - a role that women generally play in societies that are still marked by a patriarchal culture, an unbalanced gender division of labour and gender stereotypes about who should fulfil this social function. It is culturally established as a responsibility falling on mothers, daughters, sisters, grandmothers, aunts, daughters-in-law and female neighbours, among other family and social ties. As women's movements and feminist studies have emphasized, women often provide care at the expense of their rights and their economic, political, and even physical autonomy. A major or total workload of unpaid care reduces the possibility of undertaking paid employment and gaining access to positions of power under equal conditions. In its most extreme form, it prevents women from exercising their right to a life free of violence, which is closely linked to their economic autonomy. Those who participate in paid care work - for example, paid domestic workers, nurses, educators and caregiversface more precarious working conditions, with less or no access to social security and protection, lower wages and a higher probability of falling into poverty than those who participate in other sectors of the economy (ECLAC, 2013a and 2016b). This panorama is exacerbated when the interweaving of ethnic and racial inequalities and class are considered. ${ }^{4}$

Unpaid care work in households, in conjunction with minimal, zero or unequal participation in paid employment, has individual consequences throughout a woman's life cycle. Nonetheless, women remain unrecognized or unremunerated on a broader economic, political and social level, and this situation also has consequences for the wellbeing of households and the persistence of poverty (ECLAC, 2013a). Women assume the personal cost of a social function that is crucial for guaranteeing the reproduction of societies, and even the sustainability of public policies, particularly social policies. This represents women's major silent contribution to the economy and development of their countries. ${ }^{5}$

4 Most women provide care directly or indirectly in their homes, often as their main or full-time activity. Nonetheless, care work is also driven by other inequalities, apart from gender per se. Thus, poor women, indigenous women and Afrodescendants are all over-represented in paid domestic work in nearly all countries of the region (Rico and Vaca-Trigo, 2016).

5 According to the valuation and satellite accounts of unpaid work in households done in eight Latin American countries, the economic contribution made by this category is equivalent to between $11.5 \%$ of GDP in Costa Rica (2011) and 18\% in Mexico (2014). Women's contribution to the total economic value of unpaid work is considerably greater than that of men, representing between $70 \%$ (Peru) and 87\% (Guatemala) of the total GDP-equivalent value of unpaid work (ECLAC, 2017a). 
Recognizing, valuing, redistributing and influencing the dynamics of care in Latin America is an urgent priority within an agenda of human rights, gender and political and social sustainability. Intervening in the way care is accessed and provided is a precondition for halting the intergenerational transmission of poverty in households, guaranteeing universal social protection to all citizens, and moving towards more egalitarian societies.

This chapter attempts to establish care policies as a crosscutting pillar of social protection. It proposes a number of basic elements to be considered in the design of integrated care systems; and it analyses the degree of progress made in their formulation and the challenges that their implementation poses for social institutions in Latin American countries. The chapter closes with an analysis of the implications and opportunities of applying an integrated approach to these policies and fully incorporating them into social protection systems in the region, mainstreaming a genderequality approach in their design from the outset.

\section{A. Care as a public good: elements for policy design}

Care work is a social function that encompasses the series of activities, goods and relationships that preserve people's daily well-being in material, economic and emotional terms (ECLAC, 2013a, Marco and Rico, 2013). It includes the provision of goods that are essential for life, such as food, shelter, hygiene and accompaniment; as well as support and the transmission of knowledge, social values and practices through the processes of upbringing (Razavi, 2012). It is based on "face to face" relationships between those who receive care and those who provide it, whether paid or unpaid. Accordingly, care policies must cover both the caregivers and those who require care services, including children, older adults, and persons with disabilities or with a chronic or terminal illness that renders them dependent. ${ }^{6}$

In Latin America, the work of care provision is mostly done unpaid by women at home; the growth of public care services remains limited. For example, the available regional evidence shows that children up to three years of age are mostly cared for by women in households under eminently family-based regimes of well-being and the dominant patriarchal system. ${ }^{7}$

This issue has emerged as a key public policy priority since the emergence of what has been termed the "care crisis" (ECLAC, 2011), in other

Care is defined here as support or direct assistance provided to persons with some degree of dependency, that is, those who need some kind of support or assistance to carry out essential activities of daily life, such as eating, bathing, dressing, moving about and travelling outside the home (Salvador, 2015).

7 See Berlinski and Schady (2015), who consider data for Brazil, Chile, Ecuador, Guatemala, Nicaragua and Uruguay, based on the processing of several national surveys. 
words the growing trend of a population that is dependent on increasing care, with changing demands and needs, and a shrinking base of unpaid caregivers, as women's labour market participation intensifies (Rossel, 2016), without any redistribution of this work within the household owing to men's meagre participation. ${ }^{8}$ This agenda has also been consolidated as part of the social claims and human rights of the populations that require care, including elderly or disabled persons in situations of dependency.

Viewing care as a public issue means reorienting the way this social function has traditionally been conceived as the primary responsibility of families, and specifically of women. This calls into question the institutional bases that define who should assume the costs of social reproduction and how the burden of care is distributed in societies. The fact that public policies have an undeniable role in this process of change has at least three consequences.

First, it places its responsibility on other actors that extend beyond the family and include the market and civil society; and it requires a new social covenant that explicitly gives the State the role of guarantor in safeguarding the right to care (Pautassi, 2007). Within the family, it establishes the need for co-responsibility between men and women. Secondly, it highlights the need to adopt comprehensive and integrated measures on behalf of those who require care and those who provide it. Third, it implies recognizing interconnections with other social policies, including those targeting children and older adults, and also those relating to labour, health, education, social security and social protection, and gender equality.

Thus, public care policies underpin the daily physical and emotional well-being of persons who are subject to some level of dependency; and they intervene in the social organization of care, with the aim of working towards substantive equality between men and women. These policies directly affect the distribution of care responsibilities between the State, the market, families and communities; so they also affect welfare regimes and the role of social protection in how they are organized.

Some of the dimensions that can be considered in their design, mainstreaming a rights and gender approach in their institutional organization, are listed below. ${ }^{9}$ Firstly, the care provided in the home and outside it, whether paid or unpaid, and by diverse actors: individuals as members of a family or household, mainly women, the private sector, the community and public care services. Consideration should also be given to those who require and provide care, organized according to the

According to ECLAC (2011), the number of persons subject to moderate to severe dependency is set to double between 2000 and 2050.

9 This section includes proposals developed by many different authors: Batthyány (2015); Blofield and Martínez (2014); CEPAL (2013a); Ellingsaeter (1999); Huenchuan (2014); Lamaute-Brisson (2010); Marco (2007), Marco and Rico (2013) and Salvador (2011). 
different degrees of dependency of the persons being cared for. Moreover, the instruments considered must be structured according to the objectives to be safeguarded..$^{10}$ To that end, at least four structural dimensions of policies, subsystems or comprehensive and integrated care systems need to be defined: economic resources, time, services (Ellingsaeter, 1999; Pautassi, 2007) and regulatory policies that define quality standards, and the labour regulations associated with their development (Gascón and Redondo, 2014, Marco, 2014). Lastly, given their multidimensional nature, these measures need to be articulated in an intersectoral and interagency manner, through policies on health, education, gender equality, family, social security and employment, among others.

The resulting instruments are varied. Firstly, the economic resources allocated for this purpose may include direct cash transfers to hire care services, or else to compensate unpaid caregivers for their work, with the State playing a role in the payment of their social security contributions. Subsidies could also be instituted for the supply of public and private care services.

Secondly, time-related policies refer to the mechanisms and regulations that allow caregivers to take leave and have times for children and other family members in situations of dependency, with protection for their employment conditions. These may include policies to reconcile work and family care responsibilities, including those related to working hours and their flexibility as to times and places of work, as well as parental leave. These basically correspond to the scope of employment policies and the regulation of labour markets as elements of social protection (see chapter III); and, at the same time, they can be actively promoted from the private sector.

Thirdly, public services offer the most direct response to ensure that care can be accessed by the individuals who require it. They may also include benefits for caregivers, such as respite services that allow families with severely dependent members to receive home care, training and psychological support, among other things. Lastly, the existence of standards and regulations governing how care is provided, and the quality of employment in this sector, are also indicative of the role played by the State in regulating, organizing and guaranteeing the right to care, even though it may actually be provided by the private sector.

The following scheme proposes a menu of options for the design of policies and integrated care systems. Two dimensions are combined: first, policies relating to time, financial resources, services and the regulation

10 For example, Blofield and Martínez (2014) distinguish three types of policies to reconcile work and family life: (i) sequential, associated with the protection of income and employment of caregivers (leave periods, employment flexibility and part-time jobs); (ii) those that explicitly seek to shift responsibility for the provision of care away from families and women and on to the State, by promoting the service sector; and (iii) policies that seek to regulate domestic employment. 
of care; and, second, the application of these policies to the different care populations, while mainstreaming a gender and a rights-based approach in their design (see diagram V.1).

\section{Diagram V.1}

\section{Components of an integrated care policy}

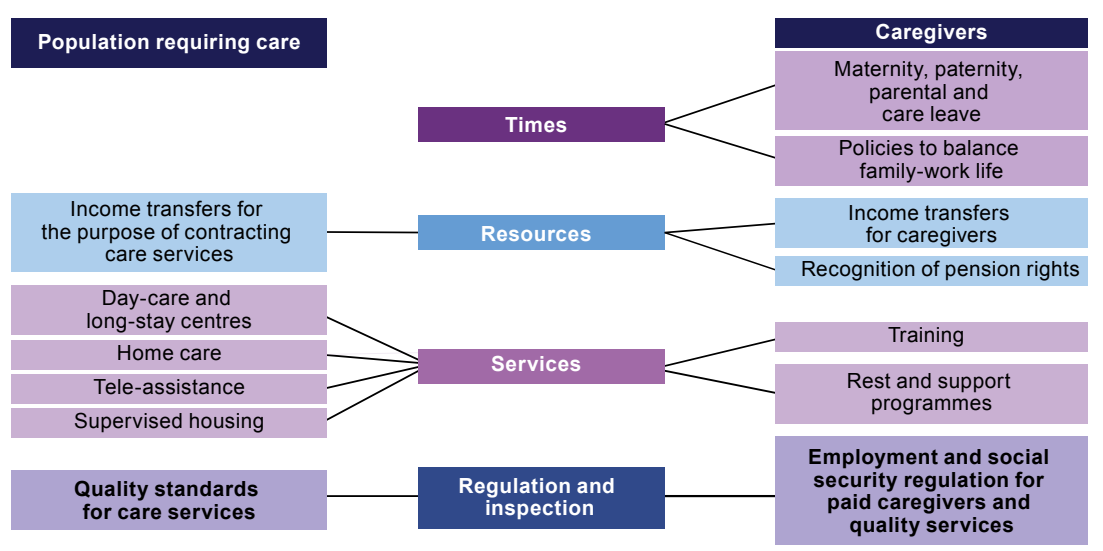

Source: M. N. Rico and C. Robles, "Políticas de cuidado en América Latina: forjando la igualdad", Gender Affairs series, No. 140 (LC/L.4226), Santiago, Economic Commission for Latin America and the Caribbean (ECLAC), September 2016.

The way care policies are designed and responsibilities are redistributed is not neutral from the standpoint of gender equality and women's autonomy. The policies can contribute to those objectives through measures that encourage co-responsibility for care between men and women. Parental leave arrangements that do not assign the responsibility and costs of reproduction and care exclusively to women, or which guarantee universal access to public care services, could also be included. Otherwise, care policies could have adverse effects on gender equality if their design reinforces maternalistic orientations that place the primary responsibility on women (Blofield and Martínez, 2014 and 2015). For example, it has been argued that paying direct cash transfers to those who provide unpaid care, usually women, helps to reinforce the gender roles that perpetuate the unequal distribution of work in the region (Matus and Vega, 2016). This would occur because the transfers reaffirm the idea that care work can be recognized through a small cash benefit, without guaranteed access to social security - far from the standards of decent work and quality employment, and with no incentive for men to participate in this work. Moreover, care services that do not include quality standards for employment in this sector, mostly undertaken by women in Latin America, consolidate the job insecurity and social vulnerability from which they suffer. 


\section{B. Integrated care policies as a pillar of social protection: institutional challenges}

As shown in diagram V.1, there are multiple interrelationships between the potential instruments of an integrated care policy and those that have traditionally been viewed as pertaining to social protection. Other examples include the regulatory instruments of the labour market, which can simultaneously perform functions such as employment, social protection and care policies, such as those that establish a minimum wage or maximum working hours (ECLAC, 2016b). Moreover, the mechanisms of pension recognition for female caregivers could include the set of non-contributory social pensions that mainly benefit women in the region. ${ }^{11}$ In other cases, programmes that are on the border between employment and social protection policies could take account of the specific vulnerability faced by unpaid caregivers. Examples are training programmes and labour intermediation services that involve cash transfers for the purpose of hiring care services, thereby allowing women to enter paid employment (ECLAC, 2016a).

An integrated care policy should be considered as a crosscutting pillar of social protection (Rico, 2014), since care needs and practices embody social risks that can render the persons who require or provide it highly vulnerable, by preventing them from exercising their social and economic rights and exposing them to income insecurity and poverty. At one extreme are the elderly, persons with disabilities or the terminally ill who, lacking economic resources or family care networks, and faced with the fragmentation of social protection systems in the region, do not have access to social care services. Families that use a large portion of their income to care for persons in situations of dependency also fall into this category. At the other extreme is a very large proportion of women in Latin America who provide care for diverse populations, without pay or social protection; and with severe restrictions on their own participation in the labour market (Rico and Robles, 2016), given the time constraints, and without social recognition for their work. According to data from the Economic Commission for Latin America and the Caribbean (ECLAC) based on time-use surveys, women perform between $71 \%$ and $86 \%$ of all unpaid work needed by households (ECLAC, 2016b, p. 62). Moreover, between $12 \%$ and $66 \%$ of women between the ages of 20 and 59 years in Uruguay and El Salvador, respectively, are out of the labour market for family reasons (ECLAC, 2016b, p. 60).

This context highlights the need for the pillar that constitutes a care policy and the social protection system as a whole, to both explicitly mainstream gender equality in order to achieve balanced and coherent integration between policy objectives, impacts and instruments.

11 A review of these pensions and their coverage can be found in Marco (2016). 
Thus, a care policy forming part of social protection systems should consolidate certain conditions. First, those who require care should receive it through quality services; access to care in the market should not intensify poverty in the home; and care work should not create barriers to education and employment under equal conditions between men and women. Second, care should not imply exclusion from social security, threaten economic autonomy or consolidate vulnerability among women caregivers; instead it should redistribute their burden.

With this social function in mind, care policies should be viewed from a comprehensive perspective, since they require coordination between different sectors and social policy actors; and they should deploy approaches and instruments to address the specifics of those who provide and require care. The perspective should also be an integrated one, considering the simultaneous operation of various instruments along with universal citizenship rights, rather than sectoral approaches and attention to specific population groups. It should also uphold the principle of equality and non-discrimination in a rights-based approach based on the mandate to take priority and positive actions in favour of those who are in a situation of greatest vulnerability or clear disadvantage, such as women.

These postulates merge with the institutional challenges facing social care in the region (see chapter II), while they also invoke the specific institutional framework of social protection in Latin America on various fronts. Firstly, they pose an organizational challenge in terms of articulating the entities that manage care policies with the coordination mechanisms of the social protection systems. These include executive secretariats, councils, social ministries and others (ECLAC, 2016a), which form part of the construction of a long-term strategy and represent a stable component of the region's social institutions.

In terms of instruments, substantive and operational overlap is also required between those that pertain to care policies and social protection. This not only means formal articulation, so that care programmes can be officially included in social protection systems, but also the possible redesign of instruments to guarantee gender mainstreaming. For example, cash transfer programmes may involve conditionalities that reinforce the unequal division of productive and reproductive work (ECLAC, 2013b), especially if there are no incentives for care to be provided jointly by men and women. The same occurs with mechanisms giving preferential access to care services for families prioritized by social protection systems that hinder women's full incorporation into employment owing to their unpaid workload; or with mechanisms to recognize pension rights recognition for women who have done unpaid care work during their life, or the relaxation of the conditions of access to social security for workers in the informal and care sectors. Consistency between the gender equality and 
rights-based approaches, considering the specifics of the life cycle, and in the design of care policies and their articulation with social protection systems requires sound institutional management, with adequate technical capacities and policies in the teams responsible for the various phases of their implementation and evaluation. It also raises a specific requirement for the consideration and implementation of social participation and oversight spaces, as well as for accountability, where the diverse views of the actors involved in social care and protection are expressed.

\section{The nascent institutionalization of care policies in Latin America: opportunities and challenges in their articulation with social protection systems}

Under a shared regulatory framework, but also with specific country features, care policies and programmes are starting to expand progressively in the region. The situation of care policies in Latin America, as described below, varies between countries that have a minimal programmatic range and those that have a broader one. All countries have at least one care policy, most frequently targeting child care. The range of situations includes pioneering experiences in countries that are moving towards creating a specific institutional framework for their approach, while also articulating integrated care policies into social protection systems, albeit in a very incipient manner. ${ }^{12}$

\section{A common and differentiated regulatory framework: is the right to care established?}

Care policies are becoming institutionalized in a national and international legal framework that is itself a work in progress. In terms of international instruments, which are indicative of the commitments assumed by the countries of the region in this area, one that stands out is the Montevideo Strategy for the Implementation of the Regional Gender Agenda within the Sustainable Development Framework by 2030, recently endorsed by all governments of the region at the thirteenth session of the Regional Conference on Women in Latin America and the Caribbean (ECLAC, 2017b). This Strategy establishes that one of the structural impediments that need to be overcome in order to advance towards a

12 The analysis presented here is based on a review of the institutional framework for care policies in 20 Latin American countries. To that end, primary data available up to 2015 was gathered in five analytical dimensions: (i) the legal-normative framework of the policies; (ii) programmatic supply; (iii) the coordinating entities; (iv) mechanisms for participation and construction of social and fiscal covenants for their operation as part of their technical-operational and planning features; and (v) their financing. These dimensions are linked to those considered in this volume for the analysis of social institutions in Latin America (see chapter I) and also ECLAC (2016a). Further background can be found in Rico and Robles (2016). 
sustainable development with equality is the gender division of labour and the unfair social organization of care. Nonetheless, the tridimensional nature of care rights, consisting of the right to provide care and to receive it and the right to care for oneself (Pautassi, 2007) is still no more than a provisional reality in international regulatory frameworks.

Although target 5.4 of the Sustainable Development Goals explicitly calls upon States to recognize and value unpaid care and domestic work through the provision of public services, infrastructure and social protection policies, together with the promotion of a shared responsibility in care (United Nations, 2015), in practice, only two human rights instruments refer comprehensively to the creation of integrated care systems as a component of social protection. These are: the Inter-American Convention on the Protection of the Human Rights of Older Persons, which is binding on its signatories and was approved in 2015 by the General Assembly of the Organization of American States (OAS, 2015), and the Political Constitution of Mexico City, of 5 February 2017. This instrument also explicitly establishes the right to care and the obligation of the authorities to set up a care system that considers both those who provide care and those who need it, and which integrates public services and policies (Article 9.B).

International conventions and treaties refer mainly to the services provided to people in situations of dependency. Examples include the Convention on the Rights of the Child (CRC) (United Nations, 1989), the Convention on the Rights of Persons with Disabilities (United Nations, 2006) and the Recommendation on Social Protection Floors, 2012 (No. 202) of the International Labour Organization (ILO, 2012). In other cases, specific instruments for caregivers are guaranteed, such as maternity leave, sanctioned by the Maternity Protection Convention, 2000 (No. 183) (ILO, 2000) and the Workers with Responsibilities Convention, 1981 (No. 156) (ILO, 1981), or the rights of paid care-providers in the Domestic Workers Convention, 2011 (No. 189) (ILO, 2011a) and the Recommendation concerning Decent Work for Domestic Workers (ILO, 2011b).

There is an important precedent in the Convention on the Elimination of All Forms of Discrimination against Women (United Nations, 1979), which highlights the concept of care as a public good together with social and gender co-responsibility, including the incentive to provide social support services and the existence of maternity leave. ${ }^{13}$ Shared responsibility in the provision of care between men and women, families, the State and the market, as well as the valuation of unpaid work, are also key concerns in the government agreements reached at the various

13 Article 5 of the Convention on the Elimination of All Forms of Discrimination against Women states that States parties should "ensure that family education includes a proper understanding of maternity as a social function and the recognition of the common responsibility of men and women in the upbringing and development of their children, it being understood that the interest of the children is the primordial consideration in all cases" (United Nations, 1979). 
sessions of the Regional Conference on Women in Latin America and the Caribbean held since the start of this century (Lima, 2000, Mexico, 2004, Quito, 2007, Brasilia, 2010, Santo Domingo, 2013, and Montevideo, 2016).

At the national level, current legislation reflects the international trend: there is a multiplicity of regulations on benefits and services for specific groups, especially for early childhood and paid caregivers, but a lack of comprehensiveness in formulating care approaches that are explicitly articulated with social protection. This situation makes it difficult for legislation to lead to a substantive reorganization of care arrangements and their distribution between men and women.

Maternity leave has been regulated by all Latin American countries, although its duration varies. Among 20 countries considered, only nine provide for leave of at least 14 weeks, which is the minimum duration established by ILO Convention No. $183 .{ }^{14}$ On the other hand, 15 countries provide for paternity leave, ${ }^{15}$ although never longer than 15 days, which is too short to encourage co-responsibility in care between men and women (Blofield and Martínez, 2015). Moreover, only three countries (Chile, Cuba and Uruguay) provide for parental leave, in other words leave to provide time to look after young children once maternity leave is completed, which can be used by fathers or mothers in different modalities, as specified by each legislation. Meanwhile, legal leave to provide care in areas other than maternity — such as the illness of a son or daughter or a relative, or in the case of adoption - are much less frequent (Blofield and Martínez, 2015; Pautassi and Rico, 2011). This disregards the fact that care is a task that lasts beyond the postnatal period and the first few weeks of a child's life, and that not only biological children have the right to be cared for.

All Latin American countries have laws that refer to the operation of care centres for children during their first few years of life. These regulate their implementation or management for the daughters and sons of workers as an employment benefit, define the role of the State in their creation, or establish so-called "comprehensive early childhood care strategies". The latter include interventions in the dimensions of health, education and early stimulation, nutrition and care, which recognize the multiplicity of areas involved in the comprehensive protection of children (De Achaval and Aulicino, 2015). Several of these systems or comprehensive policies

14 At the time of completion of the review conducted for this study, these countries were the Bolivarian Republic of Venezuela, Brazil, Chile, Colombia, Costa Rica, Cuba, Panama, the Plurinational State of Bolivia, Puerto Rico (public officials only) and Uruguay. For further information, see Economic Commission for Latin America and the Caribbean (ECLAC), Observatory on Gender Equality in Latin America and the Caribbean, [online] http://oig.cepal.org/es.

15 These countries are Argentina, the Bolivarian Republic of Venezuela, Brazil, Chile, Colombia, the Dominican Republic, Ecuador, El Salvador, Guatemala, Mexico, Paraguay, Peru, the Plurinational State of Bolivia, Puerto Rico (for public officials) and Uruguay. For further information, see Economic Commission for Latin America and the Caribbean (ECLAC), Observatory on Gender Equality in Latin America and the Caribbean [online] http://oig.cepal.org/es. 
are regulated by law. There is usually a specific entity in charge of their coordination, either through executive secretariats or ad hoc presidential commissions created for their operation, or else by sectoral entities that regulate childhood policy in the countries, although their explicit articulation with social protection systems is more varied. Several countries have decrees or laws of this type. In Chile, Law No. 20.379 of 2009 created the "Chile Crece Contigo" Subsystem for the Comprehensive Protection of Children as a component of the Intersectoral Social Protection System. In Colombia, Law No. 1.804 of 2016, created the State Policy "de Cero a Siempre" for Comprehensive Early Childhood Development. In Costa Rica, Law No. 9220 created the National Child Care and Development Network (REDCUDI) in 2014 as a universal public care system for comprehensive early childhood development. In Cuba, a pioneering 1961 law created children's circles; and in Mexico, the General Law on the Provision of Services for Comprehensive Child Care and Development, of 2011.

In the case of other population groups that require care, the existing legislation reproduces the trend described above: it tends to regulate the provision of services, especially those provided outside the home in longterm residences. ${ }^{16}$ The provision of services in the home for those who are chronically dependent remains almost invisible in the current regulations. The main exceptions are Law No. 19.353 in Uruguay, creating the National Integrated Care System; and the Organic Law of the Social Security System in the Bolivarian Republic of Venezuela, which includes home-based supporting care services for older adults who need them, as part of the Regime of Social Service Benefits for the Elderly and Other Categories of People.

In the case of caregivers, despite the substantive progress made since the signing and ratification of ILO Convention No. 189, domestic workers face specific and more precarious regulations than any other category of workers in the region (ECLAC, 2013a), in terms of their conditions of pay, working hours, leave and social security. For example, while most Latin American countries have mandated affiliation to social security by domestic workers, four countries (El Salvador, Guatemala, Honduras and Mexico) maintain a policy of voluntary affiliation, or else a special regime with reduced coverage (ECLAC, 2016b). Moreover, the legislation on unpaid female caregivers is poorly developed. Only the constitutions of the Republic of Ecuador of 2008 and of the Bolivarian Republic of Venezuela of 1999 explicitly recognize this category of worker and

\footnotetext{
For example, Decree No. 14 of Chile (2010) which regulates long-stay establishments for older adults; Executive Decree No. 3 of 1999 in Panama, which issues rules for the opening and operation of day-care centres, homes or shelters for the elderly; Resolution No. 322 of 2011 in Paraguay which regulates the authorization, registration, accreditation and inspection of older adult care centres; Supreme Decree No. 009-2010-PCM establishing minimum requirements for the operation of residential care centres for older adults in Peru; and Law No. 17.066 of Uruguay, which defines the regime governing private establishments housing older adults (1999).
} 
safeguard caregivers' right to social security. Other legislations specify mechanisms for valuing unpaid work through satellite accounts or, more specifically, for extending pension mechanisms to provide coverage, as in Chile, Peru, the Plurinational State of Bolivia and Uruguay. In Ecuador, the Organic Law for Labour Justice and Recognition of Work in the Home, of 2015, lays foundations for creating ways to recognize the right to social security for persons who do this type of work.

Only Uruguay currently has a legal framework specifically focused on care, with a comprehensive and integrated perspective, in that it refers to the target populations and caregivers and their different instruments. Law No. 19.353, passed in 2015, created the National Integrated Care System in Uruguay invoking principles such as the universal right to care, services and benefits for all people in situations of dependency, the mainstreaming of gender and generational perspectives and culturally overcoming the sexual division of labour, and the articulation and coordination of care policies. As a result, it enshrines the right to care in the country and guarantees it. It identifies populations with entitlement as people living in situations of dependency, including children up to 12 years of age and persons with disabilities and those over 65 who lack the autonomy to carry out basic activities of daily life, as well as people who provide care, whether paid or not.

The increasing attention being paid to care policies by individual countries is reflected in the recent ratification of a number of laws on maternity rights, parental leave and the recognition of care work for social security purposes, among other areas. A review of the laws passed in the countries of Latin America and the Caribbean between 2015 and 2017 shows that 12 laws of this type have been ratified in the region during the period (see table V.1).

In summary, the analysis of existing legal frameworks for care highlights a dichotomy between integrated and comprehensive care policies, and those that preserve the sectoral approach through specific services or leave arrangements. The existence of legislation that encompasses all possible institutional expressions and benefits of care is not a virtue in itself; in fact, it does not prevent the coexistence of multiple laws on the subject. The paradigm shift is associated more with the establishment of a universal right that requires the creation and articulation of benefits to be progressively guaranteed in the individual countries, which has substantive implications for care policy institutions, definition of the role of the State and the consolidation of social coresponsibility. It can also affect the mandates of entities responsible for the management of care, in terms of the early detection of the care deficits in different population groups, and the synergetic and progressive advances made towards resolving them. 


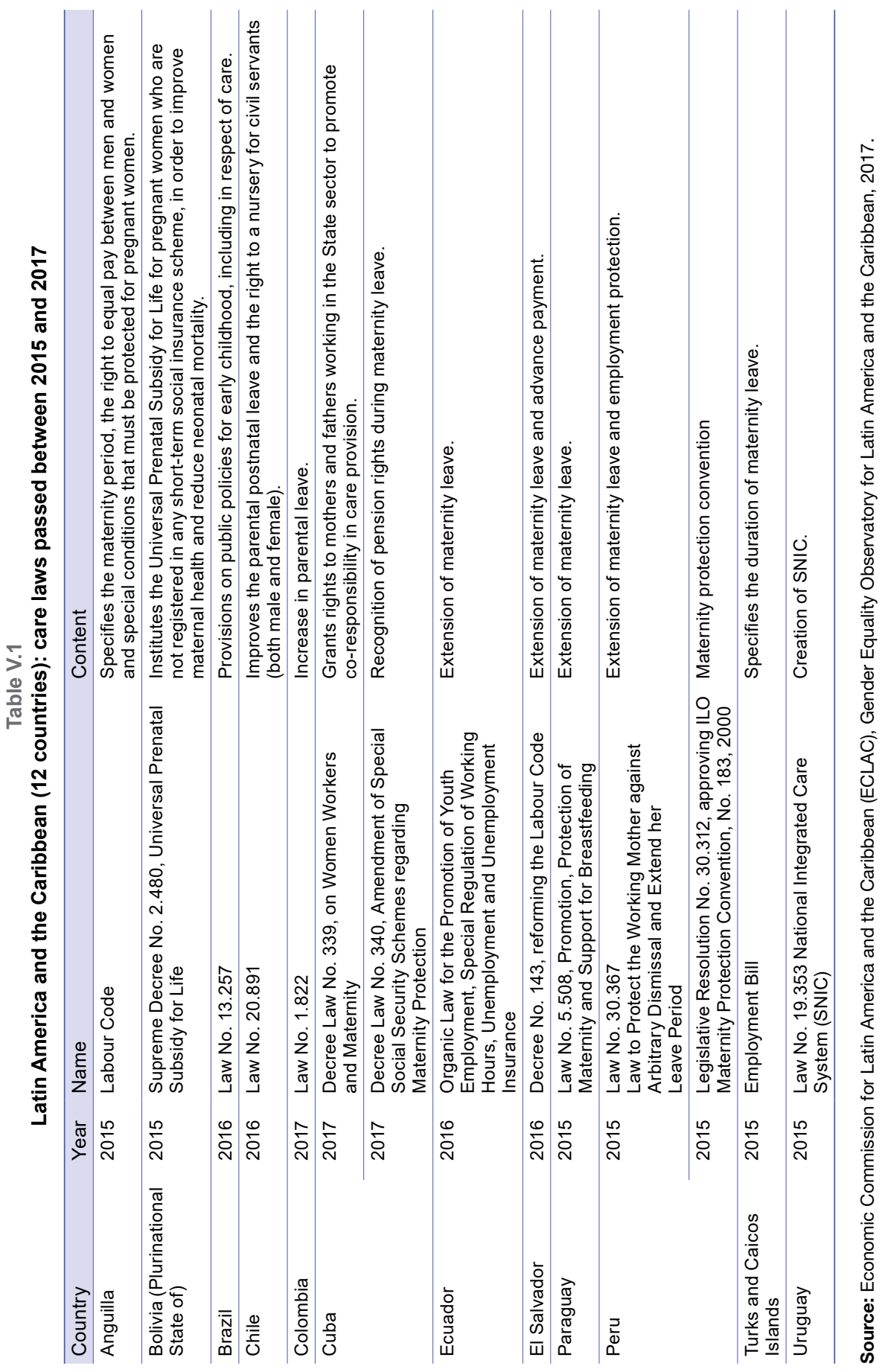




\section{Care policies and programmes: programmatic diversity and low tax burden}

In addition to the leave periods prescribed in national laws, there are a series of instruments, policies and programmes aimed at guaranteeing times, services, resources and regulations associated with the rights to provide and receive care in Latin America. Here also, the link with social protection systems is tenuous. These instruments include public services inside and outside the home to provide care to different population groups living in situations of dependency. It also includes actions on behalf of caregivers, such as training programmes; respite services or psychological support; cash transfers for the purpose of hiring care services or to recognize the unpaid care work done by family members, especially women; and the regulation of labour markets in terms of the way care services are provided in the private and public sectors, as well as the standards applicable to their operation and oversight. The origin and development of many of these programmes and policies do not have regulations. Although the existence of a legal underpinning helps to make the policies more stable, it does not guarantee this; nor does its absence necessarily imply instability. What seems to be crucial is the political will for implementation, along with the allocation of resources and the definition of a clear institutional framework to manage the policies.

Most of the care policies that exist in Latin America are targeted on child care. Around 2015, ten countries had implemented policies for comprehensive early childhood services with a care component. ${ }^{17}$ In the case of older adults, three countries have policies that refer to comprehensive care: Brazil, Costa Rica and Cuba.

At the programmatic level, all countries have public services to care for children and for elderly people in situations of dependency. The latter include both day centres and long-stay institutional services. In Costa Rica, the Progressive Care Network for Comprehensive Care of Older Persons, managed by the National Council of the Elderly (CONAPAM), seeks to coordinate initiatives led by civil society, public entities and families, with a view to formulating and implementing social protection policies and strategies to resolve care needs in old age, with a territorial management approach. Care alternatives include mechanisms such as solidarity or foster families, home assistants, community homes and external institutional centres. ${ }^{18}$

\footnotetext{
17 A review conducted in 2015, made it possible to identify fully effective legislation that creates these systems or policies in Chile, Costa Rica, Colombia, Cuba, the Dominican Republic, Ecuador, El Salvador, Mexico, Nicaragua and Paraguay (ECLAC, 2016a; Rico and Robles, 2016).

18 See National Council for Older Persons (CONAPAM), "Red de cuido" [online] http://www. conapam.go.cr/red-cuido.
} 
Foster families represent a specific care modality for persons in situations of dependency and social vulnerability, whose family situation is such that they cannot be looked after in their homes. This scheme, under which duly registered families are paid a subsidy to receive, under appropriate standards, older adults who need care, has been implemented in the Família Acolhedora (Foster Family) programme in Brazil ${ }^{19}$ and the Care Network for Comprehensive Care of Older Persons, Solidarity Families component, in Costa Rica.

Other modalities that could directly help address and recognize the situation of unpaid female caregivers include the home services that are provided to people in situations of severe dependency. In some cases, these are considered as respite services for caregivers and include training schemes to bring them into the formal sector. They may include subsidies for the hiring of personal assistants, cash transfers to unpaid caregivers, or temporary access to care centres outside the home. Although programmes of this type are less frequent, some are under way, such as the National In-home Care Programme in Argentina; the In-home Care Programme for Severely Dependent Persons in Chile; the Comprehensive Elderly Care Programme in Cuba, and the home care programme for severely dependent persons within SNIC in Uruguay. There are also training and education programmes for caregivers in Argentina, Brazil, Chile, Cuba, Ecuador, Mexico, Paraguay and Uruguay.

There are also pioneering initiatives to implement cash transfer programmes to recognize unpaid care work or enable paid caregivers or care services to be contracted. The Joaquín Gallegos Lara voucher in Ecuador provides US $\$ 240$ per month to the caregiver; and, the voucher and the provision of the Home Care Programme for Severely Dependent Persons in Chile pays US\$ 35 per month. In terms of articulation between social care and protection policies, the Tekoporã conditional transfer programme in Paraguay, implemented by the Social Action Secretariat (SAS) of the Office of the President of the Republic of Paraguay, in coordination with the National Secretariat for the Rights of Persons with Disabilities (SENADIS), includes a cash transfer to families that have a person with severe disability, in order to contribute to their care. ${ }^{20}$ Another interesting case is the Pregnancy Allowance for Social Protection programme in Argentina. This provides a cash transfer to pregnant women who are either out of the labour market or work in the informal sector, from the twelfth week of

\footnotetext{
19 See Ministry of Social Security, "Normas de funcionamento de serviços de atenção ao idoso no Brasil", 2014 [online] http://sbgg.org.br/wp-content/uploads/2014/10/servicos--de- atencaoao-idoso.pdf.

20 See Secretariat for Social Action (SAS), “Tekoporã” [online] http://www.sas.gov.py/pagina/54tekopor.html.
} 
pregnancy to the birth of the baby, under the rationale of maternity leave for those who do not have access to this social security benefit. ${ }^{21}$

In fewer cases, the cash transfer is delivered directly to the dependent person as an indirect or direct subsidy. In Argentina, the benefits of the Comprehensive Medical Assistance Programme (PAMI), run by the National Institute of Social Services for Retirees and Pensioners, include a subsidy to pay for an in-home care provider, depending on the degree of functional autonomy of the recipient person. In Colombia, there is an indirect economic subsidy for dependent elderly persons, which is paid through the Adult Welfare Centres, similar to the Progressive Care Network fort he Comprehensive Care of Older Adults. ${ }^{22}$

In addition to services, transfers and leave periods, standards and regulations are the fourth component of care policies. Development in this field varies across the countries of Latin America. In the case of dependent older adults, there are regulations governing the authorization, evaluation and supervision of long-stay centres in Argentina (although only at a decentralized level), and also in Brazil, Chile, Costa Rica, Paraguay and Peru. Only two countries, Chile and Ecuador, have regulated issued standards for the operation and functioning of day centres (Gascón and Redondo, 2014). In the case of early childhood, the standards vary from one country to another. There are indicators of management and quality in Brazil, Colombia, Ecuador, El Salvador and Peru. Various entities are responsible for compliance, including the ministries of health, education and social development (Marco, 2014).

In short, the institutionalization of care policies in the region's countries displays heterogeneous, multiple interventions with poor coordination, resulting in a multiplicity of entities responsible for their management, targeted mostly on specific population groups: institutes or commissions for children, and for older adults or persons with disabilities. Less frequently, mechanisms for the advancement of women are involved, most of them embedded in the countries' social institutions, either in social development ministries or in the Office of the President. In other cases, the policies are implemented by the sectoral education or health ministries.

Lastly, it should be noted that the level of investment in care policies is still quite low. A review of budgetary appropriations to specific programmes or integrated care policies, shows that they do not exceed

21 See National Social Security Administration (ANSES), “Asignación por Embarazo para Protección Social" [online] http://www.anses.gob.ar/prestacion/asignacion-por-embarazopara-proteccion-social-93. This benefit is linked to the Universal Child Allowance, which, through Decree No. 1602/2009, has made it possible to extend access to family benefits to informal workers through the monotributo unified tax system.

22 See Consorcio Colombia Mayor, "Programa Colombia Mayor" [online] http://colombiamayor.co/ programa_colombia_mayor.html. 
$0.4 \%$ of GDP and, in most cases, they are less than $0.03 \%$. An exception is the benefit provided by the National Institute of Social Services for Retirees and Pensioners, whose investment represents just under $1 \%$ of GDP. ${ }^{23}$ This budget is extremely small compared to total social spending relative to GDP, which, from 2012 to 2013, ranged from 8\% in the cases of Ecuador and Guatemala to $23 \%$ in Costa Rica. ${ }^{24}$ In contrast, public investment in child care services alone in the 33 countries of the Organization for Economic Cooperation and Development (OECD) in 2011 averaged 1\% of GDP and over $2 \%$ in Denmark, Iceland and Sweden. ${ }^{25}$

The available information reveals the lack of centrality of care policies, as measured by their budget density. In particular, it shows how the costs of care are absorbed by families, particularly in the form of unpaid work by women. Thus, the social investment needed to ensure quality jobs in the sector and guarantee the right to care and be cared for is underfunded. At the same time, institutional challenges will arise when shifting from investment planning focused on individual care programmes and services to an integrated system or policy, in the broader context of social protection systems.

\section{From programmes to integrated care systems? Creating and strengthening the institutional framework}

Some Latin American countries have made efforts to design comprehensive and integrated care policies and systems. These explicitly seek to rectify the fragmentation of the supply of services in this area and the gender inequalities that surround the care economy. The situation of these countries varies greatly in terms of their degree of progress, availability of resources, political priority assigned and the coordinating entity responsible. In all cases, the debate and

23 Budgetary data from around 2014 was found for the following countries: Argentina (National Early Childhood Development Programme and budget of the National Institute of Social Services for Retirees and Pensioners, Comprehensive Medical Assistance Programme); Chile Crece Contigo, Programa 4 a 7, Subsidy Fund for Long-stay Facilities for Older Adults, In-home Care Programme, Older Adult Day Care Centre Programmes); Colombia (De Cero a Siempre); Costa Rica (Progressive Care Network for the Comprehensive Care of Older Persons and the National Child Care and Development Network); Peru (National Cuna Más Programme); the Dominican Republic (National Plan for Comprehensive Protection and Care in Early Childhood "Quisqueya Empieza Contigo") and the National Integrated Care System in Uruguay. Most of the items reported do not cover care services only. For example, comprehensive care programmes for children include nutrition and health components, as well as care per se.

24 On the basis of the Economic Commission for Latin America and the Caribbean (ECLAC), Gasto público como porcentaje del Producto Interno Bruto (PIB) total y por sectores [online] http://dds. cepal.org/gasto/indicadores / tab /? indicator_id $=28$. Countries with information on total social public spending as a percentage of GDP in 2012 or 2013 are the Bolivarian Republic of Venezuela, Chile, Colombia, Costa Rica, Ecuador, El Salvador, Guatemala, Mexico, Panama, Peru and the Plurinational State of Bolivia.

25 Organization for Economic Cooperation and Development (OECD), Families and Children, September 2014 [online] http://www.oecd.org/els/family/. 
the construction of policies reflect care as a core issue of social development, which requires a higher level of articulation than has been achieved thus far. Moreover, all of them create a specific temporary or definitive institutional structure for their design and management, based on different formats.

In this connection, the case of Uruguay and the National Integrated Care System, as mentioned above, is undoubtedly the most advanced at the regional level. Nonetheless, similar efforts also exist in Chile, Colombia, Costa Rica, Ecuador, El Salvador and at the level of the Mexico City government. ${ }^{26}$ These policies have been developed in two ways. First, some countries design and implement them as components of social protection systems, such that they constitute subsystems or policies. In other countries, discussion begins under strong impetus from the mechanisms for the advancement of women, without their links to existing social protection systems always being made explicit.

In the first group of countries, which includes Chile, Costa Rica, El Salvador and Uruguay, work is coordinated by the entity in charge of social policy, the agencies responsible for care and protection of the rights of the different populations that require care (children, persons with disabilities and older adults) and mechanisms for the advancement of women. In these countries, progress is being made in implementing policies, subsystems or systems as explicit components of social protection. In most cases where the role of social authority has been defined, it is done by the body in charge of social policy, sometimes by setting up specific technical secretariats for its management, and in other cases, by creating a collegiate body for the coordination of care policy.

In Uruguay, SNIC is coordinated by the National Care Secretariat of the Ministry of Social Development and forms part of the country's social protection system. The system operates through a National Care Board, which has a strategic leadership function, and is chaired by the Minister of Social Development. It involves the Ministers of Economy and Finance, Education and Culture, Public Health and Labour and Social Security, as well as the Director of the Planning and Budget Office, the President of the Central Steering Council of the National Public Education Administration, the Chairman of the Board of Directors of Banco de Previsión Social, the Chairman of the Board of the Institute of Children and Adolescents of

26 The information detailed below includes secondary documentary sources, along with data systemized during the process of monitoring the discussion and exchange of experiences on care policies provided by the Gender Affairs Division and the Social Development Division of ECLAC on five countries in the region (Chile, Costa Rica, El Salvador, Paraguay and Uruguay), within the framework of the CEPAL-BMZ / GIZ 2014-2016 Cooperation Programme, "Structural change for sustainable and inclusive development in Latin America and the Caribbean". It also includes data from six of the region's cities, obtained through the United Nations Development Account project "Urban development, women's economic autonomy and care policies": Bogotá, Cuenca, San Salvador, Mexico City, Montevideo and Santiago. 
Uruguay, and a representative of the Congress of Regional Governors (Intendentes) and the National Institute for Women. The system also has a Care Advisory Committee, formed by representatives of civil society organizations, academic institutions, men and women workers, and the private sector.

The system includes care services provided both inside and outside the home for different population groups. In the case of early childhood, it includes maternity, paternity and parental leave; community care homes and extension of the coverage of various child care centres, as well as socio-educational inclusion grants for attendance at private child care centres, which are offered to families in vulnerable situations when public supply is insufficient. People in situations of dependency can obtain inhome care through a subsidy to be used to contract personal assistants, telecare, day centres and long-stay residences. A subsidy is also paid when these services are provided in private centres. In addition, a training programme for care providers has been implemented.

In Chile, the National Support and Care Subsystem (SNAC) is being constructed and implemented, under coordination by the Ministry of Social Development. The subsystem has been envisaged from the outset as part of the Intersectoral Social Protection System and seeks to address the situation of people who are dependent and support their caregivers, in order to contribute to the well-being of their households. It includes public and private actions with intersectoral coordination and articulation with two of the components of the Social Protection System: the Seguridades y Oportunidades subsystem and the Chile Crece Contigo subsystem, which handles child care in the country, particularly targeting those belonging to most the vulnerable $60 \%$ of households. The system is in the design phase and its aim is to coordinate access, referral, follow-up and support actions at the local level through the Local Support and Care Network, a home respite service called Chile Cuida and other care services, both in-home and institutionalized, the functional adaptation of housing and a public education programme (Rodríguez, 2016).

Costa Rica has well-established care networks for two population groups: children during their early years and older adults. Each network has a high degree of internal articulation between the instruments and actors involved in its management. These networks do not form a unified care system, but operate autonomously.

The National Child Care and Development Network (REDCUDI) establishes a child care and development system, of universal public access and solidarity-based financing, which articulates the public and private service provision modalities. It is coordinated by the Joint Social Assistance Institute through the REDCUDI Technical Secretariat, although it operates under an intersectoral management rationale with participation from the Ministry of Public Education, the National Children's Board, the Ministry 
of Labour and Social Security, the Ministry of Health, the National Institute for Women, the Costa Rican Social Security Fund, the National Institute of Apprenticeship, the National Directorate of Education and Nutrition Centres and Children's Centres for Comprehensive Care (CEN-Cinai), the National Directorate of Community Development and the municipalities. In addition, the Progressive Service Network for the Comprehensive Care of Older Adults is coordinated by the National Council for the Elderly, which is attached to the Office of the President of the Republic. It seeks to articulate initiatives by civil society, public entities and families to solve old-age care needs, with a territorial management approach. It includes alternative care such as solidarity-based or foster families, in-home assistants, community homes and external institutional centres.

In addition, El Salvador has launched a discussion on a national care policy as a component of the Universal Social Protection System (Meléndez, 2015). The nascent institutional framework that discusses its design, the Follow-up Commission for the Construction of a Care Policy in El Salvador, encompasses several institutions. ${ }^{27}$ The Commission involves active participation by the mechanism for the advancement of women, the Salvadoran Institute for the Advancement of Women (ISDEMU), together with the entity responsible for implementing the social protection system in the country, the Technical and Planning Secretariat of the Office of the President (Salvador, 2015). The aim of this process is to decide on priority actions and coordinate existing initiatives and programmes, with an explicit design emphasis on gender equality.

In a second group, which includes Colombia, Ecuador and the Mexico City government, the discussion and promotion of an integrated care policy has emerged with strong impetus from the mechanisms of advancement for women and other technical agencies; and it is based on the implementation or prior existence of interagency coordination mechanisms that facilitate the corresponding discussions.

In Ecuador, the technical-political interagency coordination desk composed of the National Assembly, the National Council for Gender Equality, the Coordinating Ministry of Social Development (MCDS), the Ministry of Economic and Social Inclusion (MIES) and the National Planning and Development Secretariat (SENPLADES), is discussing the implementation of a National Care System with a gender and rights approach (National Council for Gender Equality, undated).

27 The Follow-up Commission for the Construction of a National Care Policy comprises the National Council for Comprehensive Care for Persons with Disabilities (CONAIPD), the Salvadoran Institute for the Development of Women (ISDEMU), the Salvadoran Institute for the Comprehensive Development of Childhood and Adolescence (ISNA), the Ministry of Education, the Gender Equality Unit of the Ministry of Labour and Social Welfare, the Ministry of Health, the Directorate for Older Adults of the Ministry of Social Inclusion (SIS), the Directorate of Strategic Programmes, and the Human Rights and Gender Unit of the Technical Secretariat for Planning of the Presidency (STPP). 
In Colombia, Law No. 1.413 on the care economy, of 2010, institutionalized the Use of Time Survey and the Satellite Account for the care economy, and it also created a Multisector Commission on the care economy. Participants include the Presidential Advisory Council on Equity for Women, the Ministry of Health and Social Protection, the Ministry of Labour, the National Planning Department (DNP), the Department for Social Prosperity and the National Administrative Statistics Department (DANE) which coordinates the Commission. Since 2016, the Commission has participated with DNP in laying foundations for the National Care System of Colombia, as established in the 2014-2018 National Development Plan Todos por un nuevo país (Everyone for a new country). This system adopts a social co-responsibility approach to care and seeks to coordinate the range of services, regulation, training and information management linked to care policies in the country (DANE, 2017; Perfetti, 2016).

At the subnational level, the Commission for Promotion of the Care Economy and an Employment Equality Policy within the Mexico City government, formed in March 2014 by the Institute for Women of Mexico City and the city government's Work and Employment Promotion Secretariat, has sought to promote strategies and mechanisms for evaluating and monitoring employment policy and the care economy within Mexico City's public administration, based on non-discrimination and substantive equality between women and men. The Commission comprises various Mexico City government institutions and evaluates potential measures, such as a citizen's wage programme for caregivers and women community caregiver cooperatives (Government of Mexico City, 2014).

In short, the experiences described above represent social institutions that are still a work in progress. In most cases, their authority is in the process of being defined, although valuable progress has been made in setting up collegiate mechanisms capable of meeting the intersectoral challenges involved in coordinating actions related to care providers and recipients, involving population groups with highly diverse needs. In each of the aforementioned processes, it is worth highlighting the link, in some cases stronger than in others, that exists between the entity in charge of social policies or social protection and the respective mechanism for the advancement of women. In addition, political will plays an important role, especially presidential support for the institutionalization of these measures, and the planning of specific stages in their design and implementation. ${ }^{28}$ Where these have been implemented, the technical secretariats or councils in charge of the care policies are playing a promising role in working to identify and close coverage gaps in the

In Uruguay, the creation of SNIC was one of the priorities of the Government of President Tabaré Vázquez (Montevideo Portal, 2017). The creation of SNAC in Chile was included in the presidential programme of President Michelle Bachelet (Rodríguez, 2016). In Costa Rica, the creation of REDCUDI had backing from the then President Laura Chinchilla (Guzmán, 2014). 
existing care services; and they are responsible for ensuring the system's consistency with a gender equality approach, in addition to maintaining the interagency commissions that give rise to them. ${ }^{29}$

\section{E. Is mainstreaming advancing?}

The panorama reviewed at the regional level shows the preponderance of a family-based approach to the provision of care in Latin America, although with incipient signs of change. The State maintains a subsidiary role in the management of care policies targeted on the most vulnerable population. Except in the cases indicated in the previous section, the current policies and programmes do not yet constitute a pillar of social protection in the vast majority of Latin American countries. Moreover, the joint effect of these benefits does not ensure a gender mainstreaming approach to address the current gender division of care work (Blofield and Martínez, 2015).

One notable exception among the policies currently in operation is SNIC in Uruguay, the design of which decisively mainstreams gender. This system aligns the various instruments implemented by the system with the goal of promoting the social reorganization of care; and it integrates its operation into the country's social protection system. To that end, among other aspects, it has sought to strengthen access to services as the main benefit of the system. The delivery of direct cash transfers to caregivers has not been considered, to prevent this benefit maintaining and promoting the feminization of unpaid care work.

In other cases, the gender equality perspective has a greater presence in specific programmes that explicitly seek to address the labour market participation obstacles that affect unpaid female caregivers. For example, Programa 4 a 7 (Programme 4 to 7) in Chile, run by the Ministry of Women and Gender Equity, offers child-care services for a longer period than usual, to make it easier for women with child-care responsibilities to obtain training and employment. ${ }^{30}$

The regional experience of care policies reveals a disparate involvement of mechanisms for the advancement for women, even though the problem of care permeates the gender equality plans currently in force in the region's countries. Its role focuses more on influencing gender mainstreaming in the design and operation of programmes, as well as in the emerging integrated care systems, but less on the direct management of initiatives. Nonetheless, these entities have a greater role in integrated

29 This is established, for example, by Law No. 9.220, which creates the National Child Care and Development Network in Costa Rica, and Law No. 19.353, which created the National Integrated Care System in Uruguay.

30 See National Service for Women (SERNAM), Programa 4 a 7 [online] https:/ /portal.sernam.cl/ $? \mathrm{~m}=$ programa\& $\mathrm{i}=5$. 
training policies. The REDCUDI Interagency Technical Commission includes a representative from the executive presidency of the National Institute for Women (INAMU). In Uruguay's SNIC, the National Institute for Women participates in the meetings of the National Care Board. In other experiences currently being developed, such as a national care policy in El Salvador, the Follow-up Commission for the Construction of a Care Policy in El Salvador involves active participation by the Salvadoran Institute for the Advancement of Women (ISDEMU) in key policy decisions (Salvador, 2015). Moreover, in Chile, the Ministry of Women and Gender Equity has advised the Ministry of Social Development on gender mainstreaming in the design of SNAC (Rodríguez, 2016).

Closer articulation between the benefits and services offered in the countries, and between their objectives, would be useful. This would make it possible to mainstream gender from the design stage of articulated policies and programmes, and thus guarantee the rights of persons who require and provide care, equality between men and women, the social coresponsibility for care, and its redistribution among families, the State, the market and the community. This also involves considering analysis and intervention from the link between policies and people's daily practices, as well as care as a right of citizenship and a pillar of social protection. Public policies, as a set of measures or instruments of action, currently face the major challenge of articulating an institutional framework that coordinates, regulates and guarantees the right to care, through services and infrastructure and a series of sectoral programmes that act on this dimension of welfare. In this context, social policies have the opportunity to encourage changes in the current social and economic organization of care towards more egalitarian social relations and an economic structure that recognizes the contribution of care work to a country's development and growth, along with the close interrelationship between production and reproduction.

\section{F. Final considerations}

Care should be understood as a crosscutting pillar of social protection. The deficit for those who require it and the conditions under which it is provided are currently the source and reproductive factors of poverty and inequality, as well as a risk for the population and well-being. This approach, consistent with the idea of care as a public good, requires consideration of the social institutions needed to address this challenge. Care policies and the social protection system as a whole must consider the needs of the cared-for and the caregivers in their complexity, and mainstream a gender and human rights approach that takes account of the specifics of the life cycle in its different stages. 
A review of the current social institutional framework for care policies in Latin America, based on their legal, programmatic, financing, fiscal and organizational dimensions, reveals the growing interest of public policy in this social function. Nonetheless, this interest coexists with the fragmentation of existing actions. In several countries, care policies only cover specific services for defined population groups, such as young children, the elderly or people with disabilities. In other cases, such as in Costa Rica, care networks are formed for these population groups, without constituting a comprehensive care system. The situation of care providers is considered differently across these instruments. There is a wide range of possibilities, from systems that do not contemplate it at all, to those such as Uruguay's, which mainstream gender, take into account paid or unpaid women caregivers and aim to redistribute care and its benefits from the inception of its design.

In countries where the debate has moved on towards the creation of policies, subsystems or integrated care systems, except in Uruguay, the question of its position as a component of the social protection system has not yet been resolved, nor have programmatic redesigns been coordinated that ensure coherence and synergy among its instruments. Moreover, debates continue on the legislation to be promoted, the coordinating entities to be set up, or the mechanisms of management, social participation and accountability to be installed, as part of the emerging institutional challenges. This is explained by the incipient stage of these experiences; and they highlight the pending issues to be faced and resolved. The progress made in the creation of collegiate bodies for the design or stewardship of these policies is undoubtedly significant, insofar as it establishes the intersectoral and comprehensive approach required for their operation.

Care policies face various challenges, including the following: the adoption of decisions on expanding the coverage of existing services compared to the creating new instruments, in a context of increasing fiscal austerity, and the failure to seek new sources of financing. Solutions could be found through better taxation and control of evasion; efficient planning to avoid unnecessary duplication of efforts, where the programmatic supply of public and private service providers is greater, and specific management instruments are created that are harmoniously articulated with those already existing in social protection systems.

From the standpoint of the social institutions to be supported, the following considerations could be kept in mind to promote debate in countries that have not yet defined integrated and comprehensive care policies and in those that have taken steps in that regard. First, in view of its multidimensional nature and its needs for the different populations, intersectoral and interagency articulation is an essential requirement. Various policies and sectors intervene in its approach, including employment, health, education, gender equality and social protection. Second, the 
intersectoral challenge requires an effective guiding and coordinating entity, endowed with the attributions and financing needed not only to launch new programmes or expand coverage as may be required, but also to promote dialogue and coordination between sectors. Third, in the social protection domain, care as one of its pillars implies a definition by these systems of whether the coordination of an integrated or comprehensive policy should be managed from an existing entity (such as the technical secretariats of social protection or the social ministries), or if it is better for these functions to be assumed by an external entity or created specifically for its management (such as the National Care Secretariat in Uruguay or the REDCUDI Technical Secretariat in Costa Rica). Ultimately, the designated institutional structure must ensure active synergy between the instruments and specific guiding approaches to care and other components of social protection systems.

Comprehensiveness should be understood in terms of the necessary articulation between sectoral and care policies as components of social protection, of the actors that intervene in each of these areas at the national and local levels, and of the instruments that mainstream gender equality and human rights an approach from the outset. This could provide fundamental guidance for firmly establishing the right to care as an imperative of justice in the region.

\section{Bibliography}

Batthyány, K. (2015), "Las políticas y el cuidado en América Latina: una mirada a las experiencias regionales", Gender Affairs series, No. 124 (LC/L.3958), Santiago, Economic Commission for Latin America and the Caribbean (ECLAC), February.

Batthyány, K., N. Genta and V. Perrotta (2015), "Avanzando hacia la corresponsabilidad en los cuidados: análisis de las licencias parentales en el Uruguay", Gender Affairs series, No. 128 (LC/L.4085), Santiago, Economic Commission for Latin America and the Caribbean (ECLAC), October.

Berlinski, S. and N. Schady (eds.) (2015), The Early Years: Child Well-Being and the Role of Public Policy, Washington, D.C., Inter-American Development Bank (IDB).

Blofield, M. and J. Martínez (2015), "Are governments catching up? Work-family policy and inequality in Latin America", Discussion Paper, No. 7, New York, United Nations Entity for Gender Equality and the Empowerment of Women (UN-Women), September.

(2014), “Work,family and public policy changesin Latin America:equity, maternalism and co-responsibility", CEPAL Review, No. 114 (LC/G.2629-P), Santiago, Economic Commission for Latin America and the Caribbean (ECLAC), December.

DANE (National Administrative Department of Statistics) (2017), "Informe de gestión: Ley 1413 de 2010", Informe semestral, No. 12, Bogota, February.

De Achaval, O. and C. Aulicino (2015), "Estrategias de protección a la primera infancia en la experiencia internacional", Working Paper, No. 145, Buenos Aires, Centre for the Implementation of Public Policies Promoting Equality and Growth (CIPPEC), November. 
ECLAC (Economic Commission for Latin America and the Caribbean) (2017a), Social Panorama of Latin America, 2016. Briefing Paper, Santiago, May.

(2017b), Montevideo Strategy for Implementation of the Regional Gender Agenda within the Sustainable Development Framework by 2030 (LC/CRM.13/5), Santiago, March.

(2016a), Social Panorama of Latin America, 2015 (LC/G.2691-P), Santiago, October. (2016b), Equality and Women's Autonomy in the Sustainable Development Agenda (LC/G.2686/Rev.1), Santiago, December.

(2013a), Social Panorama of Latin America, 2012 (LC/G.2557-P), Santiago, January. (2013b), Gender Equality Observatory of Latin America and the Caribbean. Annual Report 2012: A Look at Grants, Support and Burden for Women (LC/G.2561/Rev.1), Santiago, March.

(2011), Social Panorama of Latin America, 2010 (LC/G.2481-P), Santiago, January.

Ellingsaeter, A. (1999), "Dual breadwinners between state and market", Restructuring Gender Relations and Employment: The Decline of the Male Breadwinner, R. Crompton (ed.), Oxford, Oxford University Press.

Gascón, S. and N. Redondo (2014), "Calidad de los servicios de largo plazo para personas adultas mayores con dependencia", Social Policy series, No. 207 (LC/L.3875), Santiago, Economic Commission for Latin America and the Caribbean (ECLAC), August.

Government of Mexico City (2014), "Manual específico de operación de la Comisión para el Impulso de la Economía del Cuidado y de una política de igualdad laboral al interior del gobierno de la Ciudad de México. Versión preliminar", Mexico City, August [online] http:/ / data.om.cdmx.gob.mx/impulsoeconomia/ ciecpilgcdmx/normatividad / MANUAL \%20ESPECIFICO $\% 20$ DE $\% 20$ OPERACION\%20CIECPILIGCDMX\%20VERSION\%20PRELIMINAR.pdf.

Guzmán, J. (coord.) (2014), “Red Nacional de Cuido y Desarrollo Infantil en Costa Rica. El proceso de construcción 2010-2014", Social Policy series, No. 203 (LC/L.3858), Santiago, Economic Commission for Latin America and the Caribbean (ECLAC), June.

Huenchuan, S. (2014), “'¿Qué más puedo esperar a mi edad?’ Cuidado, derechos de las personas mayores y obligaciones del Estado", Autonomía y dignidad en la vejez: teoría y práctica en políticas de derechos de las personas adultas mayores, S. Huenchuan and R. Rodríguez (eds.) (LC/L.3942), Mexico City, Economic Commission for Latin America and the Caribbean (ECLAC), December.

ILO (International Labour Organization) (2012), "Social Protection Floors Recommendation, 2012 (No. 202)", Geneva, June [online] https://www. ilo.org/dyn/normlex/en/f?p=NORMLEXPUB:12100:0::NO::P12100_ILO_ CODE:R202.

(2011a), "Domestic Workers Convention, 2011 (No. 189)", Geneva, June [online] http://www.ilo.org/dyn/normlex/en/f?p=NORMLEXPUB:12100: 0::NO::P12100_INSTRUMENT_ID,P12100_LANG_CODE:2551460,es.

(2011b), “Domestic Workers Recommendation, 2011 (No. 201)", Geneva, June [online] http://www.ilo.org/dyn/normlex/en/f?p=NORMLEXPUB:12100: 0::NO::P12100_INSTRUMENT_ID,P12100_LANG_CODE:2551502,es.

(2000), "Maternity Protection Convention, 2000 (No. 183)" Geneva, June [online] http://www.ilo.org/dyn/normlex/en/f?p=NORMLEXPUB:12100: 0::NO::P12100_INSTRUMENT_ID,P12100_LANG_CODE:312328,es. 
(1981), “Workers with Family Responsibilities Convention, 1981 (No. 156)", Geneva, June [online] http://www.ilo.org/dyn/normlex/en/f?p=NORMLEX PUB:12100:0::NO::P12100_INSTRUMENT_ID,P12100_LANG_CODE:312301,es.

Lamaute-Brisson, N. (2010), "Economía del cuidado de la niñez en Haití: proveedores, hogares y parentesco", Women and Development series, No. 95 (LC/L.3130-P), Santiago, Economic Commission for Latin America and the Caribbean (ECLAC), December.

Marco, F. (2016), "La nueva ola de reformas previsionales y la igualdad de género en América Latina”, Gender Affairs series, No. 139 (LC/L.4225), Santiago, Economic Commission for Latin America and the Caribbean (ECLAC), October.

(2014), "Calidad del cuidado y la educación para la primera infancia en América Latina: igualdad para hoy y mañana", Social Policy series, No. 204 (LC/L.3859), Santiago, Economic Commission for Latin America and the Caribbean (ECLAC), July.

(2007), "El cuidado de la niñez en Bolivia y Ecuador: derecho de algunos, obligación de todas", Women and Development series, No. 89 (LC/L.2843-P), Santiago, Economic Commission for Latin America and the Caribbean (ECLAC), December.

Marco, F. and M. N. Rico (2013), "Cuidado y políticas públicas: debates y estado de situación a nivel regional", Las fronteras del cuidado: agenda, derechos e infraestructura, L. Pautassi and C. Zibecchi (coords.), Buenos Aires, Equipo Latinoamericano de Justicia y Género (ELA)/Editorial Biblos.

Matus, M. and M. Vega (2016), "Los cuidados para la atención a la dependencia”, La economía de los cuidados, L. Gálvez (ed.), Sevilla, Deculturas Ediciones.

Meléndez,J. (2015), "Lasnecesidades de cuidadoy los desafíos para la institucionalidad social a la luz del Plan Quinquenal de Desarrollo en El Salvador", paper presented at the Technical Seminar "Los desafíos de la institucionalidad social en el desarrollo de una protección social universal bajo el enfoque de derechos", Santiago, Economic Commission for Latin America and the Caribbean (ECLAC)/ Federal Ministry for Economic Cooperation and Development (BMZ)/German Agency for International Cooperation (GIZ), 11-12 August.

Montevideo Portal (2017), "Sistema de Cuidados "sigue siendo prioridad", afirmó Arismendi", Montevideo, 27 March [online] http://www.montevideo. com.uy/contenido/Sistema-de-Cuidados-sigue-siendo-prioridad--afirmoArismendi-338586.

National Council for Gender Equality (n/d), "Instalación de la mesa técnicopolítica para el diseño e implementación del Sistema Nacional de Cuidados", Quito, unpublished.

OAS (Organization of American States) (2015), "Inter-American Convention on Protecting the Human Rights of Older Persons", Washington, D.C., June [online] http://www.oas.org/en/sla/dil/docs/inter_american_treaties_A-70_ human_rights_older_persons.pdf.

Pautassi, L. (2007), "El cuidado como cuestión social desde un enfoque de derechos", Women and Development series, No. 87 (LC/L.2800-P), Santiago, Economic Commission for Latin America and the Caribbean (ECLAC), October.

Pautassi, L. and M. N. Rico (2011), "Childcare leave: a right of children and parents", Challenges, No. 12, Santiago, Economic Commission for Latin America and the Caribbean (ECLAC)/United Nations Children's Fund (UNICEF), July. 
Perfetti, M. (2016), “Intervención: el aporte de las estadísticas a la economía del cuidado en Colombia", paper presented at the XIII Regional Conference on Women in Latin America and the Caribbean, Montevideo, Economic Commission for Latin America and the Caribbean (ECLAC), 26-28 October.

Razavi, S. (2012), "Rethinking care in a development context: an introduction", Seen, Heard and Counted: Rethinking Care in a Development Context, London, Wiley-Blackwell.

Rico, M. N. (2014), “El desafío de cuidar y ser cuidado en igualdad: hacia el surgimiento de sistemas nacionales de cuidado", Pactos sociales para una protección social más inclusiva: experiencias, obstáculos y posibilidades en América Latina y Europa, M. Hopenhayn and others (eds.), Seminars and Conferences series, No. 76 (LC/L.3820), Santiago, Economic Commission for Latin America and the Caribbean (ECLAC), May.

Rico, M. N. and C. Robles (2016), "Políticas de cuidado en América Latina: forjando la igualdad", Gender Affairs series, No. 140 (LC/L.4226), Santiago, Economic Commission for Latin America and the Caribbean (ECLAC), September.

Rico, M. N. and I. Vaca-Trigo (2016), "Trabajo doméstico remunerado en América Latina: el núcleo duro de la desigualdad de género en el mercado laboral", Santiago, Economic Commission for Latin America and the Caribbean (ECLAC), unpublished.

Rodríguez, C. (2016), “El Sistema Nacional de Apoyos y Cuidados: lineamientos principales", paper presented at the Seminar "La organización social del cuidado y los desafíos de la desigualdad: la construcción de políticas integradas de cuidado en Chile y Costa Rica", Santiago, Economic Commission for Latin America and the Caribbean (ECLAC)/Ministry of Social Development/Chilean Agency for International Development Cooperation (AGCID), 25 August.

Rossel, C. (2016), “Desafíos demográficos para la organización social del cuidado y las políticas públicas", Gender Affairs series, No. 135 (LC/L.4186), Santiago, Economic Commission for Latin America and the Caribbean (ECLAC), June.

Salvador, S. (2015), "Política de cuidados en El Salvador: opciones, metas y desafíos", Gender Affairs series, No. 129, (LC/L.4086), Santiago, Economic Commission for Latin America and the Caribbean (ECLAC), October.

(2011), "Hacia un sistema nacional de cuidados en el Uruguay", El desafío de un sistema nacional de cuidados para el Uruguay, M. N. Rico (coord.), Seminars and Conferences series, No. 66 (LC/L.3359), Santiago, Economic Commission for Latin America and the Caribbean (ECLAC), August.

Tronto, J. (1993), Moral Boundaries: A Political Argument for an Ethic of Care, New York, Routledge.

United Nations (2015), "Annex. Transforming our world: the 2030 Agenda for Sustainable Development", Draft outcome document of the United Nations summit for the adoption of the post-2015 development agenda (A/69/L.85), August [online] http://www.un.org/ga/search/view_doc. asp?symbol=A/69/L.85\&referer=/english / \&Lang=E.

(2006), "Convention on the Rights of Persons with Disabilities" (A/RES/61/106), New York, December [online] http:/ / www.un-documents. net/a61r106.htm.

(1989), "Convention on the Rights of the Child" (A/RES/44/25), New York, November [online] http://undocs.org/en/A/RES/44/25.

(1979), "Convention on the Elimination of All Forms of Discrimination against Women" (A/RES/34/180), New York, December [online] http:// undocs.org/en/A/RES/34/180. 

Part 3

Policies for specific populations and their institutional framework 

Chapter VI

\section{Life cycle and social policies: youth institutions in the region}

Daniela Trucco ${ }^{1}$

\section{Introduction ${ }^{2}$}

The position that individuals occupy in society is not determined exclusively by circumstances, efforts, decisions and personal trajectories. A structure of opportunities is provided by society as a whole, and by States, markets, families and communities, which are beyond the individual's control and condition his/her prospects for social mobility and access to well-being. A person's age is a strong marker of the distribution of well-being and power within the social structure. It is also one of the bases of social organization from which roles and responsibilities are assigned (ECLAC, 2016). The fact that each stage of the life cycle presents specific opportunities, challenges and risks (ECLAC, 2017) underscores the importance of public policies that take the specifics of each of these stages into account. It also requires consideration of how social disparities and inequalities are linked during the life cycle, since social disadvantages (or privileges) accumulate progressively.

1 Social Affairs Officer of the Social Development Division of the Economic Commission for Latin America and the Caribbean (ECLAC).

2 The author is grateful for contributions made by Gabriel Kattan (Consultant) and Renato Briceño (intern), of the Social Development Division of ECLAC. 
It is therefore important to have public policies that support people at different stages of their lives, attending to the specific needs of each period, while maintaining continuity and coordination through time (ECLAC, 2016). In this context, and given the critical nodes through which social inequality is reproduced during youth, one of the key missions of institutions devoted to this population group is to design and implement specific policies or programmes that guarantee conditions enabling young people to mobilize their capacities to implement their life projects autonomously, and to enhance the articulation and visibility of their specific needs (ECLAC, 2017).

As proposed by ECLAC, an appropriate institutional context is needed to put policies in place that respond to the multidimensional and integral nature of young people and foster their inclusion in society (Trucco and Ullmann, 2015, p. 263). This challenge, which also exists for other stages of the life cycle (such as early childhood), involves coordinating and articulating various sectors of public policy to guarantee the rights and needs of the population passing through this phase of life. Unlike other population segments or groups (which may be defined by gender, territory, ethnicity and race, among other criteria), youth is transitory and includes everyone who survives beyond childhood. This requires a complex institutional design. The institutional framework largely defines the type of policies that can be implemented to promote the social inclusion of young people; and it also determines their scope and effectiveness. Three dimensions of the institutional framework are decisive for this process: (i) the regulatory framework; (ii) the agencies that execute and coordinate youth policies; and (iii) the existence of national youth policies or plans.

The concept of youth is a social construction. Consequently, the age definitions, characteristics and roles accorded to it vary according to the historical and cultural factors of each society. Moreover, young people's transitions and life trajectories are heterogeneous; they develop in different ways and at different times, and do not necessarily follow a linear path (ECLAC/OIJ/IMJUVE, 2014). Accordingly, the first thing to be taken into account when analysing the institutional context is the youth perspective that is embedded in policies and programmes. As noted in the IberoAmerican reports on the subject (ECLAC/OIJ, 2004 and 2008, ECLAC/OIJ/ IMJUVE, 2014), the complexity of the concept of youth and how to define it underlie the variability of the policies with which it is addressed. Beyond the established age range, which in most countries is 15-24 or 15-29 years of age, what largely determines policy implementation is the substantial definition of this segment and where it is located. In other words, the place that young people occupy within society needs to be defined, along with the roles assigned to them and those from which they are excluded (CEPAL/OIJ/IMJUVE, 2014). 


\section{A. National (and supranational) legal frameworks for youth policies}

As noted in ECLAC (2017), although there is no international instrument that sets forth a comprehensive system for specifically protecting the rights of young people, there have been initiatives in this direction since 1985, when the United Nations celebrated the first International Year of Youth. The Global Forum on Youth Policies, held in Baku in 2014, agreed on basic guidelines for these policies. For example, it was decided that they should be rights-based, inclusive, participatory, gender-responsive, comprehensive, knowledge-based and evidence-informed, fully resourced, and accountable (ECLAC, 2015). Many countries in the region have been developing strategies that incorporate elements of the Baku commitment, and have adopted the youth perspective as a citizenship space, and youth as a strategic actor in the development process (ECLAC, 2017).

In Latin America, there are two important regional instruments for youth. The first is the Ibero-American Convention on Young People's Rights of 2005, signed by 16 countries, in which those rights are enshrined in areas such as health, education, work, justice, participation, gender equality and sexuality. ${ }^{3}$ The signatory States adopted the commitment to progressively incorporate decisions and adopt practical measures to view young people as key actors in their countries' development, taking current challenges into account. More recently, the Ibero-American Pact for Youth was signed at the Ibero-American Summit of Heads of State and Government, held in October 2016 in Colombia. The objective of the pact is to promote young people's participation in the global development agenda, to the recognition of the rights of young people established in the Ibero-American Convention, to develop initiatives in the area of equality and inclusion and to strengthen institutions related to youth, among other issues affecting the well-being of Ibero-American youth. ${ }^{4}$

In the Caribbean, there is also a youth development agenda in the Caribbean Community (CARICOM), ${ }^{5}$ which operationalizes the Declaration of Paramaribo of 2010 on the Future of Youth (ECLAC, 2017). This fosters the well-being of the adolescent and youth populations, along with their empowerment and participation in national and regional development.

At the national level, the existence of legislation on youth is a key to the development of policies in this regard. The respective laws or decrees create institutions, specify rights, define the objectives of the intervention, establish goals, allocate resources, and distinguish levels of responsibility

See [online] http://www.oij.org/file_upload/publicationsitems/document/20120607115106_98.pdf.

See [online] http://segib.org/documento/pacto-iberoamericano-de-juventud/.

See [online] http://cms2.caricom.org/documents/13930-cydap_2012-2017_rev.pdf. 
and articulation with the actors in question. The existence of a legal framework in this area reflects a societal consensus on the need to treat this population group with a specific approach. It also forces the different levels of government to define and implement the policies needed to attain the established objectives and to designate public budgetary resources for that purpose. The legal framework thus provides stability, permanent criteria, institutions and resources for public policies on the subject (ECLAC, 2015).

The 18 countries of Latin America all have general legislation on youth. Apart from Chile, Cuba and Uruguay, which were pioneers in the field, none of these institutionalization initiatives was established before the 2000 decade. The regulations in question aim to define the country's youth population, as well as their rights and, often, the type of public body that has responsibility for policies in this area (see table VI.1).

Table VI.1

Latin America (18 countries): national legal framework for youth

\begin{tabular}{|c|c|c|c|}
\hline Country & Relevant law & $\begin{array}{c}\text { Year of } \\
\text { promulgation }\end{array}$ & Stated aim \\
\hline Argentina & $\begin{array}{l}\text { Federal Youth } \\
\text { Council (Law } \\
\text { No. 26.227) }\end{array}$ & 2007 & $\begin{array}{l}\text { Collaborate with the design and inter-jurisdictional } \\
\text { coordination of youth policies, building strategic } \\
\text { management maps that allow the concept of } \\
\text { citizenship to be constructed on the basis of } \\
\text { values such as solidarity, equity, commitment, } \\
\text { justice, responsibility, ethics and national identity. }\end{array}$ \\
\hline $\begin{array}{l}\text { Bolivia } \\
\text { (Plurinational } \\
\text { State of) }\end{array}$ & $\begin{array}{l}\text { Law on Youth } \\
\text { (Law No. 342) }\end{array}$ & 2013 & $\begin{array}{l}\text { Guarantee young people full exercise of their } \\
\text { rights and duties, design of the institutional } \\
\text { framework, mechanisms of youth representation } \\
\text { and decision-making, and the establishment } \\
\text { of public policies. }\end{array}$ \\
\hline Brazil & $\begin{array}{l}\text { Youth Statute } \\
\text { (Law No. 12.852) }\end{array}$ & 2013 & $\begin{array}{l}\text { Establish the rights of young people and } \\
\text { guidelines for public policies on youth and the } \\
\text { National Youth System (SINAJUVE). }\end{array}$ \\
\hline Chile & Law No. 19.042 & 1991 & $\begin{array}{l}\text { Create the National Youth Institute, as a } \\
\text { functionally decentralized public service, endowed } \\
\text { with its own legal status and capital, related to the } \\
\text { President of the Republic through the Ministry of } \\
\text { Planning and Cooperation (which later became } \\
\text { the Ministry of Social Development). }\end{array}$ \\
\hline Colombia & $\begin{array}{l}\text { Youth Citizenship } \\
\text { Statute (Law } \\
\text { No. 1.622) }\end{array}$ & 2013 & $\begin{array}{l}\text { Establish an institutional framework that } \\
\text { guarantees all young people the full exercise of } \\
\text { youth citizenship in the civil or personal, social } \\
\text { and public spheres, plus effective enjoyment of the } \\
\text { rights recognized in the domestic legal system } \\
\text { and ratified in international treaties. }\end{array}$ \\
\hline Costa Rica & $\begin{array}{l}\text { General Law on } \\
\text { Youth (Law } \\
\text { No. 8.261) }\end{array}$ & 2002 & $\begin{array}{l}\text { Prepare, promote and coordinate the execution of } \\
\text { public policies targeting young people. Coordinate } \\
\text { the set of national development policies promoted } \\
\text { by public bodies, so that they include the creation } \\
\text { of opportunities, access to services, and increase } \\
\text { in the potential of young people. Promote the } \\
\text { political, social, cultural and economic participation } \\
\text { of young people, under conditions of solidarity, } \\
\text { equity and well-being. Promote and undertake } \\
\text { research into the condition of young people and } \\
\text { their families. Protect the rights, obligations and } \\
\text { fundamental guarantees of the young person. }\end{array}$ \\
\hline
\end{tabular}


Table VI.1 (continued)

\begin{tabular}{llcl} 
Country & Relevant law & $\begin{array}{c}\text { Year of } \\
\text { promulgation }\end{array}$ & Stated aim \\
\hline Cuba & $\begin{array}{l}\text { Childhood and } \\
\text { Youth Code } \\
\text { (Law No. 16) }\end{array}$ & 1978 & $\begin{array}{l}\text { Regulate the participation of children and young } \\
\text { people under } 30 \text { years of age in the construction } \\
\text { of the new society; and establish the obligations } \\
\text { of the individuals, agencies and institutions } \\
\text { involved in their education, with the objective } \\
\text { of promoting the formation of the communist } \\
\text { personality in the young generation. }\end{array}$ \\
& & \\
& &
\end{tabular}

\begin{tabular}{|c|c|c|}
\hline $\begin{array}{l}\text { Dominican } \\
\text { Republic }\end{array}$ & $\begin{array}{l}\text { General Law } \\
\text { on Youth } \\
\text { (Law No. 49) }\end{array}$ & 2000 \\
\hline
\end{tabular}

Establish a legal, political and institutional framework that guides the actions of the State and society in general, towards the definition and implementation of the set of policies needed to satisfy the needs and expectations of the country's youth, as well as effective participation by young people in decision-making processes.

\begin{tabular}{|c|c|c|c|}
\hline Ecuador & Youth Law & $2001 / 2011$ & $\begin{array}{l}\text { Recognizes the particular needs of young people } \\
\text { and promotes the full exercise of their rights. } \\
\text { In } 2011 \text {, the Law was updated to reflect the new } \\
\text { Constitution (2008) and strengthen the real } \\
\text { guarantee of rights. }\end{array}$ \\
\hline El Salvador & $\begin{array}{l}\text { General Law on } \\
\text { Youth (Decree } \\
\text { No. 910) }\end{array}$ & 2012 & $\begin{array}{l}\text { Implement public policies, programmes, strategies } \\
\text { and plans for the comprehensive development } \\
\text { of the youth population. }\end{array}$ \\
\hline Honduras & $\begin{array}{l}\text { Framework } \\
\text { Law for } \\
\text { Comprehensive } \\
\text { Youth } \\
\text { Development } \\
\text { (Decree No. 260) }\end{array}$ & 2005 & $\begin{array}{l}\text { Establish a legal, political and institutional } \\
\text { framework that promotes the full development } \\
\text { of young people. }\end{array}$ \\
\hline Mexico & $\begin{array}{l}\text { Law of the } \\
\text { Mexican Youth } \\
\text { Institute }\end{array}$ & 2012 & $\begin{array}{l}\text { Create the Mexican Youth Institute as a } \\
\text { decentralized public body, with its own legal status } \\
\text { and capital, and with technical, operational and } \\
\text { managerial autonomy, headquartered } \\
\text { in the Federal District. }\end{array}$ \\
\hline Nicaragua & $\begin{array}{l}\text { Law for } \\
\text { Promotion of the } \\
\text { Comprehensive } \\
\text { Youth } \\
\text { Development } \\
\text { (Law No. 392) } \\
\text { and its } \\
\text { Regulations }\end{array}$ & 2001 & $\begin{array}{l}\text { Promote the human development of young men } \\
\text { and women, guarantee the exercise of their rights } \\
\text { and obligations, establish institutional policies } \\
\text { and mobilize resources of the State and civil } \\
\text { society for the benefit of youth. }\end{array}$ \\
\hline Panama & $\begin{array}{l}\text { Law on the } \\
\text { National } \\
\text { Secretariat } \\
\text { for Children, } \\
\text { Adolescents and } \\
\text { the Family } \\
\text { (Law No. 14) }\end{array}$ & 2009 & $\begin{array}{l}\text { Create the National Secretariat for Children, } \\
\text { Adolescents and the Family. Strengthen the } \\
\text { institutional framework for the protection } \\
\text { and promotion of the rights of children and } \\
\text { adolescents, by consolidating the bases and } \\
\text { guiding principles of the operation of the System } \\
\text { for the Comprehensive Protection of Children } \\
\text { and Adolescents of the Republic of Panama. }\end{array}$ \\
\hline Paraguay & Decree No. 262 & 2013 & $\begin{array}{l}\text { Create the National Youth Secretariat (SNJ) as } \\
\text { an institution under public law, that governs and } \\
\text { is responsible for guiding State actions on the set } \\
\text { of public policies needed to meet the needs and } \\
\text { expectations of youth, in addition to promoting } \\
\text { youth participation in decision-making processes. } \\
\text { It replaces the National Law on Youth and Public } \\
\text { Youth Organizations (2005), which was confined } \\
\text { to the Ministry of Education and Culture. }\end{array}$ \\
\hline
\end{tabular}


Table VI.1 (concluded)

\begin{tabular}{|c|c|c|c|}
\hline Country & Relevant law & $\begin{array}{c}\text { Year of } \\
\text { promulgation }\end{array}$ & Stated aim \\
\hline Peru & $\begin{array}{l}\text { Supreme Decree } \\
\text { No. 001-2008-ED }\end{array}$ & 2008 & $\begin{array}{l}\text { Create the National Youth Secretariat (SENAJU), } \\
\text { with responsibility for formulating State policies on } \\
\text { youth that contribute to the overall development } \\
\text { of young people on issues of employability, } \\
\text { improvement of the quality of life, social inclusion, } \\
\text { participation and access to spaces in all areas } \\
\text { of human development, while also promoting } \\
\text { and supervising programmes and projects for } \\
\text { the benefit of young people. }\end{array}$ \\
\hline \multirow[t]{2}{*}{ Uruguay } & Law No. 16.170 & 1990 & \multirow{2}{*}{$\begin{array}{l}\text { Create the National Youth Institute (INJU), } \\
\text { with responsibility for formulating, executing } \\
\text { and evaluating national policies on youth, in } \\
\text { coordination with other State agencies. It should } \\
\text { also promote, plan and coordinate the activities of } \\
\text { the Youth Information Centre, which will report to } \\
\text { the aforementioned Institute, through advice and } \\
\text { training for the staff of local information units. }\end{array}$} \\
\hline & $\begin{array}{l}\text { Ibero-American } \\
\text { Convention on } \\
\text { the Rights of } \\
\text { Young People } \\
\text { (Law No. 18.270) }\end{array}$ & 2008 & \\
\hline $\begin{array}{l}\text { Venezuela } \\
\text { (Bolivarian } \\
\text { Republic of) }\end{array}$ & $\begin{array}{l}\text { National Youth } \\
\text { Law } \\
\text { (Law No. } 37.404 \text { ) }\end{array}$ & 2002 & $\begin{array}{l}\text { Regulate and develop the rights and duties of } \\
\text { youth, in order to grant young people opportunities } \\
\text { for full development towards productive adult life, } \\
\text { including the guarantees for their training, first } \\
\text { employment and participation in the development } \\
\text { process through State public policies, with } \\
\text { solidarity-based participation by the family } \\
\text { and society at large. }\end{array}$ \\
\hline
\end{tabular}

Source: D. Trucco and H. Ullmann (eds.), Youth: realities and challenges for achieving development with equality, ECLAC Books, No. 137 (LC/G.2647-P), Santiago, Economic Commission for Latin America and the Caribbean (ECLAC), 2016; and ECLAC, "Database on Social Institutionality in Latin America and the Caribbean" [online] https://dds.cepal.org/bdips/index-en.php.

\section{B. Organizational dimension: the governance of youth policies}

\section{Coordinating institutions and authority}

Most of the laws listed in table VI.1 define the type of specialized agency that is responsible for ensuring the rights of young people. One of the central missions that these institutions must consider is the provision of sufficient resources to implement specific policies and programmes that guarantee conditions for young people of both sexes to mobilize their capacity to fulfil their life projects autonomously. It should also promote a greater articulation and enhance the visibility of their specific needs and aspirations, especially on issues related to staying in school, the schoolto-work transition, job training, access to health care (especially, although not only , sexual and reproductive health), the availability of care services, prevention of violence and protection against it, and possibilities for participation and access to culture. The priorities accorded to these issues vary from one context to another, but the institutional framework aims to ensure visibility and articulation (ECLAC, 2017). 
There are various modalities of government institutions responsible for youth issues. Ministries or secretariats, vice-ministries or undersecretariats, institutes, directorates and national councils devoted to these issues can all be found in the region. Table VI.2 details the relevant agencies in 26 countries in Latin America and the Caribbean, together with their official purpose or mission. It also identifies the institution that governs the youth organization, when the latter does not have ministerial rank. Although nine countries have an institution of ministerial rank, this can be misleading, since they are often institutions that also encompass other areas (such as sports and culture) or serve priority population groups (such as women and children) and do not have large technical or financial resources (ECLAC, 2017). In seven countries, the governing body is the office of the President or Vice President of the nation. While this arrangement can be advantageous in terms of the visibility and prioritization of policies, it can also be highly contingent on the will and interests of the government of the day. The Ministry of Social Development is the authority in just five countries.

Table VI.2

\section{Latin America and the Caribbean (26 countries): articulation and oversight of government agencies dedicated to young people}

\begin{tabular}{|c|c|c|c|}
\hline Country & $\begin{array}{l}\text { Main youth } \\
\text { protection institution }\end{array}$ & Stated aim & $\begin{array}{l}\text { Coordinating or } \\
\text { steering authority }\end{array}$ \\
\hline $\begin{array}{l}\text { Antigua and } \\
\text { Barbuda }\end{array}$ & $\begin{array}{l}\text { Ministry of Education, } \\
\text { Sports, Youth and } \\
\text { Gender Affairs }\end{array}$ & $\begin{array}{l}\text { Provide quality education to children } \\
\text { and young people (from pre-school } \\
\text { to post-graduate level), and work } \\
\text { with societal actors to strengthen } \\
\text { educational, sports and youth } \\
\text { empowerment institutions, with } \\
\text { the aim of developing productive } \\
\text { citizens that are capable of learning } \\
\text { and working independently and } \\
\text { collectively and making a contribution } \\
\text { to their communities. }\end{array}$ & $\begin{array}{l}\text { Ministry of } \\
\text { Education, Sports, } \\
\text { Youth and Gender } \\
\text { Affairs }\end{array}$ \\
\hline Argentina & $\begin{array}{l}\text { National Youth } \\
\text { Directorate (DINAJU) }\end{array}$ & $\begin{array}{l}\text { Make young people protagonists in the } \\
\text { construction of the homeland. Raise } \\
\text { the status of youth issues through the } \\
\text { definition of guidelines for policies } \\
\text { aimed at the youth population, from } \\
\text { a federal and intergovernmental } \\
\text { perspective. }\end{array}$ & $\begin{array}{l}\text { Ministry of Social } \\
\text { Development }\end{array}$ \\
\hline Bahamas & $\begin{array}{l}\text { Ministry of Youth, } \\
\text { Culture and Sports }\end{array}$ & $\begin{array}{l}\text { Promote the economic, physical, } \\
\text { cultural, spiritual and social well-being } \\
\text { of young people from } 16 \text { to } 24 \text { years of } \\
\text { age nationwide in the Commonwealth } \\
\text { of the Bahamas. }\end{array}$ & $\begin{array}{l}\text { Ministry of Youth, } \\
\text { Culture and Sports }\end{array}$ \\
\hline Barbados & $\begin{array}{l}\text { Ministry of Culture, } \\
\text { Sports and Youth, } \\
\text { Youth Affairs Division }\end{array}$ & $\begin{array}{l}\text { Facilitate the development of } \\
\text { confident, proud, self-dependent } \\
\text { and creative individuals, through } \\
\text { participation in activities that } \\
\text { contribute to personal, community } \\
\text { and national development. }\end{array}$ & $\begin{array}{l}\text { Ministry of Culture, } \\
\text { Sports and Youth }\end{array}$ \\
\hline
\end{tabular}


Table VI.2 (continued)

\begin{tabular}{|c|c|c|c|}
\hline Country & $\begin{array}{l}\text { Main youth } \\
\text { protection institution }\end{array}$ & Stated aim & $\begin{array}{l}\text { Coordinating or } \\
\text { steering authority }\end{array}$ \\
\hline Belize & $\begin{array}{l}\text { Ministry of Education, } \\
\text { Youth, Sports and } \\
\text { Culture }\end{array}$ & $\begin{array}{l}\text { Ensure that all Belizeans have the } \\
\text { opportunity to acquire the knowledge, } \\
\text { skills and attitudes needed for their } \\
\text { personal development, and for full and } \\
\text { active participation in the development } \\
\text { of the nation. }\end{array}$ & $\begin{array}{l}\text { Ministry of } \\
\text { Education, Youth, } \\
\text { Sports and Culture }\end{array}$ \\
\hline $\begin{array}{l}\text { Bolivia } \\
\text { (Plurinational } \\
\text { State of) }\end{array}$ & $\begin{array}{l}\text { Plurinational Youth } \\
\text { Council }\end{array}$ & $\begin{array}{l}\text { Work with Bolivian youth, articulate } \\
\text { the country's youth organizations. }\end{array}$ & Ministry of Justice \\
\hline Brazil & $\begin{array}{l}\text { National Youth } \\
\text { Secretariat (SNJ) }\end{array}$ & $\begin{array}{l}\text { Formulate, coordinate, integrate and } \\
\text { articulate public policies on youth, } \\
\text { in addition to promoting cooperation } \\
\text { programmes with national and } \\
\text { international, public and private } \\
\text { organizations that are focused } \\
\text { on policies for young people. }\end{array}$ & $\begin{array}{l}\text { Office of the } \\
\text { President or } \\
\text { Vice-President, } \\
\text { or presidential } \\
\text { delegate }\end{array}$ \\
\hline Chile & $\begin{array}{l}\text { National Youth } \\
\text { Institute (INJUV) }\end{array}$ & $\begin{array}{l}\text { Collaborate with the government in the } \\
\text { design, planning and coordination } \\
\text { of youth policies. }\end{array}$ & $\begin{array}{l}\text { Ministry of } \\
\text { Development or } \\
\text { Social Inclusion }\end{array}$ \\
\hline Colombia & $\begin{array}{l}\text { Directorate of the } \\
\text { "Colombia Joven" } \\
\text { National Youth } \\
\text { System }\end{array}$ & $\begin{array}{l}\text { Promote public policies for youth; } \\
\text { encourage the participation of young } \\
\text { people in the different institutional } \\
\text { spaces; consolidate the National } \\
\text { Information and Knowledge } \\
\text { Management System for Adolescents } \\
\text { and Youth (SNIGCAJ); articulate } \\
\text { institutional public services for } \\
\text { youth, and promote socioeconomic } \\
\text { opportunities for this segment } \\
\text { of the population. }\end{array}$ & $\begin{array}{l}\text { Office of the } \\
\text { President or } \\
\text { Vice-President, } \\
\text { or presidential } \\
\text { delegate }\end{array}$ \\
\hline Costa Rica & Vice Ministry of Youth & $\begin{array}{l}\text { Direct and coordinate the internal and } \\
\text { external activities of the Ministry of } \\
\text { Culture and Youth, and oversee the } \\
\text { governance of the Youth Council for } \\
\text { the population of } 12 \text { to } 35 \text { years of age. }\end{array}$ & $\begin{array}{l}\text { Ministry of Culture } \\
\text { and Youth }\end{array}$ \\
\hline Dominica & $\begin{array}{l}\text { Ministry of Youth, } \\
\text { Sports, Culture and } \\
\text { Empowerment of the } \\
\text { Electorate, Youth } \\
\text { Development Division }\end{array}$ & $\begin{array}{l}\text { Provide services to empower young } \\
\text { people to develop their potential, } \\
\text { creativity and skills, as productive } \\
\text { and participatory members of their } \\
\text { society and community. }\end{array}$ & $\begin{array}{l}\text { Ministry of Youth, } \\
\text { Sports, Culture and } \\
\text { Empowerment of } \\
\text { the Electorate }\end{array}$ \\
\hline $\begin{array}{l}\text { Dominican } \\
\text { Republic }\end{array}$ & Ministry of Youth & $\begin{array}{l}\text { Promote the comprehensive } \\
\text { development of young people through } \\
\text { the formulation, coordination, monitoring } \\
\text { and evaluation of the National Youth } \\
\text { Policy. In conjunction with governmental } \\
\text { and non-governmental organizations, } \\
\text { steps are being taken to guarantee the } \\
\text { execution of programmes, plans and } \\
\text { projects that lead to the implementation } \\
\text { of sectoral policies and the application } \\
\text { of youth criteria. }\end{array}$ & Ministry of Youth \\
\hline Ecuador & $\begin{array}{l}\text { Ministry of Economic } \\
\text { and Social Inclusion } \\
\text { (MIES), National } \\
\text { Directorate of Youth } \\
\text { and Adolescence }\end{array}$ & $\begin{array}{l}\text { Encourage youth participation } \\
\text { and promote democratic practice, } \\
\text { recognizing young people as social } \\
\text { actors that contribute to social } \\
\text { transformation in the twenty-first century, } \\
\text { through a process to support and } \\
\text { strengthen youth organizations, groups. }\end{array}$ & $\begin{array}{l}\text { Ministry of } \\
\text { Economic and } \\
\text { Social Inclusion }\end{array}$ \\
\hline
\end{tabular}


Table VI.2 (continued)

\begin{tabular}{|c|c|c|c|}
\hline Country & $\begin{array}{l}\text { Main youth } \\
\text { protection institution }\end{array}$ & Stated aim & $\begin{array}{l}\text { Coordinating or } \\
\text { steering authority }\end{array}$ \\
\hline El Salvador & $\begin{array}{l}\text { National Institute } \\
\text { of Youth }\end{array}$ & $\begin{array}{l}\text { Oversee the National Youth Policy, } \\
\text { especially on issues of social } \\
\text { prevention of youth violence. }\end{array}$ & $\begin{array}{l}\text { Office of the } \\
\text { President or } \\
\text { Vice-President, } \\
\text { or presidential } \\
\text { delegate }\end{array}$ \\
\hline Guatemala & $\begin{array}{l}\text { National Youth } \\
\text { Council }\end{array}$ & $\begin{array}{l}\text { Establish systematic processes } \\
\text { to facilitate consensus among } \\
\text { organized youth sectors and } \\
\text { facilitate the construction of legal } \\
\text { frameworks, and public policies that } \\
\text { respond to the multiple demands } \\
\text { of Guatemalan youth. }\end{array}$ & $\begin{array}{l}\text { Office of the } \\
\text { President or } \\
\text { Vice-President, } \\
\text { or presidential } \\
\text { delegate }\end{array}$ \\
\hline Guyana & $\begin{array}{l}\text { Ministry of Education, } \\
\text { Culture, Youth and } \\
\text { Sport Department }\end{array}$ & $\begin{array}{l}\text { Empower Guyana's youth through } \\
\text { interactive programmes designed to } \\
\text { improve their skills and attitudes, so } \\
\text { that they can contribute significantly } \\
\text { to national development. }\end{array}$ & $\begin{array}{l}\text { Ministry of } \\
\text { Education }\end{array}$ \\
\hline Honduras & $\begin{array}{l}\text { National Youth } \\
\text { Institute (INJ) }\end{array}$ & $\begin{array}{l}\text { Establish a legal, political and } \\
\text { institutional framework to promote } \\
\text { youth development; define State } \\
\text { policies on youth; guide the actions } \\
\text { of the State, society and the family } \\
\text { on these matters, and encourage } \\
\text { active, responsible and permanent } \\
\text { participation by young people in } \\
\text { their own development and that } \\
\text { of their country. }\end{array}$ & $\begin{array}{l}\text { Office of the } \\
\text { President or } \\
\text { Vice-President, } \\
\text { or presidential } \\
\text { delegate }\end{array}$ \\
\hline Jamaica & $\begin{array}{l}\text { Ministry of } \\
\text { Culture, Gender, } \\
\text { Entertainment } \\
\text { and Sport }\end{array}$ & $\begin{array}{l}\text { Lead social transformation and } \\
\text { improve societal welfare through } \\
\text { programmes, services and activities } \\
\text { aimed at advancing youth; and also } \\
\text { contribute to economic growth and } \\
\text { progress through the development } \\
\text { of the culture industry and the } \\
\text { implementation of policies and } \\
\text { programmes that help promote } \\
\text { the Jamaica brand. }\end{array}$ & $\begin{array}{l}\text { Ministry of } \\
\text { Culture, Gender, } \\
\text { Entertainment } \\
\text { and Sport }\end{array}$ \\
\hline Mexico & $\begin{array}{l}\text { Mexican Youth } \\
\text { Institute }\end{array}$ & $\begin{array}{l}\text { Formulate public policies in favour of } \\
\text { young people to provide them with the } \\
\text { necessary tools in education, health, } \\
\text { employment and social participation. }\end{array}$ & $\begin{array}{l}\text { Office of the } \\
\text { President or } \\
\text { Vice-President, } \\
\text { or presidential } \\
\text { delegate }\end{array}$ \\
\hline Nicaragua & Ministry of Youth & $\begin{array}{l}\text { Formulate and implement policies, } \\
\text { programmes and strategies that } \\
\text { promote the conscious and active } \\
\text { participation of Nicaraguan youth in } \\
\text { the economic, political, social and } \\
\text { cultural development of the country, } \\
\text { in a model based on Christian } \\
\text { values, socialist ideals } \\
\text { and solidarity-based practices. }\end{array}$ & $\begin{array}{l}\text { Ministry without } \\
\text { portfolio }\end{array}$ \\
\hline Panama & $\begin{array}{l}\text { Ministry of Social } \\
\text { Development }\end{array}$ & $\begin{array}{l}\text { Promote human development } \\
\text { through participation, strengthening } \\
\text { of the family and the community, } \\
\text { social integration and poverty } \\
\text { reduction. }\end{array}$ & $\begin{array}{l}\text { Ministry of } \\
\text { Development or } \\
\text { Social Inclusion }\end{array}$ \\
\hline
\end{tabular}


Table VI.2 (concluded)

\begin{tabular}{|c|c|c|c|}
\hline Country & $\begin{array}{l}\text { Main youth } \\
\text { protection institution }\end{array}$ & Stated aim & $\begin{array}{l}\text { Coordinating or } \\
\text { steering authority }\end{array}$ \\
\hline Paraguay & $\begin{array}{l}\text { National Youth } \\
\text { Secretariat }\end{array}$ & $\begin{array}{l}\text { Promote, generate, coordinate and } \\
\text { implement inclusive public policies } \\
\text { aimed at satisfying the priority needs } \\
\text { of the country's youth population, with } \\
\text { emphasis on those in a situation of } \\
\text { poverty and vulnerability, in order to } \\
\text { guarantee the improvement of their } \\
\text { living conditions and their } \\
\text { active participation in all areas } \\
\text { of national development. }\end{array}$ & $\begin{array}{l}\text { Office of the } \\
\text { President or } \\
\text { Vice-President, } \\
\text { or presidential } \\
\text { delegate }\end{array}$ \\
\hline Peru & $\begin{array}{l}\text { National Youth } \\
\text { Secretariat }\end{array}$ & $\begin{array}{l}\text { Promote, articulate, coordinate, } \\
\text { monitor and evaluate policies, plans, } \\
\text { programmes, projects and actions } \\
\text { to benefit young people aged 15- } \\
29 \text { years, within a of participatory, } \\
\text { inclusive and democratic framework. }\end{array}$ & $\begin{array}{l}\text { Ministry of } \\
\text { Education }\end{array}$ \\
\hline $\begin{array}{l}\text { Trinidad and } \\
\text { Tobago }\end{array}$ & $\begin{array}{l}\text { Ministry of Gender, } \\
\text { Youth and Child } \\
\text { Development }\end{array}$ & $\begin{array}{l}\text { Provide effective leadership on gender } \\
\text { and development issues, and effective } \\
\text { formulation of evidence-based policy } \\
\text { for children and youth; implement } \\
\text { quality services and programmes, } \\
\text { guaranteeing the stakeholder } \\
\text { collaboration in planning, monitoring } \\
\text { and evaluation. }\end{array}$ & $\begin{array}{l}\text { Ministry of Gender, } \\
\text { Youth and Child } \\
\text { Development }\end{array}$ \\
\hline Uruguay & $\begin{array}{l}\text { National Youth } \\
\text { Institute }\end{array}$ & $\begin{array}{l}\text { Plan, design, advise, articulate, } \\
\text { supervise and execute public policies } \\
\text { for youth and ensure compliance. }\end{array}$ & $\begin{array}{l}\text { Ministry of } \\
\text { Development or } \\
\text { Social Inclusion }\end{array}$ \\
\hline $\begin{array}{l}\text { Venezuela } \\
\text { (Bolivarian } \\
\text { Republic of) }\end{array}$ & $\begin{array}{l}\text { National People's } \\
\text { Power Institute } \\
\text { of Youth }\end{array}$ & $\begin{array}{l}\text { Formulate and implement policies } \\
\text { aimed at achieving proactive } \\
\text { participation by young people and } \\
\text { their integration into the processes } \\
\text { of transforming a socialist homeland } \\
\text { for the construction of popular youth } \\
\text { power. Serve as the governing } \\
\text { institution in the articulation of youth } \\
\text { policies with other State entities. }\end{array}$ & $\begin{array}{l}\text { Ministry of Popular } \\
\text { Power for Youth } \\
\text { and Sports }\end{array}$ \\
\hline
\end{tabular}

Source: D. Trucco and H. Ullmann (eds.), Youth: realities and challenges for achieving development with equality, ECLAC Books, No. 137 (LC/G.2647-P), Santiago, Economic Commission for Latin America and the Caribbean (ECLAC), 2016; and ECLAC, "Database on Social Institutionality in Latin America and the Caribbean" [online] https://dds.cepal.org/bdips/index-en.php.

In the vast majority of these agencies, the main mission is to serve as authority on the subject, and as the organization that plans, articulates, coordinates and regulates and, in some cases, executes policies and programmes targeting the youth population. Some also consider themselves interlocutors of the State in the dialogue with civil society youth organizations. As has been discussed throughout this document, it is often difficult for these entities to fulfill the oversight or coordination role in relation to sectoral ministries, such as education or health, that have a major influence in the State apparatus. This is due to institutional weakness (particularly in the case of agencies without ministerial rank), or insufficient installed capacity (authorities that are subject to frequent turnover and have little experience in public management), or else lack of resources. 
Other commonly declared institutional objectives involve enhancing the role of the youth population and its potential contribution to each country's development and social environments. In a large group of countries, the objective of promoting the comprehensive well-being and development of young people, considering different dimensions, is also proposed. Lastly, some play a more targeted role in the promotion of skills and abilities among youth (the education-employment pillar).

As noted in Trucco and Ullmann (2015), most youth institutions in Latin America and the Caribbean have their own website (in $90 \%$ of the countries). In general, they publish news on the subject and information about policies and programmes that are being implemented in each country. Just over half of these sites $(60 \%)$ post information on related laws and regulations; around $40 \%$ contain publications related to youth research carried out either by the institutions themselves or by other organizations; and under $30 \%$ have statistics on the youth of their country.

\section{Citizen participation channels}

Strengthening youth participation is essential, to make decisions more relevant, sustainable and legitimate. Nonetheless, as ECLAC has noted, participation channels for young people to play an active role in the formulation, implementation, monitoring and evaluation of policies are insufficient in themselves; and they fail to capture the voice of youth in an inclusive and efficient manner. Although some participation channels operate through youth organizations, these usually lack resources, and the coordination between them tends to be weak or non-existent. Frequently, the implementation of public policies does not encourage participation by young people continuously throughout the process, but only in the final stages and in an ad hoc manner. Moreover, these participation mechanisms only operate with policies that are directly linked to the youth population and not other areas (Trucco and Ullmann, 2015, page 270).

One way of involving civil society youth organizations in decisionmaking processes would be to include them formally in the institutional framework. Most countries have a formal structure for this purpose, be it advice, a consultative network or assembly. Fifteen out of eighteen Latin American countries have one or more mechanisms or citizen groupings that have representation with the entity in charge of youth policy (see table VI.2).

The level of participation of these entities varies. It may be purely consultative, or else it may involve a greater influence in decision making. On this point, it should be noted that most countries have participation mechanisms at decision-making or even joint management level. ${ }^{6}$ There

Terms used in Sandoval, Sanhueza and Williner (2015). 
is a group of countries that have citizen councils that jointly manage participation in youth policies. At this level, people and groups are not only involved in decision-making, but also in implementation and follow-up, to ensure that decisions are properly implemented (Sandoval, Sanhueza and Williner, 2015).

There are also other types of organization where the level of participation of the citizen youth body is of a decision-making nature, and the individuals and groups that participate have a direct influence on decision making (Sandoval, Sanhueza and Williner, 2015). The result of the process is binding for the public entity that implements youth policy. Lastly, there are institutions that only have a consultative role, where the objective of the consultation process is to ascertain opinions, proposals and interests of the people and groups that participate. In this case, the consultation is not binding on the authority.

In some countries, the members of these councils are appointed, but in several cases they are elected by vote. In most (see table VI.3), the level of representation is national or intermediate (regional or state), and fewer have local or community representation.

Table VI.3

Latin America (8 countries): participation channels of youth institutions

\begin{tabular}{|c|c|c|c|c|}
\hline Country & $\begin{array}{l}\text { Mechanism of youth } \\
\text { participation in public } \\
\text { policy formulation }\end{array}$ & $\begin{array}{l}\text { Representatives } \\
\text { election method }\end{array}$ & $\begin{array}{l}\text { Citizen } \\
\text { participation } \\
\text { level }\end{array}$ & Representativeness \\
\hline Argentina & Federal Youth Council & & $\begin{array}{l}\text { Decision- } \\
\text { making }\end{array}$ & National, intermediate \\
\hline $\begin{array}{l}\text { Bolivia } \\
\text { (Plurinational } \\
\text { State of) }\end{array}$ & $\begin{array}{l}\text { Plurinational Youth } \\
\text { Council }\end{array}$ & Appointment & $\begin{array}{l}\text { Joint } \\
\text { management }\end{array}$ & $\begin{array}{l}\text { National, intermediate } \\
\text { or local }\end{array}$ \\
\hline Brazil & $\begin{array}{l}\text { National Youth Council } \\
\text { of (CONJUVE) }\end{array}$ & Election & $\begin{array}{l}\text { Decision- } \\
\text { making }\end{array}$ & $\begin{array}{l}\text { National, intermediate } \\
\text { or local }\end{array}$ \\
\hline Chile & \multicolumn{4}{|c|}{ Does not have direct youth participation organization } \\
\hline Colombia & $\begin{array}{l}\text { National, departmental } \\
\text { and local youth councils }\end{array}$ & $\begin{array}{l}\text { Election or } \\
\text { appointment }\end{array}$ & $\begin{array}{l}\text { Joint } \\
\text { management }\end{array}$ & $\begin{array}{l}\text { National, intermediate } \\
\text { or local }\end{array}$ \\
\hline \multirow[t]{3}{*}{ Costa Rica } & $\begin{array}{l}\text { National Council of } \\
\text { Public Policy for Youth }\end{array}$ & Appointment & $\begin{array}{l}\text { Joint } \\
\text { management }\end{array}$ & National \\
\hline & $\begin{array}{l}\text { National Youth Advisory } \\
\text { Network }\end{array}$ & Election & $\begin{array}{l}\text { Decision- } \\
\text { making }\end{array}$ & $\begin{array}{l}\text { National, intermediate } \\
\text { or local }\end{array}$ \\
\hline & $\begin{array}{l}\text { National Consultative } \\
\text { Network on Youth }\end{array}$ & $\begin{array}{l}\text { Election or } \\
\text { appointment }\end{array}$ & $\begin{array}{l}\text { Decision- } \\
\text { making }\end{array}$ & National \\
\hline \multirow[t]{2}{*}{ Ecuador } & $\begin{array}{l}\text { National Council for } \\
\text { Youth Policies }\end{array}$ & $\begin{array}{l}\text { Election or } \\
\text { appointment }\end{array}$ & $\begin{array}{l}\text { Joint } \\
\text { management }\end{array}$ & National \\
\hline & Local Youth Councils & Election & $\begin{array}{l}\text { Decision- } \\
\text { making }\end{array}$ & Local \\
\hline El Salvador & National Youth Council & Election & $\begin{array}{l}\text { Joint } \\
\text { management }\end{array}$ & National \\
\hline
\end{tabular}

Source: Economic Commission for Latin America and the Caribbean (ECLAC), on the basis of official information. 


\section{Sectoral plans or policies and access to resources}

The existence of a regulation does not guarantee its application or its results. Its execution requires a national youth policy or plan. The role of such a policy or plan is also critical because it provides a vision of all the programmes and activities involving a country's youth, and it makes it possible to build and consolidate a vision of what it means to be young in the specific historical context (Trucco and Ullmann, 2015, p. 267). Most countries in the region have published a national policy or plan in this area in recent years. A review of official documents posted online from the 18 Latin American countries reveals that seven have a youth policy and nine have relatively up-to-date sector plans (just two have programmes only).

An analysis of 14 of these youth policies and plans reveals a number of common elements. For example, several cases state that actions related to this population group must be adopted from a rights perspective. Moreover, some documents explicitly mention the gender perspective and declare an intention to enhance the role of youth and its contribution to development. The main lines of action are also broadly similar. In the 14 documents analysed, the theme of decent work, labour-market inclusion or entrepreneurship features as one of the main lines of action (see figure VI.1). Secondly, and in a similar number of cases (13 out of 14), the pillars of education or capacity building (often closely linked to the employment pillar) and citizen and democratic participation stand out.

Figure VI.1

Latin America (14 countries): ${ }^{a}$ main policy pillars or youth sector plan

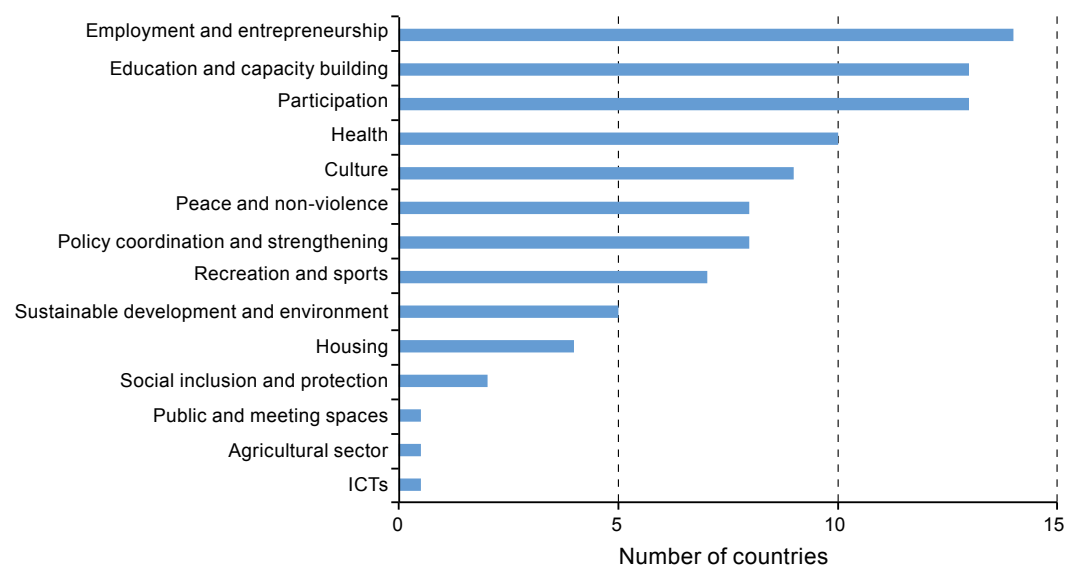

Source: Economic Commission for Latin America and the Caribbean (ECLAC), on the basis of official information. a Brazil, Colombia, Costa Rica, Dominican Republic, Ecuador, El Salvador, Guatemala, Honduras, Mexico, Panama, Paraguay, Peru, Plurinational State of Bolivia, and Uruguay. 
In many of the relevant organizations a central role is to provide a channel for the voice and participation of youth in their country ${ }^{7}$ One line of action in this regard involves measures and programmes to promote participation by youth organizations, or the training of young people in leadership skills and political participation. Several organizations, led by young people, become vehicles of formal participation in public management and mechanisms of political training for the youth of the ruling political party. This could entail the risk that the institution in question restrict its role as coordinator of youth policies generally to become a mechanism for the renewal and training of the new generations of political parties.

Health is another area of concern mentioned in the policy documents of 10 countries. Most refer to the comprehensive health of the young person, although in Honduras the focus is still exclusively on sexual and reproductive health. As mentioned by ECLAC in previous publications (Trucco and Ullmann, 2015), the low rates of morbidity and mortality of this population segment mean that a restricted health perspective tends to be applied and many of the needs of this group are rendered invisible. Hence the importance of proposing a comprehensive view of the specific needs of young people in terms of their access to health services, with mental health issues being particularly relevant.

Other important issues in sectoral youth plans and policies relate to culture. In several countries these are grouped with topics of identity, plurinationality, and recreation and sports (although, in some cases, cultural issues are addressed separately). The promotion of a culture of peace and non-violence is also a pillar on which several of the youth action strategies are articulated, above all in the Central American countries, but also in others, such as Mexico and Brazil, where rates of social violence are high.

Many of the plans or policies state a general intention to strengthen the role of the specialized agencies, as coordinators and articulators of youth policies. Eight of the 14 documents analysed make this an explicit line of action. Other prominent areas, although mentioned by fewer countries, include sustainable development or a healthy environment, housing, social inclusion and protection against poverty and vulnerability, public meeting spaces, the agriculture sector, and information and communications technologies (ICTs).

The previous section described the ways different countries institutionalize participation in public administration. 


\section{Fiscal dimension and the financing of youth policies}

Many of the region's countries have developed important action strategies based on their national youth policy or plan. Nonetheless, the resources allocated youth in public budgets are still insufficient and there are gaps between the objectives of these plans and the public budget. For example, as noted by Rodríguez (2011), public policy documents on youth prioritize issues such as excluded youth, labour market participation, the construction of citizenship and the prevention of violence. In contrast, public budgets continue to prioritize young people integrated into formal education; and while some resources are allocated to health, there is relatively little for labour market participation or the prevention of violence (ECLAC, 2015).

The challenge of financing has received worldwide attention. The Addis Ababa Action Agenda of the Third International Conference on Financing for Development is the first international instrument to explicitly recognize that investing in youth is essential if the aim is to achieve inclusive, equitable and sustainable development for present and future generations. ${ }^{8}$ This message is echoed in the work of ECLAC and other organizations that promote youth development in the region. In its most recent reports (ECLAC/UNFPA, 2012; ECLAC/OIJ/IMJUVE, 2014), ECLAC has made progress in analysing the social investment needed to implement youth policies and strategies, in order to provide a real guarantee of young people's rights. For example, ECLAC/UNFPA (2012) argues that the political will expressed in international agreements and consensuses does not necessarily generate specific policies or programmes that guarantee the conditions enabling young people to increase their capacity and independently fulfil their life projects.

Estimates presented in the last Ibero-American youth report (ECLAC/ OIJ/IMJUVE, 2014) show that total social investment in the region was equivalent to 19.1\% of GDP (about US\$ 660 billion) around 2012. Of this, the region allocates some US\$ 102 billion to social programmes that directly or indirectly benefit young people (US\$ 183 billion at 2005 prices, in purchasing power parity terms). As stated in the 2014 edition of the Social Panorama of Latin America (ECLAC, 2014), space for an expansion of public spending is currently limited, so expenditure planning needs to be improved, along with the development and strengthening of evaluation mechanisms, to ensure that resources are used more effectively and efficiently.

The Third International Conference on Financing for Development, organized by the United Nations, was held on 13-16 July 2015 in Addis Ababa. The final document, the Addis Ababa Action Agenda, is available [online] at http://www.un.org/ga/search/view_doc.asp?symbol=A/ CONF.227/L.1. 


\section{E. Final remarks}

Formulating and implementing inclusive and participatory public policies for youth, with a life-cycle perspective, is not an easy task, but implies concerted efforts and commitments. Consultations are required between young people and their organizations, together with effective and sustainable coordination between ministries, in addition to the allocation of sufficient resources and integration of the respective national policy into national development plans. Investing in this stage of the life cycle and achieving the full inclusion of young people is crucial for the development process aimed at building capacities and opportunities to make it possible to attain greater equality in Latin America and the Caribbean (Trucco and Ullmann, 2015).

ECLAC has stated that, in general, a comprehensive and multidimensional perspective on youth is not being applied in the policies that address this stage of the life cycle. For example, if one considers the main pillar of the social inclusion of the youth population (namely education and employment), there is little linkage between the policies in these two areas. Moreover, neither of the two areas covers the theme of the family and care tasks in a central or encompassing way. It is precisely at this stage of the life cycle that the need to reconcile education with employment is more pressing; and the weight of family responsibilities and caregiving can truncate young people's education and work trajectories, especially for women. Similarly, it is very important that the health, education and security sectors collaborate to address the violence faced by young people in their development and inclusion process, to be able to apply effective strategies of prevention and support for the youth population.

Regardless of the variety of modalities they implement and tasks they undertake to promote youth development in their respective countries, the agencies in charge of this issue tend to be weak (as is also true of ministries or institutions of social development), especially compared to the strength of the major sectoral ministries, such as education, labour and health. These are the oldest ministries in the history of public management in the region and have much larger budgets. National youth policies are managed by the respective coordinating bodies, which, as mentioned, have limited resources and political power. At the same time, line ministries tend to act independently on issues that affect young people. This fragmentation represents a major obstacle to the execution and monitoring of the policy and, ultimately, its effectiveness (Trucco and Ullmann, 2015).

This is one of the great dilemmas faced by the organizations called upon to articulate multisectoral initiatives. The role of coordinating other entities that have a larger budget and greater autonomy and prestige in the public domain becomes an almost impossible task. The mechanism that 
gives them some autonomy and budget is based on the commitment to execute certain specific programmes to fulfil some of the objectives of the sector plan, with a small budget and weak impact.

The priority of strengthening articulation between government actors dedicated to promoting youth development is clearly stated. Disarticulated programmes not only use scarce resources less efficiently, but they are also less effective. This reality justifies the implementation of comprehensive policies and programmes coordinated by youth bodies, arranged among the actors involved and designed according to a logic of serving youth groups in their respective environments. It is also necessary to strengthen local authorities (especially municipal ones) to implement youth social inclusion initiatives that involve greater community participation, in both their design and their execution (Trucco and Ullmann, 2015).

Given this panorama, there is a need to reflect on the essential functions to be carried out by the entities in charge of youth policy issues. It is therefore proposed to prioritize a role of coordination and articulation of initiatives, in order to streamline processes, make these issues visible in sectoral policies and promote a comprehensive approach to youth in the different sectors. This requires high-level political support in order to emphasize the youth issue and raise its profile in sectoral ministries and, at the same time, reinforce and empower the corresponding governing bodies (Trucco and Ullmann, 2015). It is also important to reduce personnel turnover in the relevant teams, so that they can take advantage of the capacities formed in these institutions, lasting beyond the governments in power.

Another of the major dilemmas that arise for social-sector institutions of this type that serve a specific population segment, is how to reconcile the specific needs of the life stage in question with the life-cycle approach, integrating the approach of the policies with those of the previous and subsequent stages. The need to implement an intergenerational approach compounds articulation between multiple sectors, and is even more difficult.

As stated in Trucco and Ullmann (2015), most of these initiatives to institutionalize actions related to youth were only established after the turn of this century. In other words, the concern of the governments of the region to give visibility and guidance to actions targeted on youth, and raise awareness of the importance of legislation and appropriate policies to respond to the needs, aspirations and demands of young people is relatively recent. Nonetheless, the existence of regulations on youth issues, and a plan or policy to implement them, is a necessary but insufficient condition for promoting the inclusion of young people. Despite the progress achieved and commitments made, the challenges described hinder the effective implementation of these measures. 


\section{Bibliography}

ECLAC (Economic Commission for Latin America and the Caribbean) (2017), Social Panorama of Latin America, 2016. Briefing Paper, Santiago, May.

(2016), The social inequality matrix in Latin America (LC/G.2690(MDS.1/2)), Santiago. (2015), "Towards the social inclusion of youth: tools for analysis and policy design", Project Documents, Studies and Research Papers (LC/M.28), Santiago. (2014), Social Panorama of Latin America, 2014 (LC/G.2635-P), Santiago.

ECLAC/OIJ (Economic Commission for Latin America and the Caribbean/IberoAmerican Youth Organization) (2008), Juventud y cohesión social en Iberoamérica: un modelo para armar (LC/G.2391), Santiago, October.

(2004), La juventud en Iberoamérica: tendencias y urgencias (LC/L.2180), Santiago, October.

ECLAC/OIJ/IMJUVE (Economic Commission for Latin America and the Caribbean/ Ibero-American Youth Organization/Mexican Youth Institute) (2014), Invertir para transformar: la juventud como protagonista del desarrollo, Madrid, September.

ECLAC/UNFPA (Economic Commission for Latin America and the Caribbean/ United Nations Population Fund) (2012), Informe Regional de Población en América Latina y el Caribe, 2011. Invertir en juventud en América Latina y el Caribe: un imperativo de derechos e inclusión, Santiago.

Rodríguez, E. (2011), "Políticas de juventud y desarrollo social en América Latina: bases para la construcción de respuestas integradas", paper presented at the Eighth Forum of Ministers of Social Development for Latin America, San Salvador, 11-12 July [online] http://www.unesco.org/new/fileadmin/ MULTIMEDIA/HQ/SHS/pdf / Youth\%20Policies \%20and\%20Social\%20 Development\%20-\%20Building\%20Integrated\%20Responses\%20ES.PDF.

Sandoval, C., A. Sanhueza and A. Williner (2015), "La planificación participativa para lograr un cambio estructural con igualdad", Manuales de la CEPAL series, No. 1 (LC/L.4069/Rev.1), Santiago, Economic Commission for Latin America and the Caribbean (ECLAC).

Trucco, D. and H. Ullmann (eds.) (2016), Youth: realities and challenges for achieving development with equality, ECLAC Books, No. 137 (LC/G.2647-P), Santiago, Economic Commission for Latin America and the Caribbean (ECLAC). 
Chapter VII

\section{Disability and public policy: institutional progress and challenges in Latin America}

Heidi Ullmann ${ }^{1}$

\section{Introduction ${ }^{2}$}

Disability is much more than a state of health. Understood in its social context, it is an experience of difference (UNICEF, 2005). It can also be an experience of exclusion and marginalization. Over recent decades, however, the countries of Latin America and the Caribbean have made significant progress in promoting and protecting the rights of persons with disabilities, and an institutional architecture to ensure that segment of the population fairer and more equitable lives has been put in place. This chapter provides an overview of that institutional architecture in the countries of Latin America, based on the framework for analysis proposed in chapter I. The first section examines the legal and regulatory dimension, at the international, regional and national levels. The second addresses the organizational dimension, and the technical and operational dimension is covered in the third section. The chapter concludes with some thoughts

Social Affairs Officer of the Social Development Division of the Economic Commission for Latin America and the Caribbean (ECLAC).

2 The author thanks Gabriel Kattan, a consultant with the Social Development Division of ECLAC, for his assistance in compiling information. 
on the progress that has been made with the institutional framework for disability in the countries of the region and the challenges that still remain to be addressed. It also offers some suggestions for strengthening that institutional framework, with a view to designing and progressively implementing better social policies to uphold the rights of persons with disabilities and ensure their inclusion.

\section{A. Legal and regulatory dimension}

As stated in chapter I, with the consolidation of democracy and as the rights-based approach has gained ground within the social sphere, the legal and regulatory dimension of society's institutional framework has grown in importance. This indicates the commitments that each country has assumed, towards both the international community and its own citizens, together with the foundations for the other dimensions of the institutional framework. In the specific case of the population with disabilities, their rights have been encoded in international, regional and national instruments.

Latin America was a pioneer in the defence of the rights of persons with disabilities, with the Inter-American Convention on the Elimination of All Forms of Discrimination against Persons with Disabilities (CIADDIS). Adopted by the Organization of American States (OAS) in 1999, it has been ratified by the 19 Latin American States that are members of the Organization (see table VII.1). The Convention aims to prevent and eliminate all forms of discrimination against persons with disabilities, and to promote their full integration into all areas of society by means of laws and social and educational programmes (OAS, 1999). At the time of its adoption, the CIADDIS provided a conceptual basis for dealing with disability. It also established a more explicit commitment towards protecting the rights of persons with disabilities than the one that the member States had assumed under general human rights instruments, which only partially or indirectly address the topic.

The OAS member States also adopted the Declaration on the Decade of the Americas for the Rights and Dignity of Persons with Disabilities (2006-2016) and its Programme of Action. In those instruments the countries agreed to the gradual adoption, within a reasonable time, of the administrative, legislative and judicial measures and public policies necessary for the effective enforcement of the Programme of Action, which addresses matters of awareness, health, education, employment, accessibility, political participation, culture, well-being, social assistance and international cooperation. 
Table VII.1

Latin America (19 countries): year of ratification or adhesion to the Inter-American Convention on the Elimination of All Forms of Discrimination Against Persons with Disabilities (1999) and the Convention on the Rights of Persons with Disabilities (2006), as of 1 April 2017

\begin{tabular}{lcc}
\hline Country & $\begin{array}{c}\text { Inter-American Convention on } \\
\text { the Elimination of All Forms of } \\
\text { Discrimination against Persons } \\
\text { with Disabilities (CIADDIS) }\end{array}$ & $\begin{array}{c}\text { Convention on the Rights } \\
\text { of Persons with Disabilities } \\
\text { (CRPD) }\end{array}$ \\
\hline Argentina & 2000 & 2008 \\
\hline $\begin{array}{l}\text { Bolivia (Plurinational } \\
\text { State of) }\end{array}$ & 2003 & 2009 \\
\hline Brazil & 2001 & 2008 \\
\hline Chile & 2001 & 2008 \\
\hline Colombia & 2003 & 2011 \\
\hline Costa Rica & 1999 & 2008 \\
\hline Cuba & & 2007 \\
\hline Dominican Republic & 2006 & 2009 \\
\hline Ecuador & 2004 & 2008 \\
\hline El Salvador & 2002 & 2007 \\
\hline Guatemala & 2002 & 2009 \\
\hline Honduras & 2011 & 2008 \\
\hline Mexico & 2000 & 2007 \\
\hline Nicaragua & 2002 & 2007 \\
\hline Panama & 2001 & 2007 \\
\hline Paraguay & 2002 & 2008 \\
\hline Peru & 2001 & 2008 \\
\hline Uruguay & 2001 & 2009 \\
\hline Venezuela (Bolivarian & 2006 & \\
\hline Republic of) & & \begin{tabular}{c} 
(C) \\
\hline
\end{tabular} \\
\hline
\end{tabular}

Source: Prepared by the author, on the basis of Ibero-American Social Security Organization (OISS), Medidas para la promoción del empleo de personas con discapacidad en Iberoamérica, Madrid, 2014.

The first references to the topic of disability in the international regulatory framework can be found in universal agreements and treaties, which set out rights to which all persons are entitled as human beings. These include the Universal Declaration of Human Rights (1948) and the International Covenant on Economic, Social and Cultural Rights (ICESCR) (1976). ${ }^{3}$ The United Nations Convention on the Rights of Persons with Disabilities (CRPD), the first human rights instrument of the twenty-first century, is clearly the most relevant piece of international law on this topic, in that it specifically seeks to support, protect and promote the rights and dignity of the population with disabilities (United Nations, 2006).

3 In addition, disability is referred to in instruments targeting specific populations, such as the Convention on the Rights of the Child (1989). 
Containing 50 articles, ${ }^{4}$ the Convention is structured around a series of principles: respect for the inherent dignity and individual autonomy of the person, non-discrimination, full and effective participation and inclusion in society, respect for differences and acceptance of people with disabilities as part of the human condition and its diversity, equality of opportunities, accessibility, equality between men and women, and respect for the development of children with disabilities (Stang, 2011).

In addition to its important function of explicitly and comprehensively setting out the rights of the population with disabilities, the Convention offers a paradigm shift in understanding disability: it proposes abandoning the biomedical approach centred on individual limitations and geared towards assistentialism in favour of an approach based on human rights that recognizes that disability is the result of interplay between long-term physical, mental, intellectual or sensory impairments which, in interaction with barriers of different kinds, may hinder certain persons' full and effective participation in society on an equal basis with others (United Nations, 2006). Rather than being an abstract and academic consideration, this paradigm shift has —or should have- a direct impact on other dimensions of the institutional framework through which this topic is addressed.

Following the ratification of the CRPD and CIADDIS, a great deal of progress has been made with the national regulations that govern the rights of persons with disabilities. It should nevertheless be noted that, in many cases, their rights were already explicitly enshrined in national constitutions prior to the adoption of those international instruments. Many constitutions contain specific articles on the topic or make express reference to people with disabilities and to sectors of the population who are to receive special protection in articles dealing with anti-discrimination efforts. In addition, there are laws, decrees, rules and regulations in other legal instruments - such as codes dealing with children, employment and the family - that govern the exercise of rights by persons with disabilities.

All the region's countries have specific laws that apply to persons with disabilities (see table VII.2). The oldest is Argentina's Law No. 22431 of 1981, on the System for the Comprehensive Protection of Disabled Persons. During the 1990s, six countries enacted legislation to regulate disability-related matters, and during the first decade of the new century a large number of new domestic laws for promoting and protecting the rights of persons with

\footnotetext{
The Convention's Optional Protocol establishes a mechanism for bringing complaints and recognizes the competence of the Committee on the Rights of Persons with Disabilities to receive and examine communications presented by persons or groups under its jurisdiction —or on behalf of such persons or groups- claiming to have suffered violations of the Convention's provisions by any State party. Most of the Latin American countries have ratified or adhered to this optional protocol.
} 
disabilities were enacted. In many cases, they were adopted when, or shortly after, the countries ratified the CRPD. By ratifying the Convention, the States Parties undertake to adopt the domestic legislative measures necessary to ensure and promote the full realization of all human rights and fundamental freedoms for all persons with disabilities (United Nations, 2006). Thus, in most cases (13 countries), these rules have full legal force.

Table VII.2

Latin America (19 countries): main legislation on the rights of persons with disabilities

\begin{tabular}{|c|c|c|}
\hline Country and year & Type & Legislation \\
\hline Argentina (1981) & Law & $\begin{array}{l}\text { Law No. 22.431, System for the Comprehensive Protection } \\
\text { of Disabled Persons }\end{array}$ \\
\hline $\begin{array}{l}\text { Bolivia (Plurinational } \\
\text { State of) (2012) }\end{array}$ & $\begin{array}{l}\text { Supreme } \\
\text { decree }\end{array}$ & Law No. 223, General Act on Persons with Disabilities \\
\hline Brazil (1989) & Law & $\begin{array}{l}\text { Law No. } 7.853 \text {, on support for persons with disabilities } \\
\text { and their social integration }\end{array}$ \\
\hline Chile (2010) & Law & $\begin{array}{l}\text { Law No. 20.422, establishing rules on equality of } \\
\text { opportunities and social inclusion for persons with disabilities }\end{array}$ \\
\hline \multirow[t]{2}{*}{ Colombia $(1997 ; 2013)$} & Law & $\begin{array}{l}\text { Law No. 361, establishing social integration mechanisms } \\
\text { for persons with limitations and enacting other provisions }\end{array}$ \\
\hline & Law & $\begin{array}{l}\text { Law No. 1.618, establishing provisions to guarantee full } \\
\text { enjoyment of the rights of persons with disabilities }\end{array}$ \\
\hline Costa Rica (1996) & Law & $\begin{array}{l}\text { Law No. } 7.600, \text { Equal Opportunities for Persons with } \\
\text { Disabilities Act }\end{array}$ \\
\hline Cuba (1996) & Resolution & $\begin{array}{l}\text { Resolution No. } 4 / 1996 \text {, creating the National Council for } \\
\text { the Attention of Persons with Disabilities }\end{array}$ \\
\hline $\begin{array}{l}\text { Dominican Republic } \\
\text { (2013) }\end{array}$ & Law & $\begin{array}{l}\text { Organic Law No. } 5 \text {, on the equality of rights of persons } \\
\text { with disabilities }\end{array}$ \\
\hline Ecuador (2012) & Law & Organic Disabilities Act \\
\hline El Salvador (2000) & $\begin{array}{l}\text { Legislative } \\
\text { declaration }\end{array}$ & Equal Opportunities for Persons with Disabilities Act \\
\hline \multirow[t]{2}{*}{ Guatemala (1996; 2008) } & Decree & Law No. 135 on the Attention of Persons with Disabilities \\
\hline & Decree & $\begin{array}{l}\text { Act Approving the National Policy for Disability and Plan } \\
\text { of Action }\end{array}$ \\
\hline Honduras (2005) & Decree & $\begin{array}{l}\text { Law No. } 160 \text { on Equity and Integral Development for Persons } \\
\text { with Disabilities }\end{array}$ \\
\hline Mexico (2011) & Law & General Act for the Inclusion of Persons with Disabilities \\
\hline Nicaragua (2011) & Law & Law No. 763 on the Rights of Persons with Disabilities \\
\hline Panama (1999) & Law & $\begin{array}{l}\text { Law No. } 42 \text {, establishing equality of opportunities for persons } \\
\text { with disabilities }\end{array}$ \\
\hline Paraguay (2012) & Law & $\begin{array}{l}\text { Law No. } 4.720 \text {, creating the National Secretariat for the } \\
\text { Human Rights of Persons with Disabilities (SENADIS) }\end{array}$ \\
\hline Peru (2012) & $\begin{array}{l}\text { Supreme } \\
\text { decree }\end{array}$ & Law No. 29.973, General Act for Persons with Disabilities \\
\hline Uruguay (2010) & Law & $\begin{array}{l}\text { Law No. } 18.651 \text { on the Comprehensive Protection of Persons } \\
\text { with Disabilities }\end{array}$ \\
\hline $\begin{array}{l}\text { Venezuela (Bolivarian } \\
\text { Republic of) (2006) }\end{array}$ & Law & Act on Persons with Disabilities \\
\hline
\end{tabular}

Source: Prepared by the author, on the basis of M. F. Stang, "Las personas con discapacidad en América Latina: del reconocimiento jurídico a la desigualdad real”, Population and Development series, No. 103 (LC/L.3315-P), Santiago, Economic Commission for Latin America and the Caribbean (ECLAC), 2011; and information from the countries. 
In two countries (Cuba and Paraguay), the national regulations created public agencies responsible for disability issues. In the remaining countries, in addition, a series of rights were made explicit (see figure VII.1). The domestic laws cover a broad array of economic and social rights, reflecting the CRPD's call for the construction of a society that upholds rights with the full participation of all persons with disabilities in social development, free of all barriers and exclusion (Vásconez and others, 2013). The rights most often addressed in the main disability laws of the region's countries are those related to health and rehabilitation, accessibility and communication, education, work and employment, and protection from discrimination. This coincides with the rights most broadly protected by the countries' national constitutions (Stang, 2011). Rights in other areas — such as access to housing, to cultural activities and to political participation- are referred to less frequently.

Figure VII.1

Latin America (19 countries): rights enshrined in the main laws on disability (Number of countries referring to the right in question)

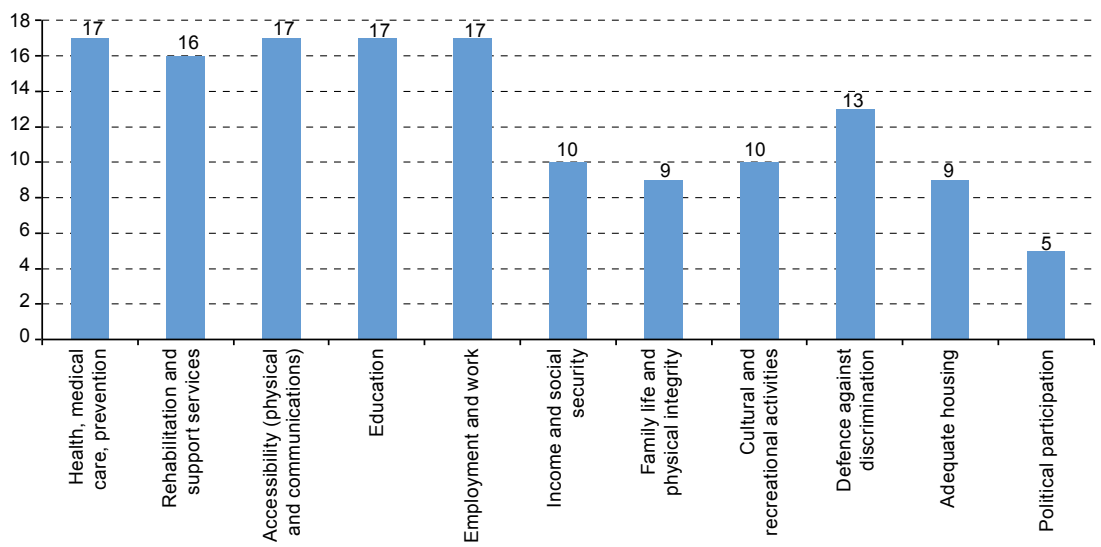

Source: Prepared by the author, on the basis of M. F. Stang, "Las personas con discapacidad en América Latina: del reconocimiento jurídico a la desigualdad real", Population and Development series, No. 103 (LC/L.3315-P), Santiago, Economic Commission for Latin America and the Caribbean (ECLAC), 2011; and information from the countries.

To summarize, extensive support for the rights of persons with disabilities exists in the regulatory frameworks at all levels (international, regional and national), urging governments to adopt a holistic and comprehensive approach towards the rights of the population with disabilities and to take steps towards creating favourable and inclusive environments. Those legal provisions confer stability and permanence and express the State's commitment to promoting and protecting the rights of 
persons with disabilities. However, translating the aspirations contained in those laws into concrete changes in the lives of persons with disabilities demands policies and institutions to implement them. Given the holistic and comprehensive approach to those rights contained in the laws in force, the institutions responsible for disability-related matters must be able to coordinate and interconnect with other agencies of the State in coherent actions to benefit this segment of the population.

\section{B. Organizational dimension}

The main international follow-up mechanism for the Convention is the Committee on the Rights of Persons with Disabilities. This body of independent experts examines reports submitted by the States Parties on the measures they have adopted to meet their Convention obligations and on the progress made since their previous reports, and it issues recommendations. ${ }^{5}$

The region's countries have also taken their first steps towards the creation of regional or subregional agencies for overseeing the rights of persons with disabilities. For example, the Southern Common Market (MERCOSUR) has a Permanent Commission for the Promotion and Protection of the Rights of Persons with Disabilities. Created in 2008, it is charged with collecting information on the human rights situation of persons with disabilities in the region and with encouraging the exchange of experiences and good practices among member States and associate members. A proposal for the creation of a subcommittee on disability within the Citizenship and Human Rights Commission has also been presented to the MERCOSUR parliament. Another example is the Andean Health Policy for the Prevention of Disability and the Comprehensive Attention and Habilitation/Rehabilitation of Persons with Disabilities of the Andean Health Organization-Hipólito Unanue Convention, brought into existence by the health ministries of the Andean subregion. This policy aims to strengthen health sector management in the Andean countries to bring about improvements in health and protection measures for preventing disabilities and for the attention, habilitation and rehabilitation of persons with disabilities, within the framework of promoting, protecting and ensuring the right to health. All this must be done in conditions of equity, promoting participation by people with disabilities and encouraging respect for their dignity and the possibility of their inclusion or reincorporation in society (Andean

To date, 18 Latin American countries have submitted reports to the Committee: Argentina, Bolivarian Republic of Venezuela, Brazil, Chile, Colombia, Costa Rica, Cuba, Dominican Republic, Ecuador, El Salvador, Guatemala, Honduras, Mexico, Panama, Paraguay, Peru, Plurinational State of Bolivia and Uruguay. 
Health Organization-Hipólito Unanue Convention, 2011). This body has become a reference point for the preparation of public policies for disability in the Andean countries.

\section{National institutions and their characteristics}

All the region's countries have government agencies to promote the rights of persons with disabilities (see table VII.3). The most common modality is intersectoral commissions (found in 12 countries) and secretariats. Above all, they are the lead authorities for matters related to disability, and most of them share other similar functions in formulating, implementing and managing policies and programmes. They are also responsible, in many cases, for intersectoral coordination and cooperation. As already stated, the challenge facing these agencies is securing the leadership and lobbying capacity needed to successfully coordinate and mobilize the technical and financial resources of the numerous sectors they comprise.

As for the authorities to which they report, there is little standardization. In 5 of the 19 countries, the agencies report to the President and, in another 5, to the Ministry of Social Development. The mandate of enforcing the CRPD falls on the public agencies charged with disabilityrelated matters and requires connections and coordination with sectoral ministries. Accordingly, being located at the highest possible level of the hierarchy represents a source of significant political support for carrying out that difficult task (United Nations, 2006). In the remaining cases, underministerial models are used, in which they are attached to ministries of labour, social development, justice or the interior and, in the case of Peru, to the Ministry of Women's Affairs and Vulnerable Populations.

These agencies have a long history in some countries, with the oldest being the National Council for Persons with Disabilities (CONAPDIS) of Costa Rica, which was created in $1973 .{ }^{6}$ In most of the countries, however, the agencies were created in the twenty-first century and, in many cases, after 2005, to follow up on and enforce the commitments assumed by the States in ratifying the CRPD and those established in domestic law. In order to avoid the duplication of efforts and dilution of responsibilities among government sectors, the Convention's States Parties must designate a focal point, to be responsible for its enforcement within the Government (United Nations, 2006). Due to their relatively recent creation, one challenge facing these agencies is maintaining their stability over time and forging lasting ties with other institutions.

Law No. 5.347 on the National Council for Rehabilitation and Special Education (CNREE) of 3 September 1973. CONAPDIS was given the lead role for disability issues. More recently, Law No. 18.547 was enacted in 2012, which restructured the institution and renamed it the National Council for Persons with Disabilities. 


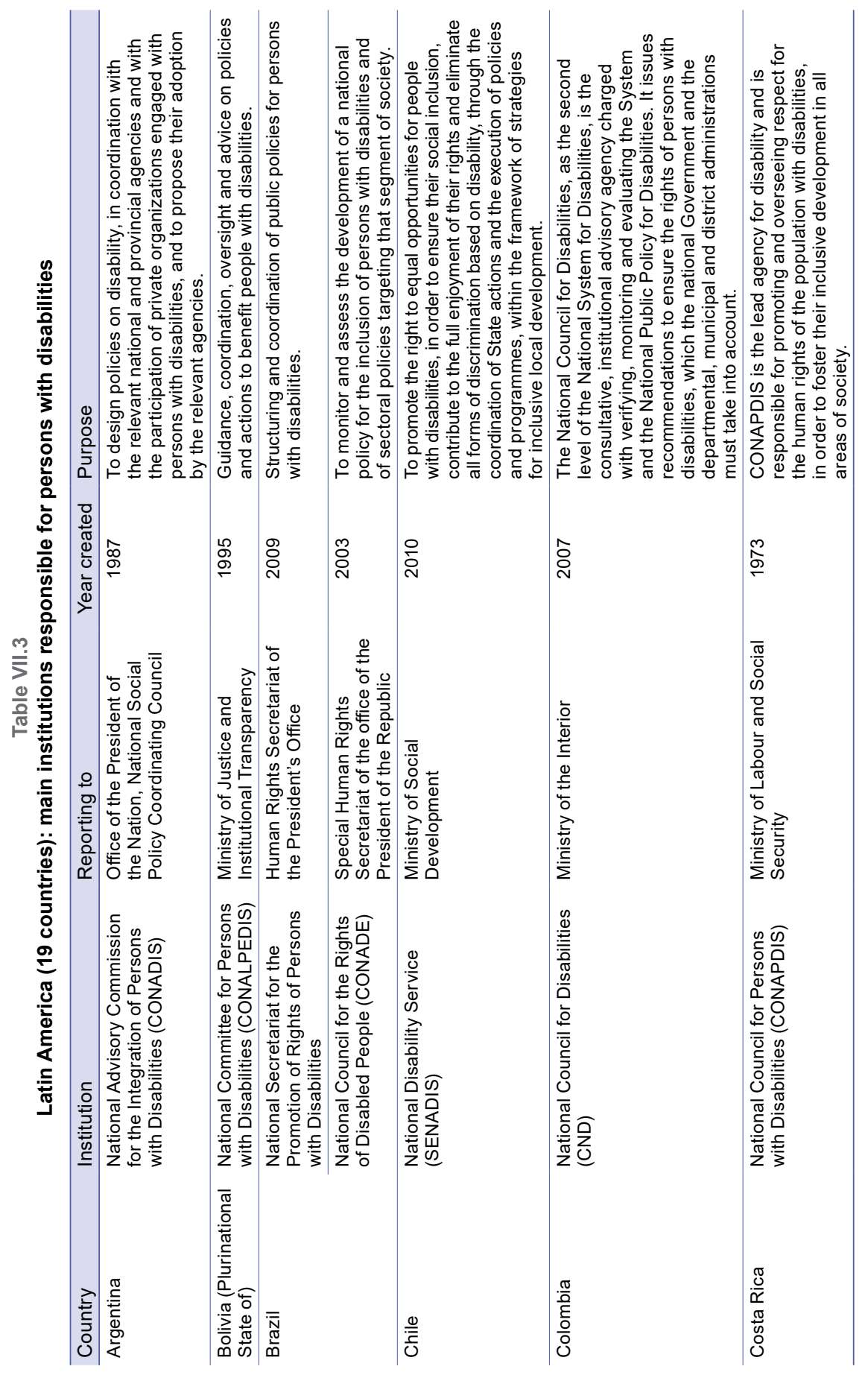




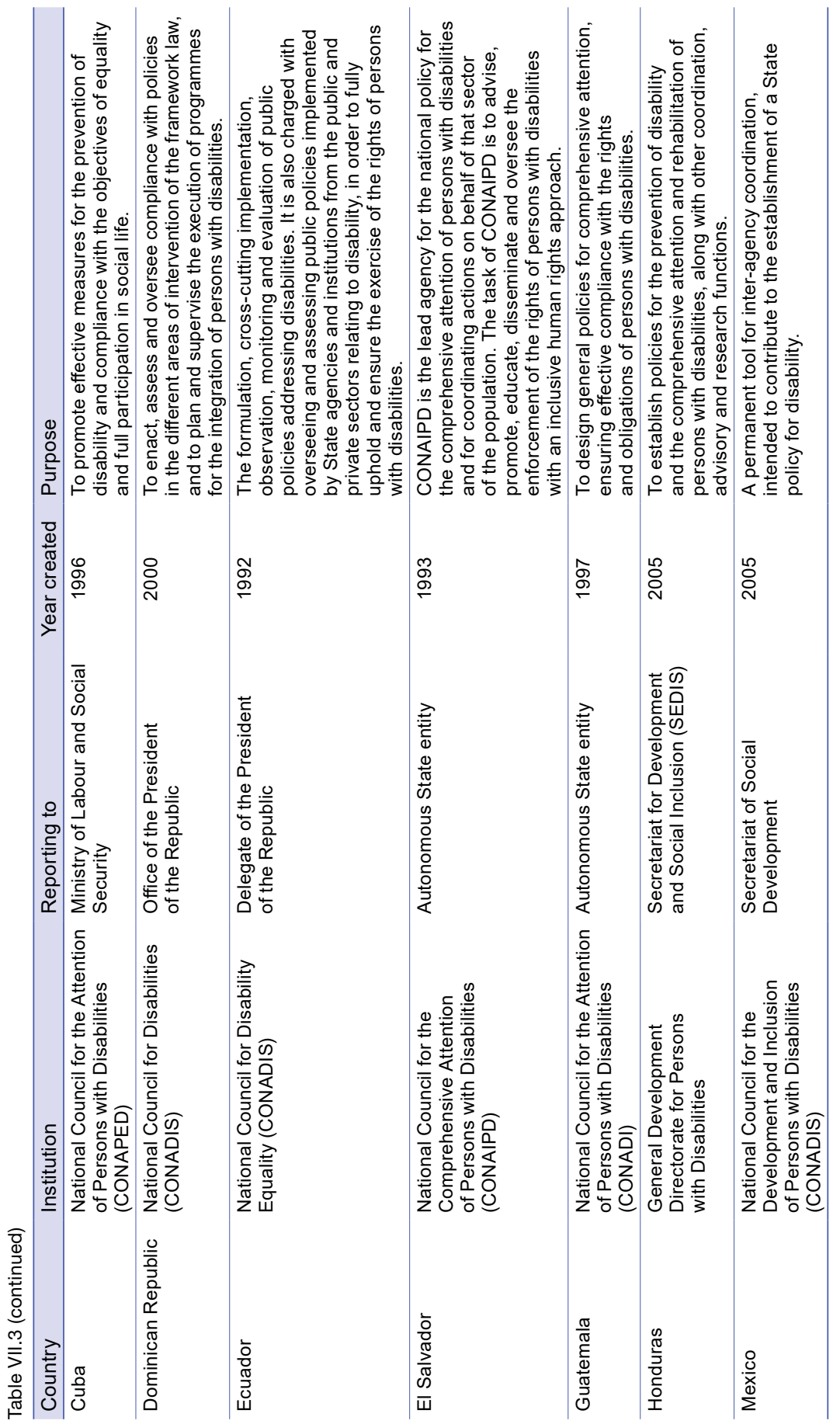




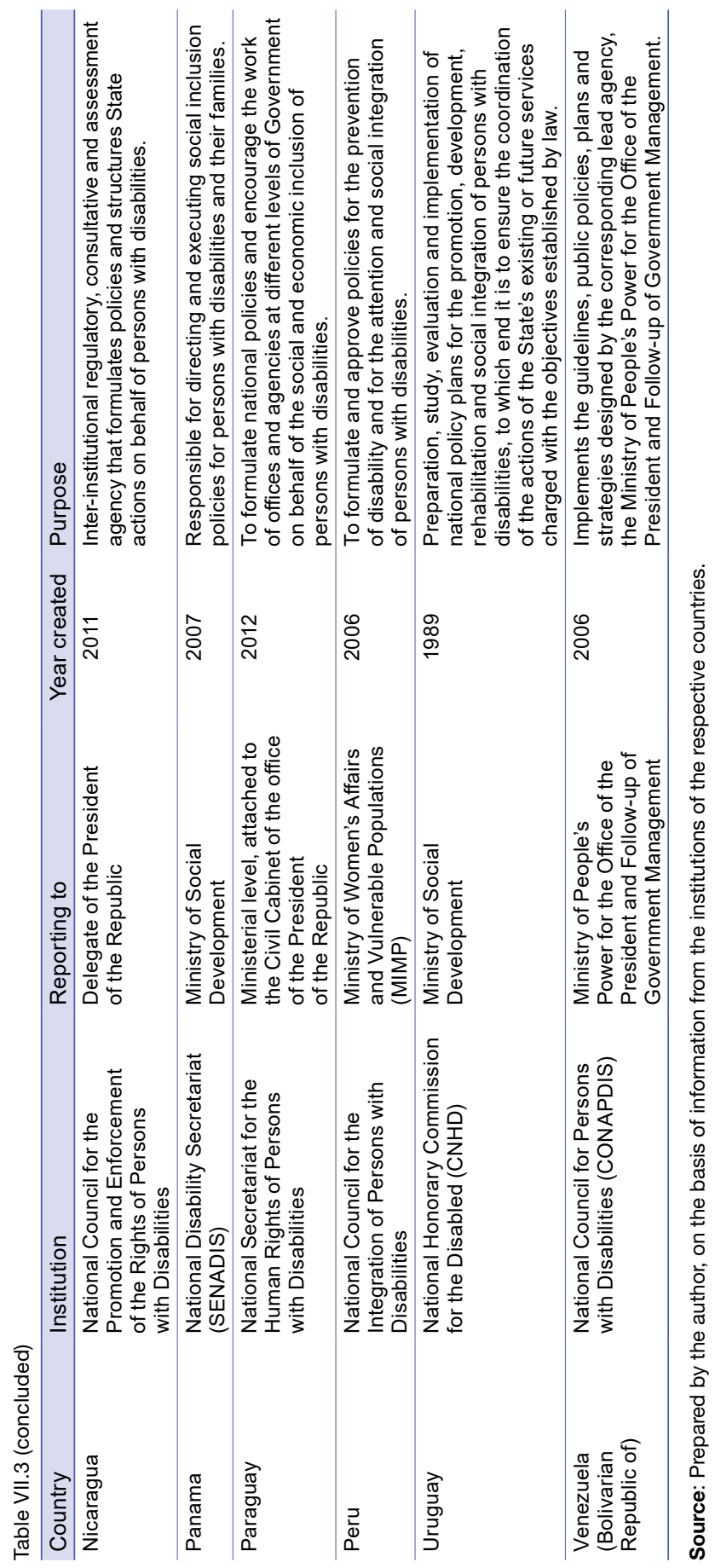


Another significant challenge for the institutions is consistently ensuring the human and financial resources necessary to achieve these ambitious goals. The visibility and weight of the institutions and of the topic of disability in general are highly variable and depend largely on the political will and interest of the Government of the day. Although references to the rights of persons with disabilities have been broadly incorporated into political discourse, that is not always accompanied by the allocation of resources needed to ensure that persons with disabilities can exercise those rights.

\section{Citizen participation in disability agencies}

Civil society organizations working on disability issues have a long history. Prior to the consolidation of the public institutional framework, it was those organizations that worked for the inclusion of persons with disabilities and gave visibility to the issue (Giler, 2012). More recently, the broad ratification of the CRPD and CIADDIS by the countries of the region gave rise to new social demands from those organizations and bolstered their mobilization. Although their objectives vary to some extent, on account of the different needs of persons with different kinds of disabilities, as a whole they have succeeded in firmly placing the topic of the rights of persons with disabilities on the region's public agenda. The organizations' slogan "Nothing about us without us" expresses the aspirations of these people and their families to be listened to and actively included in decision-making forums, not to be seen as objects of charity.

The public institutions responsible for disability policies use different mechanisms to connect with the organizations that represent and work for persons with disabilities (see table VII.4). The most common arrangement is an advisory council or committee that includes representatives of those organizations along with other actors. Different specific activities or participation exercises aimed at a wider public are also carried out. For example, in 2014 participatory processes were conducted for the preparation of Chile's Second National Disability Survey (ENDISC II), along with day-long outreach events on specific topics.

Participation in decision-making is key to making the policies that are implemented more effective and legitimate. Nevertheless, thought must be given to who is to participate in those forums or, more importantly, who is not participating and how representative the forums for participation are. The second question is particularly relevant given the wide range of life experiences faced by persons with disabilities: for example, their very different possibilities for inclusion, depending on the type of disability. It is therefore important to guarantee accessibility to forums for participation for persons with disabilities and to consider measures for expanding the scope of those forums to reach people who would otherwise be left on the margins, such as persons with mental disabilities. 


\section{Table VII.4}

\section{Latin America (12 countries): examples of citizen participation mechanisms in the main disability agencies}

\begin{tabular}{|c|c|c|}
\hline Country & Institution & Participation mechanisms \\
\hline Argentina & $\begin{array}{l}\text { National Advisory } \\
\text { Commission for the } \\
\text { Integration of Persons } \\
\text { with Disabilities } \\
\text { (CONADIS) }\end{array}$ & $\begin{array}{l}\text { The Advisory Committee's purpose is to foster civil } \\
\text { dialogue and the organizations' effective participation } \\
\text { in public policies, through joint responsibility with public } \\
\text { actions. The Committee is an essential element in defining } \\
\text { comprehensive public actions that address the real needs } \\
\text { and problems of persons with disabilities. It comprises } \\
\text { non-governmental organizations that work on topics } \\
\text { related to that segment of the population. }\end{array}$ \\
\hline Chile & $\begin{array}{l}\text { National Disability } \\
\text { Service (SENADIS) }\end{array}$ & $\begin{array}{l}\text { The task of the Consultative Council on Disability is to } \\
\text { ensure participation and social dialogue in processes } \\
\text { for the equality of opportunities, social inclusion, } \\
\text { participation and accessibility of persons with disabilities. } \\
\text { Its members include representatives of organizations that } \\
\text { work with persons with disabilities, the business sector } \\
\text { and workers' organizations. }\end{array}$ \\
\hline Cuba & $\begin{array}{l}\text { National Council } \\
\text { for the Attention } \\
\text { of Persons with } \\
\text { Disabilities } \\
\text { (CONAPED) }\end{array}$ & $\begin{array}{l}\text { CONAPED comprises the institutions and agencies } \\
\text { involved with this topic, alongside associations that } \\
\text { represent persons with disabilities. It is chaired by } \\
\text { the Minister of Labour and Social Security. }\end{array}$ \\
\hline Ecuador & $\begin{array}{l}\text { National Council for } \\
\text { Disability Equality } \\
\text { (CONADIS) }\end{array}$ & $\begin{array}{l}\text { A consultative council comprising federations of and } \\
\text { for persons with disabilities. }\end{array}$ \\
\hline El Salvador & $\begin{array}{l}\text { National Council for } \\
\text { the Comprehensive } \\
\text { Attention of Persons } \\
\text { with Disabilities } \\
\text { (CONAIPD) }\end{array}$ & $\begin{array}{l}\text { The Technical Committee, in its capacity as the plenary } \\
\text { council of CONAIPD, has representatives from } \\
\text { specialized organizations that work on topics related } \\
\text { to persons with disabilities. }\end{array}$ \\
\hline Honduras & $\begin{array}{l}\text { General Development } \\
\text { Directorate for } \\
\text { Persons with } \\
\text { Disabilities }\end{array}$ & $\begin{array}{l}\text { The Consultative Council is a body intended to assist } \\
\text { the General Development Directorate for Persons } \\
\text { with Disabilities. It comprises representatives of State } \\
\text { secretariats, representatives of organizations of persons } \\
\text { with disabilities and associations of their family members. }\end{array}$ \\
\hline Mexico & $\begin{array}{l}\text { National Council for } \\
\text { the Development and } \\
\text { Inclusion of Persons } \\
\text { with Disabilities } \\
\text { (CONADIS) }\end{array}$ & $\begin{array}{l}\text { The Consultative Assembly is an advisory and consultative } \\
\text { agency of the National Council for the Development } \\
\text { and Inclusion of Persons with Disabilities. With citizen } \\
\text { participation and a pluralistic membership who serve on } \\
\text { an honorary basis, its purpose is to analyse and propose } \\
\text { programmes and actions to impact the implementation } \\
\text { of the programme and citizen participation exercises. }\end{array}$ \\
\hline Nicaragua & $\begin{array}{l}\text { National Council for } \\
\text { the Promotion and } \\
\text { Enforcement of the } \\
\text { Rights of Persons } \\
\text { with Disabilities }\end{array}$ & $\begin{array}{l}\text { The Cabinet of the Citizen's Branch of Government for } \\
\text { Persons with Disabilities comprises organizations engaged } \\
\text { with persons with disabilities from across the country. It } \\
\text { discusses decisions and legislative changes that could } \\
\text { affect that sector of the population and serves as a forum } \\
\text { for exchanges with political leaders. }\end{array}$ \\
\hline Panama & $\begin{array}{l}\text { National Disability } \\
\text { Secretariat } \\
\text { (SENADIS) }\end{array}$ & $\begin{array}{l}\text { The National Consultative Council on Disability (CONADIS) } \\
\text { is an inter-institutional and intersectoral consultation } \\
\text { and support body. Chaired by the executive branch, it was } \\
\text { created to promote the objectives and goals pursued by } \\
\text { SENADIS in the execution of disability-related } \\
\text { social policies. }\end{array}$ \\
\hline Paraguay & $\begin{array}{l}\text { National Secretariat } \\
\text { for the Human Rights } \\
\text { of Persons with } \\
\text { Disabilities }\end{array}$ & $\begin{array}{l}\text { The National Disability Commission (CONADIS) comprises } \\
\text { organizations of and for persons with disabilities, and } \\
\text { it works closely alongside SENADIS on the design and } \\
\text { implementation of public policies for that segment } \\
\text { of the population. }\end{array}$ \\
\hline
\end{tabular}


Table VII.4 (concluded)

\begin{tabular}{|c|c|c|}
\hline Country & Institution & Participation mechanisms \\
\hline Peru & $\begin{array}{l}\text { National Council } \\
\text { for the Integration } \\
\text { of Persons with } \\
\text { Disabilities }\end{array}$ & $\begin{array}{l}\text { The Consultative Commission is the agency responsible } \\
\text { for advising the Directing Council on public policies for } \\
\text { disability, from a citizen-centred approach. It comprises } \\
\text { representatives from prominent organizations engaged } \\
\text { with disability topics, which are chosen by civil society } \\
\text { and accredited by means of a presidential resolution. }\end{array}$ \\
\hline $\begin{array}{l}\text { Venezuela } \\
\text { (Bolivarian } \\
\text { Republic of) }\end{array}$ & $\begin{array}{l}\text { National Council } \\
\text { for Persons } \\
\text { with Disabilities } \\
\text { (CONAPDIS) }\end{array}$ & $\begin{array}{l}\text { The Presidential Council of the People's Government } \\
\text { for Persons with Disabilities is tasked with assisting the } \\
\text { creation and implementation of effective public policies, } \\
\text { together with the exercise of the people's power, through } \\
\text { spokespersons within each State and municipality. } \\
\text { Information on overall needs and proposals for correction } \\
\text { and prevention are collected at people's assemblies, } \\
\text { and then presented to ministers and the President } \\
\text { of the Republic for their consideration. }\end{array}$ \\
\hline
\end{tabular}

Source: Prepared by the author, on the basis of information from the institutions of the respective countries.

In table VII.4 it is interesting to note that the mechanisms that provide a formal forum for participation by organizations for and of persons with disabilities also, in some cases, allow participation by actors from different sectors involved with that segment of the population. For example, the councils and committees in Cuba, Honduras and Panama include representatives from various ministries.

\section{Mechanisms for coordination}

One of the great institutional challenges is forging an interconnected coordinating structure. Mechanisms for horizontal coordination exist (see table VII.5). Intersectoral or inter-institutional committees and groups can be seen within the disability agencies (for example, in Argentina, Colombia and Nicaragua), as can disability commissions within the ministries and institutions associated with the disability agency (Costa Rica). Honduras has a Minister-Advisor on Disability Matters (a secretariat without portfolio), who serves as a liaison with the organizations and federations representing persons with disabilities in the country. Examples of coordinated working methods include cooperation agreements between the institutions, sectors and groups, and working panels to deal with specific topics. In Chile, for example, SENADIS set up a Technical Intersectoral Panel on the Sexual and Reproductive Rights of Persons with Disabilities in collaboration with the Ministry of Women's Affairs and Gender Equity. 
Table VII.5

Latin America (10 countries): examples of inter-institutional or intersectoral
coordination mechanisms and methods used by the main disability agencies

\begin{tabular}{|c|c|c|}
\hline Country & Institution & $\begin{array}{l}\text { Mechanism for inter-institutional } \\
\text { or intersectoral coordination }\end{array}$ \\
\hline Argentina & $\begin{array}{l}\text { National Advisory } \\
\text { Commission for the } \\
\text { Integration of Persons } \\
\text { with Disabilities } \\
\text { (CONADIS) }\end{array}$ & $\begin{array}{l}\text { The Technical Committee assists CONADIS in coordination } \\
\text { between sectors and ministries, and between the different } \\
\text { branches of Government, regarding strategies for the } \\
\text { effective enforcement of the Convention on the Rights } \\
\text { of Persons with Disabilities and of the current legal } \\
\text { provisions, with an inclusive approach. }\end{array}$ \\
\hline Chile & $\begin{array}{l}\text { National Disability } \\
\text { Service (SENADIS) }\end{array}$ & Intersectoral working panels. \\
\hline Colombia & $\begin{array}{l}\text { National Disability } \\
\text { System }\end{array}$ & $\begin{array}{l}\text { Sectoral Liaison Groups (GESs), the technical agency } \\
\text { for the preparation, consensus-building on and inter- } \\
\text { institutional coordination of plans, projects and programmes } \\
\text { of the National Council for Disabilities (CND), coordinated } \\
\text { by the Council through its Technical Secretariat. } \\
\text { The GESs involve the ministries of health and social } \\
\text { protection, education, transport, defence, trade and } \\
\text { industry, tourism, information and communications } \\
\text { technologies and the treasury, along with associated } \\
\text { institutions such as the Colombian Family Welfare } \\
\text { Institute, the National Learning Service (SENA), the } \\
\text { National Institute for the Blind (INCI) and the National } \\
\text { Institute for the Deaf (INSOR). }\end{array}$ \\
\hline Costa Rica & $\begin{array}{l}\text { National Council for } \\
\text { Rehabilitation and } \\
\text { Special Education } \\
\text { (CNREE) }\end{array}$ & $\begin{array}{l}\text { The commissions in each institution serve as the } \\
\text { counterpart to the National Council for Persons with } \\
\text { Disabilities in improving the quality of the attention given } \\
\text { to the population with disabilities for accessing the } \\
\text { different services offered by Costa Rica's institutions. } \\
\text { Some of these are known as Institutional Commissions } \\
\text { on Disability Matters (CIMADs) and others as Institutional } \\
\text { Commissions on Accessibility and Disability (CIADs). }\end{array}$ \\
\hline Ecuador & $\begin{array}{l}\text { National Council for } \\
\text { Disability Equality } \\
\text { (CONADIS) }\end{array}$ & $\begin{array}{l}\text { To formulate public policy for disability, CONADIS guides } \\
\text { the actions and convenes the institutions of all the } \\
\text { branches of Government and of the decentralized, } \\
\text { autonomous governments, together with social, political } \\
\text { and economic actors, in order to create rules, regulations, } \\
\text { decrees, directives, agreements, pacts, resolutions and } \\
\text { other acts, actions, projects and decisions. Its efforts } \\
\text { are to follow an approach based on human rights, } \\
\text { with emphasis on equality and non-discrimination, as } \\
\text { a guarantee of the individual and collective rights of } \\
\text { persons with disabilities and their families. CONADIS } \\
\text { represents the first level of the National System for the } \\
\text { Comprehensive Protection of Persons with Disabilities } \\
\text { (Article } 88 \text { of the Organic Disabilities Act) and is a part of } \\
\text { the National System for the Protection of Rights (Organic } \\
\text { National Equality Councils Act); it thus coordinates } \\
\text { actions with the Office of the People's Defender, the } \\
\text { Public Defence Office, the Office of the Attorney General } \\
\text { of the State and other agencies. }\end{array}$ \\
\hline Guatemala & $\begin{array}{l}\text { National Council for the } \\
\text { Attention of Persons } \\
\text { with Disabilities } \\
\text { (CONADI) }\end{array}$ & Inter-institutional cooperation agreements. \\
\hline Honduras & $\begin{array}{l}\text { General Development } \\
\text { Directorate for Persons } \\
\text { with Disabilities }\end{array}$ & $\begin{array}{l}\text { The Minister-Advisor on Disability Matters (a secretariat } \\
\text { without portfolio) serves as a liaison with the organizations } \\
\text { and federations representing persons with disabilities } \\
\text { in the country. }\end{array}$ \\
\hline
\end{tabular}


Table VII.5 (concluded)

\begin{tabular}{lll}
\hline Country & Institution & $\begin{array}{l}\text { Mechanism for inter-institutional } \\
\text { or intersectoral coordination }\end{array}$ \\
\hline Mexico & $\begin{array}{l}\text { National Council for } \\
\text { the Development and } \\
\text { Inclusion of Persons } \\
\text { with Disabilities } \\
\text { (CONADIS) }\end{array}$ & $\begin{array}{l}\text { Working groups and intersectoral and inter-institutional } \\
\text { committees. }\end{array}$ \\
\hline Nicaragua & $\begin{array}{l}\text { National Council for } \\
\text { the Promotion and } \\
\text { Enforcement of the } \\
\text { Rights of Persons with } \\
\text { Disabilities }\end{array}$ & $\begin{array}{l}\text { Secretariat for the Promotion and Coordination of the } \\
\text { Enforcement of the Rights of Persons with Disabilities: } \\
\text { the Council's body for technical advice and coordination. }\end{array}$ \\
& $\begin{array}{l}\text { National Council for the } \\
\text { Integration of Persons } \\
\text { with Disabilities }\end{array}$ & $\begin{array}{l}\text { The National System for the Integration of Persons with } \\
\text { Disabilities (SINAPEDIS), which carries out coordinated } \\
\text { efforts involving the three levels of government (CONADIS } \\
\text { and the regional and municipal governments) in the } \\
\text { pursuit of disability policies. }\end{array}$ \\
\hline Peru & &
\end{tabular}

Source: Prepared by the author, on the basis of information of the institutions of the respective countries.

As regards the geographical scope of the institutional framework at the subnational level, there are several different examples of mechanisms for coordination (see table VII.6). Many countries have institutionalized mechanisms for liaising with the local level, while others use more ad hoc methods. The institutionalized mechanisms include decentralized councils, committees and commissions that work at the local level. Note should also be taken of direct work under agreements and other mechanisms with local entities, such as human rights councils, and, on a more ad hoc basis, local meetings organized by disability institutions.

Table VII.6

Latin America (11 countries): examples of territorial coordination mechanisms in the main disability agencies

\begin{tabular}{lll}
\hline Country & Institution & Territorial coordination mechanism \\
\hline Argentina & $\begin{array}{l}\text { National Advisory } \\
\text { Commission for the } \\
\text { Integration of Persons } \\
\text { with Disabilities } \\
\text { (CONADIS) }\end{array}$ & $\begin{array}{l}\text { The objective of the Federal Council is to promote } \\
\text { decentralization and local and regional decision-making, } \\
\text { and to encourage permanent interrelations between the } \\
\text { government agencies and civil society organizations } \\
\text { engaged with this topic at the territorial level. }\end{array}$ \\
\hline $\begin{array}{lll}\text { National Council for } \\
\text { the Rights of Disabled } \\
\text { People (CONADE) }\end{array}$ & $\begin{array}{l}\text { Regional meetings; state and municipal councils. } \\
\text { National Disability } \\
\text { Service (SENADIS) }\end{array}$ & $\begin{array}{l}\text { The Inclusive Local Development Strategy (EDLI) is a } \\
\text { multi-programmatic mechanism intended to generate, at } \\
\text { the territorial level, a growing process of social inclusion } \\
\text { for persons with disabilities, as well as for their families and } \\
\text { organizations. It also provides a municipal support plan } \\
\text { intended to promote major intersectoral efforts for } \\
\text { establishing a long-term public policy that will strengthen } \\
\text { social inclusion plans for persons with disabilities within local } \\
\text { governments, in partnership with community organizations. }\end{array}$ \\
\cline { 2 - 2 } & $\begin{array}{l} \\
\end{array}$ &
\end{tabular}


Table VII.6 (concluded)

\begin{tabular}{|c|c|c|}
\hline Country & Institution & Territorial coordination mechanism \\
\hline Colombia & $\begin{array}{l}\text { National System for } \\
\text { Disabilities }\end{array}$ & $\begin{array}{l}\text { The system operates on four levels: (i) the Ministry of Health } \\
\text { and Social Protection as the lead agency of the system; } \\
\text { (ii) the National Council for Disabilities (CND), as the } \\
\text { consultative and institutional advisory body, responsible } \\
\text { for the verification, monitoring and evaluation of the system } \\
\text { and of the National Public Policy for Disabilities, (iii) the } \\
\text { departmental and district disability committees (CDDs), } \\
\text { as intermediate levels for consensus-building, advice, } \\
\text { consolidation and follow-up of the Public Policy for } \\
\text { Disabilities, (iv) municipal and local disability committees } \\
\text { (CMDs or CLDs), for discussing, designing and following } \\
\text { up on the public disability policy. }\end{array}$ \\
\hline Costa Rica & $\begin{array}{l}\text { National Council for } \\
\text { Rehabilitation and } \\
\text { Special Education } \\
\text { (CNREE) }\end{array}$ & $\begin{array}{l}\text { Regional lead agencies; the Municipal Commissions on } \\
\text { Accessibility and Disability (COMADs), created by Law } \\
\text { No. } 8822 \text {, are the agencies in each municipality charged } \\
\text { with overseeing local compliance with Law No. } 7600 \text {, on } \\
\text { Equality of Opportunities for Persons with Disabilities, } \\
\text { of } 2 \text { May } 1996 \text {. }\end{array}$ \\
\hline Cuba & $\begin{array}{l}\text { National Council } \\
\text { for the Attention } \\
\text { of Persons with } \\
\text { Disabilities } \\
\text { (CONAPED), } \\
\text { intrasectoral structure }\end{array}$ & $\begin{array}{l}\text { The Council works at the national, provincial and municipal } \\
\text { levels. At the latter two levels it is chaired by the Director } \\
\text { of Labour of the Organ of People's Power and the Vice- } \\
\text { President of the Government responsible for economic } \\
\text { matters. Its purpose is to formulate and evaluate the } \\
\text { implementation of the National Plan of Action for the } \\
\text { Attention of Persons with Disabilities, which includes a } \\
\text { group of programmes that address economic processes } \\
\text { and labour and social insertion. }\end{array}$ \\
\hline Ecuador & $\begin{array}{l}\text { National Council for } \\
\text { Disability Equality } \\
\text { (CONADIS) }\end{array}$ & $\begin{array}{l}\text { CONADIS works directly with the rights protection councils } \\
\text { at the canton level, which are civic oversight agencies } \\
\text { within the decentralized, autonomous cantonal } \\
\text { governments. }\end{array}$ \\
\hline Mexico & $\begin{array}{l}\text { National Council for } \\
\text { the Development and } \\
\text { Inclusion of Persons } \\
\text { with Disabilities } \\
\text { (CONADIS) }\end{array}$ & $\begin{array}{l}\text { Coordination agreements between CONADIS and State } \\
\text { governments. }\end{array}$ \\
\hline Panama & $\begin{array}{l}\text { National Disability } \\
\text { Secretariat (SENADIS) }\end{array}$ & $\begin{array}{l}\text { Regional branches responsible for implementing all its } \\
\text { actions, programmes and projects in the country's interior. } \\
\text { Each is equipped with administrative personnel, legal } \\
\text { advisors, social workers and liaison units in each province. } \\
\text { The regional directorates also coordinate with the local } \\
\text { authorities and with the regional directorates of other } \\
\text { institutions for the cross-cutting implementation of the } \\
\text { social inclusion of persons with disabilities through } \\
\text { the provincial disability councils (provincial CONADIS). }\end{array}$ \\
\hline Paraguay & $\begin{array}{l}\text { National Secretariat } \\
\text { for the Human Rights } \\
\text { of Persons with } \\
\text { Disabilities }\end{array}$ & Regional branches. \\
\hline Peru & $\begin{array}{l}\text { National Council } \\
\text { for the Integration } \\
\text { of Persons with } \\
\text { Disabilities }\end{array}$ & $\begin{array}{l}\text { Regional Coordination Council (CCR) / Local Coordination } \\
\text { Council (CCL). }\end{array}$ \\
\hline
\end{tabular}

Source: Prepared by the author, on the basis of information of the institutions of the respective countries. 


\section{The technical and operational dimension}

One of the key elements in analysing the technical and operational dimension of the institutional framework is the existence of instruments and tools for the effective and efficient pursuit of institutional objectives. Almost all the region's countries have a tool — such as a plan, strategy or policy— for guiding their public agencies' disability-related actions (see table VII.7 and box VII.1). These plans, strategies and policies follow a rights-based approach and include other approaches, such as gender and territorial perspectives, and are structured around thematic axes for action such as education, health and employment. In most of the countries, these tools provide explicit mechanisms for implementation, execution, monitoring and evaluation, by establishing lines of action, activities, deadlines, assignation of roles to different actors and timetables for evaluation. However, only a few countries (such as El Salvador, Mexico and Peru) provide indicators for monitoring the implementation of those tools. In many cases, the plans explain how they are to be incorporated into national development plans and strategies and how they are to interconnect with the mechanisms for follow-up and planning at the national level.

\section{Table VII.7}

Latin America (14 countries): national plans or strategies for promoting the rights of persons with disabilities

\begin{tabular}{|c|c|c|c|}
\hline Country & Plan & Purpose & Year \\
\hline $\begin{array}{l}\text { Bolivia } \\
\text { (Plurinational } \\
\text { State of) }\end{array}$ & $\begin{array}{l}\text { National Plan } \\
\text { for Equality } \\
\text { and Equal } \\
\text { Opportunities }\end{array}$ & $\begin{array}{l}\text { With the aim of ensuring equality and equal opportunities } \\
\text { for persons with disabilities, the Plan coordinates different } \\
\text { mechanisms for establishing social and public policies for } \\
\text { the full exercise of rights by that sector of the population } \\
\text { at the national, departmental and municipal levels. }\end{array}$ & 2006 \\
\hline Brazil & $\begin{array}{l}\text { National Plan } \\
\text { on the Rights } \\
\text { of Persons with } \\
\text { Disabilities ("Life } \\
\text { Without Limits") }\end{array}$ & $\begin{array}{l}\text { Implement new initiatives and step up governmental actions } \\
\text { already under way to benefit persons with disabilities. } \\
\text { The Plan was devised by } 15 \text { ministries with the } \\
\text { participation of CONADE. }\end{array}$ & 2011 \\
\hline Chile & $\begin{array}{l}\text { National Policy } \\
\text { for the Social } \\
\text { Inclusion of } \\
\text { Persons with } \\
\text { Disabilities, } \\
2013-2020\end{array}$ & $\begin{array}{l}\text { The instrument for guiding the management of the State's } \\
\text { institutional framework over the coming seven years, to } \\
\text { report to the public and the international organizations } \\
\text { with which Chile has entered into commitments. }\end{array}$ & 2013 \\
\hline Colombia & $\begin{array}{l}\text { National Public } \\
\text { Policy for } \\
\text { Disabilities and } \\
\text { Social Inclusion, } \\
2013-2022\end{array}$ & $\begin{array}{l}\text { To ensure the full enjoyment of the rights and fulfilment of } \\
\text { the duties of persons with disabilities, their families and } \\
\text { their caregivers over the } 2013-2022 \text { period. To create and } \\
\text { promote efficient, effective, coordinated and transparent } \\
\text { public administration processes that can translate into } \\
\text { the design and implementation of national- and territorial- } \\
\text { level plans and programmes for persons with disabilities. }\end{array}$ & 2013 \\
\hline Costa Rica & $\begin{array}{l}\text { National Policy } \\
\text { on Disability } \\
\text { (PONADIS) }\end{array}$ & $\begin{array}{l}\text { PONADIS is the public institutions' long-term political } \\
\text { framework for promoting, respecting and ensuring the } \\
\text { rights of persons with disabilities. It is based on four basic } \\
\text { approaches: human rights, inclusive development, } \\
\text { gender equity and results-based social management. } \\
\text { The policy is implemented along the following five axes: } \\
\text { democratic institutional framework; health, education, } \\
\text { work and employment; people; institutions and } \\
\text { organizations; and inclusiveness. }\end{array}$ & 2011 \\
\hline
\end{tabular}


Table VII.7 (concluded)

\begin{tabular}{|c|c|c|c|}
\hline Country & Plan & Purpose & Year \\
\hline Cuba & $\begin{array}{l}\text { National Action } \\
\text { Plan for the } \\
\text { Attention of } \\
\text { Persons with } \\
\text { Disabilities }\end{array}$ & $\begin{array}{l}\text { The Plan is a collection of strategies, actions, proposals and } \\
\text { programmes to promote the social integration and improved } \\
\text { quality of life of persons with disabilities. It is implemented } \\
\text { in all the country's provinces and municipalities through } \\
\text { different territorial inclusion and community development } \\
\text { programmes, to facilitate the creation of conditions } \\
\text { to guarantee persons with disabilities full access to } \\
\text { employment, education, culture, sport and recreation. }\end{array}$ & 2006 \\
\hline Ecuador & $\begin{array}{l}\text { National Agenda } \\
\text { for Disability } \\
\text { Equality, } \\
2013-2017\end{array}$ & $\begin{array}{l}\text { To promote and implement, in a cross-cutting fashion, in } \\
\text { the public and private sectors, equality of opportunities } \\
\text { for persons with disabilities, together with the prevention } \\
\text { of disabilities at the national level. Its specific objectives } \\
\text { are to: (i) devise strategies, programmes and projects for } \\
\text { improving the quality of life of persons with disabilities, } \\
\text { (ii) promote the prevention of disabilities, taking into } \\
\text { account the main risk factors in Ecuador, and (iii) monitor } \\
\text { compliance with the goals, policies, strategies, } \\
\text { programmes and projects in disability-related areas. }\end{array}$ & 2013 \\
\hline El Salvador & $\begin{array}{l}\text { National Policy } \\
\text { for the Attention } \\
\text { of Persons with } \\
\text { Disabilities and } \\
\text { Plan of Action }\end{array}$ & $\begin{array}{l}\text { To guarantee the observance and full enjoyment of the } \\
\text { rights of persons with disabilities in their different dimensions } \\
\text { (individual, family and community) and at the different } \\
\text { stages in the life cycle, in a way that promotes their integral } \\
\text { development, well-being and improved quality of life by } \\
\text { coordinating public and private actions towards the gradual } \\
\text { and effective elimination of physical and social barriers. }\end{array}$ & 2014 \\
\hline Honduras & $\begin{array}{l}\text { Public Policy } \\
\text { for the Exercise } \\
\text { of the Rights of } \\
\text { Persons with } \\
\text { Disabilities and } \\
\text { their Social } \\
\text { Inclusion }\end{array}$ & $\begin{array}{l}\text { To guarantee all persons with disabilities the full enjoyment } \\
\text { of their human rights, by providing conditions for their } \\
\text { exercise and enforceability and working for the social } \\
\text { transformations needed to ensure their inherent dignity } \\
\text { and access to social opportunities under conditions of } \\
\text { equality, and for respect towards differences, full inclusion } \\
\text { and non-discrimination. }\end{array}$ & 2013 \\
\hline Guatemala & $\begin{array}{l}\text { National Policy on } \\
\text { Disability }\end{array}$ & $\begin{array}{l}\text { To create opportunities for the integration and participation } \\
\text { of persons with disabilities in Guatemalan society. }\end{array}$ & 2007 \\
\hline Mexico & $\begin{array}{l}\text { National } \\
\text { Programme for } \\
\text { the Development } \\
\text { and Inclusion } \\
\text { of Persons with } \\
\text { Disabilities } \\
\text { (PNDIPD), } \\
\text { 2014-2018 }\end{array}$ & $\begin{array}{l}\text { The Programme's objectives are the following: (i) to } \\
\text { encourage the implementation of public policies that } \\
\text { guarantee the full exercise of the rights of the population } \\
\text { with disabilities, (ii) to create a culture of disability in } \\
\text { all aspects of national life, (iii) to transform the public, } \\
\text { social and private spheres, and (iv) to promote changes } \\
\text { in culture and attitude in the Government and society } \\
\text { regarding persons with disabilities. }\end{array}$ & 2014 \\
\hline Panama & $\begin{array}{l}\text { National Disability } \\
\text { Policy }\end{array}$ & $\begin{array}{l}\text { To promote and consolidate the social inclusion of the } \\
\text { population with disabilities and their families, in order to } \\
\text { guarantee their comprehensive human development. In } \\
\text { pursuit of that aim, families, communities and the State } \\
\text { will ensure the conditions for their maximum autonomy, } \\
\text { independence and participation in everyday and public life. }\end{array}$ & 2009 \\
\hline Paraguay & $\begin{array}{l}\text { National Plan } \\
\text { of Action for the } \\
\text { Rights of Persons } \\
\text { with Disabilities, } \\
2015-2030\end{array}$ & $\begin{array}{l}\text { Intended to promote, coordinate and execute public } \\
\text { policies and private sector actions, through the cross- } \\
\text { cutting implementation of an approach based on the } \\
\text { rights of persons with disabilities in plans, programmes } \\
\text { and projects, in order to guarantee equality, non- } \\
\text { discrimination, inclusion and accessibility. }\end{array}$ & 2015 \\
\hline Peru & $\begin{array}{l}\text { Plan of Equal } \\
\text { Opportunities } \\
\text { for Persons with } \\
\text { Disabilities, } \\
2009-2018\end{array}$ & $\begin{array}{l}\text { The Plan is a technical and political planning instrument } \\
\text { for actions to benefit persons with disabilities. It was } \\
\text { prepared through intersectoral cooperation, in close } \\
\text { coordination with civil society through participatory } \\
\text { consultation processes. }\end{array}$ & 2009 \\
\hline
\end{tabular}

Source: Prepared by the author, on the basis of information of the institutions of the respective countries. 


\section{Box VII.1}

\section{The evolution of approaches towards disability}

The concept of disability has evolved considerably in recent decades. Three main approaches currently exist. The first is the biomedical model, which sees disability as a personal health problem, directly caused by a congenital condition, a disease, a disorder or an accident. Second, the biopsychosocial model, which, while addressing the question of health, holds that the limitations on activity and participation faced by persons with disabilities are due to the interaction between those health difficulties and a physical and attitudinal environment that raises barriers. Finally, the social model chiefly involves the exercise of human rights and full and effective inclusion in society, on an equal footing with others. The evolution of these concepts has its roots in a series of proposals, beginning with the first International Classification of Impairments, Disabilities and Handicaps (ICIDH), adopted by the World Health Organization (WHO) in 1980, which fully reflected the biomedical model and established a correlation between impairments of the body and of the mind, handicaps and abnormality. This was followed, in 2001, by the WHO International Classification of Functioning, Disability and Health (CIF), which offers a clear and coherent description of the biological, individual and social dimensions of human functioning. The Convention on the Rights of Persons with Disabilities is based on the social model, but its definition of disability refers to interactions between physical, mental, intellectual or sensory impairments and the environment, as suggested by the biopsychosocial model.

These perspectives lead to radically different policy responses. Under the biomedical model, what is needed is action at the individual level for the provision of medical and rehabilitation services, and those responsible for such interventions are medical practitioners and rehabilitation professionals. According to this viewpoint, a person with disabilities is a target for intervention, a patient or a beneficiary. At the other end of the spectrum, the social model suggests that persons with disabilities require adjustments to their surroundings in order to achieve full participation. Thus, public actions must aim at removing barriers (both physical and attitudinal) to bring about the full participation of persons with disabilities in all spheres of life and, consequently, this is a responsibility to be borne by society as a whole. From this perspective, persons with disabilities are empowered agents who must participate actively in decision-making.

To some extent, these readings of disability coexist in Latin American societies. On the one hand, many of the groups that defend the rights of persons with disabilities have adopted the broader and more comprehensive perspectives (the biopsychosocial and social approaches) and States have gradually incorporated those approaches into their laws. On the other, policies, programmes and discourse - among public officials and society in general and even among persons with disabilities and their groups - are still characterized by the stereotypes and prejudices fostered by the biomedical approach. That complicates the work of the institutions charged with the coherent promotion of the observance of the rights of persons with disabilities.

Source: Economic Commission for Latin America and the Caribbean (ECLAC), Regional report on measuring disability: overview of the disability measurement procedures in Latin America and the Caribbean (LC/L.3860(CE.13/3)), Santiago, 2014. 
Information systems are another key aspect of the technical and operational dimension. Data to indicate the real situation of persons with disabilities are an essential component of the institutional framework, in that they assist empirically based decision-making at the different stages of management (diagnostic assessments, formulation, monitoring and evaluation of processes and impacts). Article 31 of the CRPD states that having tools to gather reliable statistical data to reveal the social situation of persons with disabilities is an obligation and is essential for monitoring compliance and developing public policies for reducing discrimination and promoting integration and equality of opportunities (United Nations, 2006). Likewise, target 17.18 of the Sustainable Development Goals calls for a significant increase in the availability of high-quality, timely and reliable data, disaggregated by disability, among others.

Quantifying persons with disabilities entails a series of challenges: the definition of disability that is to be adopted, the instrument chosen for data collection, the aspects of disability that are to be measured and the characteristics of the available sources of information (ECLAC, 2014). Although the inclusion of persons with disabilities in Latin American and Caribbean information systems is a matter of growing importance (particularly since the 2000 census round), because of the conceptual, methodological and operational differences found in the region's countries data-collection methods, it is still difficult to accurately quantify that reality and measure its evolution over time (ECLAC, 2014). The situation is further complicated by the existence of disparate and uncoordinated sources of information, particularly administrative records. The statistical invisibility of the population with disabilities is a reflection of their marginalization and exclusion and, at the same time, poses an obstacle to guaranteeing the exercise of their rights.

In response to this situation, the Statistical Conference of the Americas, a subsidiary body of the Economic Commission for Latin America and the Caribbean (ECLAC), agreed at its seventh meeting in 2013 on the creation of task force responsible for coordinating the preparation of a regional report on the statistical information available in the countries of Latin America and the Caribbean and the difficulties encountered in quantifying the situation of persons with disabilities. In 2016, the task force was transformed into a working group, charged with designing a unified approach and method for measuring disability in the region, improving the technical capacity of the region's countries for gathering and disseminating disability data and creating a support network among national and international agencies and institutions. 


\section{Final remarks}

Achieving the full inclusion of persons with disabilities in all areas of our societies is an undelayable commitment. Progress towards that goal demands an inclusive and effective institutional framework to provide a coherent and comprehensive response to the widely different needs of persons with disabilities.

The brief overview provided in this chapter indicates the existence of a legal and regulatory foundation underpinning an institutional architecture for the progressive enforcement of the rights of persons with disabilities. In this way, Latin America has demonstrated its resolved commitment with the rights of persons with disabilities. In particular, the region's broad ratification of the CRPD and the progressive alignment of domestic law with that instrument are encouraging actions. Not only do they denote a commitment to upholding the rights of the population with disabilities, they also provide a common perspective based on human rights. This is important, since one of the challenges facing the institutional framework for disability is the need for the crosscutting implementation of the topic among different sectoral ministries. Although each sector must deal with its own agenda according to its responsibilities and guidelines (UNICEF, 2005), the existence of a unified perspective on the topic of disability can help orient those actions in a common direction.

However, having a right does not always mean being able to exercise it. There is still a pronounced gap between the legal recognition of that segment of the population and the concrete attainment of their rights (Stang, 2011), which can be seen in the vast inequalities of inclusion that exist in the areas of education, employment and political participation, and in the over-representation of persons with disabilities among the poorer sectors of the population. This situation of structural exclusion is heightened if the intersections between disability and the other axes of the social inequality matrix — such as ethnic and racial origin, gender and territorial considerations - are taken into account (ECLAC, 2016).

At the organizational level, there are institutions that command some of the elements necessary for improving the situation of the population with disabilities. They have a legal framework that assigns them clear objectives and responsibilities, along with plans and policies that guide their actions in pursuit of those objectives. They also have mechanisms for horizontal and vertical coordination and cooperation 
to avoid the dispersion, duplication and fragmentation of public actions for that sector of the population, and forums for participation so that the views and perspectives of persons with disabilities can be incorporated into the decision-making process.

Nevertheless, channelling the scarce human and financial resources available to the disability institutions into the execution of projects can distract from other actions, such as oversight, the presentation of policy proposals and working for closer coordination among State actors (Mujica and Calle, 2006). Many of these institutions are focused on carrying out small programmes with a limited time frame and reach, which fail to bring about the genuine inclusion of the population with disabilities. In addition, the institutions' existence is marked by uncertainty on account of their high sensitivity to changes in government policies and economic cycles.

At the same time, the existence of a mandate and mechanisms for coordination and cooperation is not enough for that to occur in practice, above all in an efficient way. Organizations of persons with disabilities often describe the effectiveness of the existing coordination mechanisms as insufficient. Among the most frequently identified obstacles to their success are the absence of a clear legal mandate, inadequate resources, limited participation by persons with disabilities and the exclusion of people with specific types of disability (United Nations, 2014). The success of such coordination and cooperation initiatives can also depend on individual persons and their lobbying capabilities, and not necessarily on systematized and institutionalized practices. This poses a challenge, in light of the frequent rotation of personnel at the institutions responsible for disability matters.

More fundamentally, the main difficulty faced by persons with disabilities in the full enjoyment of their rights, which transcends and permeates through all the dimensions of the institutional framework, is the persistence of traditional views of disability within society. From that disempowering perspective, persons with disabilities are seen as vulnerable individuals, and no recognition is given to the fact that aspects of the situations in which they live - such poverty, discrimination and inaccessibility - are what make their existences vulnerable. This change of perspective demands a far-reaching cultural transformation based on a reassessment of human diversity. More than just the responsibility of the public institutions, this is a task that the whole of society must undertake. 


\section{Bibliography}

Andean Health Organization-Hipólito Unanue Convention (2011), Politica andina en salud para la prevención de la discapacidad y para la atención, habilitación/rehabilitación integral de las personas con discapacidad, Lima, Cellgraf SAC.

ECLAC (Economic Commission for Latin America and the Caribbean) (2016a), The social inequality matrix in Latin America (LC/G.2690(MDS.1/2)), Santiago. (2014), Regional reporton measuring disability:overview of the disabilitymeasurement procedures in Latin America and the Caribbean (LC/L.3860(CE.13/3)), Santiago.

Giler, G. (2012), La gestión de la cooperación internacional y las relaciones internacionales de la Misión Solidaria Manuela Espejo, Quito, Vice Presidency of the Republic of Ecuador.

Mujica, J. and L. E. Calle (2006), Los derechos de las personas con discapacidad en la legislación comparada, Lima, Fondo Editorial del Congreso del Perú.

OAS (Organization of American States) (1999), "Inter-American Convention on the Elimination of All Forms of Discrimination against Persons with Disabilities", Guatemala City, 7 June [online] http://www.oas.org/juridico/english/ treaties/a-65.html.

OISS (Ibero-American Social Security Organization) (2014), Medidas para la promoción del empleo de personas con discapacidad en Iberoamérica, Madrid.

Stang, M. F. (2011), "Las personas con discapacidad en América Latina: del reconocimiento jurídico a la desigualdad real", Population and Development series, No. 103 (LC/L.3315-P), Santiago, Economic Commission for Latin America and the Caribbean (ECLAC).

UNICEF (United Nations Children's Fund) (2005), “Seminario internacional: inclusión social, discapacidad y políticas públicas" [online] http://www. unicef.cl/archivos_documento/200/Libro\%20seminario\%20internacional\%20 discapacidad.pdf.

United Nations (2014), "National implementation and monitoring. Note by the Secretariat" (CRPD/CSP/2014/3), Convention on the Rights of Persons with Disabilities.

(2006) "Convention on the Rights of Persons with Disabilities" (A/RES/61/106), resolution adopted by the General Assembly, New York.

Vásconez, A. C. and others (2013), "Política de atención a personas con discapacidad en el Ecuador: hacia un modelo de exportación", Línea Sur, No. 6. 
Chapter VIII

\section{Latin American Afrodescendants: institutional framework and public policies}

Marta Rangel ${ }^{1}$

\section{Introduction ${ }^{2}$}

It is estimated that there are more than 125 million people Latin America who self-identify as Afrodescendants (ECLAC, 2015). This population group is subject to discrimination, poverty and vulnerability. Afrodescendants also face greater difficulties throughout the life cycle, for example in attaining higher levels of education and entering the labour market on an equal footing.

The Latin American region is characterized by a social inequality matrix, in which one of the determinants - ethnic and racial originforms intersecting and mutually reinforcing structuring axes with inequalities based on gender, age and territory (ECLAC, 2016a). ${ }^{3}$

Consultant of the Social Development Division of the Economic Commission for Latin America and the Caribbean (ECLAC).

2 The author is grateful for collaboration in the fiscal analysis by Varinia Tromben, Economic Affairs Officer, and Carlos Kroll, Consultant of the Social Development Division of the Economic Commission for Latin America and the Caribbean (ECLAC). The preparation of this chapter was supported by the project "Fostering equality: strengthening the capacity of selected developing countries to design and implement public policies and programmes to foster equality", funded by the United Nations Development Account.

3 For a more in-depth analysis of ethno-racial inequality and other structural determinants of the social inequality matrix, see ECLAC (2016a). 
As universal policies fail to fully address the situation of Afrodescendent people, more inclusive and better-targeted policies need to be formulated; and these can be better designed and implemented within an institutional framework that is sensitive to the need of Afrodescendent people. The Afrodescendent peoples' development agenda has advanced both nationally and regionally, as mechanisms to promote racial equality have been instituted; and civil society has made progress in guaranteeing the human, economic, social, cultural and collective rights of these peoples. Most Latin American countries today have a mechanism of some kind to promote racial equality, along with various Afrodescendent civil organizations; and ethnic-racial issues have been included in several intergovernmental forums and organizations, at both the regional and the subregional level. ${ }^{4}$

This chapter aims to shed greater light on this reality and its institutional development, in the framework of the International Decade for People of African Descent (2015-2024), during which countries are called upon to strengthen and implement institutional and legal frameworks that contribute to the development of this population group and to foster knowledge of and respect for their cultures (United Nations General Assembly resolution 68/237 of 2014). To that end, the chapter provides an overview of mechanisms for promoting racial equality in Latin America, using the analytical framework described in chapter I. It thus discusses the main elements of their legal-normative frameworks, along with the organizational models, the management tools used, and the fiscal dimension; and it highlights a number of policies implemented in recent years to promote the rights of people of African descent. Lastly, it describes some of the challenges that need to be addressed to make further progress in guaranteeing their rights.

\footnotetext{
The Human Rights Commission of the Inter-American System has a Rapporteurship on the Rights of Persons of African Descent and against Racial Discrimination; the Organization of American States (OAS) has the Secretariat for Access to Rights and Equity (SARE), which monitors the implementation of the action plan of the International Decade for People of African Descent. Since 2005, the Ibero-American General Secretariat (SEGIB) has recognized the rights of people of African descent and urged governments to guarantee these rights in various domains; and the Black Parliament of the Americas was set up in the same year. At the subregional level, the Afrodescendent Bureau of the Andean Community (CAN) was created in 2011 within the framework of the Andean Integration System. The Central American Integration System (SICA) includes the Permanent Commission of Indigenous and Afrodescendent Peoples of the Central American Parliament (PARLACEN). In 2015, the Common Market of the South (MERCOSUR) approved the creation of the Meeting of Authorities on the Rights of Afrodescendants (RAFRO). Many of these mechanisms have participation from representatives of Afrodescendent organizations in other countries.
} 


\section{A. The legal and regulatory framework}

\section{The international setting}

As part of the progress made in instituting social policies across the region in recent decades, the number of government agencies with responsibility for Afrodescendent issues has grown, and they have undergone some degree of institutional strengthening. More than a dozen Latin American countries now have a governmental agency tasked with promoting racial equality. This situation is the result of sustained and collaborative advocacy work by Afrodescendent social movements, other civil society organizations, national governments and international organizations (Rangel, 2016).

These agencies have also expanded their scope of action, from an initial focus on overcoming racism, to broader and more comprehensive aims related to building a more egalitarian society. The unfinished task of putting an end to racism, which has long been embedded in the structures of Latin American societies, clearly cannot be completed with universal policies alone - affirmative action policies have proven more effective at achieving greater racial equality. ${ }^{5}$

The vast majority of mechanisms for the promotion of racial equality in the region were created in this century, as preparations intensified for the Third World Conference against Racism, Racial Discrimination, Xenophobia and Related Intolerance, held in Durban (South Africa) in 2001. In the ensuing years, mechanisms of this type were created to fulfil the commitments adopted in the post-conference period. Nonetheless, the existence or otherwise of a specific institutional framework, or the precise moment of its creation may also reflect the history of Afrodescendent social movements in each country, as occurred in Colombia (1993), or else the existence of a high level of political will, even in countries where Afrodescendent people are relatively few, such as Argentina (1995).

As noted elsewhere in this volume, the main international legal instruments that explicitly refer to ethno-racial discrimination or to people of African descent, include the following: the Discrimination (Employment and Occupation) Convention, 1958 (No. 111) of the

In Brazil, for example, only $16.7 \%$ of Afrodescendent youth aged 18 to 24 were attending higher education in 2004, although the proportion had risen to $45.5 \%$ ten years later. In contrast, the percentages among white people were, respectively, $47.2 \%$ and $71.4 \%$, which means that the gap remains very wide and that the percentage of people of African descent who attended higher education in 2014 was still lower than that of whites ten years earlier (IBGE, 2015). The increase partly reflects the implementation of affirmative action measures for people of African descent in universities, by reserving quotas in public schools and the award of scholarships in private schools, since the beginning of the last decade (Feres Jr. and others, 2013, University of Brasilia, 2013). 
International Labour Organization (ILO); ${ }^{6}$ the International Convention on the Elimination of All Forms of Racial Discrimination (1965); ${ }^{7}$ the International Covenant on Civil and Political Rights $(1966){ }_{i}^{8}$ the International Covenant on Economic, Social and Cultural Rights (1966); ${ }^{9}$ the International Convention on the Suppression and Punishment of the Crime of Apartheid (1973); ${ }^{10}$ and the Indigenous and Tribal Peoples Convention, 1989 (No. 169) of ILO. ${ }^{11}$ Regional instruments include the American Convention on Human Rights, also known as the Pact of San José (1969), ${ }^{12}$ and the Andean Charter for the Promotion and Protection of Human Rights (2002), which contains a section devoted exclusively to "indigenous peoples and Afrodescendent communities", which recognizes several individual and collective rights. ${ }^{13}$

6 Article 1, paragraph 1: "For the purpose of this Convention the term discrimination includes: (a) any distinction, exclusion or preference made on the basis of race, colour, sex, religion, political opinion, national extraction or social origin, which has the effect of nullifying or impairing equality of opportunity or treatment in employment or occupation (...). Article 2: Each Member for which this Convention is in force undertakes to declare and pursue a national policy designed to promote, by methods appropriate to national conditions and practice, equality of opportunity and treatment in respect of employment and occupation, with a view to eliminating any discrimination in respect thereof" (ILO, 1958).

7 Part I, Article 2, paragraph 1: “States Parties condemn racial discrimination and undertake to pursue by all appropriate means and without delay a policy of eliminating racial discrimination in all its forms and promoting understanding among all races" (OHCHR, 1965).

8 Part II, Article 2, paragraph 1: "Each State Party to the present Covenant undertakes to respect and to ensure to all individuals within its territory and subject to its jurisdiction the rights recognized in the present Covenant, without distinction of any kind, such as race, colour, sex, language, religion, political or other opinion, national or social origin, property, birth or other status" (see [online] http://www.ohchr.org/ SP/ProfessionalInterest/Pages/CCPR.aspx).

9 Part II, Article 2, paragraph 2: "The States Parties to the present Covenant undertake to guarantee the exercise of the rights enunciated therein, without discrimination on grounds of race, colour, sex, language, religion, political opinion or of another nature, national or social origin, economic position, birth or any other social condition" (OHCHR, 1966).

10 Article 1, paragraph 1: "The States Parties to the present Convention declare that apartheid is a crime against humanity and that inhuman acts resulting from the policies and practices of apartheid and similar policies and practices of racial segregation and discrimination, as defined in article II of the Convention, are crimes violating the principles of international law, in particular the purposes and principles of the Charter of the United Nations, and constituting a serious threat to international peace and security". Paragraph 2: "The States Parties to the present Convention declare criminal those organizations, institutions and individuals committing the crime of apartheid". (OHCHR, 1973).

11 This agreement facilitates defending the collective rights of Afrodescendent communities, mainly in terms of the exploitation of resources in their territories without using the consultation mechanism provided for in the agreement (Articles 6 and 15) and consultations in other areas such as education and vocational training (Articles 22, 27 and 28) (ILO, 1989).

12 Part I, chapter I, article 1, paragraph 1: "The States Parties to this Convention undertake to respect the rights and freedoms recognized herein and to ensure to all persons subject to their jurisdiction the free and full exercise of those rights and freedoms, without any discrimination for reasons of race, colour, sex, language, religion, political or other opinion, national or social origin, economic status, birth, or any other social condition" (OAS, 1969).

13 Including, identity, an intercultural education, to engage in their traditional practices and to be consulted about the exploitation of non-renewable natural resources found in their lands or territories. 


\section{Legislation in the countries}

The legal framework within which mechanisms to promote racial equality are developed in the countries of the region is based on principles inspired by international and regional human rights laws that cover the whole population. It also encompasses a number of specific instruments that are considered fundamental for protecting the rights of people of African descent, given their explicit mention of these peoples.

National regulatory frameworks have different levels of specificity when referring to the protection of rights and the orientation of policies towards the Afrodescendent population, whether explicitly mentioned or as part of anti-discrimination laws. Latin American countries can thus be classified by how their legislation approaches the defence and promotion of the rights Afrodescendants. In 2009, Brazil, Colombia and Ecuador all had extensive legislation targeting people of African descent; Peru, Honduras and Costa Rica each had a small number of relevant laws targeting this population group, while countries such as Guatemala and Nicaragua had few laws targeting Afrodescendants specifically, but extensive legislation to combat discrimination generally. Lastly, countries with anti-discrimination legislation, but no legislation targeting people of African descent, included Cuba and Mexico (AfroAmerica XXI, 2009). In the present decade, this situation has changed for the better in several countries. In 2012, for example, Law 20,609 was enacted in Chile, providing for measures to combat discrimination, including that based on "race or ethnicity"; and significant progress has been made in Peru with legislation to promote Afrodescendent rights.

Over a dozen Latin American countries have national constitutions that condemn discrimination on the grounds of race, ethnicity or colour, or on the basis of gender or religion. ${ }^{14}$ Some also condemn discrimination by age, origin (national, social or family), socioeconomic status, opinion or ideas (political, philosophical) and language. Moreover, the constitutions of four countries - Brazil, Colombia, Ecuador and the Plurinational State of Bolivia- explicitly refer to people of African descent.

The 2008 Constitution of Ecuador is the one that refers most to Afrodescendants. It devotes an exclusive chapter to this population group, recognizing that the "black or Afro-Ecuadoran peoples" form part of the State and that the latter will ensure respect for their human and collective rights. ${ }^{15}$ These rights include developing their identity; preserving (inalienable, unattachable and indivisible) ownership of communal

14 Brazil, the Bolivarian Republic of Venezuela Colombia, Cuba, Dominican Republic, Ecuador, El Salvador, Honduras, Mexico, Nicaragua, Panama, Peru and the Plurinational State of Bolivia.

15 Chapter 5: Collective rights. First section. Onn the indigenous and black or Afro-Ecuadoran peoples, consisting of three articles (83, 84 and 85) (Constituent Assembly of Ecuador, 2008). 
lands; exploiting renewable natural resources; and being consulted on the exploitation of non-renewable resources, even with the possibility of sharing in the benefits and receiving compensation.

In Brazil, the current (1988) Constitution implicitly recognizes collective subjects of law and establishes racism as a crime punishable by imprisonment, which is not subject to a statute of limitations and carries no entitlement to bail. It also recognizes that Afrodescendent persons belonging to "quilombo" groups have definitive ownership of their lands, ${ }^{16}$ for which reason the State must issue the respective ownership titles (Article 68 of the Transitory provisions) ${ }^{17}$ and protect their documents and historical sites.

The Magna Carta of Colombia (1991) gives legal force to international human rights instruments, so these prevail in domestic law. The Constitution is interpreted in the light of the international treaties ratified by the country. This cleared the way for Colombia to be recognized as a multi-ethnic and multicultural nation, which gave additional momentum to legal progress in favour of indigenous, Afro-Colombian, Raizal and Roma minorities (Antón, 2010).

Since 2009, the Political Constitution of the Plurinational State of Bolivia has recognized the Afrodescendent population by noting in Article 3 that "the Bolivian nation encompasses all Bolivian men and women, indigenous-campesino and originating nations and peoples, and the intercultural and Afro-Bolivian communities that jointly constitute the Bolivian people." 18

In addition to referencing non-discrimination for the reasons mentioned above, such as race, ethnicity, gender and religion, some constitutions specifically prohibit discriminatory acts against workers or students in schools. In contrast, the constitutions of Argentina, Chile, Costa Rica, Guatemala, Paraguay and Uruguay do not mention people of African descent or the black population specifically; nor do they refer to race or skin colour; but many do address equality and non-discrimination for other reasons.

Domestic laws that can be viewed as frameworks for recognizing and defending the rights of Afrodescendent people include Brazil's Racial Equality Statute (Law No. 12.288 of 2010). This legislation embraces

16 This term refers to communities originally formed by individuals fleeing slavery. In Spanish they would be called palenques, in other words remote corners of land set apart from the cities or the countryside where escaped slaves (cimarrones) lived in freedom.

17 This latter provision was regulated in 2013 by Decree No. 4,887, which underpinned the Brasil Quilombola Programme. The term "quilombola" refers to people living in communities descended from the original Quilombos.

18 See Republic of Bolivia (2008). 
practically all dimensions of social life, including health, education, culture, freedom of religious worship and access to collective ownership of the land; and it recommends measures to promote the equality of Afrodescendent people. ${ }^{19}$ Nonetheless, while people of African descent are not mentioned specifically, other laws do have a major impact upon them. In fact, government agencies and civil society organizations have worked together to gain approval for such legislation, as exemplified by Brazil, which has legislation on the rights of domestic workers (Constitutional Amendment No. 72/2013, Complementary Law No. 150/2015), given its relevance to black women, who are over-represented in this occupation.

In Colombia, the Black Communities Act (Law 70 of 1993) is considered the key tool for protecting the rights of Afrodescendent people in the country, and several complementary legal instruments have emerged based on it. This law officially recognizes people of African descent; specifies collective property rights; establishes mechanisms to protect their culture; and offers guarantees to enable them to enjoy equal opportunities alongside the rest of society. The legislation and the policies applied aim to establish the legal frameworks needed to achieve a pluri-ethnic and multicultural country, as defined in the Constitution (Antón, 2010).

In the Plurinational State of Bolivia, Law No. 234 of 2008 recognizes rights and guarantees for the Afro-Bolivian people, including the strengthening of their specific institutions, customs, identity and values. Ecuador has the Collective Rights of Black or Afro-Ecuadoran Peoples Act (Law 46 of 2006); while in Honduras, Law 82 of 2004 regulates the collective property of Afro-Hondurans. In Nicaragua, Law No. 445 of 2002 addresses the property regime applicable to ethnic communities.

In Peru, Supreme Decree No. 004 states that the full enjoyment of fundamental rights by Afro-Peruvian people is a priority national interest, with a view to strengthening development and inclusion of this population group during the International Decade for People of African Descent. Accordingly, all sectors and levels of government are required to formulate and implement measures, programmes and projects to strengthen the fundamental rights of Afro-Peruvian people, under a vision of social inclusion and full participation by these people in all aspects of Peruvian society.

19 The Statute does not impose any direct requirement, but authorizes the adoption of measures that depend on other legal provisions. Thus, Decree No. 8.136 of 2013 created the National System for the Promotion of Racial Equality (SINAPIR), which organizes voluntary affiliation to the system by provincial and municipal governments. Two years later, 27 state agencies (provincial) and 169 municipal agencies promoting racial equality had joined the system (SEPPIR, 2015). 
Lastly, there are laws that prohibit racist manifestations and expressions and classify racism as a crime. A total of 14 countries have thus far passed legislation prohibiting racial discrimination and making it a crime subject to imprisonment. ${ }^{20}$ While this appears consistent with the fact that 13 have constitutional provisions against ethnic-racial discrimination, ${ }^{21}$ these two conditions are only satisfied simultaneously in eight countries. ${ }^{22}$

\section{B. The organizational dimension: features and characteristics}

At the national level, most Latin American countries have organizational structures to design and implement policies for people of African descent, underpinned by legal instruments.

Some of these mechanisms were created at particular moments in history, when the condition of Afrodescendants and the fight against racism featured prominently on the public agenda. Nonetheless, some of these were later downgraded within the State hierarchy, which not only undermines the stability of the defence of the rights of Afrodescendent peoples, the fight against racism and the promotion of racial equality, but also diminishes their influence and reduces the scope for public policy action (see table VIII.1).

Mechanisms to promote racial equality make use of a variety of arrangements or institutions which, in turn, occupy different places in the State hierarchy: boards, councils, institutes, secretariats, commissions, among others. The mechanism used largely depends on how governments address the cross-cutting features of policies with an ethnic-racial perspective, and on the priority they assign to the issue, since these policies require coordinated work between different levels of government, both sectoral and at the provincial or local levels. Thus, alongside the authority model, a central part of the organizational design with which policies are implemented involves the means of communication, coordination and articulation between the actors involved. Accordingly, the development and implementation of government plans related to Afrodescendent people, should take account of interaction between the racial-equality promotion mechanisms and other institutions, which occurs at various levels and with different types of organization. This is fundamental, since this type of mechanism targets specific population groups with different scopes of action to meet their needs and guarantee their rights in all spheres.

20 Argentina, Brazil, Chile, Dominican Republic, Costa Rica, Cuba, Ecuador, El Salvador, Guatemala, Mexico, Nicaragua, Panama, Peru and Uruguay.

${ }_{21}$ The Bolivarian Republic of Venezuela, Brazil, Colombia, Cuba, Dominican Republic, Ecuador, El Salvador, Honduras, Mexico, Nicaragua, Panama, Peru, and the Plurinational State of Bolivia. 


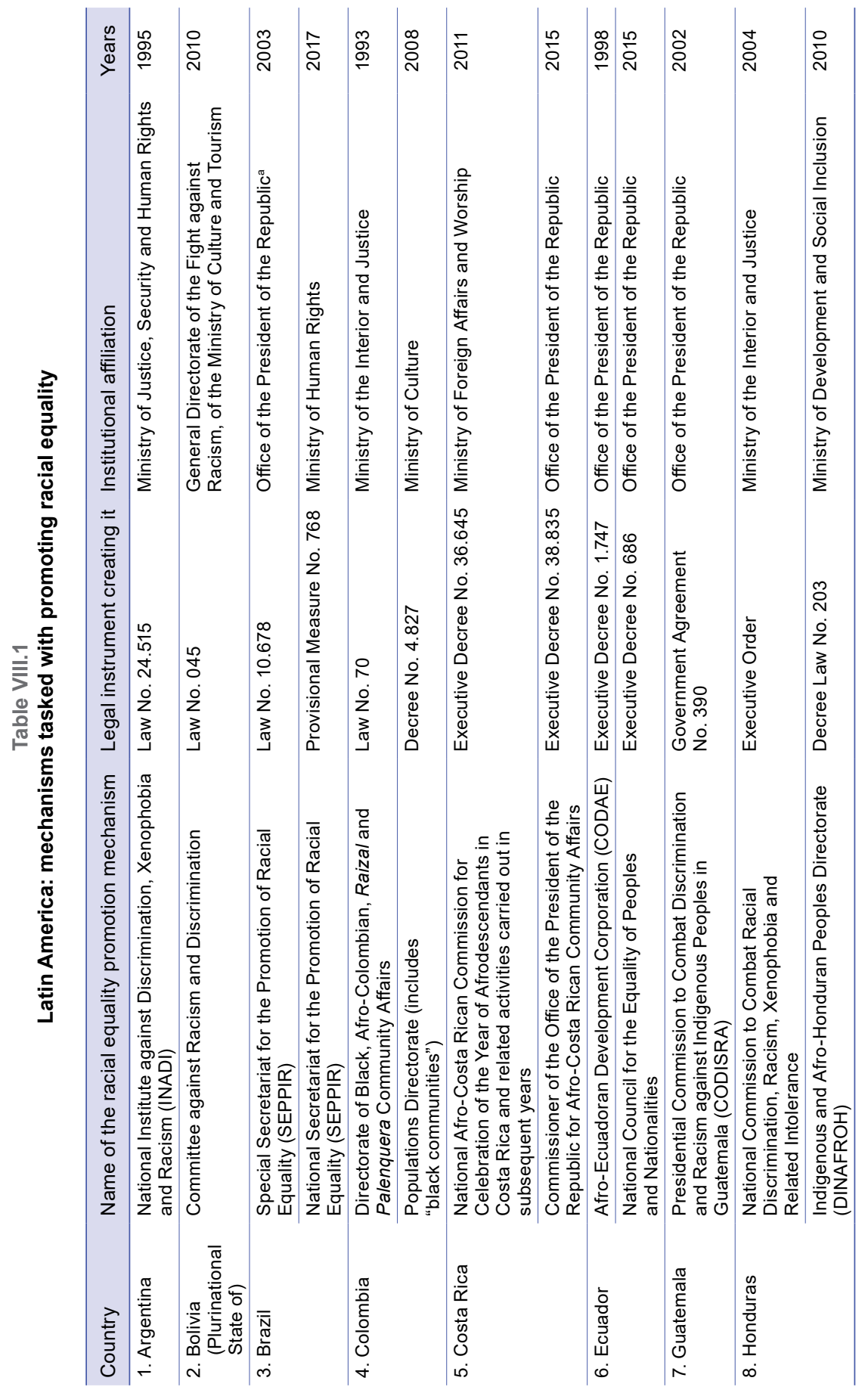




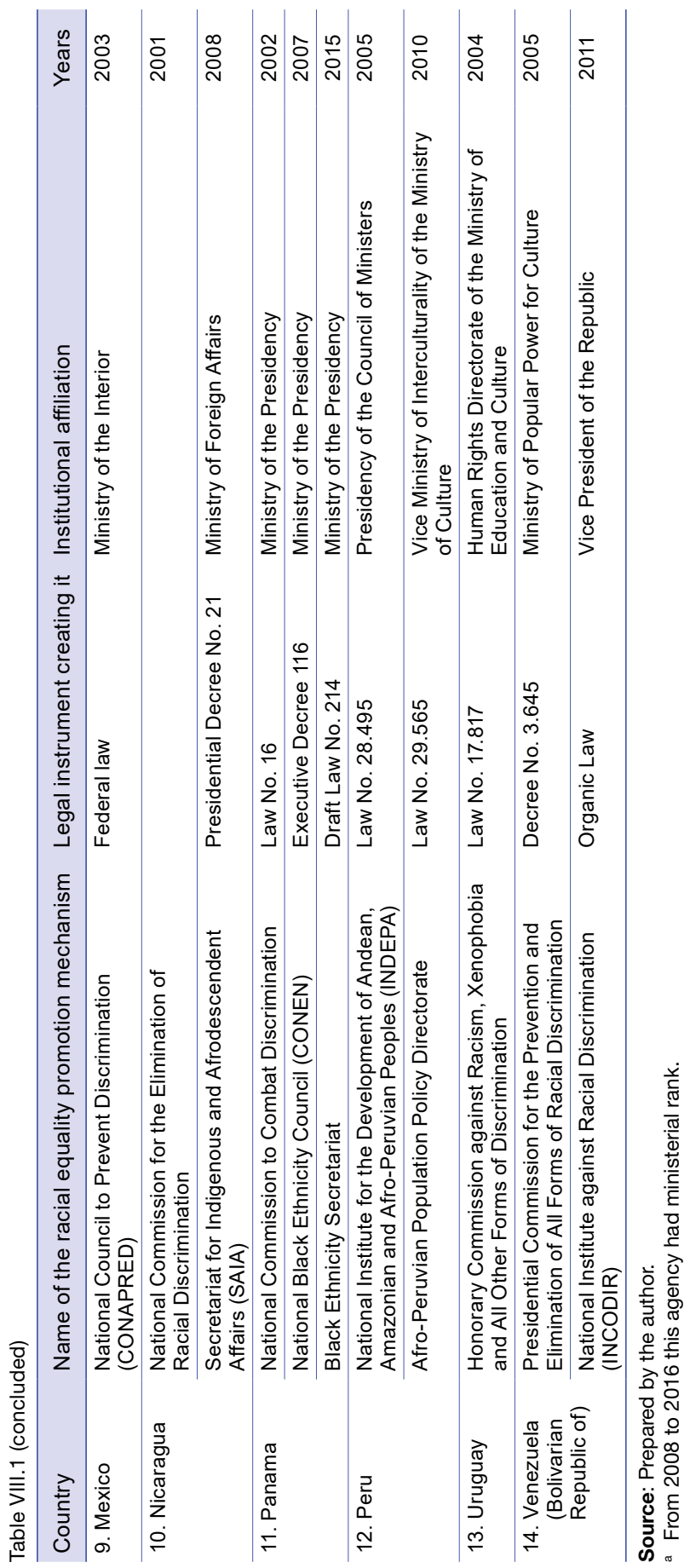


Examples of articulation can be found between the racial-equality promotion mechanisms and other government agencies at various levels, both horizontally (with other ministries and institutions responsible for sectoral policies, such as those related to health, education and poverty reduction), and vertically (with other administrative levels, such as provinces and cities). For example, the National System for the Promotion of Racial Equality (SINAPIR) of Brazil articulates the federal domain with state and municipal governments in the implementation of policies targeting people of African descent, while also acting as a coordinating entity in the federal government.

Government mechanisms also relate with other spheres of the State, such as parliament and the Public Prosecution Office. In the first case, commissions and work groups can be created; for example, the Andean, Amazonian and Afro-Peruvian Peoples, Environment and Ecology Commission $^{23}$ and the Afro-Peruvian Roundtable of the Congress of the Republic ${ }^{24}$ have been established in Peru. In terms of coordination with the Public Prosecution Office, in Brazil's Pernambuco State, the aim since 2002 has been to articulate actions with various institutions to combat institutional racism (Public Prosecution Office of Pernambuco, 2013). Likewise, in 2002 the Public Ministry of Labour created the National Coordination Unit for the Promotion of Equal Opportunities and Elimination of Discrimination in the Workplace (COORDIGUALDADE).

Lastly, mention should be made of articulation with social organizations and movements. In the Plurinational State of Bolivia, the current organizational model encompasses indigenous, campesino and intercultural organizations. In Ecuador, it includes women's organizations, Afrodescendent communities, international organizations, universities and other rights advocacy entities. In the case of Brazil, the national conferences to promote racial equality (CONAPIR) ${ }^{25}$ that have been held since 2005 represent an important mechanism for consultation and decision-making

23 Despite what its name suggests, the Commission's work in the 2009-2010 legislative period focused mainly on the problems of indigenous peoples. In the ensuing period (2011-2012), according to a report by the Ombudsman of Peru, the Commission's Work Plan did not include effective actions on behalf of Afro-Peruvians (Defensoría del Pueblo, 2011); and the update of the report of this Commission for the 2013-2014 period also fails to show any substantive progress on the subject.

24 Created in 2008 and comprising parliamentarians and former parliamentarians of African descent, together with individuals and legal entities committed to defending the rights of AfroPeruvians, it sought to profile its contribution to national development, combat racism, promote the inclusion of Afro-Peruvians and defend their fundamental rights. One of its most important achievements was the creation of the Afro-Peruvian National Museum (Defensoría del Pueblo, 2011); yet this mechanism has not received the incentives needed to continue its work and it needs to be strengthened.

25 The most recent conference was held in 2013 and mobilized around 48,000 people in 500 municipal and 26 state conferences, together with three meetings for traditional communities (SEPPIR (2014), in Rangel (2016)). 
on Afrodescendent issues. The National Council for the Promotion of Racial Equality $(\mathrm{CNPIR})^{26}$ was also established, with the primary mission of proposing policies to promote racial equality, specially targeting Afrodescendent peoples and other racial and ethnic segments of the Brazilian population. ${ }^{27}$ This Council is chaired by SEPPIR and encompasses 22 public federal agencies, 19 civil-society organizations, and persons renowned for their knowledge on the subject, appointed by SEPPIR. ${ }^{28}$

These mechanisms are often attached to the Office of the President of the Republic, or else depend institutionally on it. Next in importance are various sectoral ministries (justice, education, culture and foreign affairs), along with those of government and development and social inclusion.

The key objectives guiding the actions of agencies in charge of policies related to Afrodescendent people are to coordinate ethnic and racial issues and to develop policies to combat racism and discrimination, and foster racial equality, thus promoting intercultural citizenship. This is done by implementing policies that guarantee the full exercise of the rights of people who experience discrimination for ethnic or racial reasons, which fuels the inequalities and profound economic, social, political and cultural disparities that affect these people.

These mechanisms vary considerably in size and scope of action; some are more modest, with fewer staff and a small budget and, therefore, fulfil a narrower range of functions. Nonetheless, although the functions performed are varied, the primary mission is to formulate and implement promotion policies with a view to mainstreaming the racial perspective in public policies. Thus, the functions that most of these organizations fulfil include:

- Conducting research on the national reality.

- Preparing comparative studies on the international rights of people of African descent.

26 Created through Law No. 10.678 of 2003.

27 Other responsibilities are to: propose support, evaluation and oversight strategies; and participate in the decision-making process on policy guidelines for the promotion of racial equality, stressing inclusion of the racial dimension in national public policies. The Council is also required to review the SEPPIR budget proposal and suggest priorities in resource allocation; submit suggestions to the federal government's multiyear planning; support, analyse and present suggestions on government actions, and implement the results of the deliberations of the national conferences on the promotion of racial equality (see [online] http:/ / www.seppir. gov.br/articulacao/cnpir).

28 In addition to Afrodescendent people's organizations (and the respective intersections with the gender, youth and LGBT community), the Council includes those of indigenous and Roma communities, Arabs, Palestinians and Jews, and almost two dozen ministries and secretariats (education, health, work, justice, cities, science, social development, environment, integration, external relations, planning, agrarian development, sports, culture, communications, human rights, policies for women, among others) (see [online] http://www.seppir.gov.br/articulacao/cnpir). 
- Providing free legal advice to persons or groups that are victims of discrimination.

- Promoting the Afrodescendent culture and stimulating participation by these peoples in the formulation and execution of inclusion policies.

- Disseminating the commitments assumed by the State under international rights norms, promoting compliance and monitoring the implementation of measures to combat discrimination and foster racial equality.

- Designing and implementing anti-discrimination plans of action and awareness campaigns.

- Registering complaints of racial discrimination and assisting judicial bodies in dealing with crimes of racism.

- Promotinginclusion of the problemsandhistory of Afrodescendent peoples in the educational materials used in schools.

In addition to the above, the entities in charge of these policies in countries such as Argentina, Colombia and the Plurinational State of Bolivia have specific functions that warrant special consideration. In Argentina, the functions of INADI include verifying and denouncing the presence in the country of individuals who had participated in deaths and persecutions for reasons of race, religion, nationality or opinion during the Second World War and, in this connection, proposing new extradition treaties. ${ }^{29}$ In the Plurinational State of Bolivia, the National Committee against Racism and Discrimination fosters public recognition of natural persons or legal entities that play a key role in combating racism and discrimination, and of the heroes of indigenous peoples, Afro-Bolivians and intercultural communities. ${ }^{30}$ In Colombia, the Afro-Colombian, Raizal and Palenquera Affairs Directorate (DACN) has functions that include the strengthening of local governance based on assistance from gubernatorial offices and mayoralties, and articulation with territorial entities and those representing ethnic and vulnerable population groups. The directorate also coordinates prior consultation on projects that could affect the communities concerned, supports the resolution of conflicts in a manner consistent with the customs of the communities, and coordinates the definition of environmental agendas. ${ }^{31}$

The scale of gender, race and ethnic inequalities in fundamental areas of social development needs to be recognized, along with the fact that their overlapping affects indigenous and Afrodescendent women

\footnotetext{
See [online] http://www.inadi.gob.ar/.

See [online] http://www.noracismo.gob.bo/.

See [online] http://dacn.mininterior.gov.co/.
} 
more severely. In view of this, in addition to the specific political demands of this group (ECLAC, 2016a), some countries consider Afrodescendent women as a specific population group. For example, in Brazil, SEPPIR has worked on the issue of gender and black women in conjunction with the Secretariat for the Advancement of Women (SPSM) since its inception. These two entities provide interesting examples of interaction between two secretariats whose mission was to promote the mainstreaming of gender and race in public policies, and which collaborated on fundamental issues such as the rights of female domestic workers. ${ }^{32}$ In Guatemala, the Presidential Secretariat for Women identifies Garifuna women as a target group of the National Policy for the Comprehensive Advancement of Women. ${ }^{33}$ In Honduras, the National Institute for Women includes a representative from ethnic organizations on its Board of Directors. Lastly, the National Women's Institute of Uruguay includes a work area specifically dedicated to Afrodescendent women. It is also worth noting a decision adopted by the Southern Common Market (MERCOSUR) in 2011, which created the "MERCOSUR Strategic Plan for Social Action" with the aim of coordinating social programmes to eradicate female illiteracy, especially among Afrodescendent women.

Government mechanisms responsible for promoting racial equality in the region thus vary widely. They also operate in a world that is in a constant process of advances and setbacks due to their sensitivity to business and governmental cycles. This has led to significant changes in these mechanisms, not only in their legal formats, but also in their institutional affiliation, their organizational models and the scope of their authority. In general, such changes tend to improve the work of these mechanisms, by enhancing their capacity to influence policies and conferring greater stability and additional resources. An example of this is what happened in Ecuador with the Organic Law of Public Institutions of the Indigenous Peoples of Ecuador and the Law on the Collective Rights of the Black or Afro-Ecuadoran Peoples, which were repealed and replaced by the Organic Law on National Councils for Equality, in 2014. This has become increasingly important and represents a step forward in policies

32 Other important examples include the National Policy on Comprehensive Health Care for Women, which includes black women; the National Plan for the Promotion of Racial Equality (which emerged from the conferences on racial equality, in which the Secretariat for Policies for Women (SPM) participated) and whose objectives include combating all forms of abuse of the human rights of black women; and health policies for the black population that seek to reduce ethnic and racial differences in health conditions, especially in terms of maternal and child morbidity and mortality. http://bvsms.saude.gov.br/bvs/publicacoes/politica_nacional_ saude_integral_populacao.pd, and the gender and racial equity promotion programme (Proequidad de Género y Raza), coordinated by SPM, targeting large firms (mostly public) and other government institutions, such as municipalities and state secretariats.

33 Nonetheless, in Guatemala the Afrodescendent population is still considered as part of the indigenous population (OAS, 2011a). 
for Afro-Ecuadorans. This Law provides for the creation of National Equality Councils, including the Peoples and Nationalities Council, which is responsible for Afrodescendent issues, which aim to implement policies that guarantee equality between individuals, communities, peoples and nationalities, and to eradicate discriminatory practices (Antón, 2010).

Despite the above, in some cases institutional setbacks may also occur owing to the political context of the countries in question. Thus, in Brazil, between 2003 and 2017, SEPPIR underwent several institutional changes, ranging from the acquisition and subsequent loss of ministerial status, to changes in the ministry to which it reported, all compounded by budget cuts. ${ }^{34}$ In some cases, the mechanisms for promoting racial equality are almost symbolic and do not function officially; and, if they do succeed in functioning, sometimes they do not effectively constitute social authorities or satisfy the minimum conditions needed to exert a coordinating influence on policies. For example, in Nicaragua, a report published in 2008 by the Committee for the Elimination of Racial Discrimination (CERD), states that the National Commission for the Elimination of Racial Discrimination, created in 2001 in the Ministry of Foreign Affairs, was not legally formalized and never worked effectively. ${ }^{35}$ Another example is Panama, as reflected in a report prepared in 2010 by the Black Panamanian Organizations to review progress and weaknesses in the application of CERD in the country. ${ }^{36}$ According to this report, the Executive Secretariat of CONEN never had its own offices, and it operated with a minimal budget compared to other government agencies with similar functions.

The organizational format adopted by governmental entities promoting racial equality is crucial because it is directly related to the entity's authority and influence to propose and influence policy design and implementation, as well as its scope of action, the amount of economic and human resources at its disposal and, hence, its capacity to

34 In 2003, SEPPIR was created in Brazil, directly linked to the Office of the President of the Republic, whose incumbent participated in the ministerial and inter-ministerial meetings on an equal footing with the other ministers. In 2008, SEPPIR legally obtained the status of a ministry, which it held until October 2015, when it was incorporated, as secretariat, into the newly created Ministry for Women, Racial Equality and Human Rights. Between 2015 and 2017, SEPPIR was part of two newly created ministries that were later dissolved. Currently, it is an institutional unit of the Ministry of Human Rights with the status of national secretariat. So many institutional changes in such a short period of time, compounded by budget cuts, are worrying signs that may compromise the consolidation and progress of the important work done by SEPPIR between 2003 and 2015, in terms of the preparation and implementation of public policies to combat racism and promote racial equality in various areas. Among other areas, these relate to health, education, employment and work, the fight against poverty, promotion of family farming and agrarian reform, recognition and titling of Quilombola lands, and research and definition of indicator systems.

35 See United Nations (2008).

36 See National Coordinator of Black Panamanian Organizations (2010). 
effectively contribute to reducing inequality and racial discrimination. ${ }^{37}$ As a cross-cutting entity, well-coordinated collaboration between several policy sectors (education, health, labour, justice, among others), levels of government (national, state or provincial, municipal), and with civilsociety organizations is fundamental.

Organizational heterogeneity also reflects the population targeted and the issues addressed by each entity, as revealed by the names of the agencies: some are focused on the fight against racial or ethnic discrimination (Argentina, Bolivarian Republic of Venezuela, Mexico, Plurinational State of Bolivia and Uruguay), while others are focused only on issues related to the Afrodescendent population (Brazil, Colombia, Costa Rica, Ecuador, Panama and Peru). There are also mechanisms to promote racial equality that target indigenous peoples and people of African descent (Honduras ${ }^{38}$ and Nicaragua), or other population groups (Colombia) ${ }^{39}$ and the fight against xenophobia (Argentina and Uruguay).

Along with national agencies, some countries also have subnational or local mechanisms. For example, in Brazil as of May 2015, the National System for the Promotion of Racial Equality (SINAPIR) had 303 state or municipal organizations and councils to promote racial equality distributed throughout national territory. In Argentina, INADI has 23 provincial delegations across the country.

Some countries, such as Colombia and Ecuador, have more than one governmental body with responsibilities in promoting racial equality. Colombia has two mechanisms responsible for Afrodescendent peoples -DACN (specifically focused on the aforementioned communities and institutionally linked to the Ministry of the Interior) and the Populations Directorate (which also serves other population groups and is linked to the Ministry of Culture). In Ecuador, mechanisms for the promotion of

37 For example, in Brazil, SEPPIR had more than 100 employees before the institutional changes of this year. Meanwhile, INADI in Argentina had 429 posts in 2016 and DACN in Colombia had a staff of 33. The Commissioner of the Office of the President of the Republic for Afro-Costa Rican Community Affairs, created in 2015, consists of just three people.

38 The Garifuna people object to being called Afro-Hondurans. In 2013, an organization filed a complaint with the Public Ministry alleging "identity theft" being perpetrated against them by the Honduran State. Other demands are for the month of African heritage be abolished and a national day of the Garifuna ethnic group of Honduras be decreed; that the name of the Secretariat of Indigenous and Afro-Honduran Peoples be changed to the Secretariat for Ethnic Development of Honduras; and that the Afrodescendant University of the Americas be banned from operating.

39 In addition to the black, Afro-Colombian, Raizal and Palenque communities, the Colombian Population Directorate deals with other groups, such as indigenous peoples, Roma or gypsies, persons with disabilities, victims of armed conflicts and interest groups (urban tribes, supporter gangs, Arab communities, campesinos, young people at risk, and Afro-Colombian or Roma early childhood) (see [online] http://www.mincultura.gov.co/areas/poblaciones/Paginas/ default.aspx). 
equality (Council for the Development of the Nationalities and Indigenous Peoples of Ecuador (CODENPE), CODAE and the National Council of the Montubio People of Ecuador (CODEPMOC) are constitutionally required to become national equality councils. One of these is the National Council for the Equality of Peoples and Nationalities, ${ }^{40}$ which interacts with governing bodies and executing units and with specialized agencies in the protection of human rights at all levels of government.

As noted in chapter I, participation in decision-making through interaction with organizations and social movements is a fundamental tool for the management of policies, especially those of a cross-cutting and ethnic-racial nature. Participation gives greater legitimacy to decisions and is key to overcoming racial inequalities. When these processes are carried out in a participatory manner in the various decision-making bodies, they help make the policies implemented more effective. In this regard, several countries include organizations and representatives of people of African descent in their planning processes, such as the Plurinational State of Bolivia which includes participation by Afrodescendent organizations. In Brazil, CONAPIR, mentioned above, is an important mechanism of consultation between the government and civil society. In Colombia, a Vice Ministry for Equal Rights and Participation has been created, with competency on ethnic issues; at the parliamentary level there is the Special National Constituency for Black Communities and there is also a special constituency in the House of Representatives, in addition to departmental, district and sectoral consultative commissions. Ecuador has a Secretariat of Peoples, Social Movements and Citizen Participation; and National Councils for Equality have been created jointly by civil society and the State. In Peru, a National Policy for the Mainstreaming the Intercultural Approach was defined with participation by Afro-Peruvian organizations. Lastly, the Bolivarian Republic of Venezuela created the Afrodescendent Communities Liaison Office. It should also be noted that, in countries such as Colombia, Ecuador and the Plurinational State of Bolivia, Afrodescendent communities have to be consulted over potential exploitation of the natural resources in their territories. ${ }^{41}$

40 The other equality councils address of gender, intergenerational, disability and human mobility issues.

${ }_{41}$ The management tools for monitoring and evaluation systems and for transparency in public policies targeting the Afrodescendent population, are discussed in chapter II of this volume. When this study was in process, the only information available related to social policies in general. 


\section{The technical-operational dimension: tools management}

One of the major challenges when designing policies targeting Afrodescendent people is the lack of data sources with an ethnic or racial origin breakdown. This is basic not only from the design point of view, but also for the monitoring and evaluation of the policies. Nonetheless, until very recently, no progress had been made in the processes to identify Afrodescendent populations in censuses, surveys and administrative records; thus the statistical invisibility of these citizens has just begun to be addressed. This represents a violation of one of the basic and fundamental principles for the design of public policies, namely, the importance of defining the population on which actions must be targeted, determining where they are located and classifying them according to their specific needs. The disaggregation of data by race or ethnicity is an essential tool for highlighting problems of inequality. Currently there are only three Latin American countries (Chile, the Dominican Republic and Haiti) that do not collect census data on the self-identification of people of African descent. In contrast, only six countries have so far collected such data in their household surveys (Plurinational State of Bolivia, Brazil, Colombia, Ecuador, Peru and Uruguay) (ECLAC, 2016a).

Another important point in the management of policies targeting Afrodescendants is their inclusion in development plans. In Brazil, they have been considered in multiyear plans since 2004; and in Colombia, the black communities have been represented in the plans since 1994. In Costa Rica, the National Plan for Afrodescendants (2015-2018) seeks to reduce gaps in living standards relative to the rest of the population. In Guatemala, the Equal Opportunities Plan (2008-2023) has objectives that include the comprehensive advancement of Garifuna women. In Peru, the National Human Rights Plan of the National Development Plan for the Afro-Peruvian Population (PLANDEPA) (2015-2024) is part of the commitment assumed within the framework of the International Decade for People of African Descent. Lastly, in Uruguay, the Plan of Action for the Rights of Afrodescendants (2010-2015) sought to overcome the racial divide in Montevideo. ${ }^{42}$

The International Decade for People of African Descent (2015-2024) is expected to raise the profile of this population and its problems. This can be done at a statistical level, through exercise of the right to selfidentification in censuses, surveys, administrative records and other

For more information on the orientations of policies for people of African descent, see section 5 of this chapter. 
instruments. ${ }^{43}$ It should also be involve strengthening and implementing institutional frameworks that foster the coordination of inclusion policies to overcome racism and racial inequalities in the region.

\section{Financing}

As highlighted in chapter I, the public funding assigned to each government function can be viewed as an indicator of its priorities; and, its amount, orientation and stability partly reflect the burden of the economic or political crises suffered by the countries in question. In other words, business cycles can have adverse effects on resource allocation, and on the sustainability and institutional strengthening of organizations and social policies (ECLAC, 2016b). This also happens with policies to promote racial equality, which can be affected by economic circumstances. Nonetheless, despite the importance of financing for the sustainability of these policies, a regional comparative study is yet to be undertaken.

In view of the above, this section describes an exercise focused on the financial resources allocated to governmental mechanisms for the promotion of racial equality in selected countries, but not on the set of policies that could include the Afrodescendent population. These amounts could be higher if account were taken of the expenses incurred by entities executing programmes that include projects or activities related to universal services and those that target this population group but depend on other government departments.

Another element to be considered, which reflects the degree of institutional development in this area, is that the budgets of mechanisms to promote racial equality are not always published. Although the overall budget of a given country is available, the corresponding mechanisms are often not mentioned because the expenditure items are not sufficiently disaggregated.

Despite these constraints, it was possible to obtain relevant data from eight countries. As shown in table VIII.2, in 2016, the countries had highly dissimilar budgets, ranging from around US\$500,000 in Nicaragua to US\$ 14.5 million in Brazil. Nonetheless, the proportions that these amounts represented in the overall budgets of the respective countries were similarly small.

43 In this regard, at the regional level, the Montevideo Consensus on Population and Development devotes a chapter exclusively to people of African descent, which includes the priority measure No. 98: "Generate knowledge and reliable and timely information with a gender perspective and disaggregated by sex, age and socioeconomic status, among other variables, on Afrodescendent populations through participatory processes, paying attention to the international requirements and recommendations relating to the issue" (ECLAC, 2013). 


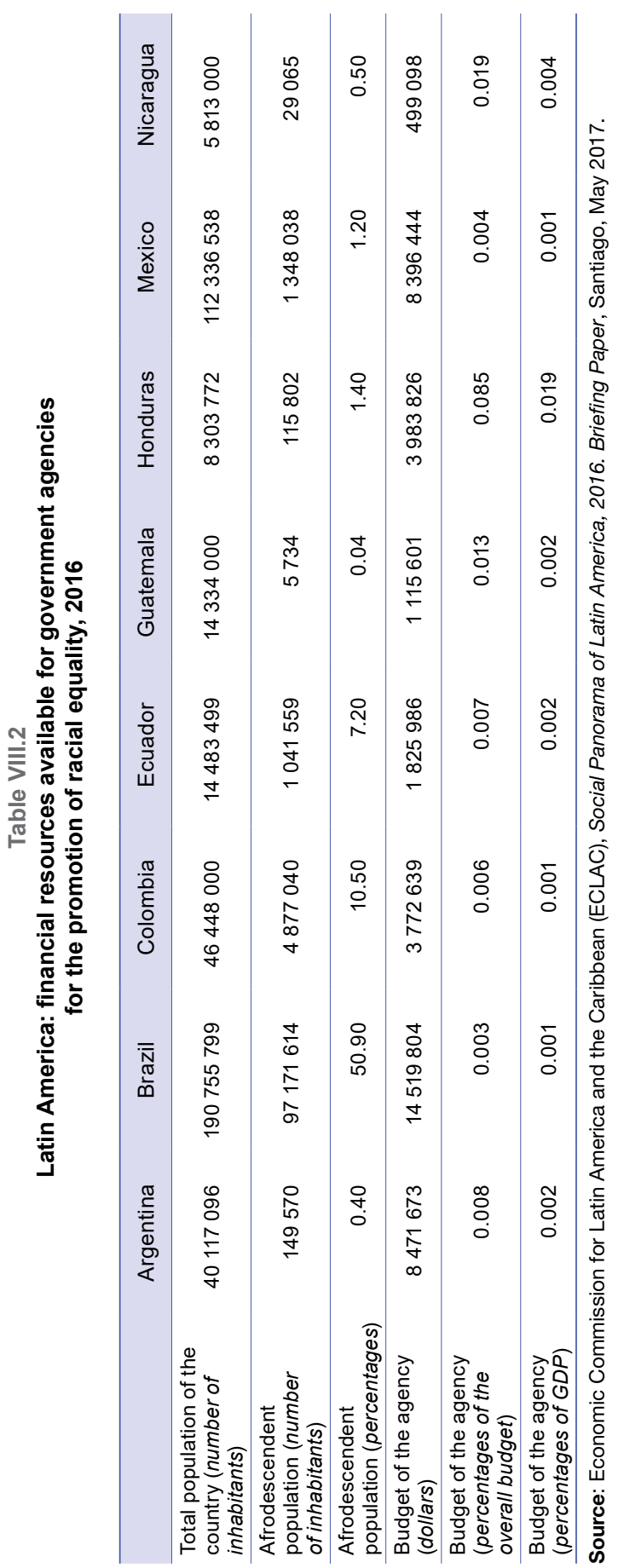


In Brazil, the SEPPIR budget in 2016 was well below the previous year's amount (around US\$25 million), although higher than in 2014 (about US\$ 10 million). That is, there was an increase of around $150 \%$ between 2014 and 2015, and a 40\% cut in 2016. ${ }^{44}$ Fluctuations of this magnitude demonstrate the instability of these institutions' budgets, related to the economic and political situation prevailing in the country, which caused the government to carry out a far-reaching fiscal adjustment that also affected SEPPIR funding.

In the case of Colombia, the Ministry of the Interior allocated roughly 11.523 billion Colombian pesos (nearly US $\$ 4$ million) to the population of African descent, equivalent to $1.12 \%$ of the entity's budget. These resources were channelled to the following areas: strengthening of organizational and consensus-building processes; improvement of communities and their governance; and promotion of economic equality, recognition, diversity and inclusion. In addition, other ministries had budgets for actions targeting the Afrodescendent population on issues such as land registration, rural development and support for artisanal production. ${ }^{45}$

\section{E. Key policies for Afrodescendants}

In response to the Afrodescendent movement, and also as a consequence of the international commitments assumed (whether through previously signed international law instruments, through the Durban Programme of Action, or through the attributions of mechanisms for the promotion of racial equality themselves), a set of policies to combat racism and promote racial equality has been deployed in several Latin American countries in recent years. This represents a step forward in the institutional development outlined thus far.

Without intending to be exhaustive, this section seeks to highlight the main policies that have been developed in recent years to eradicate racism and foster racial equality. These policies are in addition to institutional strengthening itself as an objective, and they are derived from what is described above. They were classified in three categories, as proposed by Jaccoud (2009): (i) policies to prevent and root out racism; (ii) affirmative and evaluative actions (in other words, policies of positive discrimination and appreciation of Afrodescendent culture and traditions), and (iii) strengthening of traditional communities (in territories occupied by the descendants of former slaves).

44 See [online] http://www.camara.leg.br/internet/comissao/index/mista/orca/orcamento/ OR2016/red_final/vol4/67_sec_politic_igualdade_racial.pdf.

45 See [online] http:// www.minhacienda.gov.co/HomeMinhacienda/ShowProperty?nodeId $=\% 2$ FOCS\%2FMIG_50434604.PDF\%2F\%2FidcPrimaryFile\&revision=latestreleased. 
In terms of preventing and rooting out racism, in addition to legislation that prohibits racist expression and classifies racism as a crime, some countries develop more comprehensive policies to eliminate racial discrimination. These include Ecuador (Plurinational Plan to Eliminate Racial Discrimination and Ethnic and Cultural Exclusion); Guatemala (Public Policy for Coexistence and the Elimination of Racism and Racial Discrimination) and Brazil (National Racial Equality Promotion Plan). Other ways to combat racism include interventions in territories where there is a greater density of persons of African descent and higher rates of violence and young people at social risk (Plano Juventude Viva (Brazil)); the running of online training courses (Colombia); the reception of complaints of racism and legal support for the victims (Argentina and the Plurinational State of Bolivia); the creation of observatories and platforms to combat discrimination (Argentina, Colombia and Peru) and the adoption of local regulations (Quito (Ecuador) and Callao (Peru)).

Affirmative action policies mainly involve reserving a fraction of places (or enrolment quotas) in public universities for Afrodescendants, in addition to granting scholarships in private universities. In this regard, Brazil is a reference as one of the countries that has made the most progress, by reserving quotas for Afrodescendent and indigenous people in public universities and technical education institutes ${ }^{46}$ together with a scholarship programme in private universities. ${ }^{47}$ Scholarships have also been awarded to enable persons of African descent to study for the diplomatic career; and a quota of $10 \%$ of places for Afrodescendants was established in the first phase of the selection process for the diplomatic service (OAS, 2001b). Similarly, reserved quotas were instituted in public administration and state supplier tenders. Other countries, such as the Bolivarian Republic of Venezuela, Colombia, Peru, the Plurinational State of Bolivia and Uruguay have also developed affirmative action policies.

Profile-enhancing policies include the instituting of Afrodescendant celebration days in most of the countries of the region, ${ }^{48}$ and also the teaching of African history and culture in schools (for example, in Brazil, Colombia and Uruguay) and the implementation of policies that incorporate visions and ancestral health practices targeting diseases that particularly affect Afrodescendent people (for example, in Brazil, Ecuador, Nicaragua and Peru). It is also worth noting the recognition of historical Afrodescendent figures and their cultural practices as historical heritage,

46 Since 2001, several public universities had used a variety of methods to reserve places on ethnic criteria; nonetheless Law No. 12,711 (2012), standardized these criteria.

47 Law No. 11,096/2005, University for All Program (PROUNI).

48 Argentina, the Bolivarian Republic of Venezuela, Brazil, Colombia, Costa Rica, Ecuador, El Salvador, Guatemala, Honduras, Nicaragua, Panama, Paraguay, Peru, the Plurinational State of Bolivia and Uruguay. 
and the official recognition of the value of people of African descent in nation building and in culture (for example, in the Plurinational State of Bolivia, Nicaragua, Panama and Peru).

In terms of strengthening traditional communities, the policies are mainly oriented towards the "cimarron" areas historically occupied by escaped former-slaves. Policies to strengthen these areas are not widespread, but Brazil, Colombia, Ecuador and the Plurinational State of Bolivia lead the way. In these countries, persons living in such zones are granted definitive ownership of the occupied lands, so the State must not only issue their property titles, but also develop comprehensive policies in the communities concerned.

\section{F. Conclusions and challenges}

This chapter has sought to contribute to the analysis of the Afrodescendent institutional framework in Latin America. This is fundamental for advancing the development of policies that guarantee the rights of these peoples, without discrimination and with inclusion under conditions of equality -objectives that are becoming increasingly important in the region.

Latin American countries have made progress in recent decades, albeit to varying degrees, in the creation of regulatory frameworks and institutions devoted specifically to the promotion of racial equality and to Afrodescendent peoples. The development of this institutional framework and its strengthening (or disappearance), is closely linked to business and government cycles. This means that economic crises and the political will of governments in office are fundamental for strengthening the institutional framework that safeguards the rights of people of African descent, although this situation can partly be counteracted by civil-society mobilization. Despite the difficulties, it is reasonable to claim that anti-racism legislation and governmental mechanisms for the promotion of racial equality have continued to multiply and strengthen. For example, 10 of the mechanisms mentioned here, the vast majority, were created between 2001 and 2005. They were often set up in the form of commissions that later evolved to adopt other organizational formats, such as secretariats, directorates or institutes, which often represented institutional progress. This needs to be highlighted because a major weakness of mechanisms to promote racial equality is the institutional format adopted. The format adopted will define the position that the mechanism should occupy in the State structure and the resources available for achieving the proposed objectives are both defined. 
The main strengths of the mechanisms for the promotion of racial equality include collaboration with other institutions, both public and those of civil society. This is fundamental, since it involves managing cross-cutting policies so that they incorporate the social movements associated with this problem.

A key element in the management of the Afrodescendent institutional framework involves definitively making these peoples visible in official statistics; otherwise initiatives to expand their participation in policies will be limited. Currently, while all Latin American countries bar three collect data on the self-identification of Afrodescendent people in their population censuses, only a minority collect such data in their household surveys. Although this is a long-standing and increasing demand from Afrodescendent organizations, there is still a large deficit in statistics and records disaggregated by ethno-racial self-identification, which are fundamental for the design of targeted and cross-cutting policies.

\section{Bibliography}

Afroamérica XXI (2009), “Compendio normativo: 'acciones afirmativas a favor del pueblo afrodescendiente de América Latina y legislación antidiscriminatoria"" [online]http://hutchinscenter.fas.harvard.edu/sites/all/files/COMPENDIO $\% 20$ NORMATIVO \%20REGIONAL \%20AFRODESCENDIENTE $\% 20$ DE $\% 20$ AMERICA\%20LATIN.pdf.

Antón Sánchez, J. (2010), “Implementación de los pactos y los convenios internacionales relacionados con los derechos civiles, culturales, económicos, políticos y sociales de la población afrodescendiente de Colombia, Ecuador, Perú y Venezuela", UNDP regional project "Afrodescendant Population of Latin America".

Constituent Assembly of Ecuador (2008), "Constitución de la República del Ecuador" [online] http://www.asambleanacional.gob.ec/sites/default/files/ documents/old/constitucion_de_bolsillo.pdf.

Coordinadora Nacional de Organizaciones Negras Panameñas (2010), Informe sombra ante el CERD Panamá [online] http://tbinternet.ohchr.org/Treaties/ CERD/Shared\%20Documents/PAN/INT_CERD_NGO_PAN_76_9859_E.pdf.

ECLAC (Economic Commission for Latin America and the Caribbean) (2017), Social Panorama of Latin America, 2016. Briefing Paper, Santiago, May. (2016a), The social inequality matrix in Latin America (LC/G.2690(MDS.1/2)), Santiago. (2016b), Social Panorama of Latin America, 2015 (LC/G.2691-P), Santiago. (2015), Inclusive social development: the next generation of policiesfor overcoming poverty and reducing inequality in Latin America and the Caribbean (LC/L.4056(CDS.1/3)), Santiago.

(2013), Montevideo Consensus on Population and Development (LC/L.3697) [online] https://www.cepal.org/celade/noticias/documentosdetrabajo/9/ 50709/2013-596-montevideo_consensus_pyd.pdf. 
Feres Jr., J. and others (2013), O impacto da Lei $n^{\circ} 12.711$ sobre as universidades federais. Levantamento das políticas de ação afirmativa, Rio de Janeiro, Institute of Social and Political Studies of the State University of Rio de Janeiro.

IBGE (Brazilian Geographical and Statistical Institute) (2015), Síntese de Indicadores Sociais 2015 - uma análise das condições de vida da população brasileira, Brasilia.

ILO (International Labour Organization) (1989), "Indigenous and Tribal Peoples Convention, 1989 (No. 169)" [online] http:/ / www.ilo.org/dyn/normlex/en/f? p=NORMLEXPUB:12100:0::NO::P12100_INSTRUMENT_ID:312314.

(1958), “Discrimination (Employment and Occupation) Convention, 1958 (No. 111)" [online] http:/ / www.ilo.org/dyn/normlex/en/f?p=NORMLEXP UB:12100:0::NO::P12100_ILO_CODE:C111.

Jaccoud, L. (org.) (2009), A construção de uma política de promoção da igualdade racial: uma análise dos últimos 20 anos, Brasilia, Institute of Applied Economic Research (IPEA).

OAS (Organization of American States) (2011a), The Situation of People of African Descent in the Americas (OEA/Ser.L/V/II) [online] http://www.oas.org/en/ iachr/Afrodescendants/docs/pdf/AFROS_2011_ENG.pdf.

(2011b), II Taller de Expertos/as de la Temática Afrodescendiente en las Américas, Washington, D.C.

(1969), "American Convention on Human Rights "Pact of San Jose, Costa Rica" [online] https://www.oas.org/dil/treaties_B-32_American_Convention_on_ Human_Rights.htm.

Office of Ombudsman (2011), Los afrodescendientes en el Perú: una aproximación a su realidad y al ejercicio de sus derechos, Lima.

Office of the Public Prosecutor of Pernambuco (2013), No país do racismo institucional: dez anos de ações do GT Racismo no MPPE, Recife.

OHCHR (Office of the United Nations High Commissioner for Human Rights) (1973), "International Convention of Apartheid" [online] http://undocs. org/A/RES/3068\%20(XXVIII).

(1966a), "International Covenant on Civil and Political Rights" [online] http://www.ohchr.org/en/professionalinterest/pages/ccpr.aspx. (1966b), "International Covenant on Economic, Social and Cultural Rights" [online] http:/ / www.ohchr.org/EN/ProfessionalInterest/Pages/CESCR.aspx. (1965), "International Convention on the Elimination of All Forms of Racial Discrimination" [online] http://www.ohchr.org/EN/ProfessionalInterest/ Pages/CERD.aspx.

Rangel, M. (2016), "Políticas públicas para afrodescendientes: marco institucional en el Brasil, Colombia, el Ecuador y el Perú", Social Policy series, No. 220 (LC/L.4275), Santiago, Economic Commission for Latin America and the Caribbean (ECLAC).

Republic of Bolivia (2008), "Nueva Constitución Política del Estado" [online] http://www.servindi.org/pdf/Bolivia_ConsPol_Oct2008.pdf.

SEPPIR (Special Secretariat for the Promotion of Racial Equality) (2015), Levantamento de órgãos e conselhos de igualdade racial para o SINAPIR, Brasilia. (2014), Balanço de gestão 2011-2014, Brasilia.

United Nations (2008), "Consideration of reports submitted by states parties under article 9 of the Convention" (CERD/C/NIC/CO/14), International Convention on the Elimination of All Forms of Racial Discrimination [online] http: / / www2. ohchr.org/english/bodies/cerd/docs/co/CERD-C-NIC-CO-14.pdf.

University of Brasilia (2013), Análise do sistema de cotas para negros da Universidade de Brasília. Período: $2^{\circ}$ semestre de 2004 ao $1^{\circ}$ semestre de 2013, Brasilia. 



\section{Publicaciones recientes de la CEPAL ECLAC recent publications}

\section{www.cepal.org/publicaciones}

Informes Anuales / Annual Reports

También disponibles para años anteriores / Issues for previous years also available

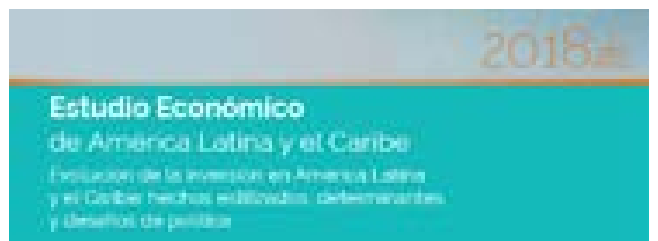

Estudio Económico de América Latina y el Caribe 2018 Economic Survey of Latin America and the Caribbean 2018 Estudo Econômico da América Latina e do Caribe 2018 Documento informativo

\section{7 ए}

Balance Preliminar de tas Economias. do Amiricating yed Caibs

\section{y el Caribe 2017}

Preliminary Overview of the Economies of Latin America and the Caribbean 2017

Balanço Preliminar das Economias da América Latina e do Caribe 2017. Documento informativo

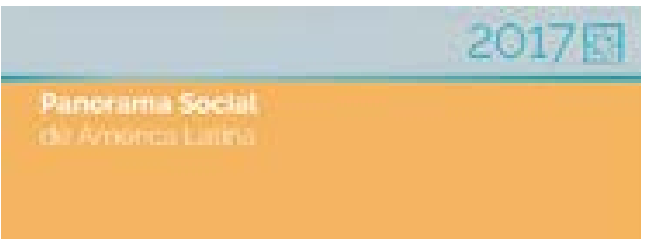

Panorama Social de América Latina 2017 Social Panorama of Latin America 2017 Panorama Social da América Latina 2017 Documento informativo

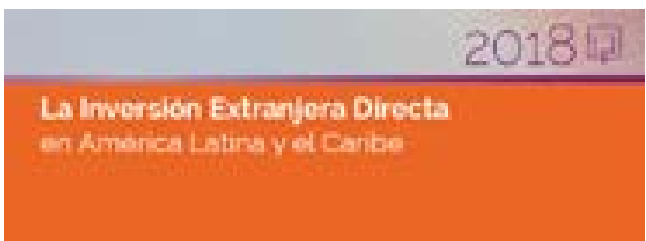

La Inversión Extranjera Directa en América Latina y el Caribe 2018

Foreign Direct Investment in Latin America and the

Caribbean 2018

O Investimento Estrangeiro Direto na América Latina e no Caribe 2018

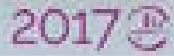

\section{Anuario Estadistico}

do Amorica Latina y crarba

Stetistical Yearbook

for Lotin Amstisa ond whe Carisbotan

Anuario Estadístico de América Latina y el Caribe 2107 Statistical Yearbook for Latin America and the Caribbean 2017

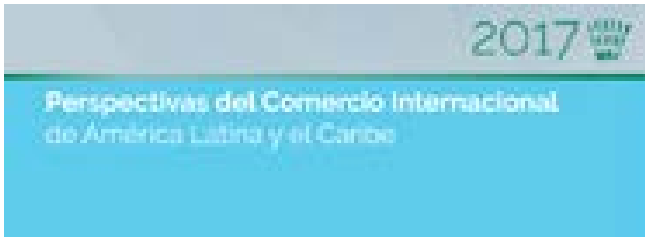

Perspectivas del Comercio Internacional de América Latina y el Caribe 2017

International Trade Outlook for Latin America and the Caribbean 2017

Perspectivas do Comércio Internacional da América Latina e do Caribe 2017 


\section{El Pensamiento de la CEPAL / ECLAC Thinking}

La ineficiencia de la desigualdad

The Inefficiency of Inequality

Horizontes 2030: la igualdad en el centro del desarrollo sostenible Horizons 2030: Equality at the centre of sustainable development

Horizontes 2030: a igualdade no centro do desenvolvimento sustentável

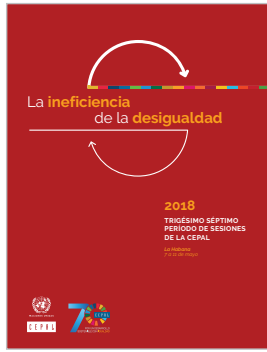

\section{Libros y Documentos Institucionales / Institutional Books and Documents}

Proyecto de primer informe regional sobre la implementación del Consenso de Montevideo sobre Población y Desarrollo

Draft first regional report on the implementation of the Montevideo Consensus on Population and Development

Acceso a la información, la participación y la justicia en asuntos ambientales en América Latina y el Caribe: hacia el logro de la Agenda 2030 para el Desarrollo Sostenible Access to information, participation and justice in environmental matters in Latin America and the Caribbean: Towards achievement of the 2030 Agenda for Sustainable Development

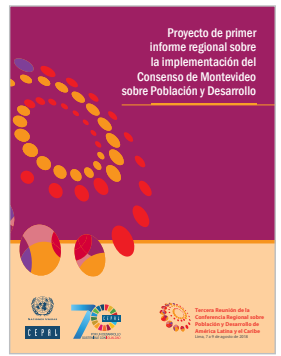

\section{Libros de la CEPAL / ECLAC Books}

Estudios sobre financierización en América Latina

Los pueblos indígenas en América (Abya Yala): desafíos para la iguadad en la diversidad, Fabiana Del Popolo (ed.)

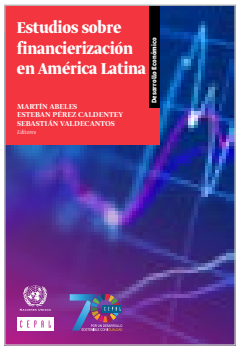

\section{Páginas Selectas de la CEPAL / ECLAC Select Pages}

Empleo en América Latina y el Caribe. Textos seleccionados 2006-2017, Jürgen Weller (comp.)

Desarrollo inclusivo en América Latina. Textos seleccionados 2009-2016, Ricardo Infante (comp.)

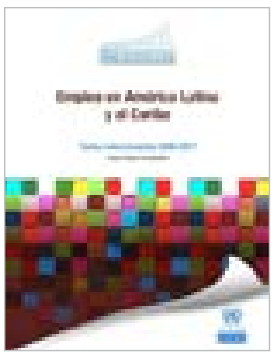


Revista CEPAL / CEPAL Review

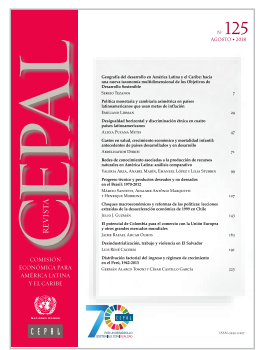

Notas de Población

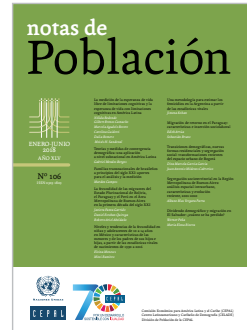

Documentos de Proyectos Project Documents

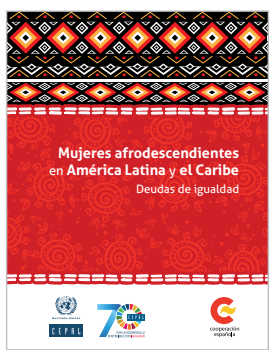

Coediciones / Co-editions

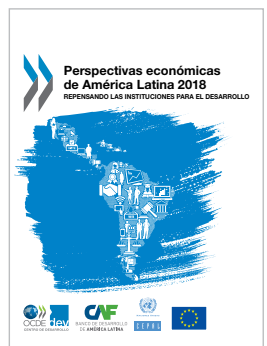

Series de la CEPAL / ECLAC Series

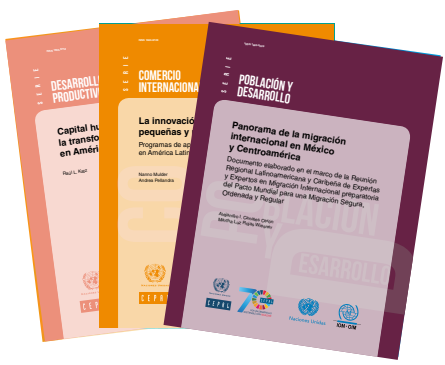

Observatorio Demográfico Demographic Observatory

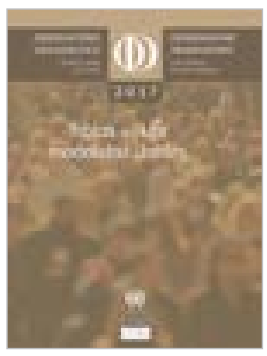

Cuadernos Estadisticos de la CEPAL

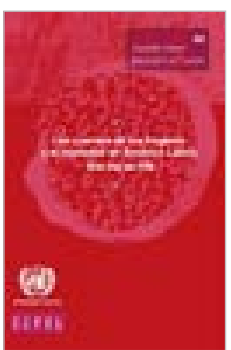

Copublicaciones / Co-publications

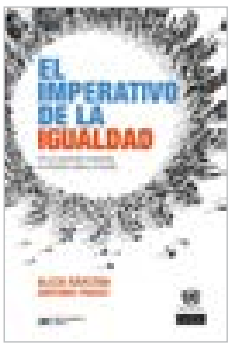




\section{Suscribase y reciba información oportuna sobre las publicaciones de la CEPAL}

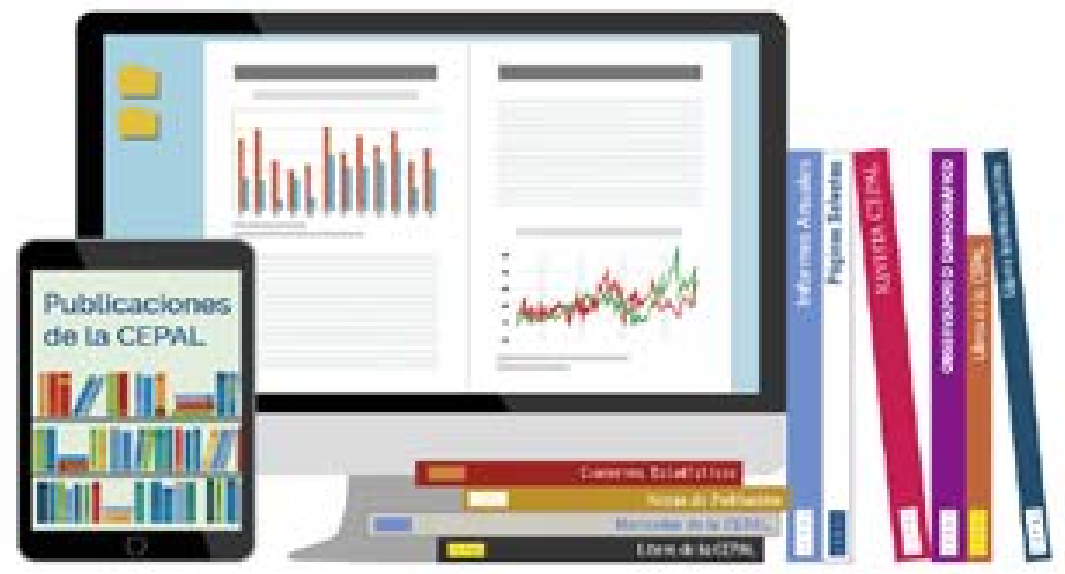

\section{wwW.cepal.org/es/registro}
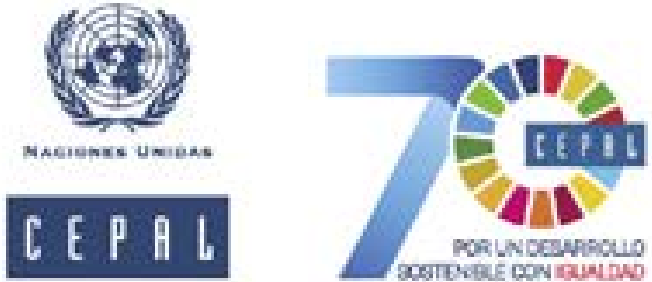

\section{www.cepal.org/publicaciones}

f facebook.com/publicacionesdelacepal

Las publicaciones de la CEPAL también se pueden adquirir a través de:

\section{shop.un.org}

United Nations Publications

PO Box 960

Herndon, VA 20172

USA
Tel (1-888)254-4286

$\mathrm{Fax}(1-800) 338-4550$

Contacto: publicationsøun,org

Pedidos: ordereun.org 


\section{Institutional \\ frameworks for \\ social policy in \\ Latin America and the Caribbean}

\section{RODRIGO MARTÍNEZ}

Editor
The world is going through a period of change. Volatile economic growth, climate change, the technological revolution, migration and the

demographic transition all reflect this, as do the impacts these changes are having on society and the challenges they pose for public policies.

Continuing the social progress made in Latin America and the Caribbean, ensuring no ground is lost and attaining the Goals of the 2030 Agenda for Sustainable Development while ensuring that no one is left behind will require new and greater public policy efforts to enhance coverage and quality. An essential part of this is to have institutions capable of meeting current and future challenges, securing viable and sustainable achievements and guaranteeing the universal exercise of rights.

This book reviews elements of the institutional framework for social policies in the region, particularly those focused on social protection. It thus discusses the leading concepts and the progress made at the regional and national level within a framework of four complementary analytical dimensions: the legal and regulatory dimension, the organizational dimension, the technical and operational dimension and the financing dimension.

E 〔 L \& 〔 www.eclac.org 